\title{
Engenharia Química: Significação de Conceitos na Construção da Aprendizagem
}

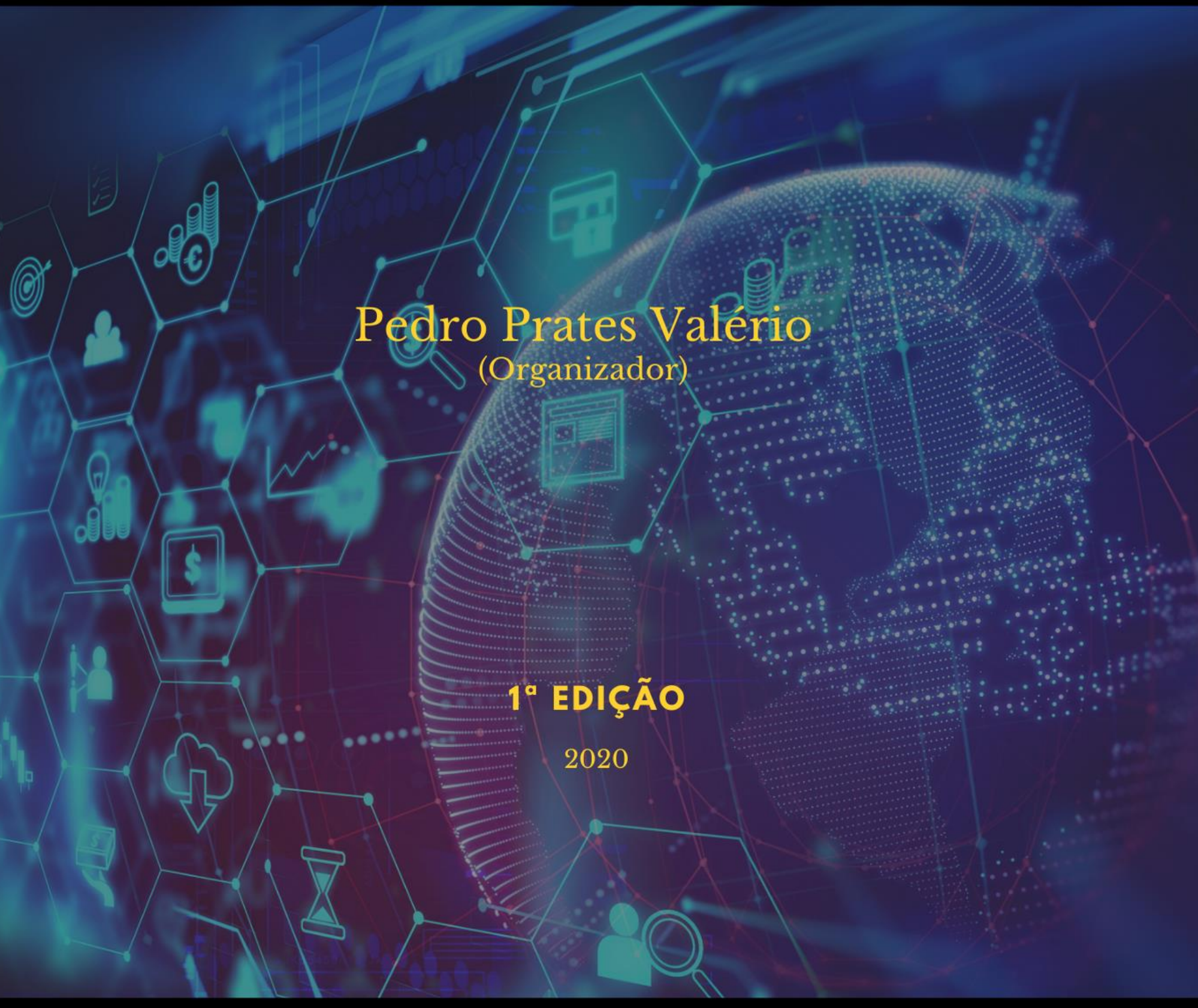

Editora Poisson 
Pedro Prates Valério

(Organizador)

Engenharia Química: Significação de Conceitos na Construção da Aprendizagem

1a Edição

Belo Horizonte

Poisson

2020 
Editor Chefe: Dr. Darly Fernando Andrade

\section{Conselho Editorial}

Dr. Antônio Artur de Souza - Universidade Federal de Minas Gerais

Msc. Davilson Eduardo Andrade

Dra. Elizângela de Jesus Oliveira - Universidade Federal do Amazonas

Msc. Fabiane dos Santos

Dr. José Eduardo Ferreira Lopes - Universidade Federal de Uberlândia

Dr. Otaviano Francisco Neves - Pontifícia Universidade Católica de Minas Gerais

Dr. Luiz Cláudio de Lima - Universidade FUMEC

Dr. Nelson Ferreira Filho - Faculdades Kennedy

Ms. Valdiney Alves de Oliveira - Universidade Federal de Uberlândia

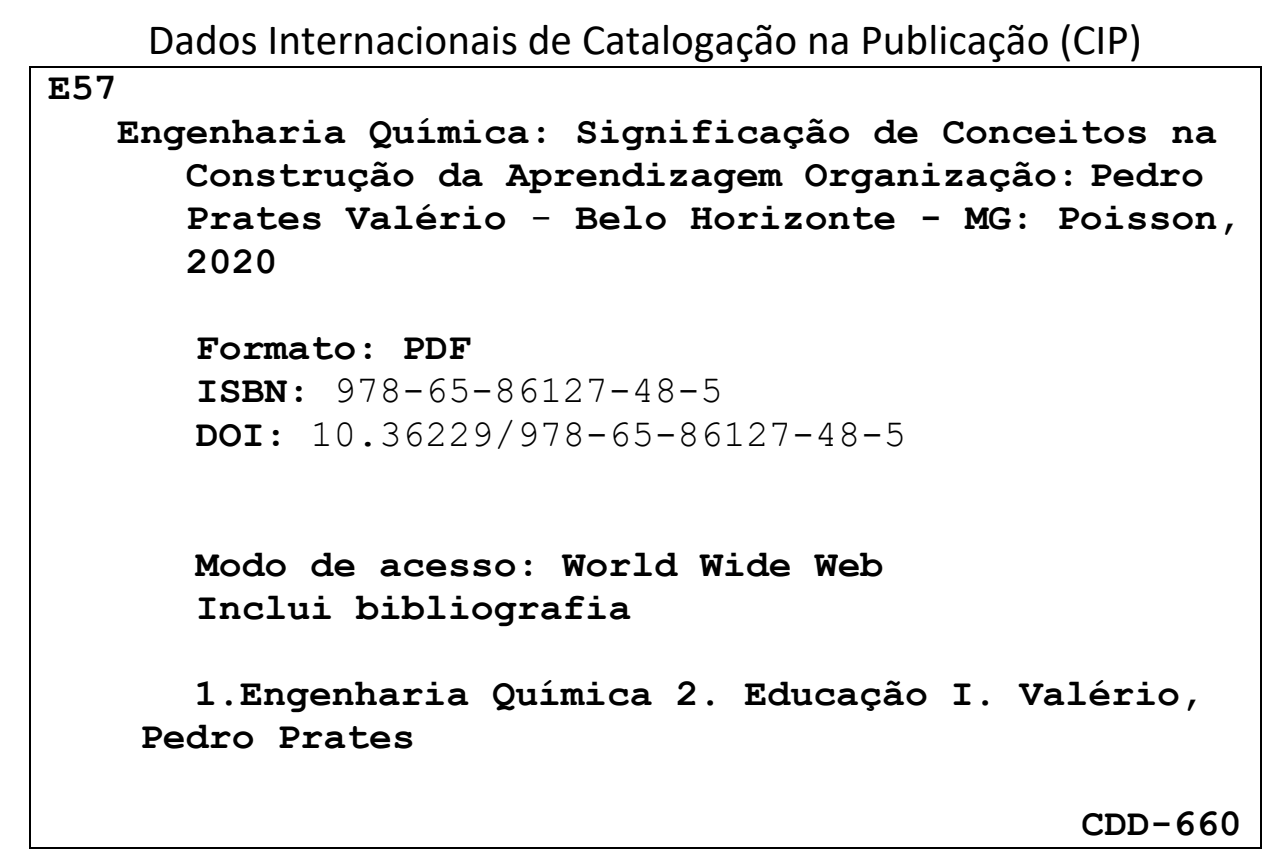

O conteúdo do livro e seus dados em sua forma, correção e confiabilidade são de responsabilidade exclusiva do seu respectivo autor.

www.poisson.com.br

contato@poisson.com.br 
"Dedico este Projeto a todas e a todos os estudantes, bem como a todas e a todos os Educadores, incluindo aqueles com os quais ainda terei a oportunidade de compartilhar momentos, vivências e construções. À minha amada esposa, ao meu filho e à minha filha. Minha Família. A todos que acreditam na construção da experiência, como base para significações." 


\section{Sobre Editor / Organizador Pedro Prates Valério}

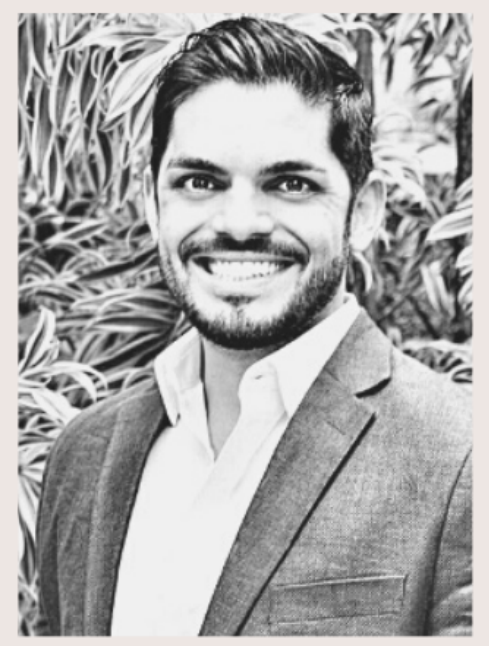

Doutor em Engenharia Química pela Universidade Federal de Minas Gerais (UFMG). Possui mestrado em Ciência de Alimentos pela UNICAMP e extensão universitária em Formação em Docência do Ensino Superior pela UFMG. Engenheiro de Alimentos, acompanhou pesquisa científica na School of Food Science and Environmental Health - DIT, na Irlanda, retornando em Período Sanduíche Doutorado. Pelo EMPRETEC, formou-se em Empreendedorismo e Desempenho Empresarial - SEBRAE/ONU. Acumula experiências, principalmente, relacionadas a Engenharias, Engenharia Química, Cinética Química, Modelagem Cinética, Controle de Qualidade, Ciência e Tecnologia de Alimentos, Compostos Bioativos, Bromatologia, Instrumentação Analítica (Cromatografia em Fase Gasosa - CC; Cromatografia em Fase Líquida de Alta Eficiência - HPLC; Espectrometria de Massas - MS), Processos Industriais, entre outras. Enquanto Docente, no Instituto Politécnico (IPOLI) do Centro Universitário UNA (Belo Horizonte, MG), ministrou Disciplinas, tais quais, Cinética Química, Operações Unitárias, Tópicos Especiais para Engenharia Química, Tópicos Avançados para Engenharia de Produção, Introdução à Engenharia, Projetos Interdisciplinares, Projetos Aplicados, Laboratórios de Aprendizagem Integrada, entre outras. No Centro Universitário de Belo Horizonte Unibh, atuou como Docente e Coordenador de Cursos de Engenharia. Atualmente, coordena os cursos de graduação em Engenharia Química, Engenharia Mecânica, Engenharia Ambiental, Engenharia de Produção, Engenharia Elétrica e Engenharia Civil, na Cidade Universitária, do Centro Universitário UNA (Belo Horizonte, MG). Enquanto Pesquisador, acumula apresentações em eventos nacionais e internacionais, participa como membro de corpo editorial, e também como revisor Ad Hoc de Periódicos Científicos. Conselheiro Suplente (Segmento II: Sociedade Civil) da Câmara de Atividades Industriais - CID e da Câmara de Políticas de Energia e Mudanças Climáticas - CEM (biênio: 2020-2022), do Conselho Estadual de Política Ambiental - Copam (Secretaria de Estado de Meio Ambiente e Desenvolvimento Sustentável - Semad MG). É membro Associado das Organizações IFT: Institute of Food Technologists, GHI: Global Harmonization Initiative, ISEKI_Food Association e ABENGE: Associação Brasileira de Educação em Engenharia. Educador. 


\section{Sumário}

Capítulo 1: Prefácio

Professor Salvador Carlos Grande

DOI: 10.36229/978-65-86127-48-5.CAP.01

Capítulo 2: Palavra Pedagógica

Professora Verônica Cristina de Almeida e Silva de Barros Figueiredo

DOI: $10.36229 / 978-65-86127-48-5 . C A P .02$

Capítulo 3: Íons cloreto: Avaliações de difusão em concreto constituído por classes de cimento portland

Wanderson de Souza Frota, Pedro Prates-Valério

DOI: 10.36229/978-65-86127-48-5.CAP.03

Capítulo 4: Hidrólise alcalina de ésteres: estudo cinético

Douglas Antônio Alves de Souza, Pedro Prates-Valério

DOI: 10.36229/978-65-86127-48-5.CAP.04

Capítulo 5: Biocompostos: Estudo da cinética de degradação térmica considerando óleo vegetal palma

Carolina Gonçalves Garcia, Pedro Prates-Valério

DOI: 10.36229/978-65-86127-48-5.CAP.05

Capítulo 6: Método de Monte Carlo: Estimativa da taxa de degradação térmica do $\beta$ caroteno

Mariane de Carvalho Sabarense, Pedro Prates-Valério

DOI: 10.36229/978-65-86127-48-5.CAP.06

Capítulo 7: Biogás e permeação de CO2: Membranas poliméricas

Gabriella de Oliveira, Pedro Prates-Valério

DOI: 10.36229/978-65-86127-48-5.CAP.07 
Capítulo 8: Breve abordagem relacionando qualidade de matéria-prima vegetal, viabilidade e aplicação

Idianara Silva, Pedro Prates-Valério

DOI: 10.36229/978-65-86127-48-5.CAP.08

Capítulo 9: Sementes de moringa oleífera aplicadas para a remoção de íons cálcio de águas: contextos industriais alternativos

Renata Motta Kusumoto, Pedro Prates-Valério

DOI: 10.36229/978-65-86127-48-5.CAP.09

Capítulo 10: Estudo de materiais propantes associado a processo de fraturamento hidráulico

Matheus Avelino Barbosa de Souza, Pedro Prates-Valério

DOI: 10.36229/978-65-86127-48-5.CAP.10

Capítulo 11: Análise do Gold Dressing Agent (GDA) como reagente alternativo ao cianeto no processo de lixiviação do ouro

Willian Dayvson Gualberto, Madrith Sthel Costa Duarte, Julio Cézar Balarini

DOI: 10.36229/978-65-86127-48-5.CAP.11 


\section{Capítulo 1 Prefácio}

Professor Salvador Carlos Grande

PhD em Engenharia Química pela UFMG (Minas Gerais, Brasil)

Docente na Faculdade de Ciências e Tecnologia da Universidade Zambeze (Beira, Moçambique)

Engenheiro Químico 
Em tempos atuais, o conhecimento segue se constituindo como base para a formação integral dos estudantes que desejam seguir caminho de Prosperidade, também considerando a esfera do saber. A aproximação entre ensino e aprendizagem converge com um cenário no qual velocidade se faz uma importante variável. Tal variável impacta positivamente o compartilhamento de informações, favorecendo o desenvolvimento de competências e atitudes requeridas pelos profissionais da contemporaneidade.

Por certo, as experiências dos estudantes ao longo de seus percursos, de seus desenvolvimentos, também trazem para mais próximo a busca por consciência e aprimoramentos. Consciência, em sentido amplo, também alinhada com constantes mudanças e adaptações. De forma geral, são diversos os autores que abordam o pensar sobre processos de formação. De forma objetiva, podem ser entendidos como urgentes os aspectos relacionados ao protagonismo dos estudantes, bem como às suas capacidades de comunicação, pensamento crítico, criatividade e resolução de problemas complexos.

De fato, a partir da história que sigo a conduzir, relacionada à minha formação enquanto docente e pesquisador, também experimentada entre Brasil e Moçambique, entendo que a aprendizagem tende a apresentar mais significado em contextos nos quais os estudantes assumem a centralidade do processo. Fundamenta-se, assim, a busca pela essência do experimentar, ressignificando acertos e erros, em prol de objetivos de engrandecimento. À centralidade do aluno, soma-se a relevância do papel mentor, dos professores. Observo que questões culturais diversas, associadas aos níveis de desenvolvimento das sociedades e comunidades, ou seja, envolvendo análises de contextos, por vezes econômicos e políticos, também são determinantes para a adoção de determinadas estratégias que culminem na formação de indivíduos, cidadãos e profissionais.

É importante se considerar, brevemente, que diversas metodologias para auxílio e potencialização das construções de conhecimentos se aderem como partes dos processos que envolvem planejamento, execução e avaliação de atividades. A partir de percepções que tenho podido colher em minha trajetória, em contínua construção, também penso ser relevante mencionar que determinadas estratégias metodológicas, a serem adotadas, podem se relacionar a eventuais disponibilidades financeiras e questões monetárias - mas não devem se limitar a estas.

Em momentos diversos, tenho percebido que a resolução de problemas e a elaboração de projetos, por parte dos estudantes, pode englobar abrangências de cenários que ampliam perspectivas e potencializam metacognição. Entendo, assim, um grato ajuste entre expectativas e resultados, na esfera do fazer e do aprender a aprender. Sabemos que, inclusive nos cursos de engenharia, constantemente se buscam estratégias construtivas, pensando nas novas realidades da sociedade.

Ao abordar, assim, de forma suscinta, questões educacionais e profissionais pelas quais guardo particular apreço, compreendo algumas das razões pelas quais o autor deste livro - um amigo, companheiro, e colega de carteira ao nível do curso de doutorado em Engenharia Química, no período em que juntos estivemos e convivemos (2013-2016) - me convidou para escrever o início deste seu projeto. Vocês, leitores, poderão observar, nas páginas que se seguem, a reunião de temas e assuntos diversos, com âmbito técnicocientífico, abordados com autonomia pelos estudantes universitários do curso Engenharia Química, quando os orientou, enquanto professor mentor, no Brasil. Hoje, atuo como professor na Faculdade de Ciências e Tecnologia, na Universidade Zambeze (em Mocambique). Nos vimos, dessa forma, em sintonia no que se refere à abordagem de nossos papéis enquanto professores dos cursos de engenharia em nossas respectivas sociedades. Temos conversado sobre estratégias na construção de conhecimento, e sobre o mundo do trabalho atual e futuro. Temos dialogado sobre Transformação.

Pois, o Professor Prates, como é carinhosamente tratado, aborda estrategicamente formas por meio das quais os estudantes também podem aprender. Nessa busca, engenheiras e engenheiros, em formação, mobilizam conhecimentos prévios, pensando criticamente, desenvolvendo habilidades e competências Hard e Essential, abrangendo circunstâncias reais, aspirações e expectativas, com propósitos de Educação Continuada - Lifelong Leraning.

Espero que os leitores possam encontrar, nos trabalhos que se seguem, capítulos do mundo técnicocientífico, associando, às suas interpretações, o apreciar da forma como os estudantes fazem face aos seus desafios. Ao mesmo tempo, enquanto expectativa, poderão observar a interação fundamental entre estudantes e professor mentor, parceiros nestas construções. 
Aos leitores mais atentos, percebo estarmos diante de uma obra aplicada que, de forma alternativa, traz conceitos concernentes a metodologias ativas e à construção do saber. Envolvendo engenharia, torna-se relativamente claro o empreendimento pelo ampliar de ambientes de aprendizagem, com um convite à sua extensão pelas páginas que se prosseguem.

Um grande abraço ao meu amigo.

A todas e todos vocês, uma ótima leitura! 


\section{Capítulo 2}

Palavra Pedagógica

Professora Verônica Cristina de Almeida e Silva de Barros Figueiredo

Mestre em Educação: Linha de Currículo

Especialista em Docência do Ensino Superior

Pedagoga 
Em termos educacionais, o desafio que se coloca para esse milênio é: promover a aprendizagem do aluno. No passado, o desafio era incluir o aluno na escola e evitar sua evasão. Atualmente, como o Brasil já superou quase totalmente esse desafio, emerge a necessidade de atribuir qualidade ao trabalho realizado nas instituições de ensino. Posto isso, o cerne do trabalho docente se desloca do "como ensinar" para o "como o aluno aprende". Esse deslocamento provoca muitas discussões, dentre elas: Os professores têm conhecimento das teorias de aprendizagem? A formação docente acompanha essa modificação? As instituições de ensino possuem materiais e estruturas favorecedoras da aprendizagem? Os currículos escolares são abertos e flexíveis? 0 estudante está disposto a aprender? Como se percebe, uma análise minuciosa desse desafio envolve muitos aspectos.

Este texto terá como recorte a aprendizagem de adultos. Certamente, ela se difere, em grande escala, da aprendizagem de crianças e adolescentes. Muitas pesquisas a esse respeito têm surgido. 0 fato faz-se, assim, muito relevante, tendo em vista que os sucessos da instituição e do aluno dependem enormemente da aprendizagem ocorrida. Mas, em nosso país, a centralidade do educando no processo de ensino é uma postura relativamente nova. Por aqui sempre se enfatizaram processos de ensino. Essa alteração no modo de praticar o trabalho docente faz com que haja necessidade de se diferenciar ensino de aprendizagem.

Entende-se por processos de ensino aqueles que são coordenados pelo professor e que ocorrem de modo coletivo, isto é, com o mesmo ritmo. Com esse foco, importa muito o que o docente fala. Por isso, existem alunos que assistem às aulas com muita atenção, tomando nota de tudo. Já a aprendizagem escolar pode ser definida como um processo particular do educando e, por isso, com ritmo e modo próprios. Para a aprendizagem, importa muito o que o aluno faz, não o que ele ouve. Sendo assim, não há uma menos valia no trabalho docente, pelo contrário, o trabalho do professor se torna decisivo para a promoção da aprendizagem, pois as atividades que os alunos desempenharão vão determinar, em grande medida, a qualidade da aprendizagem.

Retomando os conceitos acima, denota-se que a diferenciação entre eles reafirma a tendência de se considerar o estudante o cerne do processo de aprendizagem. Essa nova postura justifica-se pelo fato de que ninguém aprende para ninguém e, mais que isso, segundo Freire (2005, p.78), "ninguém educa ninguém, ninguém educa a si mesmo, os homens se educam entre si, mediatizados pelo mundo". Nesse sentido, então, reafirma-se a responsabilidade, a importância e a ética do trabalho docente. Sabendo-se que "ninguém educa ninguém", coloca-se o desafio para o educador de organizar sua aula com base em tarefas significativas e relevantes, com o objetivo de desafiar o educando a mobilizar os conhecimentos já consolidados e construir novas aprendizagens.

Por um lado, a presença da população adulta no ensino superior concretiza os ideais de educação e aprendizagem ao longo de toda a vida. Por outro, entende-se que, para alcançar esse ideal, é imprescindível garantir a qualidade na aprendizagem. Para que isso ocorra, faz-se necessário compreender como os adultos aprendem e quais mudanças são necessárias nas instituições de ensino superior para esse trabalho. Sustenta-se aqui que, para conseguir superar no ensino superior o desafio desse milênio, os comprometimentos do docente e do educando em relação à aprendizagem serão decisivos.

Sobre os adultos que frequentam o ensino superior, pode-se afirmar que possuem uma variação muito grande em suas idades, que são bastante diversos dos pontos de vista psicológico, sociológico e outros e que, por esses e outros motivos relacionados à sua diversidade, é muito difícil caracterizar essa população. Mesmo assim, acredita-se que algo que eles têm em comum diz respeito à motivação intrínseca (mesmo que em diferentes níveis) por meio da qual se manifesta o interesse em aprender uma profissão, uma vez que ingressaram, por conta própria, no ensino superior.

Outra característica desses estudantes, segundo Oliveira (2007, p. 48), é que preferem realizar "trabalhos orientados para a aplicação prática e centrados na resolução de problemas". Correia e Mesquita (2006), citados por Oliveira (2007, p. 48), defendem que "nesse contexto, as actividades em pequenos grupos e de projecto, supervisionadas ou acompanhadas pelos professores/tutores, bem como as aulas do tipo participativo, parecem ser especialmente apreciadas pelos educandos adultos no ensino superior.". Por meio desse tipo de trabalho, como resultado de seu estudo, grande parte dessa população espera que o ensino superior seja capaz de utilizar seus conhecimentos prévios e experiência para que, assim, dê sentido às novas aprendizagens que transformarão os conhecimentos anteriores.

Tendo em vista o exposto, percebe-se que, para atender aos anseios dessa população, a instituição de ensino superior deve valorizar e enriquecer sua experiência prévia e enfatizar o hábito de enfrentar 
problemas e procurar soluções para resolvê-los, algo tão presente na vida adulta. Com base nessas constatações, "incluem-se, no currículo dos cursos de graduação em Engenharia Química, propósitos e atividades que dialogam com o perfil esperado para os egressos. A partir de agora, apresentar-se-á uma análise de como foram favorecedores da aprendizagem os trabalhos de alguns alunos, realizados sob orientação do Professor Pedro Prates nessa disciplina.

O estudo apresentado no capítulo 3 discorre sobre "Íons cloreto: Avaliações de difusão em concreto constituído por classes de cimento portland". Frota e Prates-Valério apresentam um estudo baseado em pesquisa explicativa. Esse tipo de metodologia apresenta uma tentativa de conectar ideias e fatores identificados para compreender as causas e efeitos do fenômeno. Sabe-se que, para que essa conexão ocorra, o conhecimento anterior dos pesquisadores é acionado, objetivando explicar os aspectos relacionados ao problema de pesquisa.

O capítulo 4 "Hidrólise alcalina de ésteres: estudo cinético", de Souza e Prates-Valério, aproxima-se de um estudo de caso, pois, objetiva coletar dados e trabalhá-los mediante análise rigorosa então apresentada.

No capítulo 5, Garcia e Prates-Valério apresentam uma discussão sobre "Biocompostos: Estudo da cinética de degradação térmica considerando óleo vegetal palma”, por meio uma revisão bibliográfica e procedimentos experimentais de ordem quantitativa, no sentido dos objetivos propostos, também podendo ser descrito como explicativo.

No capítulo 6 "Método de Monte Carlo: Estimativa da taxa de degradação térmica do $\beta$-caroteno", de Sabarense e Prates-Valério, utilizou-se como metodologia a revisão bibliográfica e, também, procedimentos experimentais para atingir os objetivos. Podem, estes, ser descritos como explicativos, tendo em vista que buscaram a identificação da influência de determinados fatores no fenômeno estudado, a partir de abordagem quantitativa.

“Biogás e permeação de CO2: Membranas poliméricas”, de Oliveira e Prates-Valério, compõem o capítulo 7 dessa obra. Tal capítulo se desenvolveu por meio de um levantamento bibliográfico e uma pesquisa exploratória. Inicialmente, os pesquisadores partiram de conceitos fundamentais, para realizarem considerações a respeito do assunto pesquisado. Em seguida, os conhecimentos gerados reuniram-se no sentido da construção de hipóteses para a compreensão do problema de pesquisa.

O capítulo 8 "Breve abordagem relacionando qualidade de matéria-prima vegetal, viabilidade e aplicação", de Silva e Prates-Valério, caracteriza-se como um estudo que objetiva contextualizar brevemente a indústria de cosméticos, com base em revisão bibliográfica e procedimentos experimentais para atingir seus objetivos. Podem, estes, ser descritos como explicativos.

O capítulo 9 "Sementes de moringa oleífera aplicadas para a remoção de íons cálcio de águas: Contextos industriais alternativos", de Kusumoto e Prates-Valério, utilizou uma mescla de revisão bibliográfica e procedimentos, por meio de uma abordagem quantitativa, pois compara o comportamento dos dados obtidos com situações semelhantes descritas na literatura.

No capítulo 10 "Estudo de materiais propantes associado a processo de fraturamento hidráulico", de Souza e Prates-Valério, se desenvolve com base em levantamento bibliográfico. Os pesquisadores partem de conceitos fundamentais para realizar uma pesquisa exploratória.

Gualberto, Duarte e Balarini, no último capítulo da obra, "Análise do Gold Dressing Agent (GDA) como reagente alternativo ao cianeto no processo de lixiviação do ouro". 


\title{
Capítulo 3
}

\section{Íons cloreto: Avaliações de difusão em concreto} constituído por classes de cimento portland ${ }^{1}$

\author{
Wanderson de Souza Frota \\ Pedro Prates-Valério
}

Resumo: A ação deteriorante de íons cloreto em estruturas metálicas, no concreto, tende a culminar em empecilhos severos, também relacionados a estabilidade, funcionalidade, manutenção e preservação. A presente pesquisa avalia o potencial de mitigação destes íons em concreto simples constituído por três principais classes de cimento Portland convencional, utilizando-se das Normas: ASTM C1202 e NT BUILD 492, as quais avaliam tanto a penetrabilidade, quanto à difusão dos íons cloreto no seio dos espécimes, respectivamente. Observou-se que a aplicação de cimento aditivado propiciou redução de até $88 \%$ na mitigação dos íons em relação ao cimento de alta resistência inicial. Resultados sugerem redução de poros, assim como reação química envolvendo íons cloreto e cristais sólidos. Embasam-se estudos subsequentes sobre características de cimentos potencialmente resistentes à migração de íons cloreto.

Palavras-chave: Concreto. Cloreto. Mitigação.

Abstract: The deteriorating action of chloride ions on metal structures in concrete tends to culminate in severe impediments also related to stability, functionality, maintenance, and preservation. The present study evaluates the potential of mitigation for these ions in concretes composed by different types of cement, using the following standards: ASTM C1202 and NT BUILD 492. It was observed that the addition of granulated acid slag from the blast furnace and artificial pozzolan provided a reduction of up to $88 \%$ in the ions mitigation. Results suggest a reduction of pores, as well as a chemical reaction involving chloride ions and solid crystals. Subsequent studies on the characteristics of cement potentially resistant to the migration of chloride ions are based.

Keywords: Concrete, Chloride, Mitigation 


\section{INTRODUÇÃO}

O concreto é um material utilizado para aplicações estruturais diversas, incluindo construções de edifícios, viadutos, casas, pontes, obras de arte e artefatos arquitetônicos (PEREIRA, 2001). No que se refere às suas degradações, Alves, Colaço e Lourenço (2013) ressaltam empecilhos potencialmente instalados quando concernentes às preservações estruturais, além de impactos diretos sobre questões físicas e econômicas. Para Castro et al. (2017), algumas patologias do concreto, de fato, resultam em manutenções corretivas que podem custar até cinco vezes àquelas eventualmente tratadas ainda em fase de projeto.

Segundo Pereira (2001), o local onde a estrutura se encontra, assim como o ambiente ao qual está exposta, dita o rito do processo corrosivo, o qual se inicia lentamente, mas, com o aumento das contaminações e intemperismo, pode apresentar aumento de proporção e de velocidade, impossibilitando recuperações. Nesse contexto, a presença de íons cloreto (Cl-) se apresenta prejudicial em função de ação catalítica na corrosão de armaduras metálicas.

Para Tovar, Ortiz e Durán (2013), a contaminação de concretos por íons cloreto pode estar ligada à adição de inertes na composição do cimento, na mistura de agregados na construção, em resíduos industriais ou em aditivos aplicados nas usinas. Ainda segundo os autores, a ação desses íons promove a despassivação do material, ocasionando diminuição ou completa destruição de filmes passivadores, ou seja, camadas de óxidos presentes em superfícies de armaduras metálicas são quimicamente atacadas, reduzindo sessões transversais dos metais. Com a presença de umidade excessiva presente nos poros do concreto, os íons cloreto movem-se ao encontro da estrutura metálica originando, assim, ânodos localizados.

Em embasamento concordante, CEB (1982) explica que íons metálicos solubilizados em meio aquoso, nas estruturas de concretos, reagem com a água presente, formando compostos básicos insolúveis com volume mais elevado do que o do metal no estado elementar. Ocasiona-se ruptura interior do concreto por expansão.

Em estudo, Alves, Colaço e Lourenço (2013) afirmam que a reabilitação de estruturas comprometidas se dá por tratamento localizado, ou seja, pela retirada do material afetado e a reposição de nova massa, além de métodos eletroquímicos, tais quais dessalinização e proteção catódica. Além disso, Araújo, Panossian e Lourenço (2013) afirmam que avaliações de corrosão em armaduras metálicas são relativamente complexas, demandando abordagens técnicas as quais consistem em análises de concreto de recobrimento.

Segundo Wajdowicz et al. (2017), em serviços de recuperação de estruturas são necessárias abordagens particulares para casos específicos. Assim, para tais autores, a determinação de índices de esclerometria, segundo a Norma NBR 7584 (ABNT, 2012), pH do concreto, local e potencial de corrosão apresentam-se enquanto demandadas, o que, além de compor um quadro geral da corrosão, também auxilia na elaboração do custo de recuperação e manutenção da estrutura. Ressalta-se que os procedimentos descritos na NBR 7584 definem que, para a realização de tais ensaios, amostragens devem ocorrer in-situ. Assim sendo, além demandar acesso à superfície estrutural, extrai-se parcela de concreto a ser ensaiado, também visando-se às camadas interiores bem como à armadura metálica.

Considerando-se o contexto apresentado, o presente capítulo se desenvolve apoiado no objetivo primário de se avaliar o potencial de mitigação de íons cloreto em concreto simples constituído pelas três principais classes de cimento Portland convencionais: Alta resistência inicial (CPV), composto (CPII E e CPII F) e aditivado (CPIII e CPIV), na busca por sentido de potencial atenuação.

\section{REFERENCIAL TEÓRICO}

Segundo a norma brasileira NBR 6118 (2003), durabilidade de estruturas significa "Conservar a segurança, estabilidade e aptidão em serviço durante o período de vida útil, sob as condições ambientais previstas na época do projeto".

Para Jinping (2010), a vida útil média para uma estrutura de concreto deve se aproximar de 50 anos. Para determinadas construções, a exigência pode se aproximar de umas centenas de anos. Sabe-se, porém que, quando submetidas a ambientes corrosivos, tais estruturas podem apresentar redução drástica de sua durabilidade para aproximadamente 15 anos, e, na presença de agravantes, para menos de 5 anos.

Segundo Andrade (1992), na hidratação do cimento, o excesso de água presente no momento do processamento pode culminar na geração futura de poros interligados. Esta rede de poros é composta por capilares e canais que tornam o concreto poroso com permeabilidade a gases e líquidos. Em termos de 
transferência de massa, o tempo que os íons levam para alcançarem a armadura metálica a partir da interface externa, depende inicialmente do mecanismo de intrusão na estrutura, depois das concentrações externas de íons cloreto aliada a microestrutura do concreto e por último, a saturação de água, pois quando presente no interior do concreto, a força motriz para a transferência de massa de tais íons tornase apenas a concentração, ou seja, o mecanismo se dá pelo movimento difusivo.

Figueiredo e Meira (2011) afirmam que uma das principais interferências na corrosão das armaduras de aço deve-se ao tipo de cimento utilizado, o qual influenciará diretamente na qualidade do concreto. A corrosão das armaduras é dada pela formação de uma célula eletroquímica que depende de quatro componentes: um cátodo onde ocorre a reação de redução, um anodo onde ocorre a reação de oxidação, um condutor metálico, responsável pela condução de corrente elétrica, e um eletrólito o qual é de essencial importância, uma vez que sua condutividade é diretamente proporcional à velocidade dos elétrons, e consequentemente dos íons, resultando em maior velocidade de corrosão.

A Figura 1, a seguir, ilustra o processo eletroquímico mencionado.

Figura 1. Pilha de corrosão em uma barra de metal.

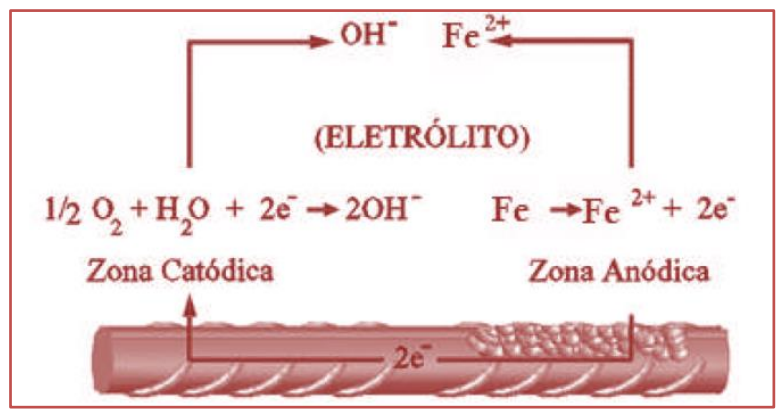

Fonte: Adaptação de Figueiredo e Meira (2011)

Tuutti (1982) descreve o processo de corrosão em duas fases: a primeira trata-se do tempo necessário para que um íon deteriorante como o cloreto chegue até a interface da armadura metálica; a segunda é a fase de propagação da corrosão, em que há a despassivação da armadura metálica e o processo corrosivo se instala efetivamente, surgindo os produtos de corrosão.

Segundo Cascudo (1997), o momento da despassivação ocorre quando a película passiva deixa de proteger a armadura contra agentes corrosivos. Dessa forma, este mesmo autor conclui que a rede de poros é a principal responsável por permitir a presença de umidade em seu interior e assim compor um meio difusivo perfeito para a introdução de íons cloreto. Também, afirma-se a existência de quatro mecanismos de transporte de massa no interior do concreto: absorção capilar, permeabilidade, migração iônica e difusão iônica, como ilustra a Figura 2.

Figura 2. Mecanismos de transporte de íons cloreto no concreto

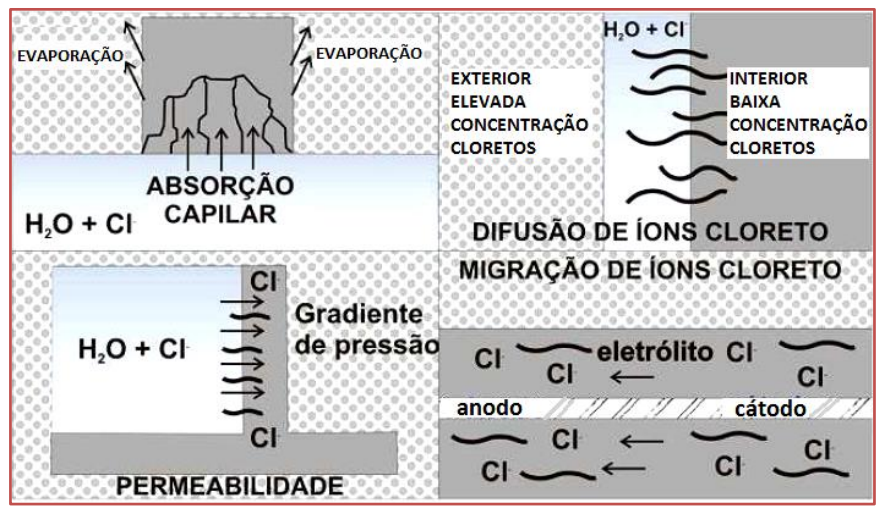

Fonte: Helene (1993) 
A migração iônica dos cloretos se dá quando há a presença de outros íons de cargas opostas à do cloreto, promovendo maior velocidade de transporte de tais íons. Já a difusão iônica tem como força motriz a diferença de concentração de íons sendo uma relação do exterior com o seio do concreto (Helene, 1993).

No Brasil, há normas que estabelecem um valor máximo de íons cloreto na massa de concreto, sempre em relação à dosagem de cimento. Tais normas são apresentadas na Tabela 1 a seguir.

Tabela 1. Normas para concentração de íons cloreto no concreto.

\begin{tabular}{|l|c|}
\hline \multicolumn{1}{|c|}{ Norma } & Teor máximo \\
\hline ACI 318 - 05 - Concreto Reforçado exposto à Íons Cloreto & 0,15 \\
\hline NP EM 206 - 1 /2007 - Concreto Simples & 0,10 \\
\hline NP EM 206 - 1 /2007 - Concreto com Armadura de Aço ou Outros Metais & 0,40 \\
\hline ABNT NBR 12655 /2006 - Concreto Armado Exposto a Ílons Cloretos & 0,15 \\
\hline ABNT NBR 12655 /2006 - Outros tipos de Construção com Concreto Armado & 0,30 \\
\hline
\end{tabular}

Fonte: ABNT (2006; 2007)

Para Page (1981) há uma coesa correlação entre a composição do cimento utilizado no concreto e os mecanismos de transporte dos íons cloreto. 0 autor observa também que concretos feitos com o cimento do tipo CP IV apresentam coeficientes de difusão menores do que os compostos por CP II F, devido ao maior teor de aluminato tricálcico - C3A. Tal aluminato complexa-se com os íons cloretos, formando uma estrutura química conhecida como cloro aluminato tricálcico hidratado, ou Sal de Friedel (3Ca0.Al203.CaCl2.10H20). Desta forma, materiais pozolânicos, os quais são ricos em aluminatos reativos, possuem alta capacidade de reação com íons de cloreto e induzem a formação de tal sal. Na figura 3, é possível observar a formação do Sal de Friedel em duas velocidades distintas. Captadas por microscópio eletrônico de varredura (MEV) com ampliação de 5000x.

Figura 3. Formação lenta Cimento (esquerda); Formação rápida pozolana (direita).
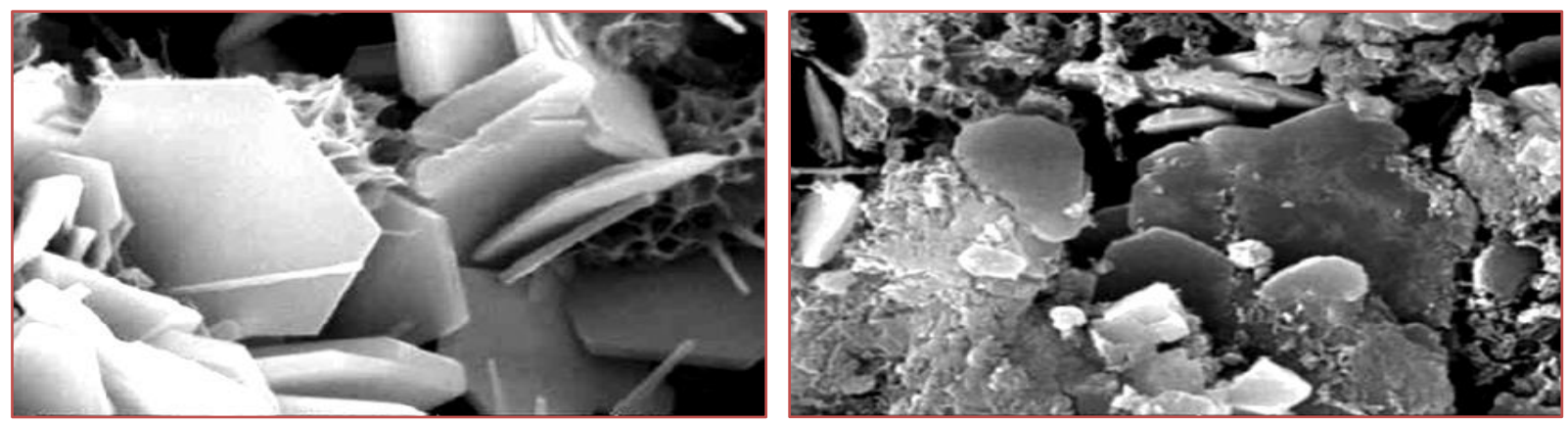

Fonte: Talero (2012)

Em suas pesquisas, Cascudo (1997) afirma que concretos compostos por cimentos com adições de materiais pozolânicos como cinzas de vulcão e argila calcinada, apresentam-se com uma estrutura mais compacta em sua pasta. Além disso, Saraswathy (2007) propõe que a utilização de material pozolânico, com substituição de até $30 \%$ da massa de cimento, reduz consideravelmente a incorporação de cloretos no concreto, pois diminuem a porosidade, além de melhorar as resistências a corrosão. Para a avaliação da resistência do concreto frente aos íons cloreto, o coeficiente de difusão é um dos parâmetros mais importantes. Atualmente, inexistem métodos padronizados pela Associação Brasileira de Cimento Portland - ABCP e pela Associação Brasileira de Normas Técnicas - ABNT, no Brasil. 


\section{METODOLOGIA}

No que se refere à metodologia empregada, implicou-se pesquisa explicativa com fim de obtenção de dados para avaliação da mitigação de cloretos por meio de rotas analíticas aceleradas, as quais avaliam a capacidade de penetrabilidade de cloretos e a difusão de íons já no seio dos espécimes, ambos em corposde-prova cilíndricos $100 \mathrm{~mm}$ de diâmetro e $50 \mathrm{~mm}$ de altura com idade de 28 dias em tanque de cura com temperatura controlada $\left(23^{\circ} \mathrm{C}+2\right)$. Para tal, considerou-se dois níveis de pesquisa sendo os níveis meso para difusividade de tais íons e macro para os ensaios de penetrabilidade:

\subsection{NÍVEL MESO}

Experimentos para a determinação do coeficiente de difusão de cloretos por meio da Norma finlandesa NT Build 492 (NT Build, 1999) Concrete, Mortar and Cement-Based Repair Materials: Chloride Migration Coefficient from Non-Steady-State Migration Experiments.

Figura 4. Aparato e Espécime

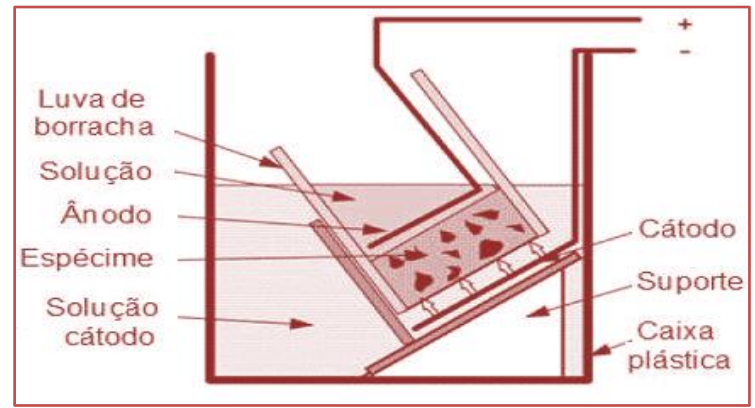

Fonte: Adaptado de NT Build (1999)

No método proposto pela Norma NT Build 492, ilustrado pela Figura 4, aplica-se um potencial elétrico externamente ao espécime (inicialmente 30 volts) forçando a migração dos íons cloreto externos em direção ao outro eletrodo (ânodo). Estando o espécime devidamente vedado em suas extremidades pela luva de borracha, os íons cloreto permeiam o corpo-de-prova, o qual após realização do ensaio, a amostra é dividida axialmente e então é pulverizada uma solução de nitrato de prata (AgNO3) na interface interna das seções divididas. 0 cloreto presente na amostra reage com a solução aspergida formando um composto clarificado de cloreto de prata $(\mathrm{AgCl})$. Mensura-se as profundidades alcançadas pelo cloreto e então calcula-se a difusão.

A construção do aparato seguiu a norma em termos de medida e materiais, os quais utilizou-se como suporte uma caixa plástica com capacidade de 20 litros, um suporte plástico com inclinação de $32^{\circ}$ para o espécime e uma luva de borracha de silicone para vedá-lo e aprisioná-lo. A região clarificada, identificada por círculos na Figura 5, representa o AgCl presente nos espécimes após o ensaio.

Figura 5. Corpo de prova NT Build 492

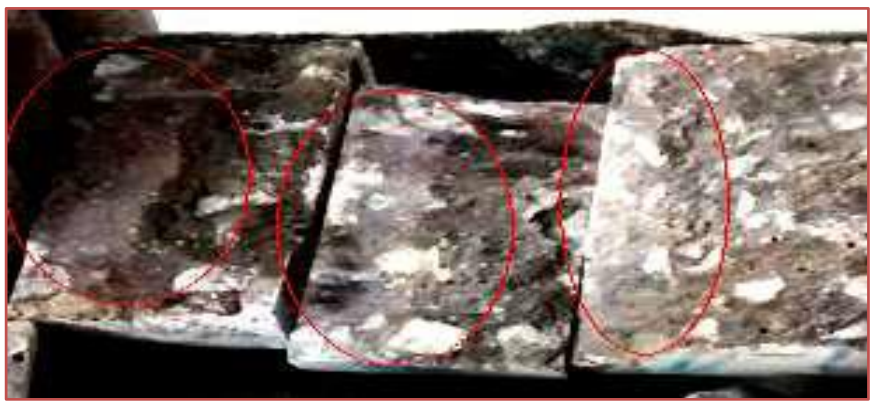

Fonte: Autores 
Tabela 02. Coeficiente de difusão para tipos de cimento Portland.

\begin{tabular}{|c|c|}
\hline$>15$ & Alta \\
\hline 10 a 15 & Moderada \\
\hline 5 a 10 & Baixa \\
\hline 2,5 a 5 & Muito Baixa \\
\hline$<2,5$ & Desprezível \\
\hline
\end{tabular}

Fonte: GJORV (2001)

Particularmente, considerando-se necessidade adicional de classificação do concreto quanto à resistência à difusão dos íons decorrentes do procedimento NT Build 492 mencionado, adotaram-se valores de coeficientes de difusão, apresentados por Gjorv (2001), como referência, tendo sido estes, medidos em diversos tipos de cimento. Tais valores adotados são apresentados na Tabela 2.

\subsection{NÍVEL MACRO}

Determinação de resistência à penetração de íons cloreto segundo a Norma Americana ASTM C1202 (ASTM, 1997) Chloride Ion Penetration Test, Carbonation Depth Test, and Saltscaling Test.

O método referente à Norma ASTM C1202, por sua vez, consiste em monitorar a quantidade de corrente elétrica passante pelos espécimes durante um período de 6 horas e uma diferença de potencial elétrico de 60 Volts em corrente contínua é mantida nas extremidades dos corpos-de-prova, estando um dos lados imerso em solução de cloreto de sódio $(\mathrm{NaCl})$ e o outro em uma solução de hidróxido de sódio $(\mathrm{NaOH})$. A carga total atravessada é então convertida em coulombs e correlacionada com a resistência à penetração dos íons cloreto na amostra, a qual recebe a classificação descrita na Tabela 3.

Tabela 3. Penetrabilidade de cloreto baseado na carga passante

\begin{tabular}{|c|c|}
\hline \multicolumn{2}{|c|}{ Carga passante (coulombs) } \\
\hline$>4.000$ & Elevada \\
\hline $2.000-4.000$ & Moderada \\
\hline $1.000-2.000$ & Reduzida \\
\hline $100-1.000$ & Baixa \\
\hline$<100$ & Insignificante \\
\hline
\end{tabular}

Utilizou-se como aparato, três células eletrolíticas específicas para tal procedimento com o auxílio de três amperímetros. Ambos os ensaios acelerados, (normas NT Build 492 e ASTM C1202) utilizou-se uma fonte de energia elétrica em corrente contínua de quatro canais e capacidade fornecimento de tensões variáveis por canal de 0 a 60 volts, com precisão de $+0,1$ volt, como ilustrado na Figura 6. 
Figura 6. Aparato ASTM C1202

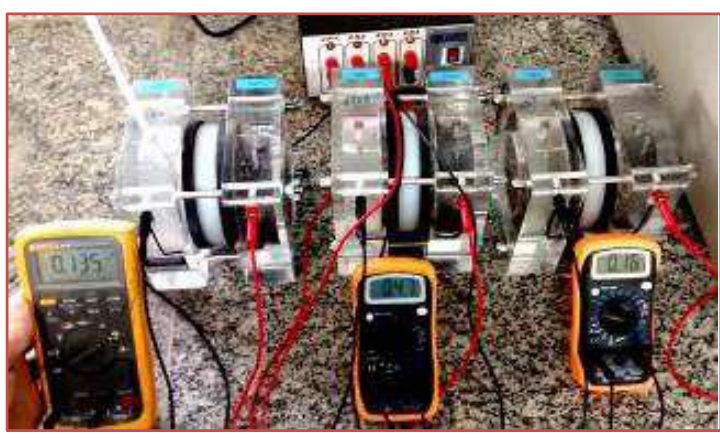

Fonte: Autores

Nesse sentido, ensaiaram-se cinco traços de concreto do tipo simples, representando as três principais classes convencionais: Alta resistência inicial - CPV, composto - CPII E e CPII F e Aditivado - CPIII e CPIV. Para a moldagem e cura dos corpos-de-prova, obedeceu-se à norma NBR 5738 (ABNT, 2003). A composição que dá base para tais traços de concreto se descreve na Tabela 4, a seguir. As identificações e descrições dos cinco tipos de cimentos utilizados, por suas vezes, podem ser verificados na Tabela 5, subsequente.

Tabela 4. Composição base: Traços de $1 \mathrm{~m} 3$ de concreto

\begin{tabular}{|c|c|c|}
\hline \multicolumn{1}{|c|}{ Material } & $\begin{array}{c}\text { Traço } \\
(\mathrm{Kg} / \mathrm{m} 3)\end{array}$ & 15,59 \\
\hline Cimento & 367 & 38,32 \\
\hline Agregado graúdo & 902 & 37,51 \\
\hline Agregado miúdo & 883 & 8,58 \\
\hline Água & 202 & $\%$ \\
\hline
\end{tabular}

Fonte: ABNT (2006)

Tabela 5. Identificações e descrições: Cimentos Composição.

\begin{tabular}{|c|c|c|}
\hline Tipo/Classe & Descrição & Norma/Característica \\
\hline $\mathrm{CPV}$ & $\begin{array}{l}\text { Adição máxima de } 5 \% \text { de material carbonático } \\
\text { (utilizado quando há necessidade de desforma } \\
\text { rápida) }\end{array}$ & $\begin{array}{l}\text { NBR 5.733: Cimento Portland de Alta } \\
\text { Resistência Inicial } \\
\text { (ABNT, 1991a) }\end{array}$ \\
\hline CP II E & $\begin{array}{l}\text { Adição máxima de } 34 \% \text { de escória granulada de } \\
\text { alto-forno (utilizado em ambientes com presença de } \\
\text { sulfatos) }\end{array}$ & $\begin{array}{l}\text { NBR 11.578: Cimento Portland } \\
\text { composto: Especificação } \\
\text { (ABNT, 1997) }\end{array}$ \\
\hline CP II F & $\begin{array}{l}\text { Adição máxima de } 10 \% \text { de material carbonático ou } \\
\text { filer (utilizado no preparo de argamassas de } \\
\text { revestimento, assentamento, pisos e pavimentos de } \\
\text { concreto) }\end{array}$ & $\begin{array}{l}\text { NBR 11.578: Cimento Portland } \\
\text { composto: Especificação } \\
\text { (ABNT, 1997) }\end{array}$ \\
\hline CP III & $\begin{array}{l}\text { Adição máxima de } 70 \% \text { de escória de alto-forno } \\
\text { (utilizado em obras de grande porte e com } \\
\text { agressividades como esgotos, pistas de aeroporto, } \\
\text { concreto protendido e barragens) }\end{array}$ & $\begin{array}{l}\text { NBR 5.735: Cimento Portland de Alto- } \\
\text { Forno } \\
\text { (ABNT, 1991b) }\end{array}$ \\
\hline CP IV & $\begin{array}{l}\text { Adição máxima de } 50 \% \text { de material pozolânicos } \\
\text { (utilizado em obras de grande volume de concreto } \\
\text { devido ao baixo calor de liberado na cura) }\end{array}$ & $\begin{array}{l}\text { NBR 5.736: Cimento Portland } \\
\text { pozolânico } \\
\text { (ABNT, 1999) }\end{array}$ \\
\hline
\end{tabular}


Os traços de concreto em questão, bem como os cimentos utilizados e os ensaios físico-químicos, foram coletados e realizados em laboratório de controle de qualidade de fábrica cimenteira em ambiente controlado $\left(23^{\circ} \mathrm{C}+2\right.$ e mínimo $50 \%$ de umidade relativa) localizada na região metropolitana de Belo Horizonte, no estado de Minas Gerais, Brasil. Vale ressaltar que a relação de água/cimento, em massa, para todos os corpos de prova ensaiados, se fixou em 0,55 , a fim de se obter apenas uma variável como componente de pesquisa (tipo de cimento). Tal valor é concordante com o que se descreve na NBR 6118 (ABNT, 2007), correspondente a componentes e elementos estruturais de concreto armado com classe de agressividade III.

\section{RESULTADOS E DISCUSSÕES}

Os valores determinados para as cargas passantes, segundo ASTM C1202, para cada um dos traços de concreto ensaiado, podem ser verificados na Tabela 6, a seguir.

Tabela 6. Carga passante segundo norma ASTM C 1202

\begin{tabular}{|c|c|c|}
\hline \multicolumn{1}{|c|}{ Concreto composto por: } & 8.298 & Penetração de íons Cloreto \\
\hline CP V Alta Resistência Inicial & 7.371 & Elevada \\
\hline CP II E & 5.022 & Elevada \\
\hline CP II F & 3.285 & Moderada \\
\hline CP III & 1.548 & Reduzida \\
\hline CP IV & Fonte: ASTM (1997)
\end{tabular}

A partir dos valores apresentados na Tabela 6, observa-se que a maior carga passante (8.298 coulombs) ocorreu para o concreto constituído por CPV ARI. Tal cimento é tido como referência devido ao maior teor de clínquer utilizado, mínimo de $90 \%$, o que não garante a complexação por reação química dos íons cloreto. Já o traço, o qual constitui-se com cimento aditivado pozolânico - CPIV (adição máxima de 50\% de material pozolânico), apresentou maior resistência à penetrabilidade de cloretos, medida em 1.548 coulombs - menor valor dentre todos os traços analisados. 0 resultado pode estar ligado diretamente à quantidade elevada de alumina reativa (Al203), proveniente do material pozolânico no cimento, a qual reage com os íons presentes, formando cloro aluminato tricálcico hidratado (3CaO.Al2O3.CaCl2.10H2O).

Com resultado próximo ao observado para CPIV, o concreto com cimento aditivado (CPIII) apresentou carga passante igual a 3.285 coulombs, se classificando como detentor de moderada penetrabilidade aos íons de cloreto. Tal resultado é condizente com a presença majoritária de sílica amorfa (SiO2) oriunda da escória de alto-forno. 0 concreto preparado com cimento composto CPII E (composição: adição de até $34 \%$ em escória de alto-forno) apresentou carga passante igual a 7.371 coulombs. Considerando-se que a adição de materiais pozolânicos e escórias de alto-forno possuem a propriedade de modificação na estrutura do concreto, resultando em diminuição da permeabilidade, bem como a difusividade iônica e porosidade capilar, tal valor ainda se mostrou elevado, segundo a norma ASTM C1202, estando possivelmente relacionado a quantidade global de adição mineral (escória de alto-forno) reduzida em relação aos concretos de cimentos aditivados (CPIII e CPIV), reduzindo assim, a concentração global de sílica amorfa e possível alumina reativa no traço analisado.

Já os corpos-de-prova confeccionados a partir do cimento composto CPII F, apresentou valor de carga passante de 5.022 coulombs. Quando comparado às demais classes de cimento, tal valor se mostrou intermediário, caracterizando-se como detentor de média resistência aos íons cloretos, porém com classificação elevada segundo a norma ASTM C1202. Fatores relacionados à sua produção podem se mostrar como principal causa: adição de até $10 \%$ de calcário calcítico, que apesar de não possuir propriedades quimicamente resistivas ao transporte de cloretos, sugere propriedades físicas que contribuem para tal mitigação, alinhando-se ao boletim técnico BT-106 Associação Brasileira de Cimento Portland (ABCP, 2002), quando afirma que a aplicação deste tipo de cimento melhora a trabalhabilidade do traço de concreto por ter ação "lubrificante" da massa. Segundo tal documento, seus grãos e partículas, quando moídos, adquirem dimensões diminutas adequadas aos espaços intersticiais do cimento e se alojam entre os maiores grãos, reduzindo assim, a porosidade do concreto, o que também é considerado 
primordial no transporte e movimentação de tais íons. Desta forma, tal propriedade intrínseca dos materiais carbonáticos, os quais, quando presentes no cimento recebem o nome de filer calcário, acaba por compensar a não contribuição química para a mitigação dos cloretos.

Ademais, avaliou-se em corpos-de-prova ainda não ensaiados, a capacidade de mitigação do transporte dos íons cloreto, os quais dados obtidos com base na Norma NT Build 492 (NT Build, 1999), são apresentados na Tabela 7, juntamente com as classificações prescritas por Gjorv (2001).

Tabela 7. Coeficiente de Difusão segundo norma NT Build 492

\begin{tabular}{|c|c|c|c|}
\hline \multirow{2}{*}{$\begin{array}{c}\text { Composição dos concretos } \\
\text { CP V ARI }\end{array}$} & $\begin{array}{c}\text { Coeficiente de Difusão } \\
(\mathrm{mm})\end{array}$ & $\begin{array}{c}\text { Poder de Difusão } \\
\text { (Ds x 1012) } \\
\text { (GJORV, 2001) }\end{array}$ & Alta \\
\hline CP II E & 50 & 51 & Alta \\
\hline CP II F & 38 & 38 & Alta \\
\hline CP III & 23 & 23 & Moderada \\
\hline CP IV & 15 & 14 & Baixa \\
\hline
\end{tabular}

Fonte: NT Build (1999)

A partir dos resultados apresentados, é razoável verificar que o valor mais elevado referente ao coeficiente de difusão ( 51 x 10-12 m2/s), se atrela ao traço de concreto preparado com adição do cimento classe CPV, contrapondo-se com os concretos preparados com os cimentos aditivados (CPIII e CPIV), os quais chegam a representar uma redução de aproximadamente $88 \%$ na difusão dos íons, atingindo valores de $6 \times 10-12 \mathrm{~m} 2 / \mathrm{s}$.

Também se observa que os traços de concreto com cimentos compostos (classe II) apresentaram resultados que descrevem o poder de difusão de cloretos como sendo ainda alto segundo Gjorv (2001), porém menores que o de classe CPV. Adicionalmente, e concordante entre os experimentos das duas normas, observa-se que quanto maior o incremento de aditivos minerais em cimentos, maior a resistência do concreto, tanto quanto a penetrabilidade externa, como a transferência de íons no interior dos espécimes.

De forma geral, a partir das Tabelas 6 e 7, verificadas, observa-se que os traços de concreto com cimentos aditivados (CPIII e CPIV) apresentam carga passante, segundo as Normas ASTM C 1202 e NT Build de moderada à reduzida e moderada à baixa, respectivamente. Por outro lado, os traços de concreto com CPV obtiveram classificações caracterizadas como alta em ambos os ensaios normatizados. Tais resultados condizem com obtidos em estudos prévios, cujos ensaios físico-químicos foram conduzidos em condições semelhantes por Mendes (2009) e Fedumenti (2013).

Frisa-se que os resultados observados, até certo ponto, concordaram com o fato de cimentos de alta resistência inicial (Classe CPV) tenderem a apresentar quantidades reduzidas de elementos potencialmente capazes de retenção e/ou mitigação dos íons cloreto, como adições minerais (sílica amorfa, alumina reativa e materiais carbonáticos com distribuição granulométricas mais finas), correlacionando-se com estudo conduzido por Page, Short e Tarras (1981).

Os cimentos que possuem maior quantidade de aditivos minerais, apresentaram os valores mais reduzidos para carga passante e para coeficiente de difusão. Sugere-se que isto seja devido ao fato de que, tanto as escórias de alto-forno quanto os materiais pozolânicos apresentam propriedades hidráulicas mais lentas que o clínquer presente no cimento. Desta forma, a cal hidratada liberada na cura do clínquer torna-se um dos principais ativadores químicos de tais materiais, surgindo assim, em idades mais longas, cristais que se desenvolvem nos espaços intersticiais criados pela água de excesso no concreto já curado e interface externa do concreto, agregando possível resistência mecânica e corroborada mitigação aos íons cloreto.

Vale lembrar que a escória de alto-forno apresenta sílica amorfa em sua composição devido ao processo produtivo do ferro-gusa e o material pozolânico possui grande quantidade de alumina reativa. Tais aditivos minerais se mostraram bastantes resistentes aos íons cloreto, uma vez que, por não possuírem 
arranjo cristalino definido, somado ao fato de suas ativações se darem após a cura do cimento, conseguiram mitigar tais íons potencialmente corrosivos para as estruturas metálicas no interior do concreto.

Frisa-se que as reações químicas, provindas dos íons cloreto com tais aditivos, resultam em cristais sólidos que se precipitam nos poros do corpo rígido, diminuindo, assim, porosidades internas, sejam elas por aumento de volume sólido, sejam por obstrução de interligações de poros.

Notabiliza-se, assim, que os resultados verificados no presente capítulo, em repetição, são análogos aqueles descritos por Mendes (2009) e Fedumenti (2013), os quais afirmam que a principal influência na movimentação dos íons cloreto dá-se pelo tipo de cimento utilizado nos traços de concreto.

\section{CONCLUSÕES}

Na busca por potencial atenuação e/ou mitigação dos íons cloreto, possibilitou-se a avaliação da influência do tipo de cimento Portland em concreto simples representando as três principais classes convencionais: alta resistência inicial (CPV), composto (CPII E e CPII F) e aditivado (CPIII e CPIV). Particularmente, o emprego de cimentos aditivados, propiciaram, de modo geral, redução considerável na movimentação dos íons cloreto por massa sólida de concreto, em relação a cimentos compostos (classe CPII) e de alta resistência inicial (CPV). Tal resultado sugere redução de poros, bem como desconexão entre esses, também indicando reações químicas dos íons cloreto com cristais sólidos presentes. Embasando-se nos ensaios realizados, em fato, confirma-se a capacidade de retenção de íons cloreto em massa sólida de concreto, utilizando-se cimentos prioritariamente aditivados, tanto com escórias de alto-forno quanto materiais pozolânicos. Nesse sentido, em situações em que haja a necessidade de proteção da armadura metálica, motiva-se o emprego de concreto potencialmente resistente à ação dos íons cloreto por meio do tipo de cimento utilizado. Naturalmente, o capítulo embasa aprofundamentos futuros que visem ao complemento de características relacionadas aos traços de concretos abordados, bem como à avaliação de variáveis que tendam à influência de transferências, então, abrangidas.

\section{REFERÊNCIAS}

[1] ABCP. ASSOCIAÇÃO BRASILEIRA DE CIMENTO PORTLAND. Guia básico de utilização do cimento Portland BT-106. 7.ed. São Paulo, 2002. 28p.

[2] ABNT. ASSOCIAÇÃO BRASILEIRA DE NORMAS TÉCNICAS. NBR 5733. Cimento Portland de alta resistência inicial. RJ, 1991a.

[3] ABNT. ASSOCIAÇÃO BRASILEIRA DE NORMAS TÉCNICAS. NBR 5735. Cimento Portland de alto-forno. RJ, 1991b.

[4] ABNT. ASSOCIAÇÃO BRASILEIRA DE NORMAS TÉCNICAS. NBR 5736. Cimento Portland pozolânico. RJ, 1999.

[5] ABNT. ASSOCIAÇÃO BRASILEIRA DE NORMAS TÉCNICAS. NBR 5738. Moldagem e cura de corpos-de-prova de concreto cilíndricos ou prismáticos. RJ, 2003.

[6] ABNT. ASSOCIAÇÃO BRASILEIRA DE NORMAS TÉCNICAS. NBR 6118. Projeto de estruturas de concreto Procedimento. RJ, 2007.

[7] ABNT. ASSOCIAÇÃO BRASILEIRA DE NORMAS TÉCNICAS. NBR 7584. Concreto endurecido - Avaliação da dureza superficial pelo esclerômetro de reflexão - Método de ensaio. RJ, 2012.

[8] ABNT. ASSOCIAÇÃO BRASILEIRA DE NORMAS TÉCNICAS. NBR 11578. Cimento Portland composto com pozolana. RJ, 1997.

[9] ALVES, H. COLAÇO, P. LOURENÇO, Z. Reabilitação de uma estrutura contaminada por cloretos utilizando a técnica da dessalinização. Corrosão e Protecção de Materiais v. 32, n. 1. 2013, p. 5-9.

[10] ANDRADE, C. Manual para Diagnóstico de Obras Deterioradas por Corrosão de Armaduras. Tradução e adaptação: Antônio Carmona e Paulo Helene. São Paulo: PINI, 1992.

[11] ARAÚJO, A. PANOSSIAN, Z. LOURENÇO, Z. Proteção catódica de estruturas de concreto. IBRACOM de estruturas e materiais. v. 6, n. 2, Abr./2013. p. 178-193.

[12] ASTM. AMERICAN SOCIETY FOR TESTING MATERIALS. C-1202. Standard Test Method for Electrical Indication of Concrete's Ability to Resist Chloride Ion Penetration. American Society for Testing and Materials - ASTM, USA, 1997. 
[13] CASCUDO, O. O controle da corrosão de armaduras de concreto: Inspeção e técnicas eletroquímicas. São Paulo, 1997.

[14] CASTRO, A. A. BOLDRIM, M. H. OLIVEIRA, M. A. M. OLIVEIRA, M. L. NUNES, M. A. C. SACRAMENTO, W. P. Revisão bibliográfica das manifestações patológicas nas estruturas de concreto armado por corrosão das armaduras. Revista SODEBRAS v. 12, n. 136, Abr./2017, p. 182-187. ISSN 1809-3957.

[15] CEB. Comité Euro-International du Béton, Bulletin d'Information n 148. Durability of Concrete Structures State-of-the-Art - 1982. Février, 1982.

[16] FEDUMENTI, M. B. Avaliação da influência da cinza de casca de arroz no comportamento de concretos com agregado reciclado de concreto em relação a propriedades mecânicas e de durabilidade, com ênfase no transporte de íons cloreto. RS, 2013.

[17] FIGUEIREDO, E. J. P.; MEIRA, G. R. Corrosão das Armaduras de Concreto. In: ISAIA, G. C. Concreto: Ciência e Tecnologia. São Paulo, IBRACON, v. 1, p. 903-931, 2011.

[18] GJORV, O. E. Service life of concrete structures and performance-based quality control. International Workshop on Innovations Concrete Materials, Whistler, Canada. 2001.

[19] HELENE, P. R. L. Contribuição ao estudo da corrosão em armaduras de concreto armado. São Paulo, SP, 1993.

[20] JINPING, C. XUESONG, Z. The study of durability of the concrete structure. In: E-Product E-Service and EEntertainment (ICEEE), International Conference on , p.1-4, 7-9 November 2010.

[21] MENDES, M. V. A. S. Avaliação das propriedades de transporte de massa em concretos contendo adições minerais. GO, 2009.

[22] NT BUILD. NORDTEST METHOD 492. Concrete, Mortar and Cement-Based Repair Materials: Chloride Migration Coefficient from Non-Steady-State Migration

[23] Experiments. Nordtest, Espoo, Finland, 1999.

[24] PAGE, C. L. SHORT, N. R. TARRAS, A. El. Diffusion of chloride ions in hardened cement pastes. Cement and Concrete Research, v. 11, n. 3. May/1981. p. 395-406.

[25] PEREIRA, V. G. A. Avaliação do coeficiente de difusão de cloretos em concretos: influência do tipo de cimento, da relação a/c, da temperatura e do tempo de cura. RS, 2001.

[26] SARASWATHY, V. SONG. H. W. Corrosion performance of rice husk ash blended concrete. Construction and Building Materials, v. 21, p. 1779-1784, 2007.

[27] TALERO. R. Synergic effect of Friedel's salt from pozzolan and from OPC coprecipitanting in a chloride solution. Construction and Building Materials, v. 33, 2012.

[28] TOVAR, T. ORTIZ, A. V. DURÁN, Y. P. V. Modelo de difusión de cloruros em probetas cilíndricas de hormigón armado sumergidas em água sintética. Revista ION, v. 26, n. 1. Jun./2013. p. 55-62.

[29] TUUTTI, K. Corrosion of steel in concrete. Stockholm, Swedish Cement and Concrete Research Institute, 469p, 1982. US-EIA - UNITED STATES ENERGY INFORMATION ADMINISTRATION.

[30] WAJDOWICZ, C. C. MONTEIRO, P. S. SANTOS, A. P. SANTOS, B. L. Estrutura analítica de partição (EAP) para orçamentos referentes à recuperação de eflorescência e lixiviações em pontes e viadutos de concreto armado. Revista SODEBRAS, v. 12, n. 140, Ago./2017, p. 95-102. ISSN 1809-3957. 


\section{Capítulo 4}

\section{Estudo cinético: Hidrólise alcalina de ésteres:2}

\section{Douglas Antônio Alves de Souza}

\section{Pedro Prates-Valério}

Resumo: Ésteres são compostos orgânicos também aplicáveis às indústrias químicas. Quando associados a uma base forte, como hidróxido de sódio ( $\mathrm{NaOH}$ ), os ésteres tendem a ser hidrolisados, produzindo sais orgânicos e álcool. Considerando aplicabilidades industriais, presente capítulo tem como objetivo estimar parâmetros cinéticos relacionados à reação de hidrólise alcalina dos ésteres acetato de etila, estearina e palmitato de isopropila. Observou-se que os parâmetros cinéticos estimados (Ea, ko, k, rA0) diferiram entre os compostos estudados. Para todos os tratamentos as concentrações de ésteres decresceram com o tempo, se tornando mais rápidas com aumento da temperatura, tendo como base o modelo de Arrhenius.

Palavras-chave: Cinética Química, Modelagem Cinética, Hidrólise Alcalina, Ésteres

Abstract: Esters are organic compounds also applicable to the chemical industries. When associated with a strong base, such as sodium hydroxide $(\mathrm{NaOH})$, the esters tend to be hydrolysed, producing organic salts and alcohol. The present work considers the industrial applicability of esters while estimating kinetic parameters related to the alkaline hydrolysis reaction of ethyl acetate esters, stearin and isopropyl palmitate. It was observed that the estimated kinetic parameters $\left(E_{a}, k_{0}, k, r_{A 0}\right)$ differed between the compounds studied. For all treatments, the concentrations of esters decreased with time, becoming faster with increasing temperature, based on the Arrhenius model.

Keywords: Chemical Kinetics, Kinetic Modeling, Alkaline Hydrolysis, Esters 


\section{INTRODUÇÃO}

Ésteres são compostos derivados dos ácidos carboxílicos pela substituição dos hidrogênios ionizáveis por grupos orgânicos, que podem ser um grupo aquila ou arila. São utilizados em indústrias químicas, dentre as quais as alimentícias, solventes, cosméticas e de produtos de higiene e limpeza. São usuais na forma de líquidos voláteis, sendo empregados como flavorizantes. São também utilizados na produção de polímeros, quando se denominam poliésteres, possuindo ésteres na cadeia principal. Entre tais poliésteres, a aplicação do Politereftalato de etileno - PET se faz amplamente conhecida, por exemplo, na produção de garrafas. Os poliésteres também se utilizam nas indústrias de adesivos, papéis, tintas e tecidos, bem como na indústria de petróleo e biocombustíveis (BHATIA, 2007; BAILEY, 2005; WANG; 2010; ZHAN, 2003).

Vale salientar que, quando associados a uma base forte, como hidróxido de sódio ( $\mathrm{NaOH}$ ), os ésteres podem ser hidrolisados, produzindo um sal orgânico e um álcool. Como exemplo, a hidrólise de acetato de etila resulta em acetato de sódio e álcool etílico. Tais produtos da hidrólise também podem ser utilizados para fins diversos na indústria química, como o estearato de sódio, que é de grande importância na produção de cosméticos e estudos como material de tampão em sistemas anfifílicos e para síntese eficiente de espiroxindoles em meio micelar aquoso. 0 Acetato de sódio, éster gerado do aceto de etila é usado para várias aplicações em alimentos, indústrias e laboratórios. É usado em decapagem, curtimento, como tampão e como componente principal de compressas elétricas. 0 acetado de sódio está sendo estudado para o uso na desnitrificação de águas residuais como um componente de nematicidas. 0 palmitato de isopropila é usado principalmente em cuidados pessoais e cosméticos com formulações como emoliente não-oleoso seco e macio. Pode ser usado como excelente solvente para óleo mineral, silicone e lanolina (BHATIA, 2007; BAILEY, 2005; WANG; 2010; ZHAN, 2003)

Em função do uso de $\mathrm{NaOH}$, a reação recebe o nome saponificação, originando-se, a partir de um éster em solução aquosa de base inorgânica, um sal orgânico e álcool. Através dessa reação, torna-se possível a produção do sabão (ULLAH, 2017). A Figura 1 ilustra a reação da hidrólise alcalina do acetato de etila.

Figura 1. Hidrólise Alcalina do Acetato de Etila

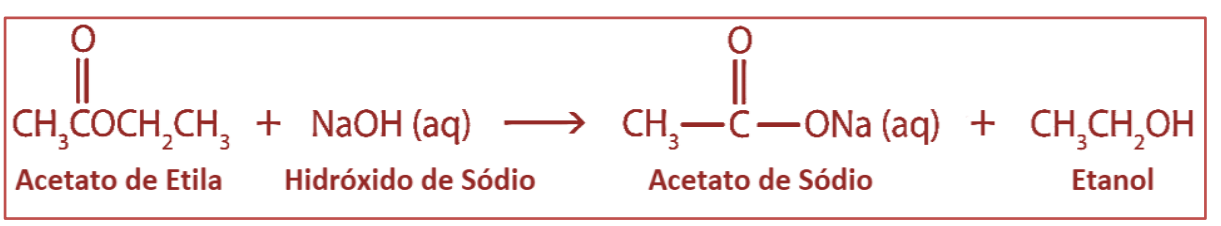

Fonte: Ball (2011)

Ressalta-se que os mecanismos de algumas da reação de saponificação possuem etapas intermediarias, por vezes indesejadas, usualmente quando operadas em reatores industriais (VASCONCELOS, 2015).

De uma forma geral, sob perspectivas industriais, as reações químicas em reatores são parte importante dos processos químicos. Sendo assim, a cinética de reações também se faz um meio para compreensão dos processos no sentido de proporcionar parâmetros que podem auxiliar no design de processos, produtos e reatores, bem como em suas avaliações e monitoramentos. Particularmente, em engenharia, dados e modelos cinéticos são estimados, avaliados e utilizados para projetar processos eficientes bem como reatores de grande escala (FOGLER 2016; KRUPSKA, 2002; VALÉRIO \& CREN, 2017).

A cinética química é a área que estuda a velocidade de reações, envolvendo um reagente ou produto. Em outras palavras, a cinética química também se define como a rapidez com que ocorre uma reação. Tal rapidez, por sua vez, se define como a mudança no número de moléculas (espécies reagentes) por unidade de volume por unidade de tempo. A mudança é proporcional à concentração de espécies reagentes, e se refere à ordem da reação. Especificamente, é relevante retomar o conceito de que a hidrólise de um éster é uma decomposição química que ocorre na presença de uma base inorgânica, envolvendo adição de água e o uso de um catalisador básico (IKHAZUANGBE \& BABALOLA, 2015). 
Figura 2. Ésteres estudados: (a) Estearina, (b). Acetato de etila e (c) Palmitato de isopropila

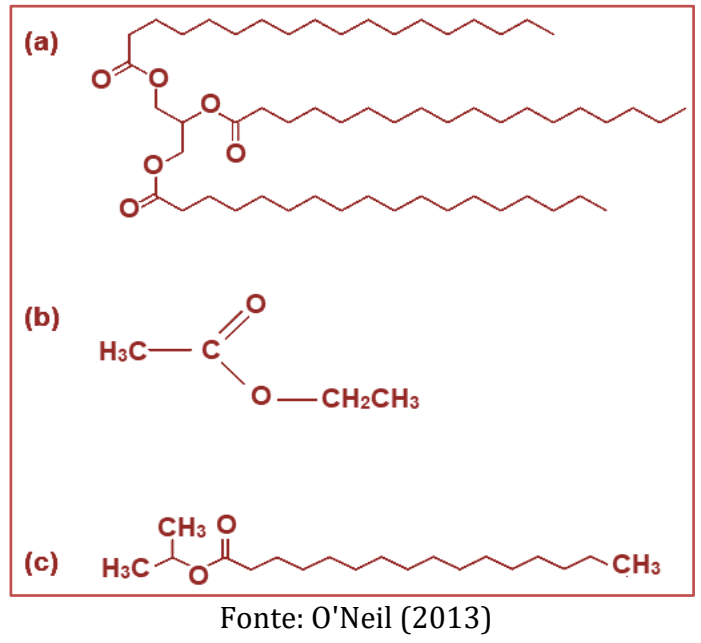

A reação de hidrólise alcalina dos ésteres é bimolecular, relativamente lenta, com ordem global de reação variável, usualmente, ordem 1. Essas características citadas, gera inconvenientes industriais devido a quantidades elevadas de matérias-primas utilizadas e da geração de produtos indesejados. Assim, é de relevância conhecer o sistema de reação trabalhado para elucidação do melhor meio para que a planta industrial seja operada de maneira segura e eficiente (DIAS, 2012; TSUJIKAWA, 1966). Considerando o contexto apresentado, o presente capítulo se desenvolve a partir do objetivo primário de se estimarem parâmetros cinéticos relacionados à reação de hidrólise alcalina dos ésteres acetato de etila, estearina e palmitato de isopropila (Figura 2), também investigando a interferência das cadeias carbônicas na velocidade de formação de produtos.

\section{REFERENCIAL TEÓRICO}

Ésteres apresentam classificações em três subgrupos, sendo lipídeos, ceras e essências. Particularmente, as essências são resultantes da associação de ácidos e álcoois de cadeia curta, formando os flavorizantes artificiais. 0 etanoato de etila é um exemplo de essência cujo flavor característico de maçã verde se utiliza em gomas de mascar e balas. A figura 3 apresenta a reação do ácido etanoico e o álcool etílico, em meio ácido, formando o etanoato de etila (DIAS, 2012).

Estudos recentes envolvendo reações de hidrólise alcalina de ésteres tendem a variar intervalos de temperatura de reação (com variações entre $35^{\circ} \mathrm{C}$ a $55^{\circ} \mathrm{C}$ ) e concentração da base forte (variação da concentração) utilizada. Ainda, a estimativa dos parâmetros cinéticos pode ocorrer em estudos que envolvem reatores contínuos e em batelada (KUHELI et al., 2011; DANISH et al., 2015; TSUJIKAWA, 1966; BURSALI et al., 2006; AHMAD, 2013; GARCIA, 2017).

Figura 3. Reação de esterificação do etanoato de etila

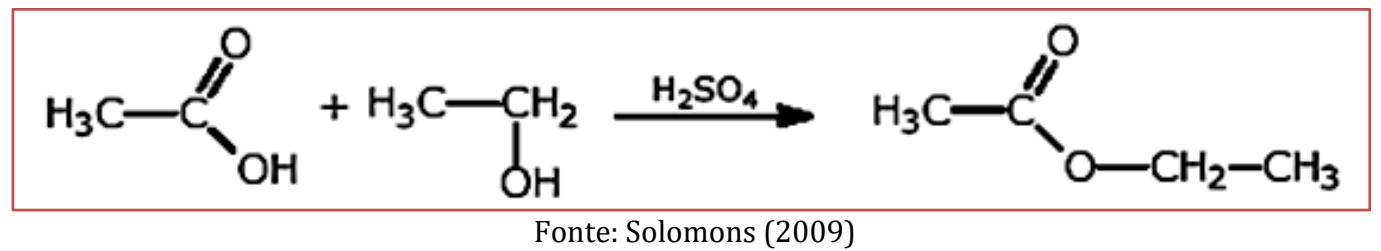

Sob a ótica da cinética química, segundo FOGLER (2016), as reações químicas estão relacionadas ao contato das moléculas e a uma quantidade de energia necessária para tais moléculas se distorcerem, alongarem ou quebrarem suas ligações, eventualmente formando novas estruturas. Essa energia é conhecida como energia de ativação e pode ser interpretada como uma barreira que os reagentes devem vencer para formação de produtos. Quanto maior a energia de ativação, mais lenta tende a ser a reação, 
consequentemente quanto menor a energia de ativação, menor a barreira energética e mais rápida a reação.

Segundo o mesmo autor, a energia de ativação pode ser determinada através de experimento que considera uma determinada reação, em diferentes temperaturas absolutas. A Lei de Arrhenius pode ser considerada a que possui ampla utilização em estudos sobre a cinética de reações, inclusive pela viabilidade experimental, também sendo expressa por meio de apenas duas variáveis usualmente dependentes. Geralmente, a Lei se aplica a temperaturas elevadas, com contribuição para frequência de colisão molecular. Considerando este conceito, a velocidade da reação química se indica diretamente relacionada ao efeito da elevação de temperatura, podendo ser calculada pela equação que a ela se atrela (ESPERSON,1981).

A velocidade de reações químicas tende a ser estudada por meio de correlações que consideram dados e modelos cinéticos. Diferentes métodos se empregam nas análises de dados experimentais, destacando-se o integral, o diferencial, o de meias-vidas, o das velocidades iniciais, o da regressão linear e o de regressão não-linear. A adequação de cada um dos métodos mencionados pode incluir relação com o mecanismo de reação e o tipo de reator (FOGLER, 2016).

Para a reação cujo enfoque tem origem no presente capítulo, recomenda-se reatores em batelada, operando isotermicamente, com coleta de dados em regime transiente e concentração medida em função do tempo. Sendo assim, os métodos integral e diferencial se adequam ao propósito (VASCONCELOS, 2015).

0 método diferencial tende a ser utilizado com aplicação direta da equação diferencial da velocidade a qual busca-se avaliação (FOGLER, 2016). 0 método integral, por sua vez, se atrela a relativa simplicidade, se empregando com frequência na estimativa de parâmetros cinéticos, em reações químicas. Salienta-se que o reconhecimento da ordem da reação se faz necessário, acompanhado de cálculos para velocidades específicas, envolvendo diferentes temperaturas, embasando experimentos que se originam também no sentido da determinação de energias de ativação. Assim, a aplicação do método integral acompanha integrações de equações diferenciais, as quais modelam sistemas usualmente em batelada (VASCONCELOS, 2015). Ressalta-se que, sendo assim, estimativas cinéticas também se aplicam às avaliações de comportamento de classes de ésteres, em hidrólise alcalina, viabilizando proposição de comparações envolvendo teoria e dados experimentais.

\section{METODOLOGIA}

\subsection{PREPARO DAS AMOSTRAS E SOLUÇÕES REAGENTES}

Inicialmente, as vidrarias foram submetidas à lavagem com ácido nítrico a $1 \%(\mathrm{v} / \mathrm{v})$, seguida por um banho com água e sabão neutro, e enxágue abundante com água deionizada. A secagem ocorreu à temperatura ambiente.

Particularmente, as amostras consistiram nas três seguintes classes de ésteres: acetato de etila, estearina e palmitato de isopropila. Para cada um dos ésteres em questão, soluções aquosas foram preparadas considerando-se três diferentes concentrações (0,04 Mol.L-1,0,08 Mol.L-1 e 0,1 Mol.L-1). 0 reagente consistiu em hidróxido de sódio ( $\mathrm{NaOH})$, em solução aquosa (0,1 Mol.L-1). Para tanto, 4 gramas do soluto foram pesados e completamente dissolvidos em 1 litro de água destilada.

\subsection{ETAPA DE AQUECIMENTO}

A etapa de aquecimento considerou um passo analítico prévio, como forma de se determinar a concentração de éster a ser utilizada em etapa posterior de estimativa dos parâmetros cinéticos. Sendo assim, tal passo foi conduzido em batelada, considerando a adição conjunta de $100 \mathrm{~mL}$ de $\mathrm{NaOH}(0,1$ Mol.L-1) e $100 \mathrm{~mL}$ de cada uma das seguintes soluções preparadas para os ésteres estudados (0,04 Mol.L1, 0,08 Mol.L-1 e 0,1 Mol.L-1), em erlenmeyers de $250 \mathrm{~mL}$. Nesse sentido, previamente às misturas das soluções em questão, promoveu-se o aquecimento individual do reagente e das amostras, até que suas temperaturas iniciais (t0: $298 \mathrm{~K}$ ) fossem atingidas. Assim, o experimento foi conduzido em condições isotérmicas. 0 monitoramento das temperaturas considerou termômetros digitais com precisão igual a \pm $1^{\circ} \mathrm{C}$. Frisa-se que a amostragem foi realizada em triplicata, com cada replicata igual a $10 \mathrm{~mL}$. Assim sendo, onze pontos de tempo $(0,30,60,90,120,150,180,210,240,270$ e 300 segundos) foram considerados para a amostragem dos ésteres estudados, em cada uma das concentrações para eles preparadas (MUKHTAR, 2008). 
Com base nos resultados obtidos, a concentração 0,1 Mol.L-1, cuja degradação variou entre 30\% e 60\%, no intervalo de tempo proposto, foi considerada para execução do passo definitivo de aquecimento e estimativa dos parâmetros cinéticos.

Desta forma, três diferentes temperaturas foram aplicadas em passo denominado definitivo, combinando os mesmos tempos descritos anteriormente, para cada um dos ésteres. A tabela 1 apresenta tais condições de tratamento térmico.

Tabela 1. Condições de tratamento térmico para os Ésteres estudados

\begin{tabular}{|c|c|c|}
\hline \multicolumn{1}{|c|}{ Éster } & $\begin{array}{c}\text { Tempos } \\
\text { (segundos) }\end{array}$ & $\begin{array}{c}\text { Temperaturas } \\
(\mathrm{K})\end{array}$ \\
\hline (0,1 mol/L) & $0 ; 30 ; 60 ; 90 ; 120 ; 150 ;$ \\
Acetato de Etila & $180 ; 210 ; 240 ; 270 ; 300$. & 288,$15 ; 298,15 ; 308,15$ \\
\hline Estearina & $0 ; 30 ; 60 ; 90 ; 120 ; 150 ;$ & 288,$15 ; 298,15 ; 308,15$ \\
\hline \multirow{2}{*}{ Palmitato de Isopropila } & $180 ; 210 ; 240 ; 270 ; 300$. & 288,$15 ; 298,15 ; 308,15$ \\
\hline
\end{tabular}

Fonte: Autores

\subsection{DETERMINAÇÃO DAS CONCENTRAÇÕES DOS ÉSTERES}

Ao longo da etapa de aquecimento, os ésteres foram determinados por método titulométrico, como forma de monitoramento de suas concentrações e degradações. Para tanto, cada alíquota de amostra coletada foi transferida para um segundo erlenmeyer de $125 \mathrm{~mL}$ contendo $25 \mathrm{~mL}$ de solução ácido clorídrico $0,1 \%$ (v/v) padronizado, sob agitação, à temperatura ambiente.

A presença do ácido clorídrico em excesso viabiliza a neutralização da solução a ser analisada, assegurando interrupção das reações, no sentido de obtenção de resultados representativos (KUHELI, 2011). Especificamente, a etapa de titulação foi realizada com solução padronizada NaOH 0,1 Mol.L-1 e adição de solução indicadora fenolftaleína, determinando-se a concentração de ésteres de forma indireta, a partir de íons hidroxila, segundo IKHAZUANGBE \& BABALOLA (2015).

\subsection{MODELAGEM CINÉTICA}

Para a etapa de modelagem cinética aplicou-se método integral. As concentrações de ésteres foram apresentadas na forma adimensional (CA/CA0), em diferentes intervalos de tempo de aquecimento $(\mathrm{t}$ ), sendo CA a concentração de ésteres (mol/L) no tempo t, CA0 a concentração de ésteres (mol/L) no tempo inicial t0 e CB a concentração de $\mathrm{NaOH}$ (mol/L) no tempo t.

Para a determinação das energias de ativação Ea e fator de frequência relacionados às reações de degradações, a equação (1) foi considerada, a partir da qual verifica-se que a taxa de degradação $\mathrm{dC} / \mathrm{dt}$ é proporcional à enésima potência da concentração de cada uma das classes de ésteres estudadas, em qualquer momento t. Destaca-se que k (s-1) é a velocidade específica e n é a ordem das reações.

$$
\frac{d C}{d t}=-k C_{A}{ }^{n} C_{B}{ }^{n}
$$

A constante de velocidade é assumida como variando com a temperatura segundo a Lei de Arrhenius, conforme equação 2 a seguir.

$$
k=k_{0} \exp \left[\frac{-E_{2}}{R T}\right]
$$


Ou, linearizando a expressão acima, obtem-se:

$$
\ln (k)=1 n\left(k_{0}\right)-\left[\frac{E_{a}}{R T}\right]
$$

Sendo:

ko: Fator de frequência, Ea: Energia de ativação, R: constante universal dos gases $(8,3144621$ $\mathrm{J} \cdot \mathrm{K}-1 \cdot \mathrm{mol}-1)$, $\mathrm{T}(\mathrm{K})$ : Temperatura medida em escala absoluta.

\section{RESULTADOS E DISCUSSÕES}

Confirme se pode verificar na Figura 4, as variações das concentrações relativas dos ésteres estudados (acetato de etila, estearina e palmitato de isopropila) são plotadas ao longo do tempo de aquecimento, considerando o passo analítico prévio (conforme descrito no item 3.2).

Figura 4. Variações das concentrações relativas de ésteres, ao longo do tratamento térmico (298,15 K): (a) Acetato de Etila, (b) Estearina e (c) Palmitato de Isopropila

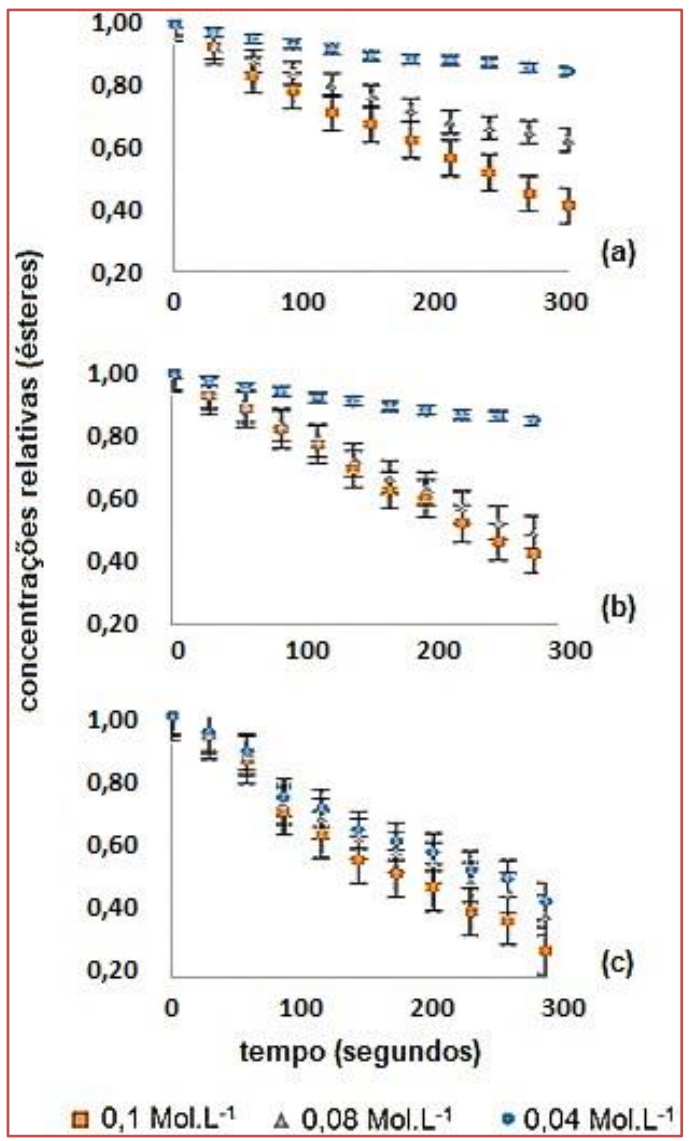

A figura 4 possibilita observar que a concentração de ésteres varia com o tempo de aquecimento, considerando condições isotérmicas. Verifica-se, ainda, que as concentrações iniciais, para os três ésteres estudados, reduziram ao longo do aquecimento. Nota-se, contudo, que para as concentrações de ésteres iguais a $0,04 \mathrm{~mol}$ e $0,08 \mathrm{~mol}$ os percentuais de degradação não superaram, respectivamente, $20 \%$ e $40 \%$ para acetato de etila, 15\% e 40\% para Estearina e 5\% e 10\% para Palmitato de Isopropila, no intervalo de aquecimento proposto. Em contrapartida, considerando as concentrações de ésteres iguais a 0,1 mol os percentuais de degradação se aproximaram de $60 \%$ para acetato de etila, 55\% para Estearina e $20 \%$ para 
Palmitato de Isopropila, no mesmo intervalo de aquecimento. Observa-se que os experimentos conduzidos considerando a concentração de 0,1 Mol.L-1, quando comparados com aqueles conduzidos considerando 0,04 Mol.L-1 e 0,08 Mol.L-1 resultaram em conversões mais significativas dos ésteres acetato de etila, estearina e palmitato de isopropila em acetato de sódio, estearato de sódio e palmitato de isopropila, respectivamente. É razoável sugerir que tais diferentes conversões se relacionam intimamente com o fato de o reagente não se fazer limitante nas reações propostas a 0,1 Mol.L-1. De fato, sabe-se que diferenças em proporções entre reagentes podem acarretar na impossibilidade da continuidade de reações, limitando conversões em produtos. Nesse sentido, a concentração 0,1 foi considerada para execução de passo definitivo de aquecimento e estimativa dos parâmetros cinéticos, uma vez feita representativa para os propósitos do capítulo, estudado, em questão.

A figura 5 ilustra os resultados obtidos para o passo definitivo, também proposto no item 3.2 do presente capítulo, portanto, considerando as temperaturas 288,15 K, 298,15 K e 308,15 K para as reações envolvendo 0,1 Mol.L-1 dos ésteres acetato de etila, estearina e palmitato de isopropila.

A partir da figura 5, observa-se redução nas concentrações adimensionais de todos os ésteres estudados, para todas as temperaturas propostas, ao longo do tratamento térmico. Verifica-se ainda que tais degradações, tendendo ao decréscimo, se tornaram mais rápidas com o aumento das temperaturas de tratamento, para todas as classes de ésteres.

Observa-se que o acetato de etila que apresentou uma maior degradação na temperatura mais elevada estudada (308,15 K). Dessa forma, considerando que a cadeia carbônica do palmitato de isopropila e da Estearina é maior do que a do acetato de etila e pode-se sugerir que os tamanhos de tais cadeias carbônicas tendem a interferir nas velocidades das reações de hidrólises de ésteres, se mostrando inversamente proporcionais.

A figura 6 possibilita determinar influência definitiva da temperatura nas degradações. Sendo assim, tendo como base o modelo de Arrhenius, os dados de concentração apresentados foram utilizados para a construção de gráficos que consideraram ln (CA/CA0) em função do tempo de reação.

Figura 5. Variações das concentrações relativas de ésteres (0,1 Mol.L-1), em função do tempo de aquecimento, em temperaturas propostas: (a) acetato de etila, (b) estearina (c) palmitato de isopropila

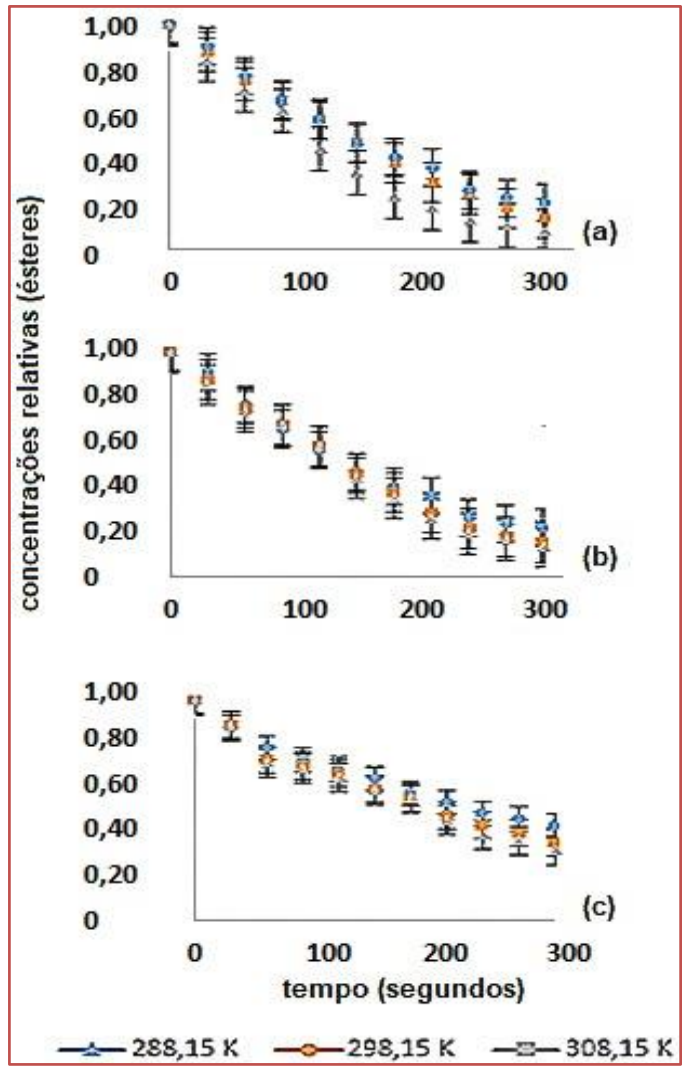


Ainda, verifica-se que os resultados obtidos entre as temperaturas 288,15 K, 298,15 K e 308,15 K também reforçam a indicação de que tal modelo de primeira ordem se mostra apropriado para descrever as reações de degradações dos ésteres Acetato de etila, estearina e Acetato de etila, se ajustando bem aos dados experimentais.

Com relevância, frisa-se que o método polinomial foi adicionalmente testado, referindo-se aos dados numéricos. Tais testes adicionais demonstraram que o valor do coeficiente de determinação obtido para tal método polinomial $(\mathrm{R} 2=0,723)$ pode ser sugerido como relativamente insatisfatório, quando comparado ao método integral aplicado para os dados obtidos experimentalmente.

Pelo método das diferenças finitas, percebe-se que os dados não tiveram um bom ajuste devido ao valor do coeficiente de determinação $\left(R^{2}=0,8217\right)$. Além disso, segundo este método, a ordem estimada para a reação foi igual a 3,9891. Tal valor não condiz com a ordem comumente reportada na literatura (VASCONCELOS et al., 2015 \& IKHAZUANGBE,2015) ou com resultado já mencionado e obtido pelo método integral.

Figura 6. In (CA/CA0), em função do tempo de aquecimento, nas temperaturas propostas: (a) acetato de etila, (b) estearina (c) palmitato de isopropila

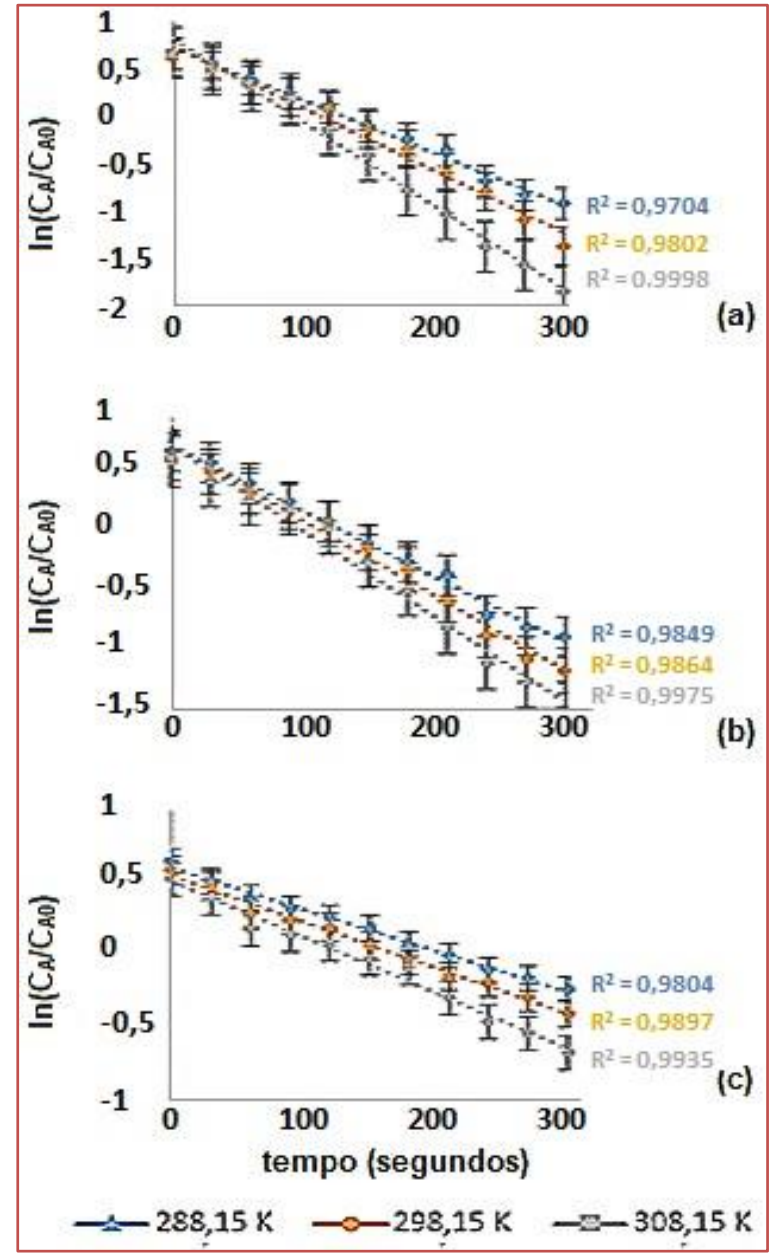

Em cronologia, portanto, as análises viabilizaram tradução de resultados analíticos em coordenadas para a construção do gráfico ln (k) em função da temperatura (T-1), ilustrado pela figura 7 . 
Figura 7. Gráfico de ln (k) em função de T-1, para acetato de etila, estearina e palmitato de isopropila

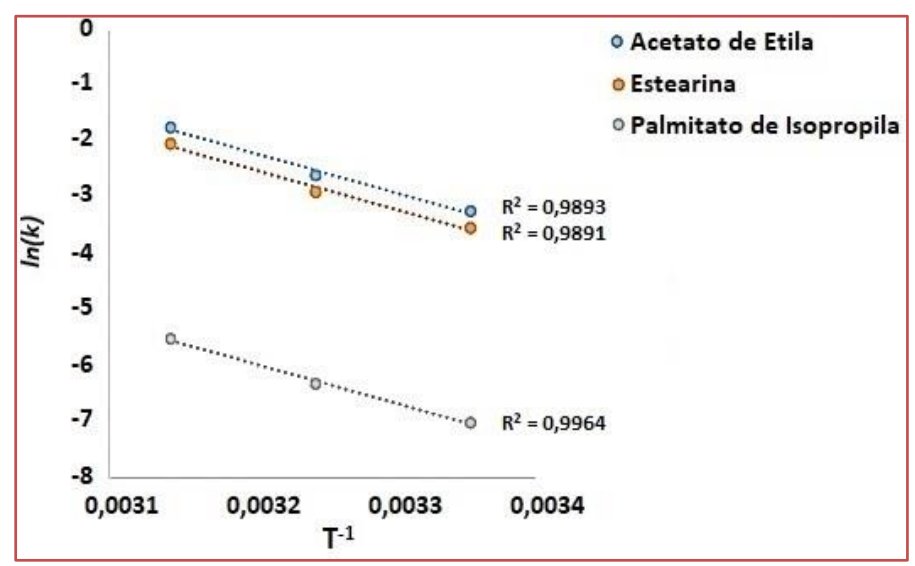

A partir da referida figura 7, considerando-se coeficientes angulares das retas e regressões lineares, viabilizaram-se cálculos das energias de ativação para as reações propostas. Os valores estimados para os parâmetros cinéticos relacionados às classes de ésteres abordadas neste capítulo se encontram compilados na tabela 2, em subsequência.

Sob a ótica de processos, segundo Fogler (2016), salienta-se que em sistemas líquidos, a constante de velocidade pode depender de parâmetros como a força iônica e o solvente escolhido, ainda que essas variáveis causam um efeito muito menor que a temperatura, pode ser comprovado através dos experimentos que há uma diferença considerável nas constantes de velocidade dos ésteres estudados. É importante ressaltar que a constante de velocidade é diretamente proporcional ao aumento da temperatura, isso foi confirmado no experimento realizado.

Tabela 2. Parâmetros cinéticos estimados para as classes de ésteres

\begin{tabular}{|c|c|c|c|c|}
\hline Classes de Ésteres & $(-\mathrm{rA0})$ & $\mathrm{k}(\mathrm{s}-1)$ & $\mathrm{Ea}(\mathrm{kJ} / \mathrm{mol})$ & k0 (s-1) \\
\hline Acetato de Etila & 0,0121 & 0,0039 & 58,89 & $7,79 \times 108$ \\
\hline Estearina & 0,0110 & 0,0029 & 58,87 & $5,7 \times 108$ \\
\hline Palmitato de Isopropila & 0,008 & 0,0009 & 58,74 & $1,72 \times 107$ \\
\hline
\end{tabular}

Fonte: Autores

Nota-se que a maior energia de ativação é do acetato de etila. Isso significa que dentre os ésteres estudados, o acetato de etila apresenta uma maior sensibilidade de velocidade de reação a variações de temperatura, o que foi comprovado em todo o experimento (FOGLER, 2016). Fazendo-se uma alusão à teoria das colisões, sabe-se que o aumento da temperatura do sistema tem como consequência o aumento das velocidades de reação. Com os resultados obtidos dos experimentos, nota-se que aumentos ou reduções nas temperaturas de processo tenderão a acarretar em variações também próximas nas sensibilidades dos ésteres. Assim, em temperaturas mais elevadas o acetato de etila seria consumido primeiro, seguido pela Estearina e por fim o palmitato de isopropila, mais uma vez confirmando que o aumento da cadeia carbônica tem como resultado uma menor velocidade de reação.

\section{CONCLUSÕES}

Foi possível estimar parâmetros cinéticos relacionados à reação de hidrólise alcalina dos ésteres acetato de etila, estearina e palmitato de isopropila, também investigando a interferência das cadeias carbônicas na velocidade de formação dos produtos formados. Os resultados obtidos para a determinação da velocidade da reação estudadas mostram que as taxas de variação dependem da concentração dos reagentes. Portanto, é possível representar essa dependência em termos de equações diferenciais que representam a lei de velocidade. As soluções dessas equações podem ser utilizadas para prever as 
concentrações de espécies, em qualquer momento após o início da reação. A forma da lei de velocidade também fornece certa compreensão sobre a série de passos elementares através dos quais a reação ocorre, como a determinação da constante de velocidade, que é diretamente proporcional ao aumento da temperatura. Isso foi confirmado no experimento realizado, onde se notou que os valores de velocidade para a reação de hidrólise dos ésteres aumentaram juntamente com a temperatura. Por fim, pode-se concluir que o aumento na cadeia carbônica é inversamente proporcional a velocidade de reação de hidrólise de ésteres, devido um menor rendimento para um mesmo tempo. Seguindo esse contexto, conclui-se que o experimento apresentou uma confiabilidade nos resultados e uma metodologia eficiente para a determinação dos parâmetros cinéticos estudados.

\section{REFERÊNCIAS}

[1] AHMAD, A., Ahmad, M.I., Younas, M., Khan, H., Shah, M.H., 2013. A Comparative Study of Alkaline Hydrolysis of Ethyl Acetate using Design of Experiment. Iran. J. Chem. Chem. Eng. 32(4), pp.33-47.

[2] AL MESFER, M. K. Experimental Study of the Influence of Process Conditions on Tubular Reactor Performance. Journal of Engineering and Applied Sciences, v. 3, n. 1, 2016.

[3] BAILEY, Alton Edward et al. Bailey's industrial oil \& fats products. 2005.

[4] BALL, David W.; Hill, John W.; and Scott, Rhonda J., "The Basics of General, Organic, and Biological Chemistry, v. 1.0" (2011). Chemistry Department Books.2. http://engagedscholarship.csuohio.edu/scichem_bks/2

[5] BHATIA, S. et al. Production of isopropyl palmitate in a catalytic distillation column: Comparison between experimental and simulation studies. Computers \& chemical engineering, v. 31, n. 10, p. 1187-1198, 2007.

[6] BURSALI, N., Ertunc, S., Akay, B., "Process improvement approach to saponification reaction using statistical experimental design" CHEM ENG PROCESS, 45 (2006), pp.980-989

[7] DANISH, M., Al Mesfer, M.K., Rashid, M.M., 2015. Effect of Operating Conditions on CSTR Performance: an Experimental Study, Int. J. Eng. Res. Appl. 5, pp.74-78.

[8] DIAS, Marcio Andrade. Modelagem cinética da esterificação de sec-butanol com ácido acético e estudo de monitoramento em linha da reação com espectroscopia de infravermelho. Tese de Doutorado. Universidade de São Paulo. 2012.

[9] ESPERSON J.H., Chemical Kinetics and Reaction Mechanism, 2nd Edition, New York, MCGraw-Hill. 1981.

[10] FOGLER H. S. Collection and Analysis of Rate Data. In: Fogler HS, editor. Elements of Chemical Reaction Engineering, 5a edição. New Jersey: Prentice Hall PTR. p 258-263, 2016.

[11] GARCIA, Carolina Gonçalves. VALÉRIO, Pedro Prates. Estudo da cinética de degradação térmica do óleo vegetal de palma. Revista e- xacta. Belo Horizonte, Uni-BH, 2017. V. 10 p, n. 2.

[12] IKHAZUANGBE, Prosper Monday Ohien; ONI, Aisosa Babalola. Reaction rate and rate constant of the hydrolysis of ethyl acetate with sodium hydroxide. American Journal of Scientific and Industrial Research, v. 6, p. 1-4, 2015.

[13] KHAN, Ihsan \& Ahmad, Muhammad Imran \& Younas, Mohammad. (2015). Optimization of saponification reaction in a continuous stirred tank reactor (CSTR) using design of experiments. Pakistan Journal of Eng. Appl. Sci. 16. 82-92.

[14] KRÜGER, Adolfo Guilerme; REIS, Camila dos Santos; POSTAL, Kahoana. Cinética da saponificação do Acetato de Etila - Determinação da constate de velocidade da reação, Universidade Federal do Paraná. Curitiba: 2013.

[15] KRUPSKA, A. et al. Determination of the rate constants from phase delay effect in chemical reactions. Kinetics and catalysis, v. 43, n. 3, p. 295-302, 2002.

[16] KUHELI.D., Sahoo. P., Saibaba. M., Murali. N, Swaminathan. P., 2011. Kinetic Studies on Saponification of Ethyl Acetate Using an Innovative Conductivity -Monitoring Instrument with a Pulsating Sensor,Int. J. Chem. Kinet 43, pp. 648-656.

[17] MUKHTAR, Hamid; HAQ, I. Production of alkaline protease by Bacillus subtilis and its application as a depilating agent in leather processing. Pak. J. Bot, v. 40, n. 4, p. 1673-1679, 2008.

[18] O'NEIL, Maryadele J. (Ed.). The Merck index: an encyclopedia of chemicals, drugs, and biologicals. RSC Publishing, 2013.

[19] SOLOMONS, T. W. Graham; Fryhle, Craig B. Química Orgânica, v. 2.9 ed. LTC - Livros Técnicos e Científicos Editora S. A., Rio de Janeiro, 2009. 
[20] TSUJIKAWA H. and Inome H., The reaction Rate of Alkaline Hydrolysis of Ethyl Acetate, Bulletin of Chemical Society of Japan, 39(9), 1837-1842(1966)

[21] ULLAH, Ihsan; AHMAD, Muhammad Imran. Optimization of Saponification Reaction in a Continuous Stirred Tank Reactor. NFC IEFR Journal of Engineering and Scientific Research, v. 1, 2017.

[22] VALÉRIO P.P.; CREN E.C. 2017. Kinetic Predictions of Total Carotenoids Retention in Macauba Oil Under Interesterification Conditions. Sodebras Journal. 12(141):219-224. ISSN 1809-3957.

[23] VASCONCELOS, Suênia Fernandes et al. Obtenção e análise dos dados cinéticos da reação de hidrólise alcalina de ésteres do Acetato de Etila em um reator Batelada agitado. Blucher Chemistry Proceedings, v. 3, n. 1, p. 943-951, 2015.

[24] WANG, Li-Min et al. Sodium stearate-catalyzed multicomponent reactions for efficient synthesis of spirooxindoles in aqueous micellar media. Tetrahedron, v. 66, n. 1, p. 339-343, 2010

[25] ZHAN, Y. Q. et al. Sodium stearate, an effective amphiphilic molecule buffer material between organic and metal layers in organic light-emitting devices. Applied physics letters, v. 83, n. 8, p. 1656-1658, 2003. 


\section{Capítulo 5}

\section{Estudo da cinética de degradação térmica considerando óleo vegetal Palma}

\section{Carolina Gonçalves Garcia}

Pedro Prates-Valério

Resumo: A palmeira Elaeis guineensis se destaca mundialmente, nos contextos econômicos e industriais. O óleo extraído da palma apresenta teores elevados de compostos nutracêuticos, dentre os quais carotenóides $(1300 \mu \mathrm{g} / \mathrm{g})$. Seu processamento térmico contribui com reações de degradação e isomerização destes compostos, influenciando produtos finais. 0 presente capítulo considera a cinética de degradação térmica ( $\mathrm{T}=403,15 \mathrm{~K}$ a 423,15K) de carotenóides, presentes em óleo de palma. Em monitoramento, realizam-se análises laboratoriais baseadas em espectrofotometria. Em contextos industriais, resultados sugerem maior retenção do composto estudado quando o processamento é conduzido a temperaturas preferencialmente reduzidas, respeitando uma cinética de degradação de primeira ordem. Assumiu-se que as constantes de velocidade $(k)$ estimadas variaram com a temperatura absoluta $(\mathrm{K})$, de acordo com a Lei de Arrhenius. A energia de ativação para a degradação térmica dos carotenoides no óleo estudado foi estimada como sendo igual a $42 \mathrm{~kJ} / \mathrm{mol}$.

Palavras-chave: Cinética; Processamento Térmico; Carotenóides; Óleo de Palma

Abstract: The Elaeis guineensis palm stands out globally, in economic and industrial contexts. The oil extracted from the palm has high levels of nutraceutical compounds, among them carotenoids $(1300 \mu \mathrm{g} / \mathrm{g})$. Its thermal processing contributes to reactions of degradation and isomerization of these compounds, influencing final products. The present chapter considers the thermal degradation kinetics ( $T=403,15 \mathrm{~K}$ to $423,15 \mathrm{~K}$ ) of carotenoids present in palm oil. Under monitoring, laboratory tests are performed based on spectrophotometry. In industrial contexts, results suggest higher retention of the studied compound when the processing is conducted at preferentially reduced temperatures, respecting first order degradation kinetics. It was assumed that the estimated velocity constants $(\mathrm{k})$ varied with the absolute temperature (K), according to the Arrhenius Law. The activation energy for the thermal degradation of the carotenoids in the studied oil was estimated to be equal to $42 \mathrm{~kJ} / \mathrm{mol}$.

Keywords: Kinetics; Thermal Processing; Carotenoids; Palm oil 


\section{INTRODUÇÃO}

Óleos vegetais se fazem relevantes na formulação e preparação de vários tipos de alimentos, atribuindo características sensoriais e tecnológicas distintas. Além disto, constituindo fontes concentradas de energia do gênero alimentício, são componentes nutricionais da dieta humana, fornecendo ácidos graxos essenciais, energia e vitaminas lipossolúveis, além de ampla variedade de componentes minoritários, dentre os quais os carotenóides (O’BRIEN, 2004; HOFFMANN, 1989). Como biomoléculas lipídicas, os óleos vegetais possuem elevada solubilidade em solventes orgânicos, com baixa solubilidade em água. São formados predominantemente por ésteres de triacilgliceróis, produtos resultantes da esterificação entre ácidos graxos e glicerol - álcool original. De forma geral, à temperatura ambiente, os triacilgliceróis denominam-se óleos, quando se encontram sob a forma líquida. Quando se encontram sob a forma sólida, são denominados gorduras (APOLINARIO et al., 2011)

No contexto de fontes naturais de óleos vegetais, a palmeira Elaeis guineensis ocupa posição de destaque mundial, com produção próxima a 62,35 milhões de toneladas (safra de 2014/2015). Com uma produtividade média igual a 5 toneladas por hectare, a palma supera inúmeras oleaginosas cultivadas de forma intensiva (SHEIL et al., 2009; SANTOS, 2008). Enfatizando sua produtividade em óleo, por área cultivada, esta se faz, em média, dez vezes mais elevada do que culturas como a soja (BASIRON, 2005). A palmicultura é caracterizada como uma atividade que possui diversos benefícios socioambientais, como a promoção da geração de emprego e renda; melhoria na renda dos trabalhadores e, consequentemente na sua qualidade de vida; aceleração do comércio local; redução do êxodo rural, com a fixação do homem no campo, com disponibilidade de emprego. Aproximadamente cinco milhões de famílias brasileiras exercem atividades profissionais relacionadas à cultura, incluindo as que se atrelam às indústrias químicas (HOMMA et al. 2000; LEVERMANN; SOUZA \& VILAS BOAS, 2002; BRITO, 2014).

Sob a ótica do processamento de óleos vegetais, incluindo o intuito alimentício, determinados óleos brutos são submetidos a processos que envolvem temperatura. Os refinos químicos ou físicos de óleos vegetais exemplificam objetivos que, especificamente, tangem remoção de impurezas e compostos indesejáveis preservam-se triacilgliceróis e determinados compostos minoritários (KELLENS \& DE GRETY, 2000).

Neste mesmo sentido, a exposição de óleos vegetais a temperaturas elevadas, por períodos de tempo prolongados, tende a contribuir com oxidação e hidrólise de triglicerídeos, comprometendo propriedades nutricionais. Compostos tais como ácidos graxos (linoléicos, palmítico, oléico), carotenóides e tocóis, entre outros antioxidantes, se degradam potencialmente, contextualizando transformações químicas e físicas. 0 processo de aquecimento deteriora óleos, provocando aumento de dienos e trienos conjugados de ligações insaturadas, aumentando índices de ácido tiobarbitúrcio, peróxidos iodo e de refração, além de exercer influência sobre a viscosidade de moléculas de triacilglicerol (COSTA NETO; FREITAS, 1996).

A partir da extração do fruto da palmeira oleaginosa (Elaeis guineensis), obtém-se o óleo de palma. No Brasil, o óleo da palma é conhecido, em sua forma bruta, como azeite de dendê (BASIRON, 2005). Este mesmo óleo bruto, e sua fração oléina, apresentam composição diferenciada quando comparados a outros óleos vegetais, contendo proporções praticamente iguais de ácidos graxos saturados e insaturados. Destaca-se o teor elevado de ácido palmítico (C16), que por ser saturado confere estabilidade térmica e oxidativa. Ainda, ressalta-se teor reduzido de ácido linoléico (C18:2) e ácido linolênico (C18:3), ambos relativamente sensíveis à oxidação (MALACRIDA e JORGE, 2003; CODEX, 2011; KHAN et al., 2011).

0 óleo de palma é uma das mais ricas fontes naturais de carotenóides (500 - 1500 ppm). Tais carotenoides são pigmentos sintetizados por bactérias, algas e plantas fotossintetizantes, sendo responsáveis pela coloração vermelho-alaranjadas característica do óleo em questão. Os carotenoides, em função de suas ações químicas (antioxidantes) e propriedades de preservação, contribuem para a estabilidade dos óleos que os contém. Tais compostos bioativos possuem atividade pró-vitamínica A e se fazem amplamente estudados em contextos que também envolvem a indústria alimentícia, farmacêutica, de cosméticos, entre outras - consideram-se aspectos, dentre os quais: retenção, estabilidade e alterações no processamento e estocagem; propriedades físico-químicas; implicações na saúde humana; biodisponibilidade e relação entre função biológica e estrutural (COPPER, 2004; KRINSKY \& JOHNSON, 2005; VALÉRIO \& CREN, 2017; TRENTINI et al., 2017).

Os carotenóides apresentam, entre suas propriedades, a capacidade de sequestrar espécies reativas de oxigênio, atuando como antioxidantes, inclusive nos próprios alimentos, protegendo as células contra danos oxidativos. É sabido que, ao longo do processamento térmico de matérias primas contendo teores dos compostos em questão, alterações, tais quais degradações e isomerizações, tendem a ocorrer influenciando a perda de suas propriedades (RODRIGUEZ-AMAYA et al., 2008). 
Diante disso, ressaltando a importância econômica e industrial dos óleos vegetais extraídos da palma, enquanto matéria-prima para processamento verifica-se ser essencial a exploração de temas que envolvam estudos cinéticos e degradações térmicas de compostos alvo, nele presentes. Neste sentido, estudos que descrevem a cinética da degradação de carotenóides em produtos vegetais, além de limitados, geram informação de extrema utilidade que possibilitam prever alterações nutricionais e a retenção de carotenóides em óleos processados, preservando suas características nutracêuticas e essenciais ao longo do processamento (ACHIR et al., 2010; LEMMENS et al., 2010; ZEB \& MURCOVIC, 2011). Ainda, particularmente, no contexto de engenharia, cinéticas reacionais se tornam relevantes, em larga escala, no projeto de equipamentos nos quais reações serão conduzidas (LEVENSPIEL, 2000).

Neste sentido, o presente trabalho tem como objetivo avaliar a cinética de degradação térmica de carotenóides, em óleo vegetal de palma, determinando os parâmetros cinéticos relacionados à degradação destes compostos.

\section{REFERENCIAL TEÓRICO}

\section{1 ÓLEO DE PALMA}

No contexto comercial e mundial de óleos, a Palmeira Elaeis guineenses se posiciona com destaque entre as principais fontes de óleos comestíveis. Particularmente, na safra 2015/2016, a produção mundial de óleo de palma superou 62 milhões de toneladas métricas. Neste mesmo cenário, em razão do crescimento populacional, observa-se a manutenção de incrementos na demanda e consumo de óleos vegetais (USDA, 2016).

No que se refere ao cultivo intensivo, o óleo de palma apresenta elevada produtividade (cinco toneladas de óleo por hectare), quando comparado a culturas como a soja (0,5 toneladas de óleo por hectare). Também, apresenta menores custos de produção, em comparação com, canola ou girassol, também utilizando quantidades mais reduzidas de fertilizantes e pesticidas, por tonelada cultivada. Na indústria alimentícia, o óleo de palma e palmiste estão presentes em produtos como margarinas, biscoitos, tortas e sorvetes. De forma geral, na indústria química, também são aplicados, como ingredientes, na formulação de materiais para higiene e limpeza, dentre os quais sabões, detergentes e cosméticos, além de lubrificantes, óleos, glicerina, ácidos e bicombustíveis (LEVERMANN; SOUZA \& VILAS BOAS, 2002).

O dedenzeiro, ou palma do dendê, apesar de sua origem africana, é uma palmeira que se desenvolve em regiões tropicais, com clima úmido e quente, justificando plantações em países com clima tropical (SAMBANTHAMURTHI \& SUDRAM, 2000; BRASIL, 2006). Seus frutos são pequenas nozes (Figura 1), alongadas e angulosas, e possuem polpa (mesocarpo) fibrosa, envolvendo o endocarpo. A coloração do mesocarpo varia do amarelo ao vermelho-alaranjado, em função dos carotenóides presentes (QUIJANO, 1997).

Figura 1. Fruto da Palma: Elaeis guineensis

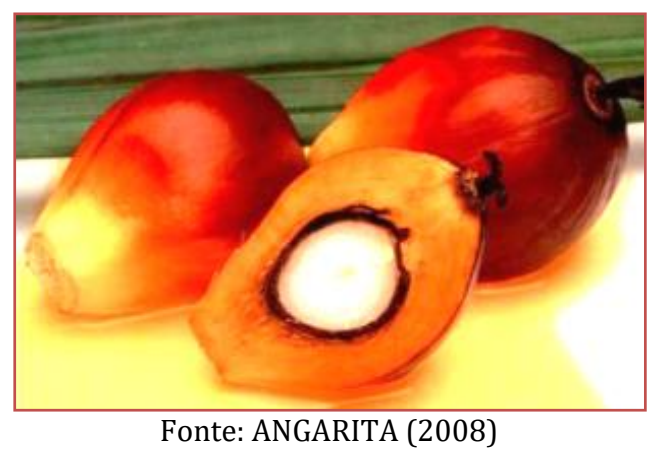

Do fruto, são extraídos dois tipos de óleo - do mesocarpo se extrai o azeite de dendê ou óleo de palma bruto; do endocarpo se extrai o óleo de palmiste. 0 rendimento, em óleo, dos cachos representa $22 \%$ para polpa bruta e $2 \%$ para palmiste (QUIJANO, 1997).

Os constituintes majoritários do óleo de palma são os triacilglicerois (95\%), compostos por cerca de $40,4 \%$ a $56,9 \%$ de ácidos graxos saturados e $43,0 \%$ a $62,5 \%$ de ácidos graxos insaturados, todos em sua 
configuração cis (SUNDRAM et al., 2003; GEE, 2007). Entre os principais ácidos graxos presentes na composição do óleo em questão estão o oléico (36,0 a 47,0\%), o palmítico (35,0 a 47,0\%) e o linoléico $(6,5$ a 15,0\%). A composição em ácidos graxos e antioxidantes, apresentada Tabela 1 a seguir, torna o óleo de palma bruto amplamente utilizado na produção de alimentos (BRASIL, 1999; LODY, 2009).

Tabela 1. Composição, em ácidos graxos, do óleo de palma bruto

\begin{tabular}{|c|c|}
\hline Ácido & $\%$ \\
\hline Láurico 12:0 & $<0,4$ \\
\hline Mirístico 14:0 & $0,5-2,0$ \\
\hline Palmítico 16:0 & $35,0-47,0$ \\
\hline Esteárico & $3,5-6,5$ \\
\hline Oléico 18:1 & $36,0-47,0$ \\
\hline Linoléico 18:2 & $6,5-15,0$ \\
\hline Linolênico 18:3 & $<0,5$ \\
\hline Araquídico 20:0 & $<1,0$ \\
\hline Saturados & $40,4-56,9$ \\
\hline Insaturados & $43,0-62,5$ \\
\hline
\end{tabular}

O óleo de palma bruto contém ainda componentes denominados minoritários, separados em dois grupos: o primeiro grupo engloba derivados de ácidos graxos, como gliceróis, ésteres, fosfatídeos, esteróis; o segundo grupo engloba compostos entre os quais hidrocarbonetos, alcoóis alifáticos, esteróis livres, tocotrienois, tocoferois, traços de metais e pigmentos. Os carotenóides e os isômeros de vitamina E (tocoferois, tocotrienois e derivados), são as duas classes de compostos minoritários com maior relevância (SAMBANTHAMURTHI e SUDRAM, 2000; LODY, 2009; CODEX, 2011).

\subsection{CAROTENÓIDES}

Entre óleos vegetais que possuem carotenóide em sua composição, podem-se citar o óleo pequi e buriti. Contudo, frente às fontes mencionadas, a palma se evidencia como fonte natural do composto, apresentando concentrações que variam de 500 a 2000 ppm (LODY, 2009; CURVELO et al., 2011; CODEX, 2011).

Os carotenóides são formados por 40 átomos de carbono, sendo classificados como tetraterpenos insaturados, constituídos por uma cadeia de hidrocarbonetos contendo entre 9 e 13 ligações conjugadas, compostas por oito unidades isoprênicas de cinco carbonos (RODRIGUEZ-AMAYA e KIMURA, 2004).

Carotenóides são considerados compostos lipofílicos ou apolares, o que os torna insolúveis em água e solúveis em solventes orgânicos, como, álcool, clorofórmio, acetona, acetato de etila, éter etílico e éter de petróleo. Os compostos em questão se destacam por sua diversidade estrutural, ampla distribuição e por suas várias funções, incluindo as biológicas. Existem na natureza, aproximadamente, 600 tipos de carotenóides. Estes são encontrados ampla variedade de algas, fungos, bactérias e leveduras. Animais são incapazes de biossintetizar os tetraterpenóides, dependendo, portanto, da obtenção por meio da ingestão (RODRIGUEZ-AMAYA, 2001; RODRIGUEZ-AMAYA et. al, 2008).

De forma geral, carotenóides são encontrados na natureza, principalmente, na forma trans, sendo divididos entre carotenos e xantofilas. Na classe dos carotenos, destacam-se o $\beta$-caroteno, $\alpha$-caroteno e licopeno, Xantofilas possuem oxigênio na cadeia, na forma de hidroxila, epóxi ou carboxila (RODRIGUEZAMAYA, 2001; NASCIMENTO, 2006).

Os carotenóides possuem capacidade de sequestrar espécies reativas de oxigênio, fazendo com que o elétron desemparelhado do radical se estabilize por ressonância. Desta forma, atuam como antioxidantes, 
protegendo as células de danos oxidativos. Também, relata-se sua interação por meio de transferência de elétrons, remoção de íons de hidrogênio e remoção de radicais livres (RODRIGUEZ-AMAYA et al., 2008).

Atividades de pró-vitamina A são atribuídas aos carotenóides compostos por um anel $\beta$-ionana não substituído, fixado a uma cadeira lateral poliênica contendo onze carbonos. A estrutura corresponde a uma molécula de vitamina A, na forma de retinol. A deficiência prolongada de vitamina A é causa de grave doença carencial, potencialmente fatal em seres humanos. $0 \beta$-caroteno apresenta maior atividade vitamínica A, sendo o mais abundante em alimentos RODRIGUES-AMAYA, 1999; SOUZA \& VILAS BOAS, 2002).

As moléculas de carotenóides possuem um sistema extenso de ligações duplas conjugadas, o que confere uma propriedade de cromóforo - responsável pela pigmentação. À medida que o número de duplas ligações aumenta, aumenta a intensidade da cor, em função do deslocamento de absorção da molécula vermelho. As estruturas insaturadas dos carotenóides tornam as matérias-primas que os contêm susceptíveis à oxidação e isomerizações, durante etapas de processamento térmico e armazenamento. Agentes como, ácidos, luz e calor contribuem adicionalmente com isomerização para a forma cis (principalmente, 9-,13- e 15-cis), reduzindo suas propriedades (SAMBANTHAMURTHI e SUDRAM, 2000; PAPA, 2007; RODRIGUEZ-AMAYA et al., 2008).

Retomando atenção ao Óleo de Palma, os principais carotenóides presentes em seu óleo são o $\alpha$-caroteno e o $\beta$-caroteno (Figura 2). Sua ocorrência depende da origem e variedade dos frutos, assim como com o genótipo e o grau de amadurecimento, além das condições de processamento e estocagem. Juntos, os compostos mencionados respondem por aproximadamente $90 \%$ dos carotenóides totais no fruto (BASIRON, 2005; CODEX, 2003).

Figura 2. Estrutura química: (a) $\alpha$-caroteno; (b) $\beta$-caroteno.

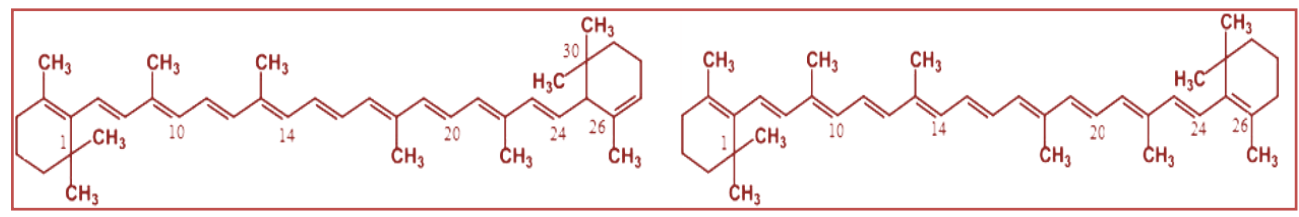

Ressalta-se que fatores como tipo de carotenóide, assim como concentração e condições ambientais, determinam o comportamento cinético de degradação. Considerando estudos sobre a degradação térmica de carotenóides, em matrizes e temperaturas diversas, autores sugerem-na como seguindo cinética de primeira ordem (HENRY et., 1998; AHMED et al., 2002), em alguns casos ordem zero (MÍNGUEZMOSQUEIRA et al., 1994) e superior a 1 (ACHIR et al., 2010; SAMPAIO, 2013).

Frente ao exposto, considerando que a exposição de carotenóides a temperaturas elevadas contribui com degradações, isomerizações e mudanças estruturais, observa-se a natural demanda científica no sentido da avaliação da cinética de degradação do óleo de palma, fonte natural de $\beta$-caroteno (OLIVEIRA, 2003; GIBON et al., 2007).

\subsection{PROCESSAMENTO DE ÓLEOS VEGETAIS}

Matérias-primas oleaginosas são obtidas, basicamente, por meio das etapas de processamento: produção de óleo bruto e coprodutos, e purificação. A produção de óleos brutos envolve etapas, dentre as quais: armazenamento, higienização, preparo e extração propriamente dita. Os óleos podem ser obtidos por prensagem mecânica ou extração com solvente. A purificação, por sua vez, envolve etapas como degomagem, desacidificação (química ou física), clarificação e desodorização. Plantas industriais destinadas ao processamento de matérias-primas oleaginosas originam, portanto, óleos de natureza bruta e refinada, para posterior utilização nas indústrias químicas (GUEDES, 2006; PIMENTA, 2010; DA SILVA, 2009; BRASIL, 2006).

O refino físico de óleos vegetais merece breve destaque, consistindo em um processo de esgotamento, no qual, sob pressões reduzidas e temperaturas elevadas, removem-se impurezas. No entanto, estas condições de processo também facilitam a ocorrência de volatilização e degradação de compostos minoritários de interesse industrial, como os carotenóides (O’BRIEN, 2004). 
O processo de obtenção dos óleos vegetais, claramente, se faz uma importante etapa produtiva, relacionada à qualidade do produto final. Sob o enfoque industrial, torna-se razoável ressaltar que o processamento térmico de produtos já formulados pode envolver etapas adicionais - branqueamento, cozimento, pasteurização, enlatamento e secagem, são usuais em indústrias alimentícias; esterilização é um exemplo de etapa que faz comum em indústrias farmacêutica e de cosmético. Sendo assim, torna-se possível extrapolar o conhecimento no sentido relevância de informações relacionadas à retenção de carotenóides em produtos finais (MAIANI et al., 2009; ARCHANJO et al., 2012).

\subsection{REFINO DO ÓLEO DE PALMA}

Considerando-se o óleo de palma bruto, obtido após o processamento de matérias-primas, segundo ANVISA (2005), sua utilização no contexto alimentício e humano é dependente do parâmetro acidez (s $2 \%)$. Neste contexto, surge o refino e o fracionamento, de matérias-primas, em indústrias químicas (RITTNER, 1996; TRUJILLO-QUIJANO, 1997).

O refino do óleo de palma bruto é feito através de um pré-tratamento com adição de ácido cítrico (natural) denominado degomagem $(\mathrm{T}=363,15$ - 373,15K). Na sequência, o óleo é tratado com adsorventes, etapa denominada branqueamento, para a remoção dos fosfolipídios e metais. Finalmente, etapas de desodorização / desacidificação ocorrem simultaneamente, com objetivo principal relacionado à remoção de odores indesejáveis, ácido graxo livre (AGL) e peróxidos. Em função de a desacidificação ser realizada de forma física (destilação), com pressão absoluta abaixo de $3 \mathrm{mmHg}(513,15 \mathrm{~K}<\mathrm{T}<533,15 \mathrm{~K})$, a etapa tende a incidir sobre destruição de carotenóides e tocoferóis. Complementarmente, submeter o óleo de palma refinado à etapa de fracionamento visa ampliação da utilização industrial. 0 processo é reversível, sem alterações químicas dos triglicerídios, sendo baseado na separação parcial e combinação de frações (oleína e estearina), a partir da diferença no ponto de fusão dos triglicerídeos, como advento tecnológico industrial (TRUJILLO-QUIJANO, 1997; RITTNER, 1996).

Segundo Sampaio (2013), a produção de óleo de palma requer tecnologias alternativas às usuais, como forma de se reduzirem AGL, retendo, ao máximo, compostos biológicos.

\section{METODOLOGIA}

O presente capítulo se desenvolve como estudo teórico-prático, envolvendo revisão bibliográfica e procedimentos experimentais de ordem quantitativa, no sentido dos objetivos propostos, também podendo ser descrito como explicativo. A amostra utilizada nos ensaios consiste em óleo vegetal, extraído de fruto da palmeira Elaeis guineensis, adquirido no comércio comum, da cidade Belo Horizonte, MG. Como instrumentos de coleta de dados iniciais, realizaram-se aprofundamentos científicos, por meio de trabalhos publicados previamente.

\subsection{TRATAMENTO TÉRMICO}

Para a realização do procedimento analítico relacionado à cinética de degradação térmica do óleo de palma, 0,2 g da amostra de óleo foram pesados em duplicata. Cada replicata foi acondicionada em tubos rosqueáveis (com proteção luminosa) previamente identificados. 0 processamento térmico das amostras, realizado em chapa aquecedora elétrica, considerou as seguintes condições de temperatura: 403,15 K, $413,15 \mathrm{~K}$ e $423,15 \mathrm{~K}$. Os tempos de aquecimento, replicados para cada uma das temperaturas mencionadas, foram definidos como sendo: 0, 10, 20, 30, 40, 50 e 60 minutos. Como forma de se assegurar que a reação ocorresse em condições isotérmicas, o monitoramento dos tempos mencionados apenas se iniciou após cada uma das temperaturas determinadas serem atingidas. 0 monitoramento térmico foi realizado utilizando-se termômetros digitais, imersos em tubos controle, espaçados fisicamente no sistema de aquecimento, os quais também continham o óleo em estudo (BANSAL et al., 2010).

Nesse sentido, à medida que cada um dos tempos de aquecimento foi atingido, as amostras processadas termicamente foram retiradas do sistema. Como forma de se interromper a degradação térmica, as amostras foram imediatamente imersas em banho de gelo e subsequentemente armazenadas sob refrigeração $\left(4 \pm 2{ }^{\circ} \mathrm{C}\right)$ até o momento das análises (MALHEIRO et al., 2009). 


\subsection{DETERMINAÇÃO DOS TEORES DE CAROTENÓIDES TOTAIS}

Os carotenóides totais foram determinados segundo associação dos métodos 958.05 (AOAC, 1997) e 122/IV (IAL, 2008). Sendo assim, os óleos de palma tratados termicamente foram diluídos em solvente éter de petróleo (grau espectrofotométrico), seguido de leitura em espectro visível a $452 \mathrm{~nm}$ conforme a metodologia, assim utilizando éter de petróleo como solvente. Os cálculos dos carotenóides totais foram realizados considerando a absorbância máxima e o valor de absortividade 2500. Os resultados se expressam em função de equivalente de $\beta$ - caroteno em $\mu$ g.g-1 de óleo (DAVIES, 1976).

Determinação dos Parâmetros Cinéticos

Os dados cinéticos experimentais foram apresentados na forma adimensional $C / C_{0}$ nos diferentes intervalos de tempo de aquecimento $(C$ corresponde à concentração de carotenóides medida após tratamento, e $C_{0}$ corresponde à concentração inicial em mg.kg-1 de óleo). A equação geral atribuída ao processo de degradação é apresentada a seguir:

$$
\frac{d C}{d t}=-k C^{n}
$$

A partir da eq. (1) é possível observar que a taxa de degradação $d C$ / $d t$ é proporcional a n-ésima (nth) potência da concentração, para qualquer tempo, sendo $n$ a ordem de reação e $k$ (min-1) a constante da velocidade de reação. Aplicando-se o método de integração na equação acima, entre $C$ e $C_{0} \mathrm{em}$ um intervalo de tempo zero (0) até $t$, tem-se:

$$
\int_{C_{0}}^{C} C^{-n} d C=-k \int_{0}^{t} d t
$$

A eq. (2) não se aplica para $n=1$, pois o termo $1 /(1-n)$ se tornaria uma indeterminado.

$$
\begin{aligned}
& C=\left[C_{0}^{1-n}-(1-n) k t\right]^{1 /(1-n)}(n \neq 1 \\
& C=C_{0} \exp (-k t)(n=1)
\end{aligned}
$$

A ordem de reação $(n)$ e a constante da velocidade de reação $k$ foram estimadas por regressão linear. Considera-se a constante da velocidade de reação variando com a temperatura absoluta T, de acordo com a equação 5, de Arrhenius. Calcula-se o fator pré-exponencial $k_{0}(\mathrm{~min}-1)$ e a energia de ativação $E_{a}$ (J·mol1). $R$ corresponde à constante dos gases ideais $(8,314 \mathrm{~J} \cdot \mathrm{mol}-1 \cdot \mathrm{K}-1)$.

$$
k=k_{0} \exp \left(\begin{array}{c}
-E_{a} \\
R T
\end{array}\right)
$$

Através do estudo de parâmetros cinéticos, como ordem de reação, energia de ativação e constante da velocidade de reação, é possível obter informações relacionadas às mudanças que ocorrem nos parâmetros de qualidade durante o processamento térmico. 0 tempo de meia vida será determinado a partir da eq. 6, conforme a ordem de reação:

$$
t_{1 / 2}=\frac{\ln 2}{K} \quad\left(1^{\mathrm{a}} \text { ordem }\right)
$$




\section{RESULTADOS E DISCUSSÕES}

A partir dos dados experimentais, é possível verificar a redução do teor de carotenóides, sempre ao longo de 60 minutos. A Figura 3 apresenta a média das medidas referentes ao teor de carotenóides, para cada uma das amostras, nos tempos monitorados.

É possível observar que a redução no teor dos compostos estudados foi acentuada para as temperaturas 403,15 K; 413,15 K e 423,15 K, em função do tempo. Tal qual observado por MAIANI et al. (2009) o processamento térmico diminui o teor de carotenóides na matriz estudada. Observa-se também o desaparecimento da cor, característica dos compostos alvo, ao longo do experimento, para todas as temperaturas. Em seu estudo sobre a cinética de degradação de $\beta$-caroteno e luteína em óleos, Achir et al. (2010) observou, durante aquecimento, que a concentração de trans- $\beta$-caroteno sempre diminuiu em função do tempo (BURTON \& INGOLD, 1984; DI MASCIO et al., 1989).

Figura 3. Teor de carotenóides em função de equivalente de $\beta$-caroteno.

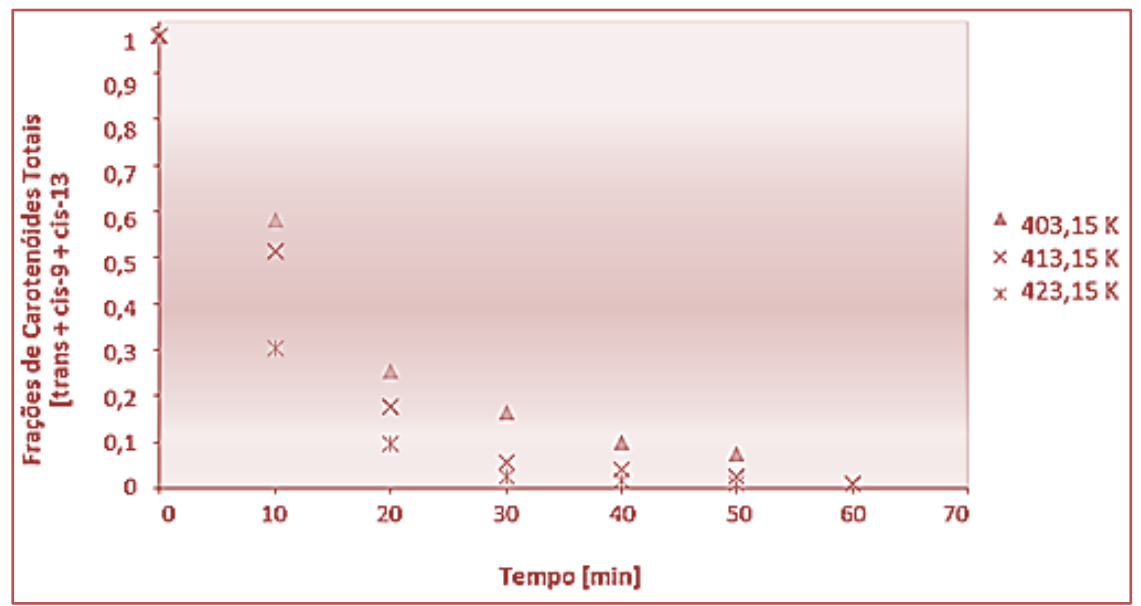

Após 20 minutos de processamento, o teor de carotenóides foi reduzido a aproximadamente $25 \%$, $17 \%$ e 1\%, para as temperaturas 403,15K, 413,15K e 423,15K. Após 30 minutos, a retenção correspondeu a 17\% para a temperatura igual a 403,15K. Comportamento semelhante foi observado no estudo conduzido por Achir et al. (2010), quando o teor de trans- $\beta$-caroteno tendeu à acentuada redução, a partir dos primeiros minutos de processamento, para todas as temperaturas operadas no tratamento. 0 autor observou valores próximos a $20 \%$ e $50 \%$, após 30 minutos de processamento a $\mathrm{T}=413,15 \mathrm{~K}$.

As duas principais alterações em carotenóides, decorrentes do processamento, são a isomerização e a oxidação. A oxidação ocorre na presença de oxigênio, metais, enzimas, lipídios insaturados e outras moléculas pró-oxidantes. Considerando atmosfera contendo oxigênio, no presente capítulo, sugere-se a oxidação como principal causa da degradação observada (SCOTT, 1992; QUIRÓS; COSTA, 2006; BURTON \& INGOLD, 1984).

Conforme se pode observar na Figura 4, os dados obtidos mostram que a reação de degradação dos carotenóides se ajusta ao modelo cinético de primeira ordem. Em reações de primeira ordem, a concentração do reagente diminui exponencialmente com o tempo numa velocidade determinada pela constante $k$ (ATKINS, 2004).

A constante da velocidade de reação $k$, independente das concentrações envolvidas, se faz constantemente dependente da temperatura. É válido ressaltar que, em sistemas líquidos, $k$ pode depender de parâmetros dentre os quais força iônica e natureza do solvente. Estas outras variáveis tendem a exercer efeito reduzido sobre a velocidade específica de reação, quando comparadas com a temperatura (FOGLER, 2002).

Com base nos dados experimentais, e nas temperaturas definidas, consideraram-se ajustes lineares e consequente estimativa dos valores correspondentes às constantes da velocidade de reação $k$ (FOGLER, 2002). A Figura 4 apresenta regressões lineares para as concentrações adimensionais em função dos tempos e temperaturas de processamento. 
Figura 4 - Concentração adimensional de carotenoides em função do tempo e temperatura de processamento.

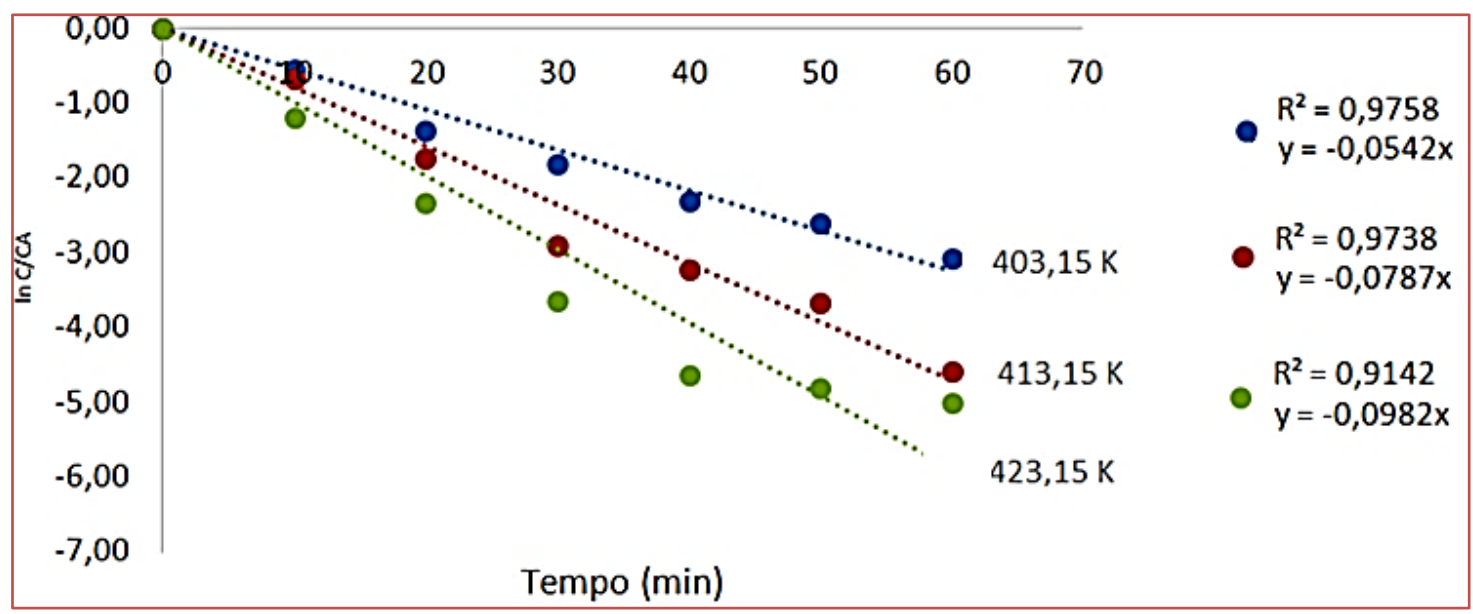

A partir das inclinações de cada uma das retas, os valores das constantes de velocidade foram estimados para cada uma das temperaturas. Com base nos valores de $k$, outra regressão foi proposta, considerando $\ln (k)$ versus 1/T (Figura 5).

Figura 5. Linearização da velocidade especifica em função do inverso da temperatura.

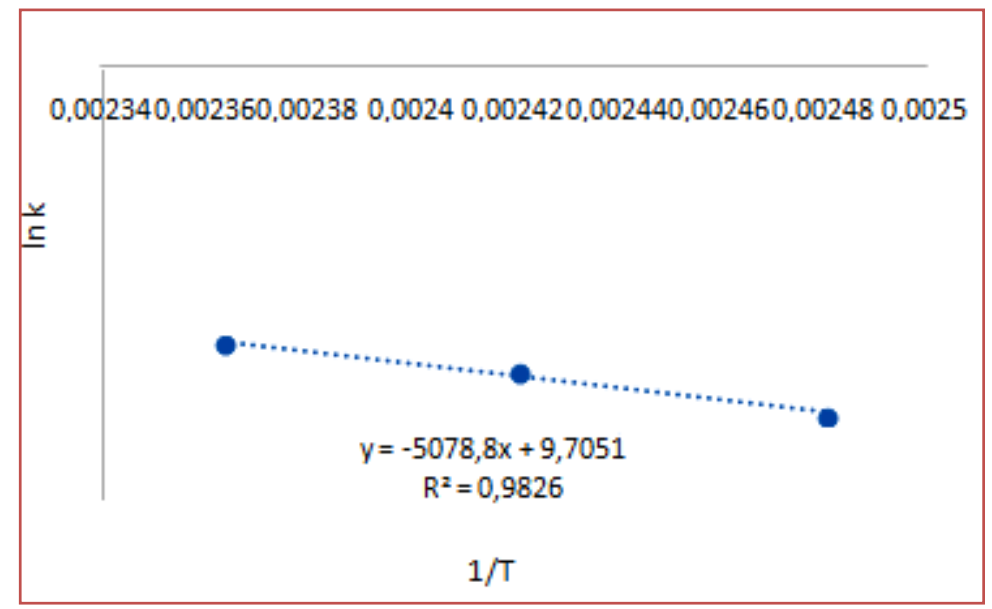

Considerando-se a equação de Arrhenius, estimaram-se os valores do fator pré-exponencial $\left(k_{0}\right)$ e da energia de ativação $\left(E_{a}\right)$. Particularmente, a energia de ativação foi determinada multiplicando-se o coeficiente angular obtido para a reta plotada pela constante universal $R(8,314 \mathrm{~kJ} / \mathrm{mol} . \mathrm{k})$. Os parâmetros cinéticos estimados, relacionados à degradação dos carotenóides em óleo de palma, ao longo do aquecimento, podem ser observados na Tab. 2 .

Tabela 2. Parâmetros cinéticos da degradação dos carotenóides ao longo do aquecimento

\begin{tabular}{|c|c|c|c|c|c|}
\hline \multirow{4}{*}{$\begin{array}{l}\text { Equivalente de } \\
\beta \text { - caroteno }\end{array}$} & $\mathrm{T}(\mathrm{K})$ & Regressão Linear & $\begin{array}{l}\text { Coeficiente de } \\
\text { determinação }\end{array}$ & $\begin{array}{c}k \\
(\min -1)\end{array}$ & $\begin{array}{c}T_{1 / 2} \\
(\min -1)\end{array}$ \\
\hline & 403,15 & $y=0,050 x+0,144$ & $\mathrm{R}^{2}=0,981$ & 0,050 & 12,8 \\
\hline & 413,15 & $\mathrm{y}=0,075 \mathrm{x}+0,120$ & $\mathrm{R}^{2}=0,975$ & 0,075 & 8,8 \\
\hline & 423,15 & $y=0,087 x+0,460$ & $\mathrm{R}^{2}=0,934$ & 0,087 & 7,1 \\
\hline
\end{tabular}


Conforme descrito no item 3.3, assumiu-se que as constantes de velocidade $(k)$ estimadas variaram com a temperatura absoluta $(K)$, dentro de precisão experimental. Valor igual a $42 \mathrm{~kJ} / \mathrm{mol}$ foi estimado para a energia de ativação. 0 valor estimado para $\ln \left(k_{0}\right)$ foi igual a 9,7 min-1. 0 valor da energia de ativação se aproxima do obtido por Achir et al. (2010), quando relacionando tal energia de ativação à degradação de isômeros do composto $\beta$-caroteno $(48 \pm 6 \mathrm{~kJ} / \mathrm{mol})$ em Oleína de Palma.

Os tempos de meia vida calculados indicam resistência relativamente reduzida ao aquecimento. Nesse sentido, é razoável sugerir que, a partir da perspectiva de processamento industrial da matéria-prima em questão, a estrutura altamente insaturada dos carotenoides naturalmente presentes torna os compostos consideravelmente sensíveis a reações de degradações térmicas (ZEB \& MURKOVIC, 2010; CASAL et al., 2010; ZEB \& MURKOVIC, 2011). Contudo, tendo em vista que processamentos térmicos se fazem operações unitárias essenciais, os processos que se fizerem indispensáveis industrialmente, devem ser conduzidos a temperaturas preferencialmente reduzidas, frente a temperaturas elevadas por tempo reduzido, visando máxima retenção de carotenóides (ACHIR et al., 2010).

\section{CONCLUSÕES}

O estudo experimental da cinética de degradação térmica dos carotenóides, no óleo de palma, conduzido no presente capítulo, possibilitou reforçar a relação existente entre processamento e degradação de biocompostos, em função da temperatura. Na busca por maior retenção, sugerem-se processos conduzidos a temperaturas reduzidas por tempos prolongados, frente a temperaturas elevadas por tempos reduzidos. No contexto de engenharia, dados cinéticos aplicados em larga escala se tornam relevantes no projeto de equipamentos nos quais reações serão conduzidas. Os resultados obtidos podem ser considerados para sugestões tecnológicas alternativas, inclusive atrelando-se a design de processos térmicos, para óleos contendo carotenoides e nutracêuticos.

\section{REFERÊNCIAS}

[1] ACHIR, N.; RANDRIANATOANDRO, V. A.; BOHUON, P.; LAFFARGUE, A., AVALLONE, S. Kinetic study of $\beta$ carotene and lutein degradation in oils during heat treatment. European Journal of Lipid Science and Technology, vol. 112,p. 349-361, 2010.

[2] AOAC - INTERNATIONAL ASSOCIATION OF OFFICIAL ANALYTICAL CHEMISTS. Official methods of analysis of AOAC International. 16. Ed; Gaitherburg: AOAC International, 1997.

[3] ANVISA (Agência Nacional de Vigilância Sanitária) -. Resolução RDC n 270, de 22 de setembro de 2005. Aprova o regulamento técnico para óleos vegetais, gorduras vegetais e creme vegetal. Diário Oficial. Brasília, DF. 23 de setembro de 2005.

[4] AHMED, J.; SHIVARE, U. S.; SANDHU, K. S. Thermal Degradation Kinetics of Carotenoids and Visual Color of Papaya Puree. Journal of Food Science, vol. 67, pp. 2692 - 2695, 2002.

[5] ANGARITA, E. E. Y. Avaliação do impacto energético e ambiental da cogeração no balanço energético e no ciclo de vida do biodiesel de óleo de palma africana. [s.l.] Universidade Federal de Itajubá, 2008.

[6] APOLINARIO, P. P. et al.. Metabolismo, oxidação e implicações biológicas do ácido docosahexaenoico em doenças neurodegenerativas. Revista Química Nova, São Paulo, v.34, n.8 p.1409-1416, 2011.

[7] ARCHANJO, A. B. et al.. Métodos de esterilização utilizados na indústria farmacêutica, farmácias,

[8] laboratórios e clínicas veterinárias. PUBVET, Londrina, V. 6, N. 36, Ed. 223, Art. 1482, 2012.

[9] ATKINS, P. J. Físico-Química. 7.ed. Rio de Janeiro: LTC, 2 v., 2004.

[10] APOLINARIO, P. P.; DEROGIS, P. B. M. C.; YAMAGUTI, T. H.; MIYAMOTO, S. Metabolismo, oxidação e implicações biológicas do ácido docosahexaenoico em doenças neurodegenerativas. Revista Química Nova, São Paulo, v.34, n.8 p.1409-1416, 2011

[11] ARCHANJO, A. B.; TONETO, F. C. S.; PEREIRA-JÚNIOR, B. R. A. Métodos de esterilização utilizados na indústria farmacêutica, farmácias, laboratórios e clínicas veterinárias. PUBVET, Londrina, V. 6, N. 36, Ed. 223, Art. 1482, 2012.

[12] ATKINS, P. J. Físico-química. 7.ed. Rio de Janeiro: LTC, 2004. 2v.

[13] BANSAL, G.; ZHOU, W.; BARLOW, P. J.; LO, H.; NEO, F. Performance of palm olein in repeated deep frying and controlled heating processes. Food Chemistry, London, v. 121, n.2, p. 338-347, 2010.

[14] BASIRON, Y. Palm oil, vol. 2, 6th ed., John Wiley and Sons, pp. 333 - 429, 2005. 
[15] BRASIL, Ministério da Agricultura e Abastecimento, Companhia Nacional de Abastecimento. Dendeicultura da Bahia. Documento Técnico, Bahia-Sergipe, p. 1-10, 41 agosto, 2006.

[16] BRASIL. Ministério da Saúde. Agência Nacional de Vigilância Sanitária, ANVISA. Resolução no 482, de 23 de setembro de 1999.

[17] BRITO, M. Palma no Brasil: a corda está quase no limite. Agro analysis, v. 34, n. 8, p. 25-26, 2014. BURTON, G.W.; INGOLD, K.U. Beta-Carotene: an unusual type of lipid antioxidant. Science, Washington, v.224, n.4649, p.569-573, 1984.

[18] CASAL, S. et al.. Olive oil stability under deep-frying conditions. Food and Chemical Toxicology, Oxford, v.48, n.10, p.2972-2979, 2010.

[19] CODEX ALIMENTARIUS (FAO/WHO). Codex standard for named vegetable oils, CODEX STAN 210 (Amended 2003 - 2005). Roma, 2003.

[20] CODEX STAN 210 Amendement. Codex Standard for Named Vegetable Oils. Codex Alimentarius Commission, 8, 11-24, 2011.

[21] COPPER, D. A. Carotenoids in health and disease: recent scientifif evaluations, research recommendations and the consumer. Journal of Nutrition, Philadelphia, v. 134, n.1, p. 221S-224S, 2004.

[22] COSTA NETO, P. R.; FREITAS, R. J. S. Boletim CEPPA. 1996.

[23] CURVELO, F. M. et al.. Qualidade do óleo de palma bruto (Elaeis guineensis): matéria-prima para fritura de acarajés. Revista Instituto Adolfo Lutz, vol. 70, p. 641-646, 2011.

[24] DAVIES, B. H. Carotenoids. In: GOODWIN, T. W. (Ed). Chemistry And Biochemistry of Plant Pigments. London: Academic Press, Cap.19, p. 38- 65, 1976.

[25] DA SILVA, I. C. C. Uso de Processos Combinados Para Aumento Do Rendimento da Extração e da Qualidade do Óleo de Macaúba. Escola de Química. Rio de Janeiro, Universidade Federal do Rio de Janeiro. Rio de Janeiro, v.1, n.1, p.99, 2009

[26] DI MASCIO, P.; KAISER, S.; SIES, H. Lycopene as the most efficient biological carotenoid singlet oxygen quencher. Archives of Biochemistry and Biophysics, New York, v.274, n.2, p.532-538, 1989.

[27] FOGLER, S. C., Elementos de Engenharia das Reações Químicas, 3ª ed., Editora LTC, 2002.

[28] GEE, P. T. Analytical characteristics of crude and refined palm oil and fractions. European Journal of Lipid Science and Technology, vol. 109 373-379, 2007.

[29] GIBON, V.; DE GREYT, W.; KELLENS, M. Palm Oil Refining. Eur. J. Lipid Sci. Technol. v. 109, pp. 315 - 335, 2007.

[30] GUEDES, A. MO. M. Estudo da extração de óleo da polpa do tucumã para fins alimentícios. 2006. 77P. Dissertação (Mestrado em Ciência e Tecnologia de Alimentos) - Universidade Federal do Pará. Belém, 2006.

[31] HENRY, L. K.; CATIGNANI, G. L.; SCHWARTZ, S. J. Oxidative Degradation Kinetics of Lycopene, Lutein and 9cis and All-trans $\beta$-carotene. J Am Oil Chem Soc., vol. 75, pp. 823 - 829, 1998.

[32] HOFFMANN, G. The Chemistry and Technology of Edible Oils and Fats and their high Fat Products, Academic Press. New York, pp. 384, 1989.

[33] HOMMA, A. K. O. et al.. P. Bases para uma política de desenvolvimento da cultura do dendê na Amazônia. In: VIÉGAS, I. J. M.; MÜLLER, A. A. (Ed.). A cultura do dendezeiro na Amazônia brasileira. Belém: Embrapa Amazônia Oriental, p. 11-30., 2000.

[34] IAL - INSTITUTO ADOLFO LUTZ - Normas Analíticas; métodos químicos e físicos para a análise de alimentos. 4 ed. São Paulo: Instituto Adolf Lutz, 2008.

[35] KEBEDE B. T. et al.. Investigating chemical changes during shelf-life of thermal and high pressure high temperature sterilised carrot purees: A 'fingerprinting kinetics' approach. Food Chem., 2015.

[36] KELLENS, M.; DE GREYT, W. Deodorization. In: O'BRIEN, R. D.; FARR, W.E.; WAN, P.J. (eds.), Introduction to fats and oil technology. 2nd edition. AOCS press, Champaign, Illinois, pp. 618, 2000.

[37] KHAN, M. I. et al.. Studies on chemical and sensory parameters of coconut oil and its olein blends with sesame oil and palmolein during wheat flour-based product frying. Journal of Food Science and Technology, 48, 175-182, 2011.

[38] KRINSKY, N. I.; JOHNSON, E. J. Carotenoid actions and their relation to health and disease. Molecular Aspects of Medicine, Elmsford, v. 26, n. 6, p. 459- 516, 2005.

[39] LODY, R. DENDÊ: símbolo e sabor da Bahia. São Paulo: Editora SENAC, p.148, 2009. 
[40] LEMMENS, L. et al.. $\beta$-Carotene Isomerization Kinetics during Thermal Treatments of Carrot Puree. Journal of Agricultural and Food Chemistry. n.58, pp.6816-6824. 2010.

[41] LEVENSPIEL, O. Engenharia das Reações Químicas, 3ª ed., Editora Blucher, 2000.

[42] LEVERMANN, R. A.; SOUZA, J. P. M. Óleo de palma: o crescimento da indústria global. Agro analysis, v. 34, n. 8, p. 25-26, 2014.

[43] MAIANI, G. et al.. Carotenoids: actual knowledge on food sources, intakes, stability and bioavailability and their protective role in humans. Molecular nutrition e food research, Weinheim, v.53, n.2, p.194-218, 2009.

[44] MALHEIRO, R. et al..; Effect of microwave heating with different exposure times on physical and chemical parameters of olive oil. Food Chem. Toxic., Oxford, v.47, n.1, p.92-97, 2009.

[45] MALACRIDA, C. R.; JORGE, N. Alterações do óleo de soja e da mistura azeite de dendê - óleo de soja em frituras descontínuas de batatas chips. Brazilian Journal Food Technology, 6, 245-249, 2003.

[46] MÍNGUEZ-MOSQUERA, M. I.; JARÉN-GALÁN, M.; GARRIDO-FERNANDEZ, J. Competition between the process of biosynthesis and degradation of carotenoids during the drying and peppers. J. Agri. Food Chem., vol. 42, pp. 645 $648,1994$.

[47] NASCIMENTO, P. Avaliação da retenção de carotenoides de abóbora, mandioca e batata doce. 79 p. Dissertação (Mestrado em Engenharia e Ciência de Alimentos) - Universidade Estadual Paulista,

[48] Instituto de Biociências, Letras e Ciências Exatas, São José do Rio Preto, 2006.

[49] O’BRIEN, R. D. Fats and oils: formulating and processing for applications. 2. Ed. Boca Raton: CRC, 616p., 2004.

[50] OLIVEIRA, J. T. G. Melhor Dosagem e Dose Econômica de TBHQ nos Óleos de Milho e Canola. Tese. Piracicaba, Mestrado (engenharia de Alimentos) - Escola Superior de Agricultura Luiz de Queiroz, Universidade de São Paulo (ESALQ/USP), 75p. 2003.

[51] PAPA, D. Fracionamento do óleo de palma com dióxido de carbono supercrítico. 100 p. Dissertação (Mestrado em Engenharia de Alimentos)- Faculdade de Engenharia de Alimentos da Universidade Estadual de Campinas, Campinas-SP, 2007.

[52] PIMENTA, T. V.; ANDRADE, M. H. C.; ANTONIASSI, R. Extração, Neutralização e Caracterização dos Óleos do Fruto da Macaúba (Acrocomia aculeata). In: XIX Congresso Brasileiro de Engenharia Química, 2012 - Universidade Federal do Rio de Janeiro. Rio de Janeiro, v.1, p.4031-4040, 2012.

[53] QUIJANO, J. A. T. Óleo de Palma: Um produto Natural. Revista Óleos \& Grãos, Mar/Abr. pp. 19 - 23, 1997.

[54] QUIRÓS, A. R.; COSTA, H. S. R. Analysis of carotenoids in vegetable and plasma samples: A review. Journal of food composition and analysis, San Diego, v. 19, n.2-3, p.97-111, 2006.

[55] RITTNER, H. Óleo de Palma: processamento e utilização. H. Rittner: São Paulo, 1996.

[56] RODRIGUES, M. I. Planejamento de experimentos e otimização de processos - 3ạ . Ed., Campinas/SP, 2014.

[57] RODRIGUEZ-AMAYA, D. B. A guide to carotenoid analysis in food. Washington, DC: OMNI Research, 64p., 1999.

[58] RODRIGUEZ-AMAYA, D. B. A guide to carotenoid analysis in food. Washington, DC: International Life Sciences Institute Press, p.64., 2001.

[59] RODRIGUEZ-AMAYA, D. B.; KIMURA, M.; AMAYAFARFAN, J. Fontes Brasileiras de Carotenóides: Tabela Brasileira de Composição de Carotenoides em Alimentos. Brasília, Ministério do Meio Ambiente, p. 101., 2008.

[60] RODRIGUEZ-AMAYA, D. B; KIMURA, M. Harvest plus handbook for carotenoid analysis. Washington, DC e Cali: International Food Policy Research Institute e International Center for Tropical Agriculture, p.58., 2004.

[61] SAMBANTHAMURTHI, R.; SUDRAM, K.;TAN,Y.: Chemistry and biochemistry of palm oil. Progress in Lipid Research, vol. 39, p. 507-558, 2000.

[62] SAMPAIO, K. A. et al.. Thermal Degradation Kinetics of Carotenoids in Palm Oil. Journal of the American Oil Chemistry Society. v.90, pp. 191-198. 2013.

[63] SANTOS, A. M. Análise do potencial do biodiesel de dendê para a geração elétrica em sistemas isolados da Amazônia. 2008. 224 f. Dissertação (Mestrado em Ciências em Planejamento Energético) - Universidade Federal do Rio de Janeiro, Rio de Janeiro, 2008.

[64] SCOTT, K. J. Observations on some of the problems associated with the analysis of carotenoids in foods by HPLC. Food Chemistry, London, v.45, n. 5, p. 357- 364, 1992.

[65] SHEIL, D. et al. The impacts and opportunities of oil palm in Southeast Asia: what do we know and what do we need to know? Bogor: CIFOR, 80p. 2009. 
[66] SOUZA, W. A. VILAS BOAS, O. M. G. "A Deficiência de Vitamina A no Brasil: um panorama". Rev. Panam Salud Publica, 12 (3), 2002.

[67] SUNDRAM, K.; SAMBANTHAMURTHI, R.; TAN, Y. Palm fruit chemistry and nutrition. Asia pacific Journal of Clinical Nutrition, vol. 12, p. 355-362, 2003.

[68] TRENTINI C. P. et al.. Oil extraction from macaúba pulpusing compressed propane. J Supercrit Fluids. 126:72-78. doi: 10.1016/j.supflu.2017.02.018, 2017.

[69] TRUJILLO-QUIJANO, J.A. Óleo de palma: um produto natural. Revista Óleos \& Grãos, p.19-23, mar/abr 1997.

[70] USDA - United States Department of Agriculture. Foreign Agricultural Service. Oilseeds: world markets and trade. Washington, DC, 36 p. 2016.

[71] VALÉRIO P.P.; CREN E.C. Kinetic Predictions of Total Carotenoids Retention in Macauba Oil Under Interesterification Conditions. Sodebras Journal. 12(141):219-224, 2017.

[72] ZEB, A.; MURKOVIC, M. Determination of thermaloxidation and oxidation products of $\beta$-carotene in corn oil triacylglycerols. Food Research International, v.10,p.1-11, 2011.

[73] ZEB, A.; MURKOVIC, M. Characterisation on the effects of $\beta$-carotene on the oxidation o triacylglycerols using HPLC-ESIMS. European Journal of science and technology, Weinheim, v.112, n.11, p.1218-1228, 2010. 


\title{
Capítulo 6
}

\section{Método de Monte Carlo: Estimativa da taxa de degradação térmica do $\beta$-caroteno ${ }^{4}$}

\author{
Mariane de Carvalho Sabarense \\ Pedro Prates-Valério
}

Resumo: A compreensão dos parâmetros de reações químicas é essencial para o desenvolvimento de processos industriais mais eficazes. 0 presente capítulo apresenta a aplicação do método estocástico de Monte Carlo com Cadeias de Markov, utilizando a abordagem de Metropolis-Hastings, no contexto de simulações cinéticas de sistemas reacionais. Avaliou-se a viabilidade do desenvolvimento de um algoritmo que simule o comportamento da degradação térmica do composto $\beta$-caroteno, em matriz oleica vegetal - óleo de palma. Para tanto, os valores de energia de ativação $86,0 \mathrm{~kJ} / \mathrm{mol}$ e $109,4 \mathrm{~kJ} / \mathrm{mol}$ são considerados como parâmetros, em relação aos quais avaliam-se as temperaturas de reação $170{ }^{\circ} \mathrm{C}, 190^{\circ} \mathrm{C}, 210^{\circ} \mathrm{C}$ e $230{ }^{\circ} \mathrm{C}$ e determinam-se as constantes cinéticas e as taxas da reação. Os resultados foram sintetizados em forma de tabelas e gráficos e então comparados a estudos experimentais prévios encontrados na literatura. A comparação indicou eficiência parcial do algoritmo desenvolvido na determinação dos parâmetros cinéticos supracitados, sendo sua eficácia restrita à menor temperatura analisada.

Palavras-Chave: $\beta$-caroteno. Método de Monte Carlo. Simulação.

Abstract: To understand chemical reactions parameters is vital to the development of more effective industrial processes. This paper presents the application of Monte Carlo with Markov Chains stochastic method, using Metropolis-Hastings approach, in chemical reaction systems kinetic simulations context. The possibility of developing an algorithm to simulate the behaviour of $\beta$-carotene compounds in a vegetable oil matrix - Palm oil during heat treatment was evaluated. Therefore, activation energies of $86,0 \mathrm{~kJ} / \mathrm{mol} \mathrm{e}$ $109,4 \mathrm{~kJ} / \mathrm{mol}$ were established as parameters and reaction temperatures of $170{ }^{\circ} \mathrm{C}$, $190^{\circ} \mathrm{C}, 210^{\circ} \mathrm{C}$ e $230^{\circ} \mathrm{C}$ were analysed to determine corresponding kinetic constants and reaction rates. Results were organised in charts and spreadsheets and compared to previous experimental data found in the literature. The algorithm developed was partially efficient to calculate the reactional parameters analysed, presenting higher efficiency for the lower temperature of simulation.

Keywords: $\beta$-carotene. Monte Carlo Method. Simulation 


\section{INTRODUÇÃO}

Os carotenóides são compostos amplamente distribuídos na natureza. Ocupando posição de destaque entre pigmentos de ocorrência natural, os carotenóides presentes em matérias-primas vegetais são tetraterpenóides (C40) sintetizados pelas plantas como metabólitos secundários. Possuindo importantes propriedades fisiológicas, com efeitos benéficos para a saúde humana, tais compostos em questão dividem-se em duas classes de moléculas: Carotenos (hidrocarbonetos) e Xantofilas (estrutura química contendo pelo menos uma função oxigênio). Na classe dos carotenos, destaca-se o $\beta$-caroteno que, além de ser um potente antioxidante, oferece uma gama de benefícios à saúde que incluem a redução do risco de doenças cardíacas e alguns tipos de câncer, proteção contra degeneração macular relacionada à idade (DMRI) e aumento do desempenho do sistema imunológico (GUL et al., 2015; MAGOSSO et al., 2016).

A biodisponibilidade do $\beta$-caroteno decorre, principalmente, da ingestão de alimentos vegetais ou de seus derivados. Neste contexto, o óleo (RODRIGUEZ-AMAYA; RODRIGUEZ; AMAYA-FARFAN, 2006) extraído da palmeira Elaeis guineensis se destaca como importante fonte do composto. Ressalta-se que o óleo de palma vem sendo amplamente utilizado pela indústria alimentícia, apresentando aplicação crescente e também difundida nas indústrias cosmética e oleoquímica - é usualmente encontrado entre matérias-primas utilizadas para fabricação de emolientes, cremes dentais, além de ceras, lubrificantes e, mais recentemente, para a produção de biocombustíveis. Retomando a atenção referente ao $\beta$-caroteno, na natureza, este carotenóide é geralmente encontrado em sua forma termodinâmica mais estável e menos solúvel - todo-trans (GUL et al., 2015). A estrutura química altamente insaturada deste composto contribui com o aumento de sua sensibilidade e labilidade a degradações tanto enzimáticas quanto não enzimáticas. A isomerização dos todo-trans-carotenos para cis ocorre como uma das etapas iniciais e principais da degradação promovida por suas exposições a temperaturas elevadas e, em menor intensidade, à incidência luminosa. Autores observam que a quantidade de isômeros cis tende a aumentar com incrementos em temperatura e tempo, em etapas de processamento (MARX et al., 2003; HIRANVARACHAT; SUVARNAKUTA; DEVAHASTIN, 2008; GUL et al., 2015).

É válido considerar que isômeros cis e trans apresentam propriedades biológicas distintas e que a atividade antioxidante do isômero trans tende a ser potencializada em relação ao isômero cis (BOHM et al., 2002). Assim sendo, torna-se importante conhecer tanto o comportamento quanto os parâmetros cinéticos das reações de isomerização térmica do $\beta$-caroteno, como forma de se obter uma estimativa do efeito do processamento térmico de matérias-primas sobre retenção e a proporção dos isômeros deste composto em determinado produto final.

Neste âmbito, uma alternativa é a utilização de métodos matemáticos para simulação do comportamento reacional de interesse. Estes métodos podem ter abordagens de natureza determinística ou estocástica. A abordagem determinística considera apenas as condições iniciais de determinado sistema, como concentração, pressão e temperatura, por exemplo, como forma de se obter um resultado final, sendo modelada a partir de uma série de equações diferenciais - para cada espécie envolvida na reação, uma equação diferencial ordinária (EDO) é solucionada (CACCHIANI, 2007). A abordagem estocástica, por sua vez, considera cada uma das etapas de reação envolvidas em determinado processo, calculando-se a probabilidade definida como a razão entre a taxa desta etapa sobre a soma da taxa de todas demais etapas envolvidas. Neste caso, com o objetivo de simular uma reação, um número aleatório é gerado e comparado com as probabilidades existentes. Basicamente, o algoritmo é executado pelo decréscimo do número de moléculas de reagentes e aumento do número de moléculas dos produtos de acordo com os coeficientes estequiométricos da reação. Um novo número aleatório é gerado e o procedimento se repete até o término do processo reacional (TIGHEZZA; ALDHAYAN; ALMTHAR, 2011).

Atualmente, diversos métodos estocásticos têm sido utilizados em simulações cinéticas de sistemas reacionais químicos ou bioquímicos, especialmente homogêneos (TIGHEZZA; ALDHAYAN; ALMTHAR, 2011). Um destes métodos, denominado Monte Carlo, tem sido amplamente aplicado nos estudos cinéticos cujas reações são de primeira e de segunda ordem (FARIAS, 2012). Neste contexto, o presente capítulo apresenta como objetivo a aplicação de conceitos do Método de Monte Carlo na criação de um algoritmo que simule o comportamento da degradação térmica do $\beta$-caroteno presente no óleo vegetal de palma e na determinação da taxa desta reação a partir dos dados simulados pelo algoritmo criado.

\section{REFERENCIAL TEÓRICO}

Os carotenóides presentes em alimentos são tetraterpenóides C40 formados por oito unidades isoprenóides C5 ligadas na forma cabeça-cauda, com exceção do centro, no qual as unidades se ligam na 
forma cauda-cauda, resultando em moléculas simétricas. A característica mais proeminente destes compostos, e que é responsável por suas funções físico-químicas e biológicas, é um extenso sistema de duplas ligações conjugadas centralmente simétricas (RODRIGUEZ-AMAYA; KIMURA; AMAYA-FARFAN, 2008).

Enquanto pigmentos naturais, os carotenóides são sintetizados por plantas, algas, fungos, leveduras e bactérias. A maioria dos animais, incluindo o ser humano, é incapaz de sintetizá-los, acumulando-os a partir da dieta. Os carotenóides estão entre os compostos pigmentares mais importantes na alimentação em função de seus efeitos benéficos à saúde - relatam-se: imunomodulação e redução do risco de contrair doenças crônicas degenerativas como câncer, doenças cardiovasculares, catarata, degeneração macular e fortalecimento do sistema imunológico. Além dos efeitos benéficos mencionados, alguns carotenóides são precursores da vitamina $A$, sendo utilizados no combate à deficiência desta vitamina (RODRIGUEZAMAYA; RODRIGUEZ; AMAYA-FARFANIL, 2006).

Dentre os mais de 600 carotenóides identificados atualmente, aproximadamente 50 atuam como precursores da vitamina $A$, sendo a presença de pelo menos um anel $\beta$-ionona não substituído, em suas estruturas, o pré-requisito para esta característica. Em função de o composto todo-trans- $\beta$-caroteno possuir dois anéis $\beta$-ionona, ele pode ser clivado em duas moléculas de vitamina $A$, possuindo a maior atividade pró-vitamínica A entre os demais carotenóides (SCHIEBER; CARLE, 2005; PALMERO et al., 2013).

Por apresentarem estruturas químicas altamente insaturadas, os carotenóides encontram-se ainda mais susceptíveis à oxidação e a isomerizações durante etapas diversas de processamento e armazenamento das matérias-primas que os contém. No caso do $\beta$-caroteno, a isomerização da forma todo-trans para isômeros cis implica em alteração do seu metabolismo e na biodisponibilidade da molécula, além da redução da atividade pró-vitamínica A. Em comparação com o todo-trans- $\beta$-caroteno, o isômero 13-cis- $\beta$ caroteno e o isômero 9-cis- $\beta$-caroteno, ambos comumente relatados em frações oleicas processadas termicamente, apresentam, respectivamente, $53 \%$ e $38 \%$ da atividade pró-vitamínica A (MINGUEZMOSQUERA; HORNERO-MENDEZ; PEREZ-GALVEZ, 2002; BOVI, 2015).

\section{1 ÓLEO DE PALMA}

A relevância industrial e científica da palma (Elaes guineensis) se relaciona, inclusive, ao fato de seu óleo ser um dos mais comercializados no mercado mundial de compostos graxos. Na safra 2015/2016 esta cultura contribuiu com aproximadamente 40\% dos 178 milhões de toneladas métricas de óleos vegetais extraídos e distribuídos mundialmente - também se destacam a soja (29\%), a canola (15\%) e o girassol (8\%). Atualmente, o Brasil ocupa a segunda posição entre os maiores produtores de oleaginosas, com produção superior a 109 milhões de toneladas métricas, precedido pelos Estados Unidos, cuja produção se aproxima de 116 milhões de toneladas métricas (DEPARTAMENTO DE AGRICULTURA DOS ESTADOS UNIDOS, 2018). Particularmente, o óleo de palma tem sido largamente utilizado nos segmentos alimentício, cosmético e oleoquímico devido à crescente demanda por produtos que contenham constituintes bioativos, adicionados ou preservados. Incrementos na demanda também se relacionam com a necessidade de maior rendimento em óleo vegetal por área cultivada (SAMPAIO, 2011). Em sua forma bruta, o óleo da palma possui entre 500 e $1.500 \mathrm{mg} / \mathrm{kg}$ de carotenóides, dependendo de sua variedade, os quais lhe conferem coloração vermelho-alaranjada. Destes carotenóides, cerca de $90 \%$ correspondem a alpha e $\beta$-carotenos (MAYAMOL et al., 2007).

Sabidamente, o processamento de óleos vegetais envolve etapas de refino que tem por objetivo a remoção de impurezas. Este refino pode ser realizado por via química ou por via física.

Particularmente para o óleo de palma, o refino físico tende a ser aplicado nos casos em que índices de acidez elevados tendem a contribuir com perdas excessivas de óleo no refino químico, devido a reações de saponificação e arraste mecânico deste óleo pela emulsão formada, além da remoção de pigmentos durante o tratamento alcalino (ROSSI et al., 2001).

Nos processos físicos, o óleo é submetido a temperaturas relativamente altas (entre 200 e $260{ }^{\circ} \mathrm{C}$ ) e, devido a esta exposição, estima-se que seja destruída no refino uma quantidade de $\beta$-caroteno suficiente para suprir a necessidade de vitamina A da população mundial (MAYAMOL et al., 2007).

Considerando que a perda mencionada resulta também da conversão das espécies todo-trans- $\beta$-caroteno em seus isômeros cis, é razoável verificar que o estudo do comportamento cinético deste carotenóide durante o processamento térmico se justifica na predição do teor de retenção do isômero todo-trans. 
Até o presente momento não há consenso sobre a ordem da reação de degradação do $\beta$-caroteno durante o tratamento térmico, havendo relativa escassez de estudos em relação aos parâmetros cinéticos desta reação. Há autores que sugerem modelos de degradação de primeira ordem (VALÉRIO; CREN, 2017 ; XIAO et al., 2018), de ordem zero (SILVA, 2015) e ainda de terceira ordem (ARCHIR et al., 2010), o que leva à necessidade da utilização de modelos matemáticos como ferramentas para a melhor compreensão e extrapolação dos dados obtidos experimentalmente.

\subsection{MODELAGEM CINÉTICA}

De acordo com (ARCHIR et al., 2010), a modelagem cinética da degradação térmica pode ser genericamente representada pela Equação 1.

$$
\frac{d C}{d t}=-k C^{n}
$$

A taxa de reação, representada pela variação da concentração ao longo do tempo (dC/dt) é proporcional à enésima potência da concentração do reagente, sendo $n$ a ordem da reação e $k$ a constante de reação (FOGLER, 2016). Integrando esta equação entre $C_{0}$ e $C$ do tempo zero até o tempo $t$, obtém-se:

$$
\int_{C_{0}}^{C} \frac{d C}{C^{n}}=-\int_{0}^{t} k \cdot d t
$$

A Equação 2 não se aplica para $n=1$, pois neste caso se tornaria indeterminada, portanto, têm-se as Equações 3 e 4 .

$$
\begin{aligned}
& C=C_{0} \exp (-k t)(n=1) \\
& C=\left[C_{0}^{1-n}-(1-n) k t\right]^{\frac{1}{1}-n}(n \neq 1)
\end{aligned}
$$

Assume-se que a constante de reação varia com a temperatura absoluta segundo a lei de Arrhenius (Equação 5).

$$
k=k_{0} \exp \left(\frac{-E_{a}}{R T}\right)
$$

Em que ko representa o fator pré-exponecial $\left(\mathrm{s}^{-1}\right)$, Ea a energia de ativação $(\mathrm{J} / \mathrm{mol})$, T a temperatura $(\mathrm{K})$ considerada constante durante o tratamento térmico - e R a constante dos gases $\left(8,314 \mathrm{~J} \mathrm{~mol}^{-1} \mathrm{~K}^{-1}\right)$.

Combinando a Equação 5 com as Equações 1, 3 e 4, obtêm-se, respectivamente, as Equações 6, 7 e 8.

$$
\begin{aligned}
& \frac{d C}{d t}=-k_{0} \exp \left(\frac{-E_{a}}{R T}\right) C^{n} \\
& C=C_{0} \exp \left(-\left[k_{0} \exp \left(\frac{-E_{a}}{R T}\right)\right] t\right)(n=1)
\end{aligned}
$$




$$
C=\left[C_{0}^{1-n}-(1-n)\left[k_{0} \exp \left(\frac{-E_{a}}{R T}\right)\right] t\right]^{\frac{1}{1}-n}(n \neq 1)
$$

Apesar de ser possível o cálculo experimental da taxa de reação, a simulação matemática permite estimar esta taxa em diversas condições de reação diferentes auxiliando, também, no planejamento experimental.

\subsection{ABORDAGENS MATEMÁTICAS}

A abordagem determinística, desenvolvida em meados do século XX, envolve a utilização de equações diferenciais ordinárias (EDO's) para resolver uma série de reações químicas, considerando as concentrações das espécies como variáveis (CACCHIANI, 2007). Esta abordagem, no entanto, apresenta limitações referentes aos seguintes aspectos randômicos do sistema: mesmo que o sistema evolua de forma específica em relação à posição, velocidade e população molecular de cada espécie química, ele não se mantém constante, especificamente, em relação à população das espécies isoladamente; a indeterminância quântica não pode ser evitada - em uma reação unimolecular é impossível determinar o momento exato em que ocorre a isomerização da molécula, por exemplo; os sistemas químicos raramente são mecanicamente isolados, com interferência em seu comportamento (GILLESPIE, 2007).

Considerem-se as quantidades de cada espécie química em um vetor de estado, segundo a Equação 9.

$$
X(t)=\left[\begin{array}{l}
X_{1}(t) \\
X_{2}(t) \\
X_{n}(t)
\end{array}\right]
$$

Na qual $\mathrm{X}_{\mathrm{i}}(\mathrm{t})$ é um valor inteiro não negativo que representa a quantidade de moléculas da espécie $i$ presentes no momento $t$.

Este vetor é alterado no momento em que qualquer uma das reações às quais o sistema está sujeito ocorrem. Assim sendo, a abordagem das alterações do sistema em termos de probabilidade de ocorrência de uma das reações a partir do estado atual torna-se mais simplificada do que seguir toda a dinâmica do sistema (HIGHAM, 2008).

Este raciocínio leva à abordagem estocástica que, através de conceitos probabilísticos, busca descrever o comportamento real do sistema ao levar em consideração suas especificidades e aleatoriedades (GILLESPIE, 2007). Dentre os diversos métodos estocásticos, o Método de Monte Carlo se diferencia dos demais por apresentar um erro absoluto de estimação da ordem de $\mathrm{n}^{-1 / 2}$ enquanto os demais possuem erros que decrescem, nos melhores casos, à taxa $\mathrm{n}^{-1 / m}$, onde $m$ representa o número de elementos do problema (MULLER, 2008). Em termos práticos, esta diferença representa aumento da eficiência computacional ao se utilizar os métodos estocásticos, dentre os quais o Método de Monte Carlo.

\subsection{MÉTODO DE MONTE CARLO}

Em uma abordagem generalista, o método estocástico de Monte Carlo se divide em três etapas básicas: estabelecimento das populações de interesse e de seus respectivos comportamentos distribucionais, amostragem aleatória e criação da distribuição de frequência da estatística de interesse (MULLER, 2008).

A partir deste conceito, diversos modelos com diferentes objetivos têm sido formulados nas últimas décadas. Dentre estes, destacam-se: Simulação Direta de Monte Carlo, Monte Carlo Cinético, Monte Carlo Quântico, Monte Carlo com Cadeias de Markov e Quase-Monte Carlo (MULLER, 2008).

Particularmente sobre a dinâmica de Monte Carlo com Cadeias de Markov, ou MCMC, a abordagem de Metropolis-Hastings, permite a análise de partículas (ou moléculas) que obedecem à distribuição de Boltzmann, que descreve a maneira como uma dada energia E se distribui ao longo de um grande número de partículas em um sistema em equilíbrio térmico com volume e número de partículas definido, considerando as probabilidades de transição de estado das moléculas (P) dependentes tanto da energia de ativação como da temperatura do sistema (FARIAS, 2012) de acordo com a Equação 10. 


$$
P=\exp \left(-\beta E_{a}\right)
$$

Em que $E_{a}$ representa a energia de ativação e $\beta$ é a constante de Boltzmann representada pela Equação 11.

$$
\beta=\left(k_{b} T\right)^{-1}
$$

Na qual $k_{b}$ é a constante de Boltzmann e $T$ é a temperatura absoluta.

Considerando a reação de degradação térmica do todo-trans- $\beta$-caroteno como uma isomerização irreversível, tem-se a Equação 12.

$$
\stackrel{k}{\rightarrow} \emptyset
$$

Em que A representa o all-trans- $\beta$-caroteno, $k$ representa a constante de reação e $\emptyset$ representa os isômeros cis formados.

Para determinar o número de moléculas de $\mathrm{A}$ em tempos posteriores ao momento inicial da reação $(\mathrm{t}>0)$ utilizando o MCMC, torna-se necessária a formulação de um algoritmo que, seguindo uma sequência de passos pré-estabelecidos, permita o cálculo do parâmetro de interesse. Apesar da existência de estudos que envolvem o desenvolvimento de algoritmos para simulação de reações químicas unimoleculares (CONCEIÇÃO, 2004; FARIAS, 2012; NASCIMENTO, 2013; TAMAKI; WESTPHAL; PEREIRA, 2002), não foram encontrados algoritmos específicos para a degradação térmica do $\beta$-caroteno.

\subsection{TEORIA DE COLISÕES E FATOR DE PROBABILIDADE}

Segundo Russel (1994), a Teoria das Colisões, formulada no início do século XX, afirma que a ocorrência de uma reação depende da colisão entre moléculas. Segundo esta teoria, a velocidade de reação é diretamente proporcional, portanto, à frequência de colisões ' $Z$ ' (colisões por tempo) entre as moléculas. A velocidade também é diretamente proporcional à concentração dos reagentes ' $[A]$ ' e depende da fração destas moléculas que possuem energia igual ou maior que a energia de ativação da reação. Em aderência, tal fração pode ser expressa pela distribuição de Maxwell-Boltzmann (e-Ea/RT).

Ainda de acordo com Russel (1994), apesar de não fazer parte originalmente da Teoria de Colisões, é importante considerar um fator adicional: para que uma reação ocorra é necessário que a orientação relativa das moléculas envolvidas seja favorável a tal reação. Este efeito, denominado efeito estérico, limita a reação a colisões bem-sucedidas. 0 fator estérico ' $p$ ', ou fator de probabilidade, representa a fração de colisões bem-sucedidas em relação ao total de colisões.

\section{METODOLOGIA}

\subsection{CARACTERIZAÇÃO DA PESQUISA}

De acordo com as definições descritas por Gerhardt e Silveira (2009), este capítulo se caracteriza como um estudo teórico e original. A metodologia utilizada mesclou revisão bibliográfica e procedimentos experimentais para atingir os objetivos deste capítulo, podendo estes serem descritos como explicativos, buscando a identificação da influência de determinados fatores no fenômeno estudado, e a abordagem adotada é qualitativa, comparando o comportamento dos dados obtidos com situações semelhantes, descritas em literatura. 


\subsection{COLETA DE DADOS}

Os dados iniciais necessários para a realização das simulações foram obtidos dos estudos de Archir e colaboradores (2010) e SAMPAIO (2013).

Foram determinadas como parâmetros de simulação as temperaturas de $170{ }^{\circ} \mathrm{C}, 190{ }^{\circ} \mathrm{C}, 210{ }^{\circ} \mathrm{C}$ e $230{ }^{\circ} \mathrm{C}$ assumindo que a reação aconteça em condições isotérmicas - por serem valores pertencentes à faixa de temperatura usual de tratamento térmico do óleo de palma, mais especificamente, à faixa de temperatura aplicada ao refino físico do óleo de palma. As concentrações iniciais para cada temperatura foram determinadas com base no estudo de degradação de carotenóides realizado por Sampaio (2013), assumindo que a concentração de $\beta$-caroteno corresponda à totalidade dos carotenóides medidos no óleo de palma no momento que o sistema atinge condições isotérmicas nas temperaturas definidas, conforme descrito na Tabela 1. Sendo assim, salienta-se que duas energias de ativação ( $E_{a}$ ) distintas foram consideradas: $86,00 \mathrm{~kJ} / \mathrm{mol}$ e 109,4 $\mathrm{kJ} / \mathrm{mol}$, de acordo com os valores propostos nos estudos experimentais supramencionados (ARCHIR et al., 2010; SAMPAIO, 2013).

Tabela 1. Parâmetros iniciais para simulação

\begin{tabular}{|c|c|c|}
\hline $\begin{array}{c}\text { Temperatura } \\
\left({ }^{\circ} \mathrm{C}\right)\end{array}$ & $\begin{array}{c}\text { Energia de Ativação } \\
\left(\mathrm{kJ} \cdot \mathrm{mol}^{-1}\right)\end{array}$ & $\begin{array}{c}\text { Concentração Inicial: } \beta \text {-caroteno } \\
\left(\mathrm{mg}_{\mathrm{kg}}{ }^{-1} \text { óleo }\right)\end{array}$ \\
\hline 170 & 86 e 109,4 & 1074,0 \\
\hline 190 & 86 e 109,4 & 974,0 \\
\hline 210 & 86 e 109,4 & 579,0 \\
\hline 230 & 86 e 109,4 & 23,0 \\
\hline
\end{tabular}

\subsection{TRATAMENTO DOS DADOS}

Os parâmetros pré-determinados foram utilizados como inputs em um algoritmo de Monte Carlo com a dinâmica de Metropolis-Hastings desenvolvido durante o estudo abarcado pelo presente capítulo. Este algoritmo considerou a aplicação de uma função de probabilidade baseada na distribuição de Boltzmann como parâmetro determinante da ocorrência ou não da reação estudada e para a determinação da variação da concentração de $\beta$-caroteno no óleo de palma, ao longo do tempo, a partir da comparação desta probabilidade com números gerados de forma aleatória. Os resultados foram obtidos a partir da média de uma série de repetições do procedimento de cálculo (passo de Monte Carlo). 0 algoritmo desenvolvido foi codificado na linguagem computacional MATLAB (Software Matlab® - versão R2015a) na forma de um script para realização dos cálculos. Os resultados foram sintetizados em forma de tabelas e gráficos para a realização da análise e discussão dos resultados.

A influência do fator estérico na probabilidade de reação foi avaliada, posteriormente, como forma de concluir sobre a relevância deste parâmetro na análise. Para determinar o fator estérico mais adequado para cada temperatura estudada foram realizados testes com simulações preparatórias, considerando seu valor entre 0,1 e 1,0. Os dados obtidos foram comparados com o comportamento observado experimentalmente, como forma de se determinar o valor inicial mais adequado para este parâmetro. Considerando que ao longo da reação o consumo do reagente reduz a quantidade de moléculas sujeitas à colisão e, consequentemente, o fator estérico se reduz, este parâmetro foi considerado variável também nas simulações, convencionando-se redução de seu valor inicial em 0,002 unidades a cada intervalo de medição, ao longo do tempo total de reação. Os resultados obtidos após a inserção do fator estérico foram comparados com o comportamento experimental registrado no estudo de Sampaio (2013), sendo utilizados para determinar a constante e a taxa de reação referentes a cada temperatura associada às energias de ativação pré-determinadas. A reação foi assumida como sendo de primeira ordem (XIAO et al., 2018) e o coeficiente de correlação $\left(\mathrm{R}^{2}\right)$ correspondente foi utilizado para avaliar o ajuste dos dados obtidos. As determinações da constante e da taxa de reação foram realizadas por meio da aplicação das concentrações iniciais experimentais (SAMPAIO, 2013) aos dados de degradação percentuais obtidos a partir da simulação proposta e posterior regressão das curvas de concentração (mg/kg óleo) em função do tempo. 


\section{RESULTADOS E DISCUSSÕES}

\subsection{ANÁLISES PRELIMINARES DA DEGRADAÇÃO DE B-CAROTENO EM DIFERENTES TEMPERATURAS}

Considerando a probabilidade de ocorrência de reação de acordo com a distribuição de Boltzmann, sem influência do fator estérico $(p=1)$, foram obtidos os resultados descritos nas Figuras 1 e 2.

Figura 1. Variação da concentração de $\beta$-caroteno considerando energia de ativação de 86 kJ.mol-1

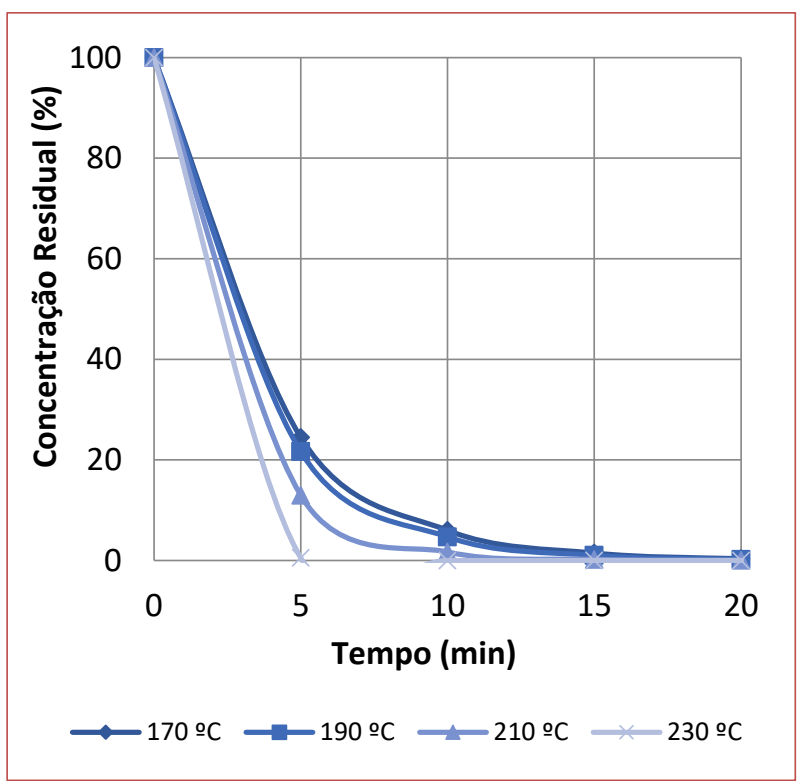

Fonte: Autores

Figura 2. Variação da concentração de $\beta$-caroteno considerando energia de ativação de 109,4 kJ.mol-1

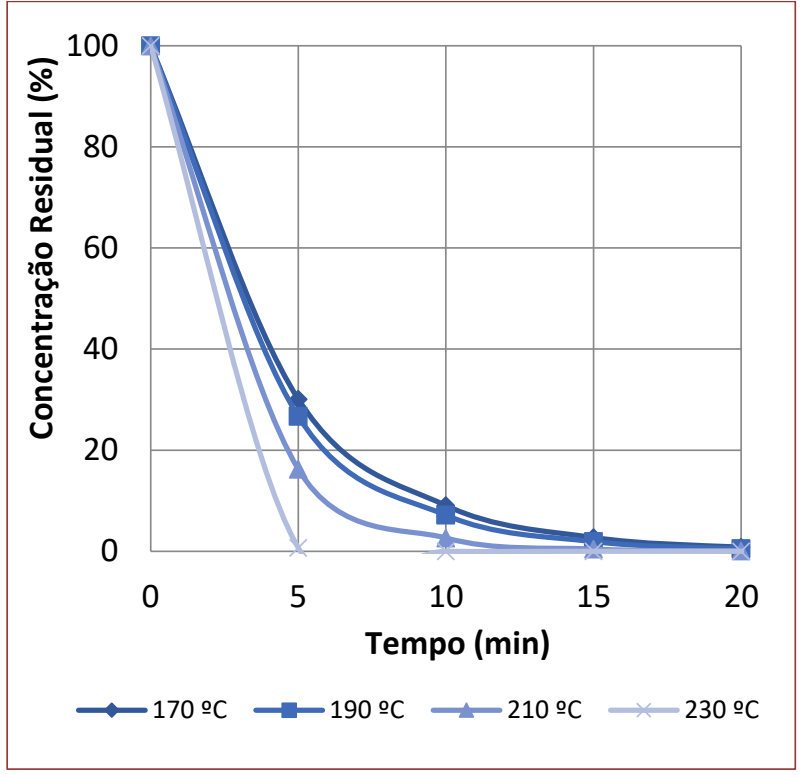

Fonte: Autores

Observa-se que, de acordo com estas simulações, para ambas as energias de ativação propostas, o reagente é rapidamente consumido, não havendo retenção de $\beta$-caroteno após 20 minutos de reação, para todas as temperaturas estudadas. 
A diferença nas energias de ativação propostas para simulação exerceu pouca influência no resultado observado. Ainda assim, verificou-se que, de forma discreta, o aumento da energia de ativação resultou em reduzida variação da concentração ao longo do tempo, trazendo coerência ao considerar que quanto mais elevada é a energia de ativação maior é o aporte de energia necessária para que determinada reação ocorra. Salienta-se que os resultados obtidos são coerentes com aqueles realizados por Garcia e Valério (2017), que observou consumo quase total a partir de 30 minutos para uma temperatura de $150{ }^{\circ} \mathrm{C}$, porém, divergem do observado por Sampaio (2013), cujos experimentos indicaram o consumo total de carotenóides apenas a partir de 60 minutos de reação e somente para temperaturas acima de $210^{\circ} \mathrm{C}$. Considerando o exposto por Valério e Cren (2017), a análise de diferentes estudos relacionados à degradação térmica de carotenóides indica que este processo seja complexo e dependa de fatores associados à matrix e ao alimento estudado e, ainda, considerando a relevância da Teoria das Colisões no processo em questão, o fator estérico foi inserido no cálculo de probabilidade como forma de aproximar o comportamento simulado ao comportamento observado no estudo experimental utilizado como base.

\subsection{APLICAÇÃO DO FATOR ESTÉRICO À ANÁLISE DE DEGRADAÇÃO}

Os fatores estéricos, definidos após os testes com simulações preparatórias, para cada temperatura analisada, de acordo com a aproximação do comportamento simulado em relação ao comportamento observado experimentalmente (GERHARDT; SILVEIRA, 2009), assim como o valor determinado para a variação deste parâmetro ao longo dos intervalos de medição, foram inseridos no algoritmo de simulação, estando descritos na Tabela 2.

Tabela 2. Fatores Estéricos adotados

\begin{tabular}{|c|c|c|}
\hline $\begin{array}{c}\text { Temperatura } \\
\left({ }^{\circ} \mathrm{C}\right)\end{array}$ & $(\mathrm{p})$ & $\begin{array}{c}\text { Redução do Fator Estérico por } \\
\text { Iteração }\end{array}$ \\
\hline 170 & 0,10 & 0,002 \\
\hline 190 & 0,15 & 0,002 \\
\hline 210 & 0,38 & 0,002 \\
\hline 230 & 0,40 & 0,002 \\
\hline
\end{tabular}

Observa-se que, à medida que a temperatura se eleva, o fator estérico adotado também tende a apresentar valor maior, o que ocorre, provavelmente, em função do aumento da agitação das moléculas, com aumento do número de colisões e, por consequência, da probabilidade de colisões efetivas.

É possível perceber que a variação dos valores do fator estérico ocorre de forma mais considerável para as temperaturas de $190^{\circ} \mathrm{C}$ e $210^{\circ} \mathrm{C}$, indicando que tal parâmetro tende a variar de forma não linear.

As Figuras 3 e 4 apresentam resultados obtidos a partir da aplicação dos fatores descritos na Tabela 2, como parâmetros de simulação, considerando um período de reação igual a 140 minutos.

Considerando os valores das energias de ativação 86,0 kJ/mol e 109,4 kJ/mol estudadas, observou-se sua influência sobre o comportamento da reação simulada. A degradação do $\beta$-caroteno ocorreu de forma discretamente mais significativa para o valor de Ea igual a $86 \mathrm{~kJ} / \mathrm{mol}$. Para esta energia de ativação a concentração de $\beta$-caroteno se reduziu para 38,6\% após 70 minutos de reação, enquanto para a energia de ativação igual a 109,4 kJ/mol, após o mesmo período de tempo, a concentração remanescente se reduziu para $41,5 \%$.

Em comparação com os resultados obtidos sem a inserção do parâmetro fator estérico, as simulações realizadas com sua inserção resultaram em maior retenção do carotenóide, para ambas as energias de ativação avaliadas. Particularmente, para as temperaturas iguais a $170{ }^{\circ} \mathrm{C}$ e $190{ }^{\circ} \mathrm{C}$, observou-se $\beta$ caroteno remanescente mesmo após 140 minutos de reação. 
Figura 3. Variação da concentração de $\beta$-caroteno ao longo do tempo: Ea $=86 \mathrm{~kJ}^{\mathrm{mol}}{ }^{-1}$

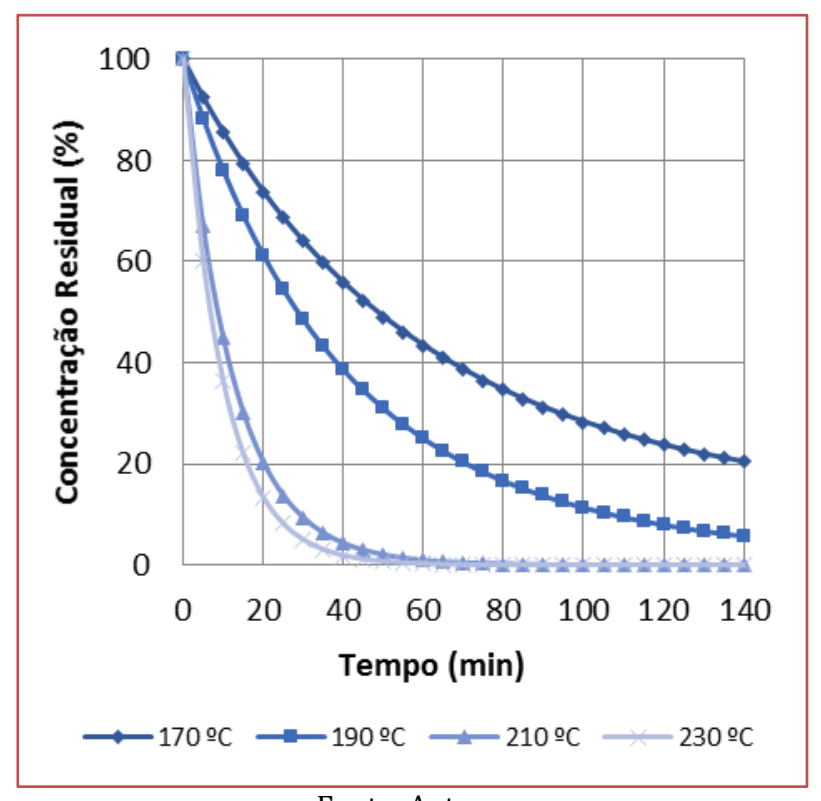

Fonte: Autores

Figura 4. Variação da concentração de $\beta$-caroteno ao longo do tempo: Ea = 109,4 kJ.mol-1

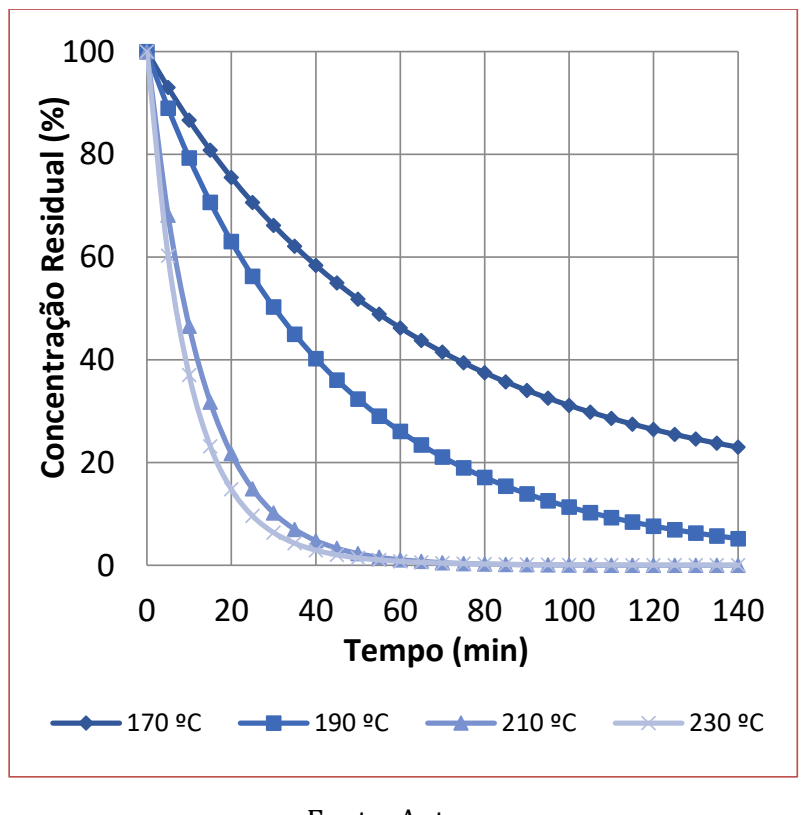

Fonte: Autores

Para as temperaturas $210{ }^{\circ} \mathrm{C}$ e $230{ }^{\circ} \mathrm{C}$, no entanto, em comparação com $170^{\circ} \mathrm{C}$ e $190{ }^{\circ} \mathrm{C}$, a degradação ocorreu de forma mais acentuada, havendo uma redução brusca da concentração de $\beta$-caroteno nos primeiros 40 minutos de reação, com consumo quase total do reagente após este momento.

No que se refere ao comportamento observado experimentalmente (SAMPAIO, 2013), a inserção do fator estérico resultou na aproximação dos resultados simulados daqueles observados por SAMPAIO (2013) e reproduzidos na Figura 5. Observa-se, tanto nas simulações quanto nos resultados experimentais, o consumo quase total de $\beta$-caroteno após 40 minutos de reação para as temperaturas de $210{ }^{\circ} \mathrm{C}$ e $230 \stackrel{\circ}{\circ} \mathrm{C}$. 
Figura 5. Variação da concentração de $\beta$-caroteno ao longo do tempo de reação

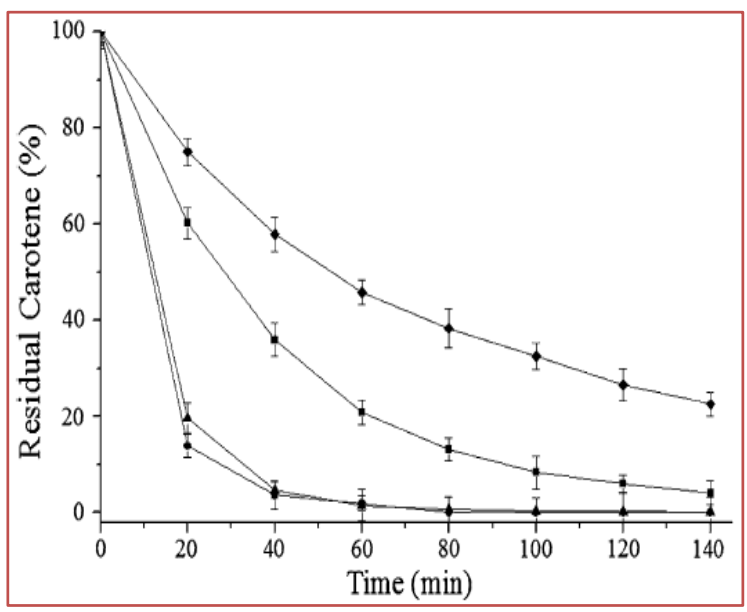

Fonte: Sampaio (2013)

As simulações ainda, analogamente aos resultados experimentais, retratam degradação mais lenta nas temperaturas mais baixas, com mais de $20 \%$ de $\beta$-caroteno remanescente após 140 minutos de reação para $170^{\circ} \mathrm{C}$ e com reagente remanescente, ainda que em baixa concentração, após 140 minutos de reação para $190^{\circ} \mathrm{C}$. Tal semelhança indica que os dados resultantes das simulações possam ser utilizados para estimar parâmetros da reação em questão, incluindo a taxa de degradação.

\subsection{CÁLCULO DAS CONSTANTES E DAS TAXAS DE REAÇÃO}

Considerando um tempo total de reação igual a 140 minutos (SAMPAIO, 2013), com medições realizadas em intervalos de tempo iguais a cinco minutos, as simulações possibilitaram estimar a variação da concentração de $\beta$-caroteno ao longo do tempo, para cada temperatura e para cada energia de ativação analisadas. Os resultados podem ser visualizados nas Tabelas 3 e 4 .

A partir dos dados tabelados, considerando uma reação de primeira ordem e utilizando uma regressão exponencial, foram obtidas as funções que relacionam a concentração de $\beta$-caroteno com o tempo. Estas funções, assim como os seus respectivos coeficientes de correlação, estão expressas na Tabela 5.

É razoável observar que os coeficientes de correlação para as três temperaturas mais baixas possuem valores próximos a um, reforçando a indicação de que a reação de degradação térmica do $\beta$-caroteno segue uma cinética de primeira ordem, diferentemente do proposto por Sampaio (2013), que considera a reação de degradação térmica do $\beta$-caroteno como sendo de ordem fracionária e igual a 1,3.

Para a temperatura de $230 \stackrel{\circ}{\circ}$, o coeficiente de correlação apresenta valor consideravelmente inferior aos demais. Tal resultado pode indicar que o modelo desenvolvido não se aplica adequadamente a esta condição experimental, sendo necessária revisão futura do modelo para ampliar sua abrangência. 
Tabela 3. Variação da concentração $(\mathrm{mg} / \mathrm{kg})$ de $\beta$-caroteno: $\mathrm{Ea}=86 \mathrm{~kJ} / \mathrm{mol}$.

\begin{tabular}{|c|c|c|c|c|}
\hline Tempo (minutos) & $170^{\circ} \mathrm{C}$ & $190^{\circ} \mathrm{C}$ & $210^{\circ} \mathrm{C}$ & $230^{\circ} \mathrm{C}$ \\
\hline 0 & 1074,00 & 974,00 & 579,00 & 23,00 \\
\hline 5 & 992,81 & 859,46 & 387,58 & 13,85 \\
\hline 10 & 919,45 & 795,82 & 260,03 & 8,37 \\
\hline 15 & 852,86 & 673,03 & 174,97 & 5,07 \\
\hline 20 & 792,29 & 597,16 & 118,00 & 3,08 \\
\hline 25 & 737,30 & 530,73 & 79,79 & 1,88 \\
\hline 30 & 678,25 & 472,49 & 54,14 & 1,15 \\
\hline 35 & 641,72 & 421,26 & 36,82 & 0,71 \\
\hline 40 & 599,94 & 376,45 & 25,01 & 0,43 \\
\hline 45 & 561,92 & 336,91 & 17,08 & 0,27 \\
\hline 50 & 527,23 & 302,04 & 11,70 & 0,17 \\
\hline 55 & 495,33 & 271,36 & 7,99 & 0,10 \\
\hline 60 & 466,22 & 244,08 & 5,50 & 0,06 \\
\hline 65 & 439,48 & 219,93 & 3,82 & 0,04 \\
\hline 70 & 414,99 & 198,60 & 2,61 & 0,03 \\
\hline 75 & 392,33 & 179,70 & 1,85 & 0,02 \\
\hline 80 & 371,60 & 162,76 & 1,27 & 0,01 \\
\hline 85 & 352,49 & 147,76 & 0,87 & 0,01 \\
\hline 90 & 334,87 & 134,31 & 0,64 & 0,00 \\
\hline 95 & 318,66 & 122,24 & 0,41 & 0,00 \\
\hline 100 & 303,83 & 111,62 & 0,29 & 0,00 \\
\hline 105 & 290,09 & 101,98 & 0,23 & 0,00 \\
\hline 110 & 277,31 & 93,31 & 0,17 & 0,00 \\
\hline 115 & 265,60 & 85,61 & 0,12 & 0,00 \\
\hline 120 & 254,75 & 78,60 & 0,06 & 0,00 \\
\hline 125 & 244,66 & 72,37 & 0,06 & 0,00 \\
\hline 130 & 235,42 & 66,62 & 0,06 & 0,00 \\
\hline 135 & 226,94 & 61,56 & 0,06 & 0,00 \\
\hline 140 & 219,10 & 56,88 & 0,06 & 0,00 \\
\hline
\end{tabular}


Tabela 4. Variação da concentração (mg/kg) de $\beta$-caroteno: Ea = 109,4 kJ/mol

\begin{tabular}{|c|c|c|c|c|}
\hline $\begin{array}{c}\text { Tempo } \\
\text { (minutos) }\end{array}$ & $170^{\circ} \mathrm{C}$ & $190^{\circ} \mathrm{C}$ & $210^{\circ} \mathrm{C}$ & $230^{\circ} \mathrm{C}$ \\
\hline 0 & 1074,00 & 974,00 & 579,00 & 23,00 \\
\hline 5 & 998,00 & 866,96 & 394,70 & 13,86 \\
\hline 10 & 930,51 & 772,28 & 296,41 & 8,52 \\
\hline 15 & 867,90 & 688,42 & 184,06 & 5,33 \\
\hline 20 & 810,76 & 614,11 & 125,93 & 3,41 \\
\hline 25 & 758,57 & 548,17 & 86,27 & 2,21 \\
\hline 30 & 710,77 & 498,92 & 59,12 & 1,47 \\
\hline 35 & 667,17 & 438,11 & 40,59 & 0,99 \\
\hline 40 & 627,00 & 392,23 & 27,91 & 0,68 \\
\hline 45 & 590,27 & 351,42 & 19,22 & 0,47 \\
\hline 50 & 556,33 & 315,28 & 13,26 & 0,34 \\
\hline 55 & 525,19 & 282,85 & 9,15 & 0,24 \\
\hline 60 & 496,51 & 254,02 & 6,31 & 0,18 \\
\hline 65 & 470,09 & 228,40 & 4,63 & 0,13 \\
\hline 70 & 445,82 & 205,51 & 3,01 & 0,10 \\
\hline 75 & 423,37 & 185,06 & 2,08 & 0,08 \\
\hline 80 & 402,64 & 166,75 & 1,45 & 0,06 \\
\hline 85 & 383,53 & 150,39 & 1,04 & 0,05 \\
\hline 90 & 365,80 & 135,68 & 0,69 & 0,04 \\
\hline 95 & 349,59 & 122,53 & 0,52 & 0,03 \\
\hline 100 & 334,34 & 110,74 & 0,35 & 0,03 \\
\hline 105 & 320,37 & 100,22 & 0,23 & 0,02 \\
\hline 110 & 307,38 & 90,78 & 0,17 & 0,02 \\
\hline 115 & 295,24 & 82,21 & 0,12 & 0,02 \\
\hline 120 & 284,18 & 74,51 & 0,06 & 0,01 \\
\hline 125 & 273,76 & 67,60 & 0,06 & 0,01 \\
\hline 130 & 264,20 & 61,46 & 0,06 & 0,01 \\
\hline 135 & 255.40 & 55,91 & 0,06 & 0,01 \\
\hline 140 & 247,13 & 50,84 & 0,06 & 0,01 \\
\hline
\end{tabular}

A partir das funções descritas na Tabela 5, de acordo com (3), foram obtidas as constantes de reação para cada temperatura simulada. Através da derivação destas funções, de acordo com (1), foram calculadas as taxas iniciais de reação para cada energia de ativação proposta. Os valores das taxas e constantes de reação estão descritos na Tabela 6. 
Tabela 5. Funções da concentração de $\beta$-caroteno, em relação ao tempo de reação

\begin{tabular}{c|c|c|c|c|}
$\begin{array}{c}\text { Energia de Ativação } \\
\text { Temperatura }\end{array}$ & \multicolumn{2}{c}{$86,0 \mathrm{~kJ} / \mathrm{mol}$} & \multicolumn{2}{c}{$109,4 \mathrm{~kJ} / \mathrm{mol}$} \\
$170{ }^{\circ} \mathrm{C}$ & $\mathrm{C}(\mathrm{t})$ & $\mathrm{r}$ & $\mathrm{C}(\mathrm{t})$ & 0,9891 \\
\hline $190^{\circ} \mathrm{C}$ & $\mathrm{C}=970,92 \mathrm{e}^{-0,011 \mathrm{t}}$ & 0,9891 & $\mathrm{C}=978,26 \mathrm{e}^{-0,010 \mathrm{t}}$ & 0,9992 \\
\hline $210^{\circ} \mathrm{C}$ & $\mathrm{C}=872,77 \mathrm{e}^{-0,020 \mathrm{t}}$ & 0,9959 & $\mathrm{C}=924,96 \mathrm{e}^{-0,021 \mathrm{t}}$ & 0,9932 \\
\hline $230^{\circ} \mathrm{C}$ & $\mathrm{C}=434,86 \mathrm{e}^{-0,071 \mathrm{t}}$ & 0,9914 & $\mathrm{C}=481,20 \mathrm{e}^{-0,071 \mathrm{t}}$ & 0,9590 \\
\hline
\end{tabular}

Tabela 6. Constantes e taxas de reação estimadas

\begin{tabular}{|c|c|c|c|c|}
\hline \multirow{2}{*}{$\begin{array}{c}\text { Energia de Ativação } \\
\text { Temperatura }\end{array}$} & \multicolumn{2}{|c|}{$86,0 \mathrm{~kJ} / \mathrm{mol}$} & \multicolumn{2}{|c|}{$109,4 \mathrm{~kJ} / \mathrm{mol}$} \\
\hline & $\mathrm{k}\left(\min ^{-1}\right)$ & Taxa Inicial $\left(\mathrm{min}^{-1}\right)$ & $C(t)$ & $\mathrm{r}^{2}$ \\
\hline $170^{\circ} \mathrm{C}$ & 0,0110 & 11,8140 & 0,0100 & 10,7400 \\
\hline $190^{\circ} \mathrm{C}$ & 0,0200 & 19,4800 & 0,0210 & 20,4540 \\
\hline $210^{\circ} \mathrm{C}$ & 0,0710 & 41,1090 & 0,0710 & 41,1090 \\
\hline $230^{\circ} \mathrm{C}$ & 0,0720 & 1,6560 & 0,0550 & 1,2650 \\
\hline
\end{tabular}

0 valor obtido para a constante de reação referente à temperatura $170{ }^{\circ} \mathrm{C}$ se aproxima de valores registrados em estudos precedentes que consideram procedimentos analíticos experimentais (SAMPAIO, 2013). No entanto, para as demais temperaturas percebeu-se divergência crescente dos valores estimados. Tal divergência pode ser consequência da labilidade inerente ao composto $\beta$-caroteno, e fundamenta a necessidade de estudos futuros que visem à determinação de uma função de probabilidade de reação que melhor se adeque ao comportamento desta substância.

O valor calculado para as taxas de reação, de forma análoga, se mostra próximos a valores correspondentes experimentais (ARCHIR et al., 2010) apenas para a temperatura de $170 \stackrel{\circ}{\circ}$. Para as demais temperaturas observou-se que o aumento da taxa de reação ocorreu em menor proporção em relação ao esperado, reforçando o potencial para a realização de estudos que complementem o tema proposto no sentido da otimização da aplicação da ferramenta de simulação desenvolvida.

\section{CONCLUSÕES}

Os resultados apresentados no presente capítulo mostram que a aplicação do método estocástico de Monte Carlo com Cadeias de Markov, utilizando a abordagem de Metropolis-Hastings, se mostra promissora no contexto de simulações cinéticas de sistemas reacionais. 0 algoritmo desenvolvido foi capaz de simular o comportamento da degradação térmica do composto $\beta$-caroteno, presente em matriz vegetal - óleo de palma - possibilitando a verificação de valores próximos aos obtidos em estudos experimentais anteriores. Foi possível realizar o cálculo da constante, da taxa e da ordem da reação, parâmetros cinéticos de fundamental importância para o estudo e análise de reações químicas, obtendo resultados semelhantes aos obtidos experimentalmente $[24,33]$ para uma das temperaturas analisadas.

Em função da labilidade do composto estudado, observa-se o acelerado decréscimo de sua concentração, consequência da incidência de temperatura ao longo do tempo. Diante disto, verificou-se a necessidade de estudos futuros para o aprimoramento da aplicação do algoritmo desenvolvido no sentido de adequá-lo à alta labilidade do $\beta$-caroteno, permitindo que a simulação através do Método de Monte Carlo seja representativa considerando variações na temperatura do processo analisado 


\section{REFERÊNCIAS}

[1] ARCHIR, N. et al. Kinetic Study of $\beta$-carotene and Lutein Degradation in Oils During Heating Treatment. Eur. J. Lipid Sci Technol. v.112. p. 349-361. 2010. ISSN: 1438-9312.

[2] BOHM, V. et al. Trolox Equivalent Antioxidant Capacity of Different Geometrical Isomers of $\alpha$-carotene, $\beta$ carotene, Lycopene and Zeaxanthin. Journal Agric Food Chem. v.50, p.221-226. 2002. ISSN: 0021-8561.

[3] BOVI, G. G. Óleo de Buriti (Mauritia flexuosa L.) nanoemulsionado: produção pr método de baixa energia, caracterização físico-química das dispersões e incorporação em bebida isotônica. Universidade de São Paulo USP. Faculdade de Zootecnia e Engenharia de Alimentos. Pirassununga, SP. 2015.

[4] CACCHIANI, L. Simulation and Analysis of Chemical Reactions using Stochastic Differential Equations. Università Degli Studi di Torino - Facoltà di Scienze Matematiche, Fisiche e Naturali. Torino, Itália. 2007.

[5] CONCEIÇÃO, E. L. T. Uma Comparação por Simulação de Monte Carlo de Estimadores de Regressão NãoLinear Robustos em Problemas de Engenharia Química. Universidade de Coimbra - Departamento de Engenharia Química. Coimbra, Portugal. 2004.

[6] DEPARTAMENTO DE AGRICULTURA DOS ESTADOS UNIDOS. Oilseeds: Markets Trade. 2018.

[7] FARIAS, R. R. Uma Análise das Reações Químicas Homogêneas e Elementares via Método de Monte Carlo. Universidade Estadual do Sudoeste da Bahia - Departamento de Química e Exatas. Jequié, BA. 2012.

[8] FOGLER HS. Elements of Chemical Reaction Engineering. Prentice Hall PTR. 5a Edição. 2016.

[9] GARCIA, C. G. VALÉRIO, P. P. Estudo da Cinética de Degradação Térmica do Óleo Vegetal de Palma. Revista Exacta. v. 10. nำ 2. 2017. ISSN: 1984-3151.

[10] GERHARDT, T. E. SILVEIRA, D. T. Métodos de Pesquisa. Universidade Federal do Rio Grande do Sul. UFRGS Editora. 1a edição. 2009. ISBN: 978-85-386-0071-8.

[11] GILLESPIE, D. T. Stochastic simulation of chemical kinetics. Annu Rev. Phys. Chem. 2007. 58. 35-55.

[12] GUL, K. T. et al. Chemistry, Encapsulation and Health Benefits of $\beta$-carotene - A Review. Cogent Food \& Agriculture. vol. 1. 2015. ISSN: 2331-1932.

[13] HIRANVARACHAT, B. SUVARNAKUTA, P. DEVAHASTIN, S. Isomerization Kinetics and Antioxidant Activities of $\beta$-carotene in Carrots Undergoing Different Drying Techniques and Conditions. Food Chemistry. v.107, p.15381546. 2008. ISSN: 0308-8146.

[14] HIGHAM, D. J. Modeling and Simulating Chemical Reactions. Society for Industrial and Applied Mathematics Review. vol. 50. p.347-368. 2008. ISSN: 1095-7200.

[15] MAGOSSO, M. F. et al. Acrocomia aculeata prevents toxicogenetic damage caused by the antitumor agent cyclophosphamide. Genetics and Molecular Research, 2016. v.15 p. 1-14.

[16] MARX, M. et al. Effects of Thermal Processing on trans-cis-isomerization of $\beta$-carotene in Carrot Juices and Carotene-containing Preparations. Food Chemistry. v. 83. P. 609-617. 2003. ISSN: 0308-8146.

[17] MAYAMOL, P. N. et al. Process Technology for the Production of Micronutrient Rich Red Palm Olein. J. Am. Oil Chem Soc. v. 84. p.587-596. 2007. ISSN: 1558-9331.

[18] MULLER. A. Simulação Estocástica: o Método de Monte Carlo. Universidade Federal do Paraná Departamento de Estatística. Curitiba - PR. 2008.

[19] MINGUEZ-MOSQUERA, M. I. HORNERO-MENDEZ, D. PEREZ-GALVEZ, A. Carotenoids and Provitamin A in Functional Foods. Methods of Analysis for Functional Foods and Nutraceuticals. W. J. Hurst (Ed.) p. 101-157. 2002. ISBN: 978-15-667-6824-5.

[20] NASCIMENTO, F. P. Uma Introdução ao Estudo de Reações Químicas Mononucleares e Elementares Via Método de Monte Carlo. Universidade Estadual do Sudoeste da Bahia - Departamento de Química e Exatas. Jequié, BA. 2013.

[21] PALMERO, P. et al. Novel targeted approach to better understand how natural structural barriers govern carotenoid in vitro bioaccessibility in vegetable-based systems. Food Chemistry. 2013. v.141. p.2036-2043.

[22] RODRIGUEZ-AMAYA, D. B. RODRIGUEZ, E. B. AMAYA-FARFANL, J. Advances in Food Carotenoid Research: Chemical and Technological Aspects, Implications in Human Health. Mal J. Nutri. Vol. 12; p. 101-121. 2006. ISSN: 1394035X.

[23] RODRIGUEZ-AMAYA, D. B. KIMURA, M. AMAYA-FARFAN, J. Fontes Brasileiras de Carotenóides: Tabela Brasileira de Composição de Carotenóides em Alimentos. Ministério do Meio Ambiente. Brasília, DF. 2008. ISBN: 97885-773-8111-1. 
[24] ROSSI, M. et al. The Effects of Bleaching and Physical Refining on Color and Minor Components of Palm Oil. Journal of the American Oil Chemists Society. v.78. p. 1051-1055. 2001. ISSN: 1558-9331.

[25] RUSSEL, J. B. Quimica Geral. Volume 2. 2ª edição. Editora Pearson. 1994. ISBN: 978-85-346-0151-1.

[26] SAMPAIO, K. A. Desacidificação por Via Física de Óleo de Palma: Efeito da Composição do Óleo, das Perdas de Compostos Nutracêuticos e Cinéticas de Degradação. UNICAMP - Departamento de Engenharia de Alimentos. Campinas, SP. 2011.

[27] SAMPAIO, K. A. Thermal Degradation of Carotenoids in Palm Oil. J Am Oil Chem Soc. v.90. p. 191-198. 2013. ISSN: 1558-9331.

[28] SILVA, C. E. L. Termodinâmica de Interação entre $\beta$-caroteno e Proteínas do Leite. Tese de Mestrado. Programa de Pós-Graduação em Ciência e Tecnologia de Alimentos - Universidade Federal de Viçosa. Viçosa, Minas Gerais, 2015.

[29] SCHIEBER, A. CARLE, R. Occurrence of Carotenoid cis-isomers in Food: Technological, Analytical and Nutritional Implications. Trends in Food Science \& Technology. v.16. p. 416-422. 2005. ISSN: 0924-2244.

[30] TAMAKI, R. N. L., WESTPHAL, T. M., PEREIRA, R. D. Simulação Estocástica Aplicada às Reações Químicas. Universidade Federal do Rio Grande FURG. Rio Grande, RS. 2002.

[31] TIGHEZZA, A.; ALDHAYAN, D.; ALMTHAR, A. Implementation of Net-Event Monte Carlo Algorithm in Chemical Kinetics Simulation Software of Complex Isothermal Reacting Systems. Journal of Saudi Chemical Society. v.15, p.351-355. 2011. ISSN: 1319-6103.

[32] VALÉRIO, P. P. CREN, E.C. Kinetic Predictions of Total Carotenoids Retention in Macauba Oil Under Interesterification Conditions. Sodebras Journal. 2017. 12(141):219-224. ISSN 1809-3957.

[33] XIAO, Y. et al. Thermal Degradation Kinetics of all-trans and cis-carotenoids in a Light-induced Model System. Food Chemistry. 2018. v.239. p.360-368. ISSN: 0308-8146 


\section{Capítulo 7}

\section{Biogás e permeação de $\mathrm{CO}_{2}:$ Membranas Poliméricas ${ }^{5}$}

\section{Gabriella de Oliveira \\ Pedro Prates-Valério}

Resumo: A busca contínua por garantir suprimento energético atrelado à sustentabilidade se encontra entre desafios atuais relacionados à crescente demanda mundial. Neste cenário, a utilização de biomassa como fonte para produção de biogás tem merecido destaque em cenários que também integram objetivos científicos e industriais. Nesse sentido, o presente capítulo relaciona membranas poliméricas à permeação de dióxido de carbono $\left(\mathrm{CO}_{2}\right)$, considerando biomassa e produção de biogás. Conceitos fundamentais relacionados à purificação de gases e obtenção de biometano, bem como a materiais e morfologias de membranas, e processos e mecanismos de separação de gases, são levantados bibliograficamente. Aspectos socioambientais são considerados, atrelando-se à necessidade de planejamento futuro de oferta energética, no sentido de estabelecerem-se padrões razoáveis de racionalidade na utilização de recursos naturais.

Palavras-chave: Membranas Poliméricas, Biometano, $\mathrm{CO}_{2}$

Abstract: The ongoing pursuit of ensuring energy supply has been intimately linked to sustainability while among current challenges related to growing demands. In this scenario, to utilize biomass as a source for biogas production has deserved attention and prominence in scenarios that also integrate scientific and industrial objectives. In this sense, the present chapter relates carbon dioxide $\left(\mathrm{CO}_{2}\right)$ permeation and polymer membranes concerning biogas production. In this framework, fundamental concepts related to processes of gas purification and obtainment of biomethane are raised bibliographically. Moreover, processes and mechanisms of separation, as well as usual materials and membranes morphologies, are approached. Socioenvironmental aspects are expressed, linked to the need for future planning of energy demand and supply, to establish reasonable standards that may also allow dealing with natural resources rationally

Keywords: polymeric pembranes, biometane, $\mathrm{CO}_{2}$ permeation 


\section{INTRODUÇÃO}

Em tempos atuais, o crescimento mundial da demanda energética tem conduzido indústrias e sociedade em sentidos que também envolvem buscas por fontes alternativas de energia. É usual tais buscas tenderem ao comprometimento com questões ambientais, inclusive visando ao suprimento de necessidades humanas. Particularmente, no que se refere ao Brasil, o país possui potencial conhecidamente elevado para à exploração e transformação de fontes sustentáveis no sentido do provimento de energias renováveis. Entre tais fontes, citam-se a hidráulica, solar, eólica, maremotriz e geotérmica e biológicas (FERNANDES, 2012).

Em relação às fontes biológicas, as utilizações de biomassa e microrganismos se difundem no cenário técnico-científico, inclusive, com número crescente de publicações em periódicos nacionais e internacionais (INNOCENTE, 2011; LIZCANO, 2015; DANTAS, 2010).

Mais especificamente, a biomassa se caracteriza como fonte matéria orgânica, de origem animal ou vegetal, passível de ser transformada em energia por meio da energia solar, uma vez que utiliza dessa fonte para transformação em energia química, através de processos biológicos de microrganismos. Enquanto renováveis, fontes de matérias orgânicas podem ser consideradas inesgotáveis quando exploradas de forma racional, em espaço de tempo bem definido. Indiretamente, biomassas provém de fontes solares, envolvendo processos biológicos, viabilizando-se transformações em energia química (FLAUSINIO, 2015).

É de conhecimento comum que matérias orgânicas se originam de forma heterogênea, sendo compostas, inclusive, por resíduos de origem animal e vegetal. Quimicamente, moléculas orgânicas são compostas por Carbono e Hidrogênio, realizando ligações covalentes do tipo $\mathrm{C}$-H. No que se refere à decomposição de matérias orgânicas, os processos ocorrem, principalmente, por meio de ações de bactérias, na ausência de oxigênio, se relacionando diretamente com a produção de biogás. Sendo assim, é válido observar que o setor agropecuário nacional, incluindo a suinocultura, além de apresentar elevado potencial econômico, se destaca quanto à geração de dejetos. Tais dejetos, quando utilizados como adubos, podem se relacionar à contaminação de solos e do lençol freático, bem como à poluição de rios e proliferação de doenças. Utilizações racionais consideram suas aplicações domo matérias-primas para produção do biogás (VILELA, 2005).

Em contextos que envolvem biodigestão de dejetos suínos, a eficiência de processos conduzidos em biorreatores envolve controles de parâmetros tais quais temperatura, $\mathrm{pH}$, concentração de sólidos e composição dos substratos. A decomposição da matéria orgânica ocorre de forma anaeróbica, com produção de biogás e é representada pela seguinte expressão (1). Este biogás formado é constituído de gás metano $\left(\mathrm{CH}_{4}\right)$, gás carbônico $\left(\mathrm{CO}_{2}\right)$ e outros gases em menor proporção e pode ser queimado, quando purificado (OLIVEIRA e HIGARASHI, 2006, TRENTIN et al., 2017).

Matéria orgânica $+\mathrm{H}_{2} \longrightarrow \mathrm{CH}_{4}+\mathrm{CO}_{2}+$ biomassa $+\mathrm{NH}_{3}+\mathrm{H}_{2} \mathrm{~S}+$ calor

A purificação de biogás consiste em separar o gás metano dos outros gases e existem diversos métodos com esta finalidade, sendo o Processo de Separação por Membranas - PSM relativamente difundido para obtenção de biometano. 0 biometano se torna passível de utilização para processos que envolvem a queima, devido a sua densidade energética e capacidade calorífica, sendo utilizado como fonte de movimentação de turbinas e obtenção energia elétrica. Atualmente, tornam-se cada vez mais comum a utilização de biometano para abastecimento energético das próprias unidades geradoras dos insumos (ALCÓCER et al., 2014; CERVEIRA, 2016).

Considerando o contexto introdutório que se apresenta, o presente capítulo objetiva a realização de um levantamento bibliográfico compreensivo, relacionando membranas poliméricas à permeação de dióxido de carbono $\left(\mathrm{CO}_{2}\right)$, considerando biomassa e produção de biogás.

\section{METODOLOGIA}

O estudo apresentado no presente capítulo se desenvolveu com base em levantamento bibliográfico. Alguns dos conceitos fundamentais, os quais possibilitam realizar considerações a respeito da aplicação potencial de membranas poliméricas em processos envolvendo separação de dióxido de carbono $\left(\mathrm{CO}_{2}\right)$, foram pesquisados. Sendo assim, realizou-se pesquisa exploratória a partir da qual os conhecimentos 
gerados reuniram-se no sentido da construção de hipóteses, estimulando a compreensão da aplicabilidade de membranas, relacionando-a a questões energéticas, sustentáveis e industriais.

\section{REFERENCIAL TEÓRICO}

\subsection{INSUMOS E PRODUÇÃO DE BIOGÁS}

O processo de produção de biogás por meio de biodigestores vem sendo utilizado desde 1950, inicialmente nos países China e Índia, tendo sido implantado no Brasil aproximadamente em 1970. Na metade do século XIX, resíduos urbanos passaram a ser utilizados como insumo para alimentação de biodigestores. No século XX, iniciaram-se os desenvolvimentos de biodigestores capazes de serem alimentados com dejetos animais. Atrelado a isso, determinou-se relevância que associa biodigestão e atividades agropecuárias (OLIVEIRA, 2009).

Particularmente, a suinocultura é uma prática licenciada no Brasil, sendo uma atividade geradora de renda e fonte de alimentos para ampla parcela da população nacional. No entanto, o manejo adequado de suínos, bem como o descarte dos dejetos oriundos de tal prática, demanda planejamento no sentido de se privar poluições potenciais de rios, assim como contaminações de solos e lençóis freáticos, além de proliferação de doenças (DIAS, 2012).

Dejetos provenientes de manejos suínos podem produzir, aproximadamente, $560 \mathrm{~m}^{3}$ de biogás por tonelada de material seco, sendo 50\% constituído por gás metano. Segundo Gaspar (2003), tal potencial produtivo compensa o fato de sua utilização resultar em processamentos relativamente mais lentos. De fato, conforme se pode verificar na Tabela 1, a seguir, insumos de origem bovina produzem 270 $\mathrm{m}^{3}$ /tonelada de biogás, sendo $55 \%$ deste valor a quantidade de metano presente nesta produção, totalizando em $148,5 \mathrm{~m}^{3} /$ tonelada de metano. Este valor resulta em $131,5 \mathrm{~m}^{3} /$ tonelada de gás metano de diferença da utilização de insumos suínos em relação aos insumos bovinos. A seguinte Tabela 1 possibilita uma comparação considerando a produção de biogás e os insumos mencionados.

Tabela 1. Produção de biogás por biomassa

\begin{tabular}{c|c|c}
$\begin{array}{c}\text { BIOMASSA UTILIZADA } \\
\text { (DEJETOS })\end{array}$ & $\begin{array}{c}\text { PRODUÇÃO DE BIOGÁS } \\
\text { ORIGEM: MATERIAL SECO } \\
\left(\mathrm{m}^{3} / \text { tonelada }\right)\end{array}$ & $\begin{array}{c}\text { PERCENTUAL DE GÁS METANO } \\
\text { PRODUZIDO }\end{array}$ \\
Bovinos & 270 & $55 \%$ \\
\hline Suínos & 560 & $50 \%$ \\
\hline Equinos & 260 & Variável \\
\hline Ovinos & 250 & $50 \%$ \\
\hline Aves & 285 & Variável \\
\hline
\end{tabular}

Processos conduzidos em biodigestores se iniciam com a inserção da matéria-prima. Sendo assim, a viabilização da decomposição anaeróbica origina biogás, o qual se compõe por metano (60\% a 65\%) e gás carbônico (35\% a 40\%), dispostos de acordo com as fórmulas estruturais, ilustradas pelas expressões (2) e (3), apresentadas a seguir. Destaca-se que bases tais quais nitrogênio, hidrogênio e gás sulfídrico também se originam no processo, em proporções que se tornam ínfimas frente às mencionadas para metano e gás carbônico. A composição do biogás resulta em densidade energética, com poder calorífico variando entre 5.000 e $7.000 \mathrm{kcal} / \mathrm{m}^{3}$. Quando purificado, ou seja, após a retirada de água e gás carbônico da mistura, aproximadamente $12.000 \mathrm{kcal} / \mathrm{m}^{3}$ de energia põem ser obtidos. Tal purificação dá origem ao biometano (HIRANO, 2015; CERVEIRA, 2016). 
<smiles>C</smiles>

Frente ao exposto, torna-se, contudo, relevante ressaltar que determinados parâmetros de processo tendem a influenciar a eficiência da digestão anaeróbica, inclusive relacionando-se diretamente com atividade enzimática e consequente produção de biogás. Entre tais parâmetros, tal qual já mencionados, a temperatura de processo, o potencial hidrogeniônico $(\mathrm{pH})$, a concentração de sólidos e a composição dos substratos tendem a se difundir, com aplicabilidade. Com relevância, controles relacionados à temperatura de processos exercem influência, inclusive, sobre atividades enzimáticas. Variações bruscas de temperatura podem ocasionar alteração no volume do gás, bem como no grau de fermentação e no tempo de retenção dos dejetos no biodigestor. Frisa-se que o controle de parâmetros de processo, de forma geral, contextualiza etapas posteriores à obtenção de biogás, inferindo significado à de biometano (PECORA, 2006; ALCÓCER et al., 2014).

\subsection{PROCESSO DE SEPARAÇÃO DE GASES: PURIFICAÇÃO E OBTENÇÃO DE BIOMETANO}

Retomando a questão que se relaciona à separação de gases, esta pode ser realizada por adsorção, que é embasada no princípio de transferência de massa, na qual uma substância gasosa ou líquida se adere e fica retida à superfície de um sólido, como resultado da interação entre moléculas. Em relação à purificação de biogás, recomendam-se aplicações de processos contínuos, compostos por quatro tanques que operem etapas distintas. Além disto, destaca-se que o gás deve se encontrar isento de umidade e de sulfeto de hidrogênio (H2S) (GUELFI, 2007).

Segundo Cerveira (2016), meios alternativos que também viabilizam a realização de etapas de separação de gases envolvem absorção física ou química, consistindo na utilização de líquidos - usualmente água como solventes polares com afinidade por componentes da mistura gasosa. É denominada química a absorção considera reações químicas entre os componentes. Absorção física, por sua vez, não envolve reações químicas. Contudo, vale frisar que a implementação do modelo demanda equipamentos grandes, quando objetiva-se à obtenção de biogás com quantidade significativa de metano (PEISINO, 2009; MAGALHÃES et al., 2016).

De acordo com Trentin et al. (2017) é possível realizar a separação do $\mathrm{CO}_{2}$ e $\mathrm{CH}_{4}$ por criogenia, uma vez que os gases possuem valores diferentes de temperatura e pressão para se liquefazerem. Contudo, o gasto energético nesse procedimento tende a ser elevado, quando comparado a processos mais difundidos, implicando no pouco manuseio da técnica.

O Processo de Separação por Membranas - PSM é o mais indicado para separação de gases devido a vantagens como eficiência energética, baixo custo de investimento e operação e construção simples sobre os outros processos citados. Pode ser combinado com outros processos, além de já substituir alguns métodos já aplicados. Este fundamenta-se pela utilização de uma membrana que tem como função, a separação de componentes por meio de uma força motriz - geralmente é utilizado o gradiente de potencial químico, podendo ser indicado pelo gradiente de pressão e de concentração - que impede o transporte de um ou vários componentes, sendo o componente menos permeável aquele que ficará retido na membrana enquanto o componente de interesse será o mais permeado e posteriormente acondicionado.

A Figura 1 a seguir apresenta a indicação do gradiente de pressão e de concentração como força motriz mencionada. A figura 2, por sua vez, ilustra o mecanismo de separação mencionado (HABERT, BORGES e NOBREGA, 2006; PEISINO, 2009). 
Figura 1. Indicação do gradiente de pressão e de concentração como força motriz

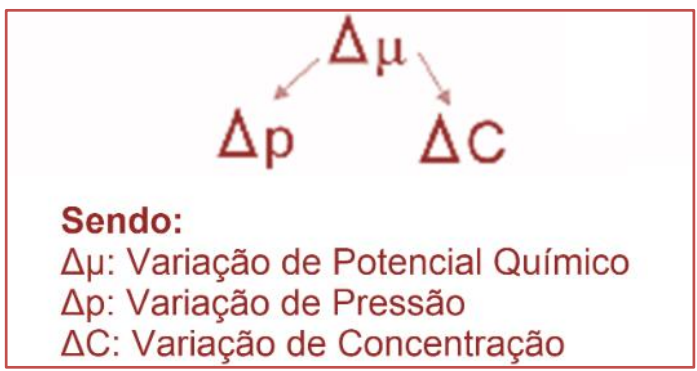

Fonte: Habert, Borges e Nobrega (2006)

Figura 2. Ilustração do mecanismo de separação

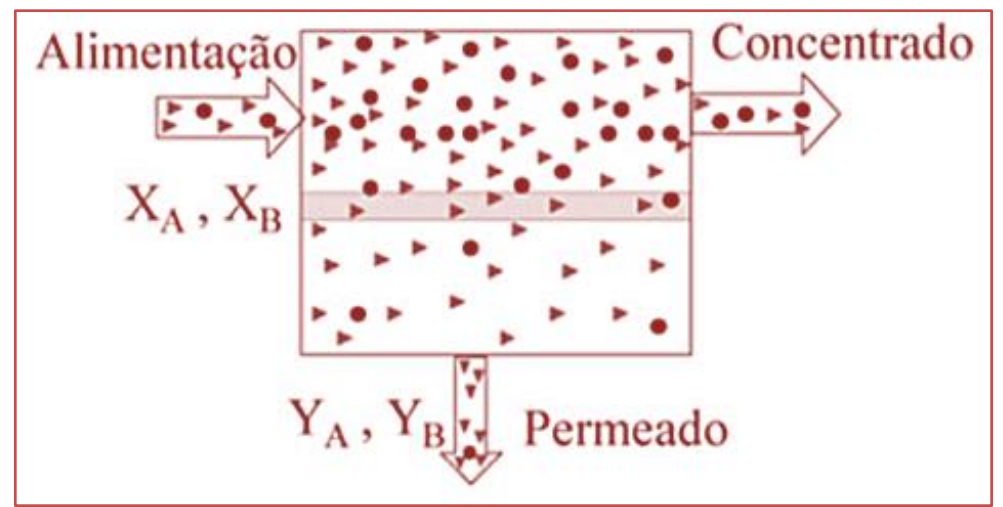

Fonte: Habert, Borges e Nobrega (2006)

\subsection{PROCESSO DE SEPARAÇÃO DE GASES}

São divididos em processos que envolvem a difusão do solvente, sendo denominados processos de osmose, que englobam a microfiltração, ultrafiltração e osmose inversa e os que envolvem difusão do soluto, que são denominados processos de diálise e enquadram a eletrodiálise, pervaporação e permeação gasosa, sendo o último o mais indicado para separação de gás carbônico e gás metano (BALDASSO, 2008; NÓBREGA, 2016).

Para a separação por permeação de gases, existem duas características que influenciam na eficiência do processo, sendo elas a seletividade e permeabilidade, as quais se associam com o mecanismo de transporte. A seletividade é a passagem de um componente escolhido pela membrana, interferindo na capacidade de recuperação de um componente, na área da membrana requerida e na vazão de alimentação necessária. Já a permeabilidade determina a quantidade de componente a ser transportado pela membrana (AMBROSI, 2012).

Membranas, sintéticas ou não, quando aplicadas ao contexto em questão, possuem a finalidade de restringir o transporte de um ou mais componentes do biogás, podendo ser classificadas de acordo com suas morfologias e materiais. Tais morfologias e materiais exercem influência em tal transporte (SUSUKI et al., 2016).

\subsection{MORFOLOGIA DAS MEMBRANAS}

A morfologia é uma categorização da membrana que interfere tanto no tipo de aplicação quanto na eficiência do processo. Pode ser dividida em membranas anisotrópicas (assimétricas) - quando há variação na morfologia ao longo da seção transversal - e isotrópicas (simétricas) - quando os poros possuem as mesmas características ao longo da seção transversal que compõe a camada. A Figura 3 ilustra os dois tipos de membranas utilizados industrialmente (TRINDADE, 2014). 
As membranas podem ser subdivididas em densas ou porosas. Membranas porosas são empregadas quando o transporte das substâncias ocorre em fase fluida, pois a seletividade acontece de acordo com a diferença entre os tamanhos das moléculas e os poros das membranas. Membranas densas são utilizadas quando há etapas de dissolução (absorção e mistura homogênea) e difusão das substâncias envolvidas na separação (ALMEIDA, 2002).

Membranas caracterizam-se, ainda, como integrais e compostas. São consideradas integrais as membranas que possuem homogeneidade de material em sua composição. Em casos de heterogeneidade de materiais, as membranas poliméricas se classificam como compostas (PARAENSE, 2017).

0 transporte que envolve membranas porosas ocorre, preferencialmente, por convecção. Nestes casos, o tamanho dos poros tende a se encontrar na faixa de 0,1 e 10,0 $\mu \mathrm{m}$. Quando considerando membranas densas, transportes tendem a ocorrer pelo modelo sorção-difusão (AMBROSI, 2012).

Assim sendo, sorção de gases em polímeros consiste em um processo que abrange fenômenos simultâneos de absorção e adsorção. A capacidade de sorção é avaliada considerando-se número total de poros, forma e tamanho, além da área superficial do sólido (MAGRO, 2013).

Figura 3. Morfologia de membranas

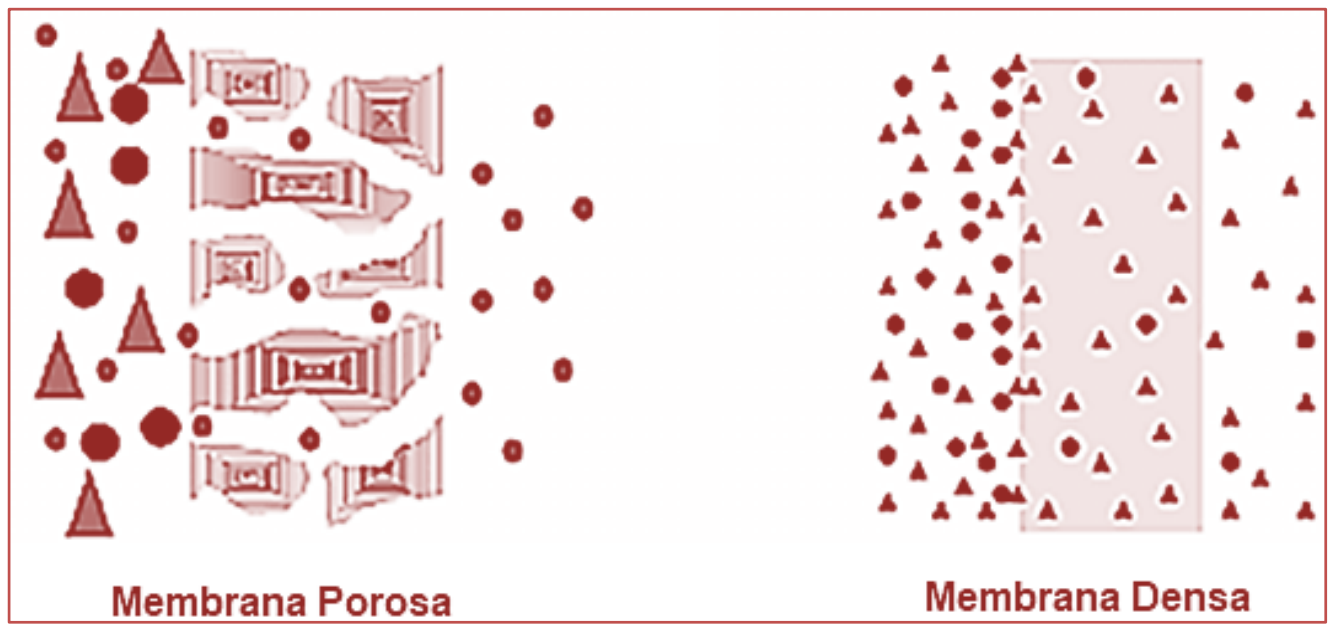

Fonte: Habert, Borges e Nobrega (2006)

\subsection{PRODUÇÃO DE MEMBRANAS: MATERIAIS}

Os materiais utilizados para as produções de membranas definem suas classificações. Sendo assim, membranas orgânicas são produzidas com materiais poliméricos, biológicos ou sintéticos. Membranas inorgânicas consideram materiais cerâmicos, metálicos ou vítreos. Apesar das membranas orgânicas apresentarem custo de produção relativamente mais reduzidos, as membranas inorgânicas apresentam vantagens quanto à durabilidade.

Tabela 2. Materiais Usualmente Utilizados em Membranas Comerciais

\begin{tabular}{|l|c|}
\multicolumn{1}{|c|}{ Membranas Poliméricas } & Membranas Não Poliméricas \\
\hline Acetato de celulose & Cerâmicas \\
Poli(éter sulfona) & Carbono \\
Poli(acrilonitrila) & Óxidos metálicos \\
Poli(éter imida) & Metais \\
Poli(carbonato) & \\
Poli(sulfona) & \\
\hline
\end{tabular}

Fonte: Adaptado de Habert, Borges e Nobrega (2006) 
A Tabela 2 possibilita a verificação de materiais usualmente utilizados nas composições de membranas comerciais. Adicionalmente, destaca-se que a utilização de acetato de celulose visa a separação de CO2 e CH4 e são inseridas nos módulos de separação (AMBROSI, 2012; PERTILE, 2013; NÓBREGA, 2016).

\subsection{MÓDULOS DE SEPARAÇ̃̃o DE GASES}

Módulos consistem em componentes acondicionam membranas, os quais associam elementos necessários para possibilitar o procedimento de separação. Suas aplicações, por vezes dependem de conhecidas variações atreladas ao custo de reposição, viscosidade e suspensão de sólidos devido aos pequenos canais com tendência ao entupimento e tempo de residência dos componentes gasosos. Tais módulos são normalmente divididos em planos (espiral e placa plana) ou cilíndricos (tubular e fibra-oca) (NÓBREGA, 2016).

Figura 4. Módulo de Fibra-Oca

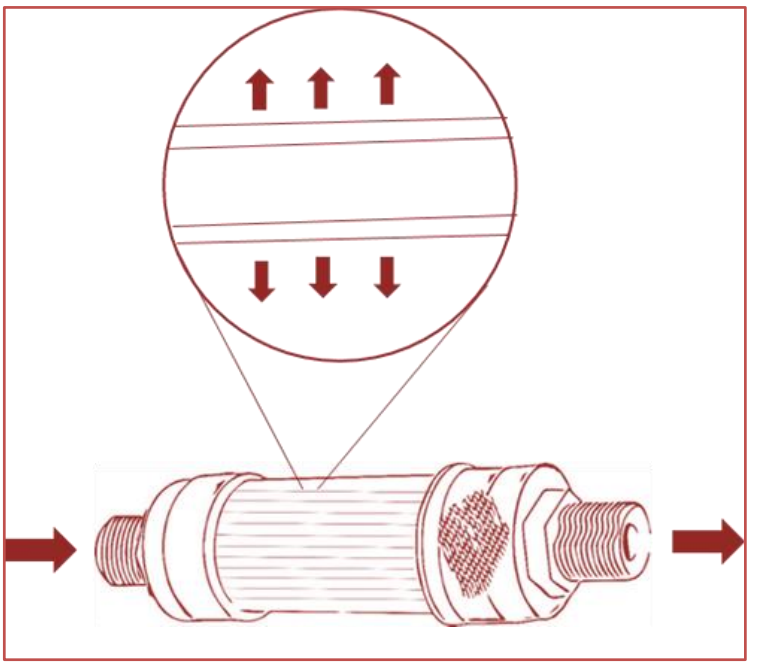

Fonte: Adaptado de Lautenschlager et al. (2009)

Segundo Cerveira (2016), a escolha do módulo pode envolver fatores como vantagens providas em relação a condições operacionais, assim como particularidades relacionadas às correntes de alimentação. Considerando separação de $\mathrm{CO}_{2}$ e $\mathrm{CH}_{4}$, em escala industrial, o modelo fibra-oca, ilustrado na Figura 4, tende a ser mais utilizado em função de sua densidade de empacotamento, a qual se mostra mais elevada quando comparada ao módulo tubular - que, devido a esta característica, possui desvantagem econômica. Sendo assim, tal modelo apresenta área de membrana mais elevada, por unidade de volume. Além disto, sua versatilidade quanto a aplicação em diferentes fluxos também consiste em vantagem operacional.

\section{CONSIDERAÇõES FINAIS}

O presente capítulo exploratório possibilita proximidade com alguns dos conceitos fundamentais relacionados a membranas poliméricas, no contexto da permeação de dióxido de carbono $\left(\mathrm{CO}_{2}\right)$ proveniente da produção de biogás, considerando-se biomassa. Tais processos se mostram, de fato, relevantes, inclusive ao integrar objetivos científicos e industriais, em abordagens que trazem suas bases em aspectos socioambientais. Tais aspectos vêm sendo amplamente discutidos na atualidade, também tendendo a envolver eficiência energética e sustentabilidade. Sendo assim, é razoável sugerir suas relações com necessidades de planejamento futuro, visando às ofertas energéticas. Isto, no sentido de se estabelecerem padrões razoáveis de racionalidade, na utilização de recursos naturais. Frente ao cenário em questão, no que se refere a âmbitos industriais e vertentes associadas à engenharia química, a utilização de biodigestores se amplia, inclusive no sentido de projetos de biorreatores. Dimensionamentos desta natureza impactam em taxas de produtividade e na qualidade de biogás obtido como intermediário do biometano. 
Trazem-se à tona potencialidades relacionadas às relações custo-benefício. Em progressão, a reutilização e manejo racional de materiais orgânicos torna os processos de cogeração viáveis, fundamentados pela simultaneidade de múltiplas formas de obtenção de energia - sendo térmica e a elétrica, as mais usuais e difundidas no cenário nacional Brasileiro. Neste ponto, vale reforçar o fato de a exploração sustentável de fontes alternativas de energia deverem possuir também abrangência tão mais ampla quanto possível, inclusive no que se refere ao design de processos. Estes, por suas vezes, devem buscar a visualização integral da cadeia de exploração de matérias-primas, sendo includentes termos relacionados a eficiência, otimização e responsabilidade ambiental.

Tendo em vista tal contexto, destaca-se que pesquisas e desenvolvimentos de tecnologias associados a Processos de Separação por Membranas (PSM), se fazem imperativos na busca por formas de obtenção de biometano. Entre objetivos e desafios oriundos da aplicação de membranas poliméricas, a facilidade de instalação, de operação e viabilidade de scale-up, devem ser destacadas como como alcances passíveis e pontuais na separações e purificações de gases. Contudo, ressalta-se que tratamentos prévios de correntes de alimentação, assim como gasto energético relativamente elevado, na compressão de gases, também fazem parte de conjunturas concernentes à Permeação de Gases quando utilizando pressão como força motriz.

Nesse sentido, o presente levantamento sugere continuidades de estudo, por exemplo, envolvendo verificação prática de integração de processos de tratamento de corrente de alimentação, envolvendo purificação de gases e aplicações de membranas poliméricas. Fazem-se relevantes às remoções de líquidos e particulados, em buscas por eficiências em âmbitos que se façam aplicáveis industrialmente.

\section{REFERÊNCIAS}

[1] ALCÓCER, J. Produzindo Biogás a partir de Resíduos de Frutas para gerar Energia Elétrica. Revista Sodebras [on line]. v.9, n.103. Jul/2014, p.113-116. ISSN 1809-3957

[2] ALMEIDA, K. M. Tratamento do efluente alcalino do branqueamento da polpa de celulose pelo processo de separação por membranas. Tese de Mestrado. Universidade Federal do Rio Grande do Sul, 2002.

[3] AMBROSI, A. Síntese e caracterização de membranas de poli(dimetilsiloxano) e de triacetato de celulose para a separação de gases. Tese de Mestrado. Universidade Federal do Rio Grande do Sul, 2012.

[4] BALDASSO, C. Concentração, purificação e fracionamento das proteínas do soro lácteo através da tecnologia de separação por membranas. Tese de Mestrado. Universidade Federal do Rio Grande do Sul, 2008.

[5] CERVEIRA, G. S. REMOÇÃO DE CO2 DO BIOGÁS POR PERMEAÇÃO EM MEMBRANAS. Tese de Mestrado. Universidade Federal do Rio de Janeiro, 2016.

[6] DANTAS, D. N. Uso da biomassa da cana-de açúcar para geração de energia elétrica: análise energética, exergética e ambiental de sistemas de cogeração em sucroalcooleiras do interior paulista. Tese de Mestrado. Universidade Federal de São Paulo, 2010.

[7] DIAS, M. I. Estudo Da Viabilidade Econômica da Implantação de Biodigestor Modelo Indiano em Granja de Suínos de Pequeno Porte. Tese de Mestrado. Universidade Federal de Minas Gerais, 2012.

[8] FERNANDES, D. M. Biomassa e Biogás da Suinocultura. Tese de Mestrado. Universidade Federal do Rio de Janeiro, 2012.

[9] FLAUSINIO, B. D. Produção de Energia Elétrica a Partir do Aproveitamento do Bagaço de Cana-de-Açúcar Gerado no Setor Sucroalcooleiro de Minas Gerais. Tese de Doutorado. Universidade Federal de Minas Gerais, 2015.

[10] GASPAR, R. M. Utilização de Biodigestores em Pequenas e Médias Propriedades Rurais com ênfase na Agregação de Valor: Um Estudo de Caso na Região de Toledo-Pr. Tese de Mestrado. Universidade Federal de Santa Catarina, 2003.

[11] GUELFI, L. R. Estudo de Adsorção Para Purificação e Separação de Misturas na Indústria Petrolífera. Universidade Federal do Paraná, 2007.

[12] HABERT, A. C.; BORGES, C. P.; NOBREGA, R. Processo de Separação por Membranas. e-Papers: FAPERJ. p. 13. 2006. ISBN 85-7650-085-X

[13] HIRANO, M. Y. Geração de energia por microturbina alimentada à biogás em uma propriedade rural - estudo de caso. Tese de Mestrado. Universidade Estadual Paulista Julio de Mesquita Filho, 2015.

[14] INNOCENTE, A. F. Cogeração a Partir da Biomassa Residual de Cana-de-Açúcar - Estudo de Caso. Tese de Mestrado. Universidade Estadual Paulista Julio de Mesquita Filho, 2011. 
[15] LAUTENSCHLAGER, S. R.; FILHO, S. S. F.; PEREIRA, O. Modelação matemática e otimização operacional de processos de membrana de ultrafiltração. Eng. Sanit. Ambient., v.14, n.2, p.215-222. ISSN 1809-4457

[16] LIZCANO, J. V. Poder calorífico, energia e cinzas da biomassa de cana-de-açúcar irrigada por gotejamento, para diferentes variedades, lâminas e processos de maturação. Tese de Mestrado. Universidade Federal de São Paulo, 2015.

[17] MAGALHÃES, C. F. B.; BATISTA, C. S.; RODRÍGUEZ, J. L. M.; ROCHA, C. A. A. Dispositivo de Controle de Emissão Atmosférica Aplicada na Construção de Tijolo e Cerâmica. Revista Sodebras [on line]. v. 11, n.121, Jan./2016, p. 1531092. ISSN 1809-3957

[18] MAGRO, R. D. Remoção de Bisfenol A de águas contaminadas através de processos de separação por membranas e de sorção. Tese de Mestrado. Universidade Federal do Rio Grande do Sul, 2013.

[19] NÓBREGA, R. M. Eficiência de Membranas Filtrantes de Nanofiltração e Osmose Inversa no Pós-Tratamento de Esgoto Doméstico. Tese de Bacharelado. Universidade Federal do Rio Grande do Norte, 2016.

[20] OLIVEIRA, R. D. Geração de energia elétrica a partir do biogás produzido pela fermentação anaeróbia de dejetos em abatedouro e as possibilidades no mercado de carbono. Tese de Bacharelado. Universidade de São Paulo, 2009.

[21] OLIVEIRA, P. A.; HIGARASHI, M. M. Geração e Utilização de Biogás em Unidades de Produção de Suínos. 2006. Disponível em < www.embrapa.br/suinos-e-aves/busca-de- publicacoes/-/publicacao/856124/geracao-e-utilizacaode-biogas-em-unidades-de-producao-de-suinos>. Acesso em novembro, 2017.

[22] PARAENSE, M. O. Permeação de Gases Através de Membrana Composta por Grafeno e Poli(Dimetilsiloxano). Tese de Mestrado. Universidade Federal de Minas Gerais, 2017.

[23] PECORA, V. Implantação de uma unidade demonstrativa de geração de energia elétrica a partir do biogás de tratamento do esgoto residencial da USP - estudo de caso. Tese de Mestrado. Universidade de São Paulo, 2006.

[24] PEISINO, A. L. Membranas Anisotrópicas Densas para a Remoção de CO2 e H2S. Tese de Mestrado. Universidade Federal do Rio de Janeiro, 2009.

[25] PERTILE, C. Avaliação de processos de separação por membranas como alternativas no tratamento de lixiviado de aterro sanitário. Tese de Mestrado. Universidade Federal do Rio Grande do Sul, 2013.

[26] TRENTIN, V. M; BEAL, L. L.; ZELINSKI, R.; DUARTE, J. Andrade, M. Z. Geração de Biogás e Tecnologias De Purificação A Biometano. In: $2^{\circ}$ CEASB. Lages, SC, 2017.

[27] TRINDADE, C. D. Uso de processos de separação por membranas no tratamento de efluentes de linhas de revestimento nanocerâmicos à base do ácido hexafluorzircônio. Tese de Doutorado. Universidade Federal do Rio Grande do Sul, 2014.

[28] SUSUKI, F. F.; PARAÍSO, P. R. ALMEIDA, P. H. S.; ITO, A.; BERGAMASCO, R. Produção e caracterização de membranas poliméricas, usando os aditivos cloreto de potássio e de lítio, em condições idênticas. 2016. Disponível em <www.uff.br/engevista/seer/index.php/engev

[29] ista/article/view/711/365> Acesso em 17 de novembro de 2017.

[30] VILELA, F. S. Tratamento de águas residuárias de suinocultura em reatores anaeróbicos de batelada: eficiência de fermentação e diversidade microbiana. Tese de Mestrado. Universidade Federal de Minas Gerais, 2005. 


\section{Capítulo 8}

\section{Breve abordagem relacionando qualidade de matéria- prima vegetal, viabilidade e aplicação}

\section{Idianara Silva}

\section{Pedro Prates-Valério}

Resumo: Em tempos atuais, a procura por matérias-primas alternativas, em sentido de desenvolvimento de produtos que atendam às recentes e variadas demandas mercadológicas, tem se feito necessária. Neste contexto, o presente capítulo se desenvolve, por meio de uma breve abordagem, considerando parâmetros de qualidade do óleo vegetal extraído mecanicamente do mesocarpo de frutos da macaúba (Acrocomia aculeata). Avaliam-se parâmetros fundamentais, abordando viabilidade e aplicação de frutos coletados após liberação natural dos cachos da palmeira em estudo, em contato com o solo. 0 estudo contextualiza a indústria de cosméticos, como elemento adicional para seu desdobramento, respeitando sistemas determinados com base em cultura regional, em contexto empírico, para coleta dos frutos e obtenção dos óleos. Verificação microbiológica se complementa em resultados físico-químicos, sugerindo práticas de colheita e pós colheita enquanto altamente influentes na qualidade final do óleo do fruto.

Palavras-chave: Óleos vegetais, Macaúba, Análises Químicas, Indústria Química

Abstract: In current times, the demand for alternative raw materials, in the sense of developing products that can meet contemporary and varied market demands, has become necessary. In this context, the present chapter is designed, briefly approaching quality parameters of a vegetable oil mechanically extracted from the mesocarp of macaúba fruit (Acrocomia aculeata). Fundamental parameters are assessed also considering the viability and application of fruit collected after the natural release of palm bunches and prolonged contact with the soil. The study contextualises the cosmetics industry as an additional element for its development, respecting systems which were determined based on regional and local cultures, in an empirical context, for fruit collection and oil extraction. Microbiological verification is complemented by physical-chemical results, suggesting harvest and post-harvest practices while highly influential in the final quality of the oil studied

Keywords: Vegetable oils, Macauba, Chemical Analysis, Chemical Industry. 


\section{INTRODUÇÃO}

No contexto da expansão e intensificação de práticas extrativistas, as palmeiras são importantes fontes de recursos naturais nos países tropicais. Típica do cerrado Brasileiro, a palmeira macaúba (Acrocomia aculeata) é considerada a de mais ampla dispersão em território nacional. Presente, por exemplo, nos estados de Minas Gerais, Tocantins e Mato Grosso, seu potencial econômico e industrial vem sendo continuamente enfatizado por gerações de pesquisadores (Andrade et al., 2006; Evaristo et al., 2016).

No que se refere à produtividade da cultura, vale ressaltar que em um hectare podem ser encontradas até 200 palmeiras na forma nativa, cujas produções podem se aproximar de 25 toneladas de cocos por ano notória entre vegetais que, como a soja, também se cultivam em solos brasileiros. A produtividade em óleo, por sua vez, pode chegar a 6 toneladas por hectare, ou seja, próxima à da palma Africana (Elaeis guineenses). Considerando que a elevada produtividade em óleos tem sido um critério primário para a seleção de culturas comerciais, (Rodriguez-Amaya et al., 2008), a macaúba apresenta destaque potencial como fonte oleica alternativa. Considerando sustentabilidade, a cultura já vem sendo utilizada na recuperação de áreas degradadas, o que também agrega valor para a integralidade de sua cadeia produtiva (CETEC,1983; Valério et al., 2014).

O estádio ótimo de maturação da Acrocomia aculeata é verificado entre os meses de Novembro e Março, quando os frutos se soltam espontaneamente dos cachos das palmeiras. É sabido que o contato prolongado de tais frutos com o solo potencializa contaminações por floras microbianas e fungos produtores de enzimas lipolíticas. Tais enzimas contribuem de forma efetiva com a liberação de ácidos graxos de triacilgliceróis e, consequente, com aumento da acidez dos óleos. Destaca-se que a adoção de boas práticas, quando nas etapas de colheita e pós-colheita do fruto, assim como nas etapas de processamento e extração do óleo, minimizam alterações potenciais, contribuindo com aumento da qualidade de produtos finais (Farias, 2010; Evaristo et al., 2016, Lobato, 2014).

Salienta-se que a produção do óleo dos frutos da macaúba tende a ser, por vezes, realizada de forma ainda rudimentar, aquém de seu potencial econômico e industrial. Visando incentivar a ampliação do cultivo da palmeira, o Governo Federal brasileiro, através do Ministério do Desenvolvimento Agrário, tem incorporado valor à cultura, inserindo-a na relação de produtos extrativos. Com efeito, o governo Federal definiu preços mínimo por quilograma do fruto fresco, para a safra 2014/2015, fomentando a agricultura familiar. Em publicação realizada no ano 2016, no Diário Oficial da União, agricultores familiares individuais ou cooperados tornaram-se aptos ao usufruto continuo da Política de Garantia de Preço Mínimo para os Produtos da Sociobiodiversidade (Lobato, 2014), diga-se, com incremento contínuo dos valores mínimos fixados para as safras 2016/2017. Durante o período descrito, verificou-se a valorização de $423 \%$ no preço mínimo mencionado. É válido salientar que o crescimento que se observa para o incentivo à produção e exploração da cultura em questão tem convergido, também, com incrementos de estudos e publicações, científicos, atrelados à cultura em questão (Silva et al., 2014; Chaiyasit et al., 2007; Nunes et al., 2015; Prates-Valério et al., 2019).

Entre fatores que contribuem para o interesse científico, crescente, em relação à palmeira em questão, destaca-se a composição química dos óleos extraídos de seus frutos, incluindo as presenças de ácidos graxos monoinsaturados e poli-insaturados, além de minerais e vitaminas. Particularmente, o óleo extraído do mesocarpo não apresenta fatores antinutricionais e teores elevados (até 67\%) de ácidos graxos monoinsaturados (MUFA), principalmente ácido oleico. Ainda, se destaca quanto à presença de compostos nutracêuticos, entre os quais carotenóides (até $378 \mathrm{mg} / \mathrm{kg}$ de óleo) e tocoferóis ( $212 \mathrm{mg} / \mathrm{kg}$ de óleo) (Bora \& Rocha, 2004; Hiane et al., 200; Nunes et al., 2015; Trentini et al., 2017).

Perspectivas positivas atreladas ao processamento os óleos em questão, inclusive no que se refere ao suprimento de parte de demandas nacionais, já vêm se fundamentando. Indica-se que o interesse na exploração da Acrocomia aculeata tem ido ao encontro de expectativas e necessidades de setores industriais, incluindo aquelas atreladas às indústrias de cosméticos, farmacêutica e alimentícia (Coimbra, 2010). Particularmente, segundo (ABIHPEC, 2017), a indústria de cosméticos e higiene segue registrando incremento, desde 2014, quando movimentou aproximadamente 43 bilhões de reais, sob perspectiva nacional. Em tal mercado, a procura por novas tecnologias e matérias-primas para o desenvolvimento de novos produtos também tende a ocorrer com dinamismo. De forma convergente, setores de pesquisa e desenvolvimento registram resultados positivos no que tange à aplicação dos óleos vegetais alternativos aos já usuais, para elaboração de produtos para tratamento cutâneo e capilar. Em aderência, sugere-se que óleo da macaúba apresenta atividades funcionais, inculindo cutânea hidratante, protetora, reparadora e estimulante (Callegari et al., 2014). 
No contexto de práticas produtivas relacionadas à indústria de cosméticos, órgãos responsáveis por controle e fiscalização trazem atuação em sentido de garantia de qualidade de produtos, assim como do bem-estar de consumidores. Tais órgãos, por vezes de vigilância, exigem o cumprimento de boas práticas e, assim, a adoção de padrões que tangibilizam quesitos quantitativos e qualitativos. Tais exigências se aplicam, por exemplo, a indústrias e fornecedores de matérias-primas, considerando cadeias produtivas (ANVISA, 2013).

Trazendo atenção, portanto, para ferramentas analíticas que se adequem a propósitos de qualificação, controle e monitoramento de matérias-primas, produtos finais se envolvem laboratorialmente com fundamentos que promovam viabilidade de verificações, figurando, comumente: índice de acidez, $\mathrm{pH}$, ponto de fusão, viscosidade, densidade, cor, odor e, entre outras, análises microbiológicas. As relevâncias de monitoramentos, controles e adequações se toram claras, atreladas a indústrias de processamento, padrões e qualidade (ANVISA, 2013).

Considerando o cenário apresentado, e visando o levantamento de informações que se somem, potencialmente, a cenários futuros, o presente capítulo se desenvolve, por meio de uma breve abordagem, considerando parâmetros de qualidade do óleo vegetal extraído mecanicamente do mesocarpo de frutos da palmeira Acrocomia aculeata. Avaliam-se parâmetros fundamentais, abordando viabilidade e aplicação de frutos coletados após liberação natural dos cachos da palmeira em estudo, em contato com o solo. 0 estudo contextualiza a indústria de cosméticos, como elemento adicional para seu desdobramento, considerando sistema regional, em contexto empírico, para coleta dos frutos e obtenção dos óleos. Verificação microbiológica se complementa em resultados físico-químicos, avaliando práticas de colheita e pós colheita enquanto influentes na qualidade final do óleo.

\section{REFERENCIAL TEÓRICO}

\subsection{A PALMEIRA MACAÚBA: Acrocomia aculeata}

Acrocomia aculeata (macaúba) é uma das palmeiras mais difundidas nos Neotrópicos. Ocorren naturalmente em ambientes caracterizados por floresta semideciduais ou savanas, bem como em áreas antropizadas, como locais desmatados e pastagens. Semelhantemente à maioria das palmeiras, a macaúba requer de 4 a 8 anos para iniciar a frutificação. Podendo alcançar até 25 metros de altura, a palmeira possui espinhos longos e pontiagudos ao longo de seu tronco. A palmeira, quando adulta, frutifica durante quase todo o ano, com produtividade de até 4 a 6 toneladas de óleo comestível por hectare (Pires et al, 2013; Rettore \& Martins, 1983).

0 fruto da Acrocomia aculeata possui forma de esfera, parcialmente achatada, com tamanho variando entre 2,5 e 5,0 cm. Constitui-se de uma casca externa dura de coloração marrom/amarelada, com uma polpa interna amarela (mesocarpo) fibrosa e oleosa, e uma castanha interna, dura, que contém em seu interior uma ou duas amêndoas oleaginosas. Todas as partes que compõem o fruto apresentam potencial para exploração econômica, sendo, essa, mais uma característica da cultura. Os óleos extraídos da polpa e da amêndoa do fruto são prontamente comestíveis e aplicáveis a processos industriais. Destaca-se que, a cultura da Macaúba também se faz importante fonte de renda para comunidades carentes, inclusive na região norte de Minas Gerais. Neste cenário, o estabelecimento de procedimentos que tendem à operação facilitada, e a custos reduzidos, vem proporcionando viabilidade para a instalação de unidades sustentáveis sob pontos de vista social, econômico e ambiental. As tortas residuais da extração têm merecido destaque na produção de farinhas alimentícias e rações animais, enquanto o endocarpo possui potencial para a produção de carvão vegetal e carvão ativado (Caño-Andrade et al., 2006; Silva, 2010; Silva \& Andrade, 2011; Rettore \& Martins, 1983; Lorenzi, 1992). A figura 1 ilustra a secção de um fruto, apresentando partes, mencionadas, que o compõem.

A coleta de frutos da macaúba, em regiões tropicais, tende a ocorrer entre os meses novembro e março, podendo se estender pelos demais, dependendo de características climáticas, incluindo volume pluviométrico. Usualmente, em sistemas mais rudimentares, tal coleta ocorre em convergência com desprendimentos naturais, dos frutos, dos cachos das palmeiras, considerando seus contatos prolongados com solos. Conforme mencionado no parágrafo 3, da seção anterior desse capítulo, torna-se relevante destacar que triacilgricerídeos, de forma geral, se fazem susceptíveis a decomposições catalisadas por enzimas lipolíticas produzidas por microrganismos naturalmente presente nos solos, efetivos quanto à aceleração da formação de ácidos graxos livres - AGL, no óleo de macaúba. Tal reação pode ser favorecida por lesão da queda dos frutos, e acelerada pelo calor e pela luz. Assim, deve-se considerar que, uma vez registrados eventuais valores elevados para índices de acidez, é possível se concluir sobre possibilidade de 
aprimoramento da gestão de procedimentos de coleta/colheita dos frutos, até a extração de óleo (Parducci \& Fennema, 1978; Farias, 2010; Evaristo et al., 2016, Lobato, 2014).

Figura 1. Composição do Fruto da Macaúba.

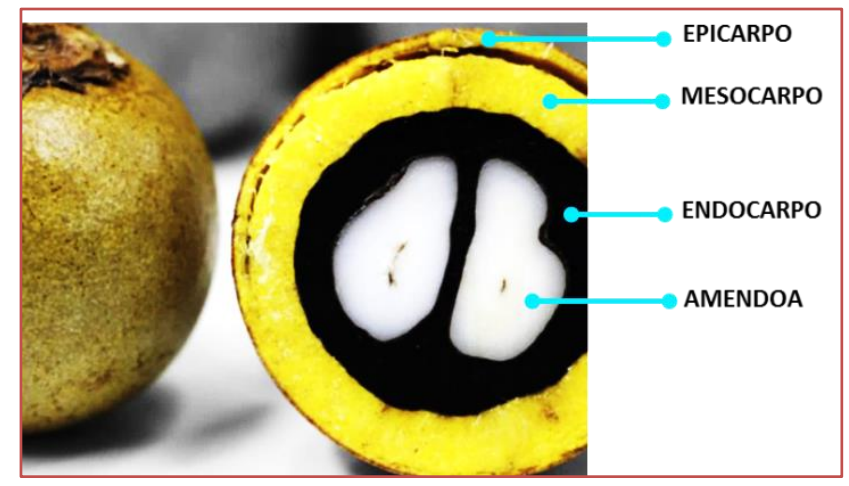

Fonte: Silva et al. (2015)

Sob a ótica da qualidade necessária para matérias-primas a serem processadas, a utilização de frutos tão mais frescos quanto possíveis é de importância central no processo produtivo dos óleos da macaúba. A Figura 2, por meio de diagrama de blocos, viabiliza a visualização de etapas usualmente aplicadas ao processamento da macaúba, considerando mesocarpo quanto amêndoa. Segundo (Silva et al., 2014) a extração do óleo do mesocarpo da macaúba pode ser realizada à temperatura ambiente (a frio) ou à temperatura de $60^{\circ} \mathrm{C}$ (quente). Os autores em questão também consideram que tendência à condução de processos em batelada, bem como caldeiras para geração de vapor, definindo variações de temperaturas e pressões, para etapas de aquecimento, em rotas de processamento do fruto.

Figura 2. Etapas usuais de processamento: Fruto da Macaúba

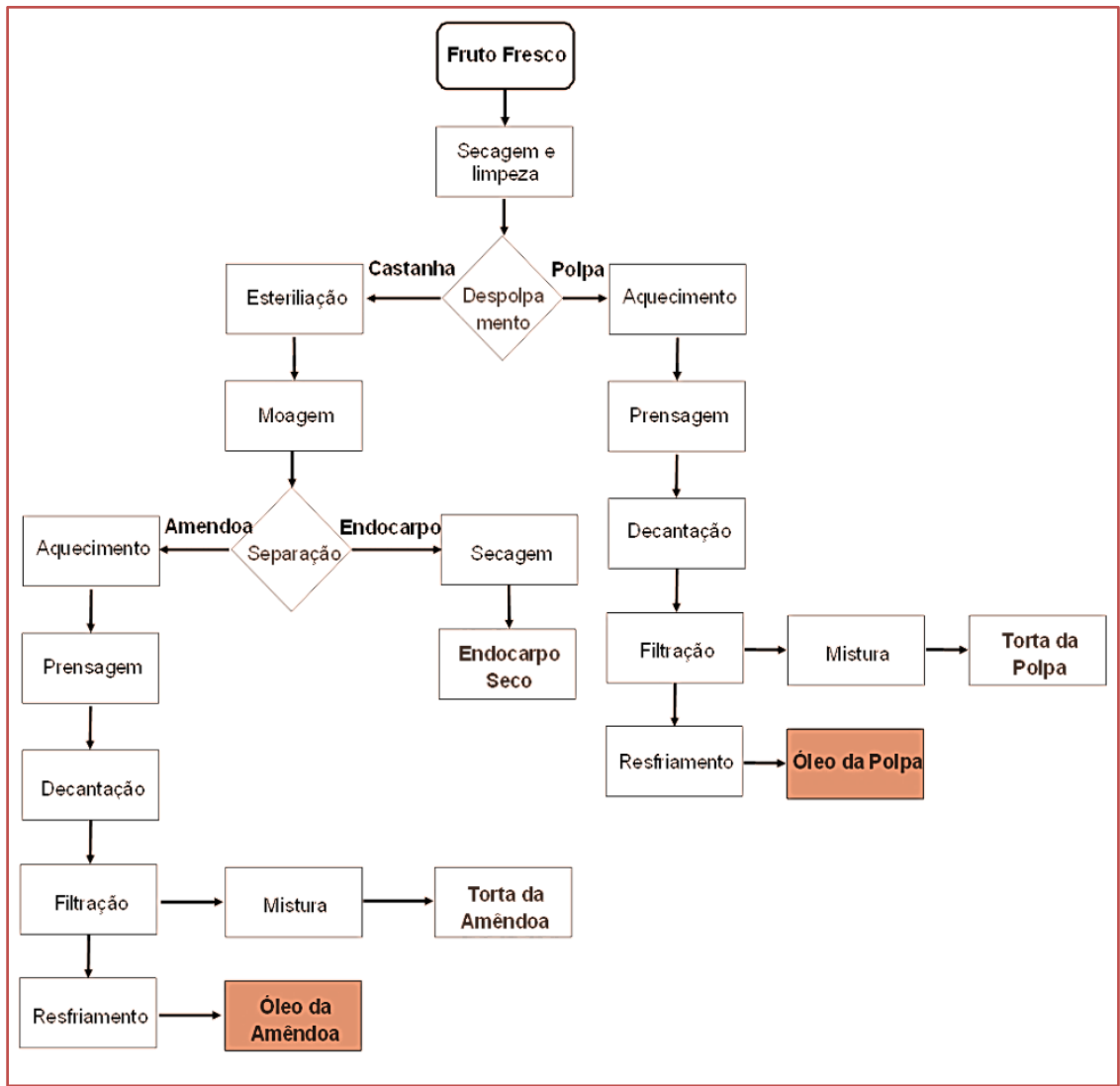

Fonte: SILVA et al. (2014) 


\subsection{PARÂMETROS DE IDENTIDADE E QUALIDADE DOS ÓLEOS (MESOCARPO)}

Estudos apontam que óleos brutos, extraídos do mesocarpo de frutos frescos da macaúba, apresentam os ácidos oleico (aproximadamente 60\%) e palmítico (aproximadamente 20\%) como preponderantes na composição de ácidos graxos. Alguns autores tendem à comparação do perfil em questão com o azeite de oliva - o qual apresenta, em média, $55-83 \%$ de ácido oleico e $8-20 \%$ de ácido palmítico, também se referido a análises de proporções de ácidos graxos em óleos extraídos da palmeira Elaeis guineenses). A concentração relativamente elevada de carotenoides (até $378 \mathrm{mg} / \mathrm{Kg}$ de óleo), majoritariamente, $\beta$ caroteno (80 a $90 \%$ dos carotenoides totais) também se destaca como forte característica dos óleos em questão. Concentrações de tocoferóis podem se aproximar de $212 \mathrm{mg} / \mathrm{kg}$ de tocoferóis (Coimbra e Jorge, 2012; Nunes et al., 2015).

Os carotenóides, assim como os tocoferóis, são considerados antioxidantes naturais que, quando preservados, contribuem com efeitos benéficos para a saúde humana, aumentando a estabilidade do óleo da macaúba - em função de ações químicas (antioxidante) e propriedades de preservação (Chaiyasit et al., 2007).

Especialmente sobre carotenoides, o $\beta$-Caroteno apresenta $100 \%$ de atividade pró-vitamínica A (Rodriguez-Amaya \& Kimura, 2004). Sob a perspectiva de processamentos térmicos, estes tetraterpenóides tendem à degradação, quando submetidos a processamentos com incidência de temperatura (Garcia \& Valério, 2017). Somando-se a conhecimentos que embasem embasar buscas por preservação de carotenoides, salienta-se que suas degradações são inibidas pela presença de antioxidantes, contudo, também decorrentes de oxidação enzimática e não enzimática. Os níveis de tais oxidações trazem dependência de disponibilidade de oxigênio no meio de exposição, bem como do nível de insaturação das cadeias carbônicas, considerando a estrutura de compostos alvo. Tal degradação, de forma geral, se estimula com incidência luminosa, bem como com a presença de calor, metais, enzimas e peróxidos. Processos oxidativos podem, de fato, favorecer oxidação de outros compostos insaturados (Rodriguez-Amaya \& Kimura, 2008; Parducci \& Fennema, 1978; Achir et al., 2010).

Ainda sobre processamentos térmicos, ressalta-se que a exposição a temperaturas elevadas, por períodos de tempo prolongados, somando-se eventual armazenamento inadequado, tende suscetibilizar ainda mais óleos contendo carotenoides à oxidação e hidrólise, também, de triglicerídeos. 0 processo de aquecimento, portanto, deteriora potencialmente os óleos vegetais, provocando aumento de dienos e trienos conjugados de ligações insaturadas, também contribuindo com o aumentando dos índices de acidez, peróxidos iodo e de refração (Costa et al.,1996). Sendo assim, destaca-se que, além da relevância das adoções de adequadas práticas de colheita e pós-colheita, etapas de processamento e armazenamento contribuem com a preservação tanto de biocompostos quanto dos próprios produtos finais que os contém (Rodriguez-Amaya \& Kimura, 2004).

Considerando o exposto, é válido considerar a forma, por vezes, ainda rudimentar, de exploração da Acrocomia aculeata. Para a cultura, a qualidade do óleo, enquanto matéria prima, converge com a eventual viabilidade de aplicação, sendo dependente de etapas que se iniciam na coleta dos frutos, percorrendo cadeias de processamentos, emsentido da obtenção de produtos para fins industriais diversos (CETEC, 1983; Callegari et al., 2014). Considerando as informações descritas, torna-se razoável a observação do fato de a acidez dos óleos extraídos dos frutos da macaúba possuírem relevância pra decisões a serem tomadas em contextos diversos, incluindo o industrial. De fato, quando elevada, pode restringir a utilização da matéria prima para propósitos de obtenção de produtos finais. Sabe-se que o índice de acidez também suporta indícios referentes ao estado de conservação de óleos vegetais (CAC, 2015; CETEC, 1983; Bobbio, 2001).

\section{METODOLOGIA}

De acordo com as definições descritas por Gerhardt e Silveira (2009), este capítulo se caracteriza como um estudo teórico e original. 0 estudo contextualiza a indústria de cosméticos, como base adicional para seu desdobramento. Verificação microbiológica se complementa em resultados físico-químicos, sempre considerando um sistema regional, com base empírica, de coleta dos frutos e extração dos óleos. Sendo assim, a metodologia utilizada mesclou revisão bibliográfica e procedimentos experimentais para atingir os objetivos expostos, podendo, estes, serem descritos como explicativos, buscando potencial identificação da influência das naturezas de fatores, em fundamentos pesquisados. 


\subsection{COLETA E PREPARO DA AMOSTRA}

As amostras consistiram em óleos extraídos mecanicamente do mesocarpo de frutos de palmeiras Acrocomia aculeata. Tais frutos foram coletados após soltura natural dos cachos das palmeiras, estando sempre em contato direto com o solo - a medição do tempo de contato com o solo não foi monitorada. As palmeiras se fizeram naturais de práticas extensivas de cultivo, estando localizadas no vilarejo Serra dos Alves, distrito de Itabira (Lote 1) e na região da Serra do Cipó, distrito de Santana do Riacho (Lote 2), ambos no estado de Minas Gerais. Após coleta, os frutos não foram lavados, sendo acondicionados à temperatura ambiente. Respeitou-se procedimento estabelecido com base em cultura regional, em contexto empírico, para processamento do óleo do fruto da macaúba, do vilarejo e do distrito identificados, enterrando aqueles coletados, em solo natural, por período entre 15 e 30 dias, em local coberto. Ainda seguindo o procedimento, aguardou-se o que, na cultura dos municípios, se denomina fermentação do mesocarpo dos frutos. Após o período descrito, o mesocarpo, anteriormente fortemente aderido ao endocarpo, se apresentou solto e exsudativo, favorecendo extração do óleo.

\subsection{EXTRAÇÃO DO ÓLEO}

Os mesocarpos foram prensados em pilão de madeira, até obtenção de consistência pastosa. Posteriormente, a pasta foi colocada em panela e aquecida a uma temperatura igual a $100^{\circ} \mathrm{C}$. Durante $\mathrm{o}$ aquecimento, observou-se evaporação da água naturalmente presente no fruto, com remanescência do óleo. As amostras de óleo foram armazenadas à temperatura ambiente, em recipiente de plástico.

\subsection{ANÁLISES FÍSICO-QUÍMICAS}

Índice de Acidez: 0 índice de acidez foi determinado de acordo com metodologia da Farmacopéia Brasileira, identificada pelo número 5.2.29.7, a partir da qual o resultado é expresso em mg KOH/g de amostra (Farmacopéia Brasileira, 2010). Para tanto, $3 \mathrm{~g}$ de amostra foram pesados em erlenmeyer de vidro com capacidade igual a $250 \mathrm{~mL}$. Adicionaram-se $50 \mathrm{~mL}$ de solução éter etílico: etanol (1:1), além de solução indicadora fenolftaleína. Realizaram-se, então, titulações, em triplicata, considerando solução KOH (0,1 Molar). A equação 1 foi considerada para a determinação do índice de acidez.

$$
m g \text { de } K O H / g=\frac{(A-B) \times M \times 56,109}{W}
$$

Em que A representa o volume $(\mathrm{mL})$ da base utilizada na titulação da amostra, B representa o volume $(\mathrm{mL})$ da base utilizada na titulação do branco, M representa a molaridade da base após padronização, W representa a massa $(\mathrm{g})$ da amostra

Teores de Carotenóides: Valores medidos para carotenóides totais foram expressos em função de equivalente de $\beta$-caroteno ( $\mu \mathrm{g} / \mathrm{g}$ ) de óleo (DAVIES, 1976). A daterminação foi realizada espectrofotométricamente (espectrofotômetro UV/Vis: modelo BEL SP 2000) conforme Rodriguez-Amaya \& Kimura (2004) e AOAC (1997). Para tanto, as amostras de óleos (Lotes 1 e 2) foram diluídas em $10 \mathrm{~mL}$ de solvente n-hexano (P.A.), sendo submetidos à leitura em espectro visível $(\lambda=450 \mathrm{~nm})$. Os cálculos dos carotenóides totais foram realizados considerando a absorbância mensurada, em associação com o valor de absortividade $\mathrm{A}_{1 \mathrm{~cm}}{ }^{1 \%}=2592$, conforme equação 2 .

$$
\text { Teor de Carotenóides }(\mathrm{mg} / \mathrm{kg})=\frac{\text { Absorbância } \times \text { solvente }(\mathrm{ml}) \times 1000}{\text { Absortividade } \times \text { massa }(\mathrm{g})}
$$

Densidade e Viscosidade: Para as análises de viscosidade e densidade, utilizaram-se os métodos da Farmacopéia Brasileira, identificados como V.2.7 e V.2.5, respectivamente (Farmacopéia Brasileira, 2010). 
Análises Microbiológicas: As análises microbiológicas envolveram técnica Pour Plate, em sentido de viabilização das contagens de mesófilos, bolores e leveduras, coliformes fecais, coliformes totais e sthaphylococcus.

\section{RESULTADOS E DISCUSSÕES}

Considerando a metodologia descrita para o desenvolvimento do capítulo em questão, envolvendo revisão bibliográfica e procedimentos experimentais, buscando potencial identificação da influência das naturezas de fatores, em fundamentos pesquisados, a tabela 1 apresenta a compilação de valores determinados laboratorialmente para os seguintes parâmetros físico-químicos: densidade $\left(25^{\circ} \mathrm{C}\right)$, viscosidade $\left(25^{\circ} \mathrm{C}\right)$, cor, carotenóides totais e índice de acidez.

Tabela 1. Análises Físico-Químicas

\begin{tabular}{|l|c|c|}
\hline \multicolumn{2}{|c|}{ Tipo de Análise } & Óleo de Macaúba (Mesocarpo) \\
\hline Densidade $\left(25^{\circ} \mathrm{C}\right)$ & $0,909 \mathrm{~g} / \mathrm{mL}$ & Amostra 2 \\
\hline Viscosidade & $50 \mathrm{cP}$ & $0,911 \mathrm{~g} / \mathrm{mL}$ \\
\hline Cor & Amarelo & $250 \mathrm{Cp}$ \\
\hline Carotenoides & $10,81 \mathrm{mg} / \mathrm{Kg} \pm 0,44$ & Laranja \\
\hline Índice de Acidez & $75,54 \mathrm{mg} \mathrm{de} \mathrm{KOH} / \mathrm{g}$ & $40,37 \mathrm{mg} / \mathrm{Kg} \pm 0,16$ \\
\hline
\end{tabular}

Pode-se observar que o valor determinado experimentalmente para densidade relativa $(0,909$ e 0,911 $\mathrm{g} / \mathrm{mL}$ ) se encontra ligeiramente abaixo da faixa $(0,9176$ a $0,9256 \mathrm{~g} / \mathrm{mL})$, reportada por Rettore e Martins (1983). Sabe-se que variações em parâmetros físico-químicos relacionados à macaúba também possuem origem em diferenças entre regiões e períodos de colheita, podendo ser, estas, prováveis causas das variações observadas. De fato, como fora de se estabelecer ponderação mais pontual a esse respeito, estudos que as considerem são sugeridos. Acima disso, salienta-se que a densidade se faz relevante enquanto parâmetro de identidade e qualidade, inclusive, para diferenciação e identificação de matérias primas vegetais. De forma geral, a viscosidade pode ser entendida como a resistência de determinado material ao escoamento. Via de regra, líquidos mais viscosos tendem ao escoamento com menos facilidade. Para os a viscosidade determinada no estudo que se conduziu (50 e $250 \mathrm{cP}$ ) puderam se observar valores acima da referência (46,4 cP) também mencionada por Rettore e Martins (1983). Vale, nesse ponto, certa aproximação com contextos nos quais ações de bombeamentos que se façam necessárias podem ser comprometidas por elevações em tal parâmetro. Acima disso, em soma aos contextos de investigações, torna-se relevante trazer acabo o fato de potenciais alterações oxidativas de ácidos graxos, por vezes, contribuírem com variações em valores verificados, também para densidade, particularmente, com tendência à elevações em viscosidades (Perkins \& Angelo, 1992).

Considerando natureza qualitativa, a cor do óleo do mesocarpo da Acrocomia aculeata foi avaliada. Verificaram-se tonalidades que variaram entre amarelo e vermelho. Considerou-se tal atributo sensorial como sendo determinante em contextos produtivos, atrelando-o a determinação quantitativa de carotenóides. Particularmente, os valores obtidos para carotenoides totais em função de $\beta$-Caroteno $(10,81$ e $40,37 \mathrm{mg} / \mathrm{Kg}$ ), se encontraram bem abaixo de valor referenciado (378 $\mathrm{mg} / \mathrm{Kg}$ ), por exemplo, por Coimbra e Jorge (2012). Extrapolando possíveis ponderações que se atrelem a alcances de efetividades experimentais, sugere-se que valores mensurados para os compostos em questão podem se relacionar diretamente à degradação do óleo estudado, em função das práticas adotadas, com base em cultura regional, em contexto empírico, para coleta dos frutos e obtenção dos óleos, conforme descrito em itens anteriores desse capítulo. De toda forma, frisa-se que a degradação de tais compostos afeta a qualidade pró-vitamínica natural, especificamente, para o óleo estudado, acima de tudo, divergindo de valores definidos em estudos anteriores ( 300 a $378 \mu \mathrm{g} / \mathrm{g}$ ), como inerentes, para o teor de $\beta$-caroteno nos óleos dos frutos da palmeira Acrocomia aculeata (Coimbra e Jorge, 2012; Rufino et al., 2010; Ramos et al., 2008).

Certamente, a degradação pontual, em questão, comprometeria a utilização dessa mesma matéria-prima, considerando propósitos industriais entre os quais alguns dos que se definem para a indústria de 
cosméticos. Ainda, é necessário destacar que a degradação dos carotenoides pode acompanhar a degradação e a oxidação lipídica. Indício de tais reações pode ser obtido por meio da análise do índice de acidez. A verificação do perfil graxo demanda técnicas analíticas, tais quais cromatografia gasosa, sendo sugerida para estudos posteriores.

Os valores de acidez determinados para o óleo em estudo se definiram como sendo 75,54 mg de $\mathrm{KOH} / \mathrm{g}$ (lote 1) e 92,26 mg de $\mathrm{KOH} / \mathrm{g}$ (lote 2). Uma vez que tais valores para a acidez tenham sido recordados como mais elevados do que valores usualmente referenciados para o óleo em questão, deve-se considerar que tal incremento poderá, de fato, ter sido causado por gestão indevida do fruto coletado, das solturas dos cachos à extração dos óleos. Rettore e Martins (1983) e Evaristo et al. (2016) também reportam elevação de 45 e 47 vezes, respectivamente, na acidez de óleos da macaúba, quando a matéria-prima foi exposta a condições adversas, incluindo contato contínuo do fruto com o solo. Certamente, é razoável observar que, de fato, a acidez elevada reportada pode comprometer a destinação do óleo para propósitos específicos, deixando de atender a requisitos de qualidade, podendo comprometer estabilidade de produtos finais. Produtos muitos ácidos ainda podem contribuir com corrosão de equipamentos que com eles entre em contato (César, et al., 2014; Silva, et al., 2016; Souza, et al., 2015).

Verificações microbiológicas se complementam nos resultados físico-químicos, em sentido de sugestão de práticas de colheita e pós colheita enquanto altamente influentes na qualidade final do óleo extraído dos frutos da palmeira Acrocomia aculeata. A tabela 2 apresenta os meios de cultura utilizados nas análises dos óleos, descrevendo suas finalidades.

Tabela 2. Temperatura, Tempo de Incubação e Meios de Cultura Utilizados

\begin{tabular}{|l|l|c|c|}
\hline \multicolumn{2}{|c}{ Meio de Cultura e Tipos de Colônia } \\
\multicolumn{1}{|c}{ Meio de Cultura } & \multicolumn{1}{c|}{ Tipo de Colônia } & $\begin{array}{c}\text { Temperatura de } \\
\text { Incubação }\left({ }^{\circ} \mathrm{C}\right)\end{array}$ & $\begin{array}{c}\text { Tempo de } \\
\text { incubação }\end{array}$ \\
\hline $\begin{array}{l}\text { Casein Soyabean } \\
\text { Digest Agar (Casoy) }\end{array}$ & $\begin{array}{l}\text { Bactérias (mesófilos, coliformes fecais,coliformes } \\
\text { totais e sthaphylococcus) }\end{array}$ & $35 \pm 2$ & 72 horas \\
\hline HC Agar Base & Fungos, Bolores e Leveduras & $25 \pm 2$ & 72 horas \\
\hline
\end{tabular}

Nas análises microbiológicas dos óleos, realizadas no para o presente capítulo, contaminações para microrganismos mesófilos, coliformes fecais, coliformes totais, sthaphylococcus, bolores e leveduras não foram constatadas. Queiroz et al. (2014), por suas vezes, reportaram presença de fungos e bactérias, nos óleos do estudo. Ressalta-se que, além de condições do meio analisado, se tornaria de natureza relativa a busca por eventual comparação entre resultados de estudos sem que definições pontuais atreladas a condições de coleta/colheita, pós-colheita e extração fossem abordadas. Nesse sentido, para o presente capítulo, opta-se por levantar sugestões que se relacionem à correta adequação de meios de cultura (Casein Soyabean Digest Agar - Casoy; HC Agar Base), como embasamento que traga sentido de busca por propósitos e resultados analíticos.

Em complemento, ressaltam-se novamente enzimas lipase, carboxil-esterases, produzidas por microrganismos, as quais possuem triacilgliceróis como substratos naturais, contribuindo com ações catalisadoras, contextualizando reações hidrolíticas, bem como formações de ligações éster, produção de glicerol e liberação de ácidos graxos (Resende, 2014; Bornscheuer, 2002). Torna-se, assim, razoável reforçar a probabilidade de os procedimentos de coleta/colheita e pós-colheita, e também de extração, adotados para o desenvolvimento do presente capítulo terem comprometido potencialmente a qualidade final dos óleos extraídos. De fato, os resultados físico-químicos verificados, particularmente, para acidez, não necessitam ser interpretados com estreita dependência dos obtidos com natureza microbiológica, uma vez que as ações enzimáticas e o crescimento de microrganismos não ocorre, necessariamente, em concomitância.

\section{CONCLUSÕES}

O presente capítulo possibilita aproximação entre abordagens analíticas e contextos que também se fazem de natureza empírica. Particularmente, no que tange à avaliação de práticas de coleta dos frutos da palmeira Acrocomia aculeata, após liberação natural dos cachos da palmeira em estudo, em contato com o 
solo, a obtenção mecânica de seus óleos viabilizou breve abordagem que considera parâmetros fundamentais atrelados à utilização das matérias-primas avaliadas. Contextualizou-se a indústria de cosméticos, apenas como elemento adicional para desdobramento do capítulo. Verificação microbiológica se complementou em resultados físico-químicos, reforçando práticas de colheita, pós-colheita e formas extração enquanto altamente influentes na qualidade final do óleo do fruto da macaúba. De fato, a extração realizada utilizando-se pilão se destaca, tendo sido aplicada posteriormente à soltura natural dos frutos, dos cachos das palmeiras, com promoção de contato prolongado com o solo, seguida de cozimento do extrato oleico. Chama-se, mais uma vez, atenção para o fato de a gestão das práticas que inter-relacionam procedimentos de coleta e extração se fazerem fortemente relacionadas à obtenção de óleos vegetais com qualidade adequada a fins de utilização. Em sentido de fomento, contínuo, à cadeia produtiva da macaúba, a aproximação empírica mencionada também traz relevância e conscientização, uma vez que se faz sabido o fato de a exploração da palmeira em questão ocorrer de forma, por vezes, ainda rudimentar, e aquém de seu já comprovado potencial econômico e industrial. Para estudos futuros, recomendam-se, fortemente, aqueles que contribuam com a avaliação compreensiva e profunda dos parâmetros de qualidade dos óleos Acrocomia aculeata, inclusive, como alimento funcional e como matéria-prima industrial alternativa. Caracterização abrangente do óleo em questão, certamente, apoiará cientistas e indústrias, bem como pesquisas atreladas à indústria de processamento, estabelecendo padrões relacionados à composição, identidade e qualidade do óleo, enquanto matéria-prima, também considerando tópicos relacionados à saúde a elementos funcionais, para uma das palmeiras reconhecidamente mais produtivas em óleo comestível, no mundo.

\section{REFERÊNCIAS}

[1] ACHIR, N.; Randrianatoandro, V. A.; Bohoun, P.; Laffargue, A.; Avallone, S. Kinetic study of $\beta$-carotene and lutein degradation in oils during heat treatment. Eur J Lipid Sci Technol (2010). 112:349-361.

[2] AOAC - INTERNATIONAL ASSOCIATION OF OFFICIAL ANALYTICAL CHEMISTS. Official methods of analysis of AOAC International. 16. Ed; Gaitherburg : AOAC International, 1997

[3] Associação Brasileira da Indústria de Higiene Pessoal, Perfumaria e Cosméticos - Panorama do Setor de Higiene Pessoal, Perfumaria e Cosméticos, Disponível em https://abihpec.org.br/, acessado em 17/06/17.

[4] Agência Nacional de Vigilância Sanitária - ANVISA - Regulamento Técnico de Boas Práticas de Fabricação para Produtos de Higiene Pessoal, Cosméticos e Perfumes, Resolução RDC № 48 de 25/10/13.

[5] ANDRADE, Maria H. C. - ÓLEO DO FRUTO DA PALMEIRA MACAÚBA - PARTE I UMA APLICAÇÃO POTENCIAL PARA INDÚSTRIAS DE ALIMENTOS, FÁRMACOS E CÓSMETICOS, em I TECNIQ Seminário sobre Tecnologia na Indústria Química, 2006.

[6] BOBBIO, P.A.; BOBBIO, F.O. Química do Processamento de Alimentos. Livraria Varela, 3. ed., 2001. 143 p.

[7] Bora, P. S., Rocha, R., Macaiba palm: Fatty and amino acids composition of fruits macaíba: Composición de aminoácidos y ácidos grasos de frutos macaíba: Composición de aminoácidos e ácidos graxos de froitos. CYTA-Journal of Food 2004, 4, 158-162.

[8] CAC [Codex Alimentarius Commission], 2015. Codex standard for named vegetable oils. Available from: www.fao.org/input/download/standards/336/CXS_210s_2015.pdf (Accessed 2017 June 14).

[9] CAÑO ANDRADE, M.H. / ANDRADE, M.H.C.; VIEIRA, A. S.; AGUIAR, H. F.; CHAVES, J. F. N.; NEVES, R.M.P.S.; MIRANDA, T. L S; SALUM, A. Óleo do Fruto da Palmeira Macaúba Parte I: Uma Aplicação Potencial Para Indústrias de Alimentos, Fármacos e Cósmeticos. Anais do II ENBTEQ - Encontro Brasileiro sobre Tecnologia na Indústria Química. São Paulo : ABEQ, 2006. v. 1.

[10] BORNSCHEUER, U.T. Microbial carboxyl esterases: Classification, properties and application in biocatalysis. FEMS Microbiol. Rev, v. 26, p. 73-81, 2002.

[11] CALLEGARI F. C. et al - PERSPECTIVAS DA UTILIZAÇÃo DOS ÓLEOS DA MACAÚBA (ACROCOMIA ACULEATA (JACQ.) LODD. EX MART) NO DESENVOLVIMENTO DE COSMÉTICOS; COBEQ, Florianópolis, 2014.

[12] CÉSAR, Aldara da Silva et al - The prospects of using Acrocomia aculeata (Macaúba) a non-edible biosisel feedstock in Brasil. Renewable and Sustainable Energy Reviews, pág 1213-1220, 2015.

[13] CHAIYASIT, W., Elias, R. J., McClement, D. J., \& Decker, E. A. (2007). Role of physical structures in bulk oils on lipid oxidation. Food Science and Nutrition, 47, 299-317.

[14] CERRATINGA - Macaúba. Disponível e: http://www.cerratinga.org.br/macauba/, acessado em 10/10/2016;

[15] CETEC - FUNDAÇÃO CENTRO TECNOLÓGICO DE MINAS GERAIS - Produção de combustíveis líquidos a partir de óleos vegetais: Estudo das oleaginosas nativas de Minas Gerais, Belo Horizonte, 1983. 
[16] CODEX (2015): CODEX - Codex Standard for Named Vegetable Oils (FAO/WHO). CODEX STAN 33 -1981. Codex Alimentarius: International Food Standard, Roma, Itália, rev. 3, amend. 4. 2015

[17] COIMBRA MC, Jorge N. 2012. Fatty acids and bioactive compounds of the pulps and kernels of Brazilian palm species, guariroba (Syagrus oleraces), jeriva (Syagrus romanzoffiana) and macauba (Acrocomia aculeata), J Sci Food Agric 92:679-684. doi: 10.1002/jsfa.4630

[18] COSTA NETO, P. R.; FREITAS, R. J. S. Boletim CEPPA. 1996.

[19] DAVIES, B. H. Carotenoids. In: GOODWIN, T. W. (Ed). Chemistry And Biochemistry of Plant Pigments. London: Academic Press, 1976. Cap.19, p. 38-65.

[20] EVARISTO AB, Grossi JAS, Pimentel LD, Goulart SM, Martins AD, Santos VL, Motoike SY. 2016. Harvest and post-harvest conditions influencing macauba (Acrocomia aculeata) oil quality attributes. Ind Crops Prod 85:63-73. doi: 10.1016/j.indcrop.2016.02.052

[21] FARIAS, T. M. Biometria e processamento dos frutos da macaúba (Acrocomia sp) para a produção de óleos. FEQ - EE - UFMG. Belo Horizonte, MG. Brasil. v.1, n.1, p.93, 2010

[22] Hiane, P., Filho, M. R., Ramos, M., Macedo, M., Bocaiúva, Acrocomia aculeata (Jacq.) Lodd., pulp and kernel oils: Characterization and fatty acid composition. Braz. J. Food Technol. 2005, 8, 256-259.

[23] GARCIA, C. G. VALÉRIO, P. P. Estudo da Cinética de Degradação Térmica do Óleo Vegetal de Palma. Revista Exacta. v. 10. no 2. 2017. ISSN: 1984-3151.

[24] GERHARDT, T. E. SILVEIRA, D. T. Métodos de Pesquisa. Universidade Federal do Rio Grande do Sul. UFRGS Editora. 1a edição. 2009. ISBN: 978-85-386-0071-8.

[25] INTERNATIONAL ASSOCIATION OF OFFICIAL ANALYTICAL CHEMISTS (AOAC). Official methods of analysis of AOAC International. 16. Ed; Gaitherburg : AOAC International, 1997.

[26] KEIS K et al. INVESTIGATION OF PENETRATION ABILITIES OF VARIOUS OILS INTO HUMAN HAIR FIBERS. J Cosmet Sci, 2005; 56 (5): 238-95

[27] LOBATO, Breno - MACAÚBA É MATÉRIA-PRIMA PROMISSORA PARA BIODIESEL. Disponível em: https://www.embrapa.br/, acessado em 30/10/2016.

[28] LORENZI, H. - ÁRVORES BRASILEIRAS: MANUAL DE IDENTIFICAÇÃO E CULTIVO DE PLANTAS ARBÓREAS NATIVAS DO BRASIL. NOVA ODESSA, SP: Plantarum, 1992.

[29] NUNES, Angela A.; Favaro, Simone P.; Galvani, Fabio; Miranda, Cesar H. B. Good practices of harvest and processing provide high quality Macauba pulp oil. Eur. J. Lipid Sci. Technol. (2015), 117, 2036-2043.

[30] Parducci, L., Fennema, O., Rate and extent of enzymatic lipolysis at subfreezing temperatures. Cryobiology $1978,15,199-204$

[31] Perkins, E. G., in: St. Angelo, A. (Eds.), Lipid Oxidation in Food, American Chemical Society, Washington, DC 1992, pp. 310-321.

[32] QUEIROZ, L. A. L. - AVALIAÇ̃̃O DOS MICRORGANISMOS PRESENTES NOS FRUTOS DA MACAÚBA (ACROCOMIA ACULEATA) APÓS DIFERENTES TRATAMENTOS PÓS-COLHEITA, COBEQ, Florianópolis, 2014.

[33] RELE AS \& Mohile RB. EFFECT OF MINERAL OIL, SUNFLOWER OIL, AND COCONUT OIL ON PREVENTION OF HAIR DAMAGE. J Cosmet Sci, 2003; 54 (2): 175-92.

[34] RETTORE, R.P.; Martins, H. - PRODUÇÃO DE COMBUSTÍVEIS LÍQUIDOS A PARTIR DE ÓLEOS VEGETAIS: ESTUDO DAS OLEAGINOSAS NATIVAS DE MINAS GERAIS, Projeto da Fundação Centro Tecnológico de Minas Gerais CETEC, Belo Horizonte, vol.1, 1983.

[35] RAMOS, M. I. L., Siqueira, E. M. A., Isomura, C. C., Barbosa, A. M. J., \& Arruda, S. F. (2007). Bocaiuva (Acrocomia aculeata (Jacq.) Lood) improved vitamin A status in rats. Journal of Agricultural and Food Chemistry, 22, 3186-3190.

[36] Ramos, M. I. L., Filho, M. M. R., Hiane, P. A., Neto, J. A. B., Siqueira, E. M. D. A., Nutritional quality of the pulp of bocaiuva Acrocomia aculeata (Jacq.) Lodd. Food Sci. Technol. 2008, 28, 90-94.

[37] RESENDE, Alessandra Abrão - LEVEDURAS ASSOCIADAS A FRUTOS DA MACAÚBA (Acrocomia aculeata (JAQ.) LODD. EX MART): DIVERSIDADE E CARACTERIZAÇÃO QUANTO À PRODUÇÃO DE EXOENZIMAS E FATORES DE CRESCIMENTO. Belo Horizonte, 2014.

[38] RODRIGUEZ-Amaya, D. B., Kimura, M., \& Amaya-Farfan, J. (2008). Fontes Brasileiras de carotenóides: Tabela brasileira de composição de carotenóides em alimentos. Brasília: MMA/SBF.

[39] RODRIGUEZ-Amaya, D. B. (2002). Brazil: a bounty of carotenoid sources. Sight and Life Newsletter, 4, 3-9. 
[40] RODRIGUEZ-Amaya, D. B., \& Kimura, M. (2004). HarvestPlus Handbook for carotenoid analysis. Washington, DC: International Food Policy Research Institute; Cali: International Center for Trop. Agriculture (Technical Monograph).

[41] Rufino, M. D. S. M., Alves, R. E., de Brito, E. S., Pérez-Jiménez, J., Saura-Calixto, F., Mancini-Filho, J., Bioactive compounds and antioxidant capacities of 18 non-traditional tropical fruits from Brazil. Food Chem. 2010, 121, 9961002.

[42] SILVA,G.C.; ANDRADE,M.H.C. (2011) Development and Simulation of a New Oil Extraction Process from fruit of macauba Palm Tree. J.of Food Process Engineering, v.1.

[43] Silva, G. C. R. (2010). Industrial process oils extraction of the fruit of Macauba: Proposing Route, Simulation and Analysis of Economic feasibility. M.Sc. Thesis, p.204, (In: Portuguese), Belo Horizonte, UFMG.

[44] SILVA, Gisele Cristina Rabelo - EXTRAÇÃO DOS ÓLEOS DO FRUTO DA MACAÚBA NO NORTE DE MINAS GERAIS ROTA DE PROCESSAMENTO E VIABILIDADE ECONÔMICA, Rev. de Economia Agrícola, São Paulo, v. 61, n. 1, p. 23-34, jan./jun. 2014.

[45] SILVA, Larissa Noemi et al - Synthesis and characterization of esters from different alcohols using Macauba almond oil to substitute diesel oil and jet fuel, Fuel 166 pág 453-460, 2016.

[46] SILVA, Larissa Noemi et al - Production of Cold-Flow Quality Biodiesel from High-Acidity On-Edible Oils Esterification and Transesterification of Macauba (Acromia Aculeata) Oil Using Variuos Alcohols, Bioenerg. 9 pág 864873,2016

[47] SOUZA, Gredson Keiff et al - Synthesis of ethyl esters from crude macauba oil (Acrocomia aculeate) for biodiesel production, Fuel 165 pág 360-366, 2016.

[48] TRENTINI, Caroline Portilho - LOW-PRESSURE SOLVENT EXTRACTION OF OIL FROM MACAUBA (ACROCOMIA ACULETA) PULP: CHARACTERIZATION OF OIL AND DEFATTED MEAL; Ciência Rural, Santa Maria, v.46, n.4, p.725-731, abr, 2016.

[49] TRENTINI, Caroline Portilho - CARACTERIZAÇÃO DO ÓLEO E DO FARELO DESENGORDURADO DA POLPA DE MACAÚBA OBTIDOS A PARTIR DA EXTRAÇÃO COM SOLVENTES ORGÂNICOS A BAIXA PRESSÃO; Florianópolis, 2014.

[50] Trentini, C. P., Santos, K. A., da Silva, E. A., Garcia, V. A. D. S., Cardozo-Filho, L., da Silva, C., Oil extraction from macauba pulp using compressed propane. J. Supercrit. Fluids 2017, 126, 72-78.

[51] VALÉRIO P. P. - PERSPECTIVAS PARA UM NOVO PRODUTO ALIMENTÍCIO A BASE DE ÓLEO EXTRAÍDO DO FRUTO DA MACAÚBA (Acrocomia aculeata (Jacq.) Lodd. ex Mart); Florianópolis, 2014. 


\title{
Capítulo 9
}

Sementes de Moringa oleífera aplicadas para a remoção de íons cálcio de águas: contextos industriais alternativos

\author{
Renata Motta Kusumoto \\ Pedro Prates-Valério
}

Resumo: Considerando-se a capacidade adsortiva usualmente atrelada a sementes de Moringa oleifera, estudos têm sido conduzidos em contextos alternativos para tratamento potencial e redução de dureza residual de águas industriais. O presente capítulo se desenvolveu a partir da avaliação da remoção de íons cálcio de águas, aplicando-se sementes de Moringa oleífera em escala laboratorial. Os resultados obtidos mostraram redução de 96,9\% na dureza de amostras cujas concentrações de carbonato de cálcio se aproximaram de $45.321 \mathrm{~g} / \mathrm{L}$. Amostras com $6.040 \mathrm{~g} / \mathrm{L}$ de CaCO3 apresentaram redução de 65,5\%, também, nas durezas mensuradas.

Palavras-chave: Moringa oleifera, dureza, cálcio, engenharia química

Abstract: Considering the known adsorptive capacity of Moringa oleifera seeds, studies have been conducted in alternative contexts for potential treatment and reduction of the residual hardness of industrial waters. The present chapter was developed from the evaluation of the calcium removal of water, from the application of Moringa oleifera seeds. The results showed that there was a reduction of $96.9 \%$ of the hardness of samples whose concentrations of calcium carbonate were defined as close to $45.321 \mathrm{~g} /$ L. Samples with $6,040 \mathrm{~g} / \mathrm{L}$ of $\mathrm{CaCO} 3$ showed a reduction of $65.5 \%$, also, in the hardnesses measured.

Keywords: Moringa oleifera, hardness, calcium, Chemical Engineering 


\section{INTRODUÇÃO}

Em tempos atuais, considera-se que o elemento água, além de amplamente aplicado a processos industriais, é também uma das principais necessidades humanas. Enquanto recurso natural, é suporte primordial aos ecossistemas. Desta forma, destinada ao consumo e às atividades socio-econômicas, a água é usualmente captada em rios, lagos, represas, aquíferos e também, por vezes, no subsolo. Sua disponibilidade exerce, portanto, influência direta na saúde, na qualidade de vida e no desenvolvimento socioeconômico mundial (SOUZA, 2000).

As interações da água com o solo, no qual ela se encontra, influenciam na natureza da água, pois a mesma apresenta propriedade de absorver impurezas adicionais contidas no solo. Além disso, as águas das chuvas possuem pequenas quantidades de matérias orgânicas e gases dissolvidos da atmosfera. Tais fatos fazem com que haja variação de quantidade em sua composição mineral (BLUMBERG \& NETTO, 1956). Logo, a água pode possuir elevada concentração de cátions, dentre os quais cálcio $\left(\mathrm{Ca}^{2+}\right)$ e magnésio $\left(\mathrm{Mg}^{2+}\right)$. Quando isso acontece, a água é determinada como dura. Essa característica tem influência direta na utilização dessa água nas indústrias (GASPAROTTO, 2011).

De fato, tal qual salientado, é de amplo conhecimento que a utilização industrial de águas duras pode acarretar em inconvenientes, tais quais corrosão, perda de eficiência na transmissão de calor em caldeiras, inclusive por formação de incrustações, assim como entupimentos em tubulações e depósitos na superfície de equipamentos, com dificultação dos processos de limpeza (KOSLOSKI et. al., 2015).

Desta forma, é razoável observar que há a necessidade de busca por alternativas para que se tenha uma redução da dureza de águas. Além dos coagulantes químicos, como o sulfato de alumínio $\left(\mathrm{Al} 2\left(\mathrm{SO}_{4}\right)_{3}\right)$ e sais de ferro (III), pode-se utilizar os coagulantes de origem vegetal. Eles vêm apresentando uma alternativa aderente ao propósito de baixo custo (Moura, 2013), como é o caso da utilização das sementes da Moringa oleifera para remoção de cálcio e magnésio, conforme avaliou Fochesatto et al. (2016).

Neste contexto, têm-se como objetivo avaliar a eficiência de sementes trituradas da Moringa oleifera na redução da dureza da água, expressada em carbonato de cálcio $\left(\mathrm{CaCO}_{3}\right)$, como forma de verificação de sua utilização como alternativa para o tratamento potencial de águas industriais.

\section{REFERENCIAL TEÓRICO}

Originalmente, compreende-se a dureza da água como a medida da capacidade de precipitar sabão, sem formação de espuma, até que o processo se esgote. A dureza é usualmente expressada em miligramas por litro de carbonato de cálcio que contém o mesmo número total de íons bivalentes $\left(2^{+}\right)$. A dureza é uma característica importante de águas naturais. De fato, comumente, os íons cálcio e magnésio formam sais insolúveis na água com os ânions dos sabões (SKOOG, et. al., 2006).

Os sabões são principalmente precipitados pelos íons cálcio $\left(\mathrm{Ca}^{2+}\right)$ e magnésio $\left(\mathrm{Mg}^{2+}\right)$, comumente presentes na água, mas também podem ser precipitados por outros íons metálicos, como o ferro $\left(\mathrm{Fe}^{2+}\right)$, alumínio $\left(\mathrm{Al}^{2+}\right)$, manganês $\left(\mathrm{Mn}^{2+}\right)$, estrôncio $\left(\mathrm{Sr}^{2+}\right)$, zinco $\left(\mathrm{Zn}^{2+}\right)$, entre outros (GASPAROTTO, 2011).

Em termos químicos, a dureza da água também pode se definir com aderência à equação 1 , a seguir.

$$
\text { Dureza }=\left[\mathrm{Ca}^{2+}\right]+\left[\mathrm{Mg}^{2+}\right]
$$

Vale ressaltar que a dureza da água, pode ser temporária ou permanente. Na primeira, o cálcio e o magnésio encontram-se ligados a bicarbonatos $\left(\mathrm{Ca}\left(\mathrm{HCO}_{3}\right)_{2}\right) /\left(\mathrm{Mg}\left(\mathrm{HCO}_{3}\right)_{2}\right)$, que precipitam quando a água que contém esses sais é fervida e assim a dureza é parcialmente removida, vindo a incrustar em destiladores e demais sistemas de água quente. As equações 2 e 3 , a seguir, representam as reações relacionadas à dureza temporária da água.

$$
\begin{aligned}
& \mathrm{Ca}\left(\mathrm{HCO}_{3}\right)_{2} \rightarrow \mathrm{CaCO}_{3}(\mathrm{~s})+\mathrm{H}_{2} \mathrm{O}+\mathrm{CO}_{2}(\mathrm{~g}) \\
& \mathrm{Mg}\left(\mathrm{HCO}_{3}\right)_{2} \rightarrow \mathrm{MgCO}_{3}(\mathrm{~s})+\mathrm{H}_{2} \mathrm{O}+\mathrm{CO}_{2}(\mathrm{~g})
\end{aligned}
$$


Já a permanente, é quando o cálcio e o magnésio se encontram associados a sulfatos, não podendo ser removida com a fervura da água. A soma das durezas, temporária e permanente, é conhecida como dureza total da água e geralmente é expressa em mg/L de CaCO 3 . (GASPAROTTO, 2011) \& (SKOOG, et. al., 2006).

É importante salientar que, o Ministério da Saúde (Brasil, 2006), por meio de material de apoio à estruturação da vigilância e do controle da qualidade da água para consumo humano, preconiza que a água pode ser classificada, quanto à sua dureza, em mole ou branda ( $<50 \mathrm{mg} / \mathrm{L}$ de CaCO3), moderada (entre $50 \mathrm{mg} / \mathrm{L}$ e $150 \mathrm{mg} / \mathrm{L}$ de $\mathrm{CaCO}_{3}$ ), dura (entre $150 \mathrm{mg} / \mathrm{L}$ e $300 \mathrm{mg} / \mathrm{L}$ de CaCO3) e muito dura (> 300 $\mathrm{mg} / \mathrm{L}$ de CaCO3).

0 Ministério da Saúde brasileiro ainda afirma, através da portaria 518/2004 (Brasil, 2004), que o valor máximo permitido para consumo humano é igual a $500 \mathrm{mg} / \mathrm{L}$. Mesmo se tratando de um valor alto, nessa magnitude, usualmente não são encontrados em águas superficiais no Brasil, podendo ocorrer em aquíferos subterrâneos (GASPAROTTO, 2011)

Kosloski, et. al. (2015), afirma que a presença de sais na água não causa danos à saúde, porém, Piveli (1994), relata que em âmbito industrial, a dureza é relevante, principalmente em sistemas de água quente como caldeiras, trocadores de calor, entre outros. Como já citado, com o aumento da temperatura, formam-se carbonatos que precipitam e se incrustam podendo, até mesmo, levar diversas caldeiras à explosão.

De fato, a condução na transferência de calor é o processo pelo qual o calor flui de uma região de temperatura mais alta para outra de temperatura mais baixa, dentro de um meio ou entre meios diferentes em contato físico direto (ÇENGEL, 2009).

Sendo assim, fica evidente que a utilização de águas duras em indústrias exige tratamentos, para que se torne adequada aos processos. Neste sentido, considerando os novos paradigmas, os agentes coagulantes naturais vêm demonstrando vantagens em comparação aos químicos, afinal possuem baixa toxidade, baixo índice de produção de lodos residuais e por serem biodegradáveis. (POZZOBON, L. KEMPKA, A. P., 2015).

Entre coagulantes naturais, a Moringa oleifera vem sendo uma das plantas mais utilizada nos processos de bioadsorção da água. Originária da Índia, a Moringa oleifera pertence à família Moringaceae que é composta apenas de um gênero (Moringa) e possui 14 espécies conhecidas. Com uma propagação por sementes, mudas ou estacas, esta árvore já se espalhou pelo mundo, sendo encontrada principalmente em regiões trópicas, além de possuir um rápido crescimento, podendo frutificar em seu primeiro ano de vida. (FRANCO, 2015)

A Moringa oleifera é constituída de um caule grosso, atingindo em torno de 10 metros de altura. Suas folhas são bipinadas com foliólulos de até $3 \mathrm{~cm}$ de comprimento e seu fruto é simples, seco do tipo cápsula loculicida, contendo três valvas que se abrem longitudinalmente, evidenciando suas sementes. (PATERNIANI, J. E. S.; MANTOVANI, M. C.; SANT`ANNA, M, R, 2007) \& (RAMOS et all, 2010).

Suas sementes, segundo RAMOS et all (2010), possuem três asas ou alas, é globosa, de coloração castanhomédio e as asas, são castanho-claro. Além disso, possuem aminoácidos com forte capacidade de aglutinação (ácido glutâmico, prolina, metionina, e arginina) que atuam como floculantes, aglutinando e sedimentando partículas sólidas presentes na água (POZZOBON, L. KEMPKA, A. P., 2015).

De acordo com Schneider (1995), o processo de biossorção é a remoção de metais pesados, ou demais compostos através de um material biológico. Essa remoção pode acontecer por adsorção ou absorção. No caso da utilização das sementes da moringa como biossorvente, Lima (2015) afirma que a remoção ocorre por adsorção, processo pelo qual há transferência de massa da fase fluida para a superfície do sólido usado como adsorvente.

Segundo Vieira (2008) e Alagumuthu (2012), citados por Lima (2015), a bioadsorção apresenta-se como alternativa vantajosa quando comparada aos métodos convencionais, uma vez que utiliza materiais de baixo custo, e também pelo fato dos bioadsorventes serem biodegradáveis e não nocivos à saúde.

Lima (2015) evidencia que os trabalhos de Raj et al. (2010), Mendes e Coelho (2007), Alagumuthu (2012), Sharma et al. (2005), Marques et al. (2012) e Almeida (2010) apresentaram resultados efetivos quando utilizaram a moringa como bioadsorvente na remoção de metais.

Além disso, entre estudos recentes sobre o uso de coagulantes naturais na redução da dureza da água, considerando a Moringa oleifera, Fochesatto, et. al. (2016), constatou-se a remoção efetiva de cálcio e magnésio. 
Desta maneira, o presente estudo, objetiva avaliar a remoção de cálcio da água através da utilização de sementes de Moringa oleifera como bioadsorvente potencialmente aplicável a contextos industriais.

\section{METODOLOGIA}

\section{Caracterização da Pesquisa}

De acordo com as definições descritas por Gerhardt e Silveira (2009), este trabalho se caracteriza como um estudo teórico e original. A metodologia utilizada mesclou revisão bibliográfica e procedimentos experimentais para atingir os objetivos deste estudo, podendo, estes, serem descritos como explicativos, buscando a identificação da influência de determinados fatores no fenômeno estudado, e a abordagem adotada, também quantitativa, compara o comportamento dos dados obtidos com situações semelhantes descritas na literatura.

\subsection{B - COLETA DE DADOS}

A partir do levantamento bibliográfico sobre o uso da Moringa oleifera como bioadsorvente na remoção de metais, embasando escolha metodológica para avaliação da remoção de cálcio da água, por meio de utilização de sementes de Moringa oleifera como bioadsorvente.

Nesse contexto, optou-se orientação que considera dados apresentados por Fochesatto et al. (2016), considerando análise da remoção do íon cálcio $\left(\mathrm{Ca}^{2+}\right)$, coincidente com análise concernente ao presente estudo.

Sendo assim, frutos de indivíduos de $M$. oleifera localizados na cidade de Carmo do Cajuru, região metropolitana de Belo Horizonte - MG foram coletados diretamente da árvore. Posteriormente à coleta, sementes in natura foram trituradas em um processador e levados ao laboratório do Centro Universitário - UNA, unidade Aimorés - Belo Horizonte.

Em seguida, as sementes foram pesadas e dividas em três grupos, de 10 g cada.

Após essa separação, foram preparados três grupos de soluções, sendo cada grupo composto por duas soluções, de $100 \mathrm{ml}$ cada, com a mesma concentração de carbonato de cálcio. A diferenciação entre as duas soluções de mesmo grupo se deu na composição, pois uma tratou-se de "solução padrão" contendo apenas água destilada e carbonato de cálcio $\left(\mathrm{CaCO}_{3}\right)$, enquanto a outra solução, tratando-se de "solução com $M$. oleifera", além de água e $\mathrm{CaCO}_{3}$, também possuía pó das sementes de moringa. Essa diferenciação dentro de cada grupo foi importante para se avaliar o potencial das sementes de $M$. oleifera, na redução de dureza de águas, considerando íons cálcio.

Para o preparo de cada "solução com M. oleifera", misturou-se 10 g de pó de semente da moringa com 100 $\mathrm{ml}$ de água destilada e $\mathrm{CaCO}_{3}$ em um béquer, o qual foi deixado no agitador magnético por um período de 7 horas. Respeitado esse tempo, esperaram-se mais 3 horas para decantação e então, foi retirado somente o líquido da solução livre da supernadante, obtendo desta maneira a "solução com M. oleifera".

Assim, as soluções padrão analisadas foram os seguintes:

Amostra 1: $\quad$ Concentração de $421 \mathrm{mg} / \mathrm{L}$ de $\mathrm{CaCO}_{3}$

Amostra 2: $\quad$ Concentração de $6.040 \mathrm{mg} / \mathrm{L} \mathrm{de} \mathrm{CaCO}_{3}$

Amostra 3: $\quad$ Concentração de $45.321 \mathrm{mg} / \mathrm{L} \mathrm{de} \mathrm{CaCO}_{3}$

As soluções prontas foram então enviadas à empresa LIMNOS, localizada na cidade de Vespasiano, na região metropolitana de Belo Horizonte, Minas gerais, onde foram realizadas análises de dureza total da água. Para tanto, utilizou-se espectrofotometria de Absorção Atômica para avaliação da dureza quantificada em carbonato de cálcio $\left(\mathrm{CaCO}_{3}\right)$, em miligramas por litro, conforme Standard Methods (1998). 


\section{RESULTADOS E DISCUSSÕES}

A Figura 1 a seguir é apresentada como forma de ilustrar as sementes trituradas de Moringa oleifera.

Figura 1. Sementes de Moringa oleifera trituradas e agrupadas.

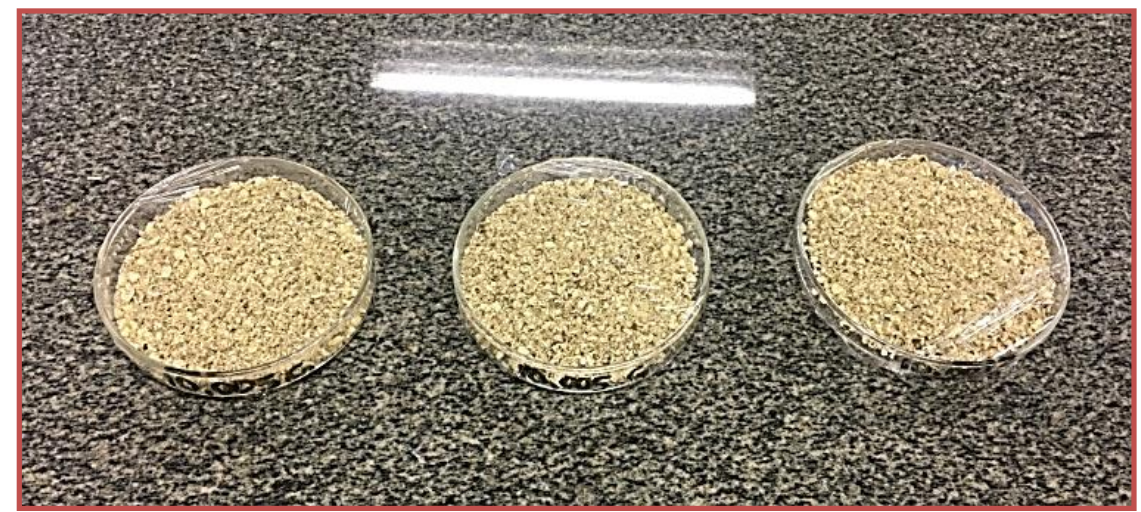

Fonte: Autores

A figura 2A ilustra as soluções padrão preparadas nas concentrações $420 \mathrm{mg} / / \mathrm{L}, 6.040 \mathrm{mg} / / \mathrm{L}$ e 45.321 mg//L. A Figura 2B, por sua vez, ilustra as soluções tratadas com sementes de Moringa oleifera.

Figura 2. Soluções padrão (A). Soluções tratadas com sementes de Moringa oleífera (B)

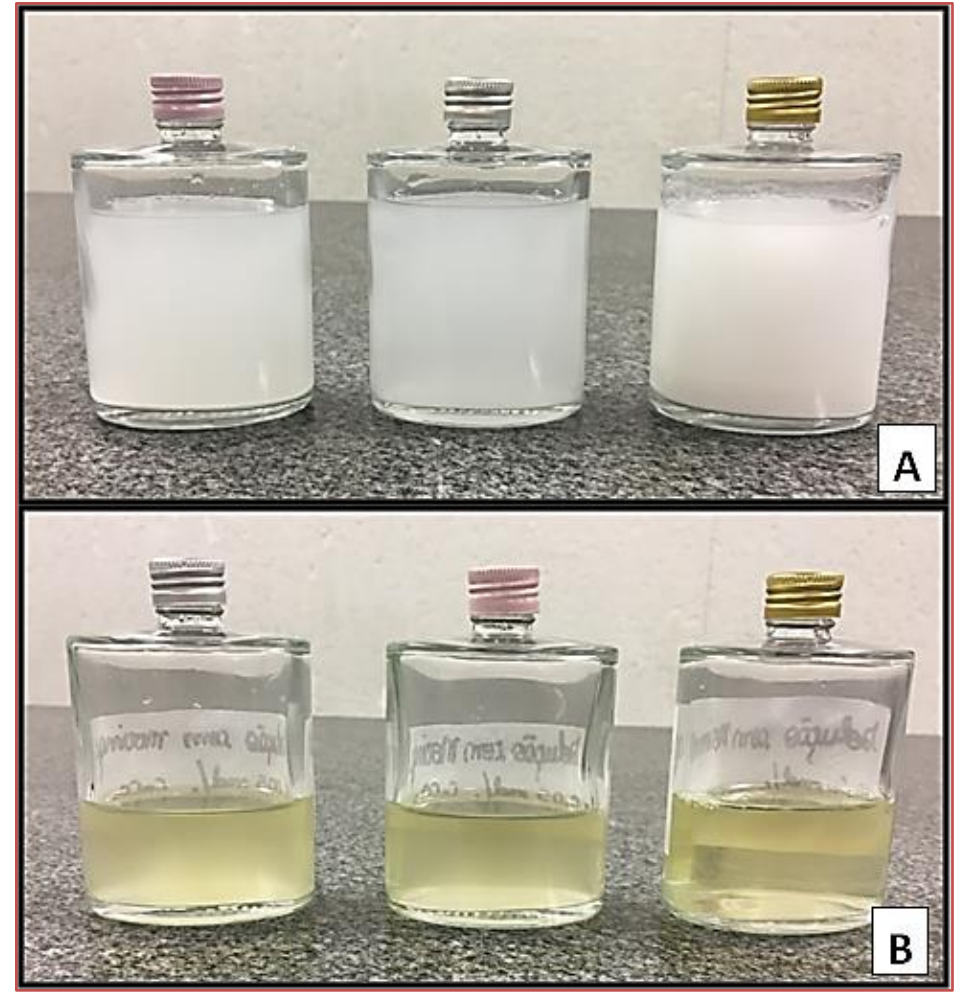

Fonte: Autores

As figuras apresentadas possibilitam uma avaliação visual da redução da dureza das soluções padrão utilizadas no estudo. De fato, as soluções enriquecidas com carbonato de cálcio tendem a apresentar uma coloração esbranquiçada que, após contato com as sementes de $M$. oleifera passam a apresentar translucidez. De toda forma, tal avaliação qualitativa, convenientemente, dá lugar às avaliações quantitativas discutidas a seguir. 
A tabela 1 apresenta os resultados obtidos experimentalmente, para a dureza expressada como carbonato de cálcio (CaC03), nas amostras analisadas. 0 gráfico (Figura 3), na sequência, evidencia as reduções mencionadas.

Tabela 1. Dureza: Expressa em Carbonato de Cálcio

\begin{tabular}{|c|c|c|c|}
\hline \multirow{2}{*}{ Amostra } & \multicolumn{2}{c|}{ Dureza em CaCO3 (mg/L) } & Redução \\
\cline { 2 - 4 } & Solução padrão & Solução tratada com M. oleifera & $-128,4$ \\
\hline 1 & 421 & 960 & 65,5 \\
\hline 2 & 6.040 & 2.082 & 96,9 \\
\hline
\end{tabular}

Figura 3. Evidencia da redução da dureza nas soluções tratadas com sementes de Moringa oleifera.

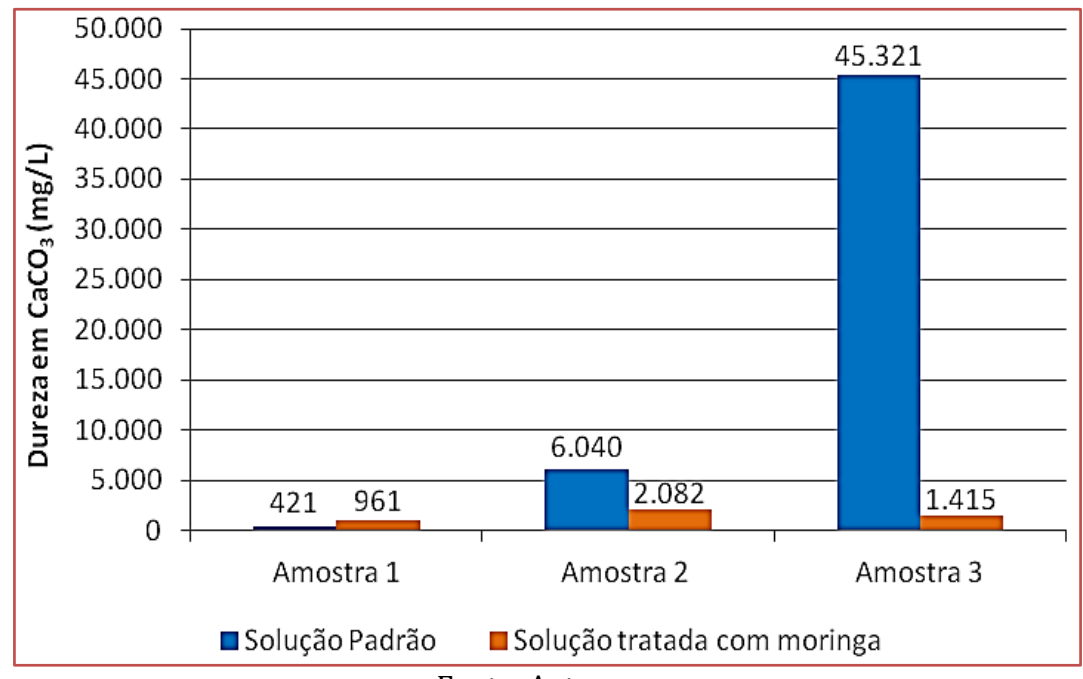

Fonte: Autores

Conforme se pode observar, a Tabela 1 possibilita analisar o comportamento do experimento realizado no sentido de redução da dureza (CaCO3) das amostras de água analisadas. Conforme esperado, a amostra 2 apresentou uma redução substancial $(65,5 \%)$ na concentração de carbonato de cálcio, quando comparando a solução tratada $(2.082 \mathrm{mg} / \mathrm{L})$ com $M$. oleifera e a solução padrão $(6.040 \mathrm{mg} / \mathrm{L})$. Tal observação sugere que as sementes de Moringa oleifera apresentam potenciais como bioadsorvente na redução de cálcio da água.

Em aderência, Fochesato (2016) observa em seu estudo com moringa que a casca da mesma utilizada como bioadsorvente removeu totalmente o íon cálcio a partir da dosagem de $24 \mathrm{~g} / \mathrm{L}$. Coelho, por sua vez, reforça o destaque das sementes da moringa como bioadsorvente eficaz na remoção parcial de prata e manganês na água (MENDES \& COELHO, 2007).

Coerentemente, o comportamento similar de redução da dureza, em carbonato de cálcio (96,9\%), pode ser observado para a amostra 3, ao se compararem as soluções inicial (45.321 mg/L) com a solução tratada com as sementes estudadas $(1.415 \mathrm{mg} / \mathrm{L})$.

A partir da observação em questão, uma breve discussão surge no sentido de avaliar a eficiência das sementes, como forma de se ressaltar seu ponto máximo quanto à bioadsorção.

Quando se são comparadas as amostras 2 e 3 quanto aos percentuais de redução da dureza, pode-se sugerir que, aparentemente, quanto maior a concentração de carbonato de cálcio na solução, maior tende a ser a eficiência da moringa na remoção de íons cálcio, uma vez que para a amostra 2, ocorreu a redução de $65,5 \%$ enquanto para a mostra 3 o percentual de remoção foi de $96,9 \%$. Contudo, salienta-se que, para conclusões mais pontuais a este respeito, um número maior de amostras, com ampla variação de soluções devem ser avaliadas. 
Vale salientar que, ao se observar a amostra 1, ao se confrontar a solução inicial (421 mg/L) com a solução tratada com as sementes estudadas (961 mg/L), nota-se que um aumento de 540,1 mg/L de carbonato de cálcio na solução. Esse resultado, diferente do esperado, pode ter ocorrido em decorrência de erro laboratorial. Além disto, pode-se sugerir que soluções com concentrações reduzidas em cálcio tendem a apresentar evidências menos claras quanto à redução da dureza e, consequentemente, quanto à eficiência da moringa.

Com destaque, que Fochesato (2016) obteve 100\% de remoção de íons cálcio quando se utilizou concentrações de $24 \mathrm{~g} / \mathrm{L}$ até $40 \mathrm{~g} / \mathrm{L}$ de carbonato de cálcio e empregou a casca das sementes de moringa como bioadsorvente. Já no presente estudo, foi usado como bioadsorvente, não apenas a casca, mas toda a semente da M. oleifera.

No entanto, esse fato não alterou a eficiência da moringa como potente bioadsorvente na remoção de cálcio na água, afinal, os resultados mostram que houve redução de 96,9\% da dureza da amostra cuja concentração de carbonato de cálcio era de 45,3 g/L.

Apesar do potencial observado para a cultura estudada, a moringa ainda vem se desenvolvendo no sentido de se tornar cultivada de forma intensiva. Assim, seu uso em grandes quantidades se faz, de certa forma, limitado. Porém, sua utilização, associada a outros floculantes químicos, entre os quais, sulfato de alumínio (Al2(SO4)3) e sais de ferro (III), pode ser de interesse sob as esferas de sustentabilidade e até mesmo de custos.

Neste sentido, considerando os novos paradigmas e também visando a sustentabilidade, os agentes coagulantes naturais, tais como a Moringa oleifera se apresentam como uma alternativa, afinal são de baixo custo, biodegradáveis, possuem baixa toxidade, baixo índice de produção de lodos residuais e não são nocivos à saúde.

Desta forma, sugere-se que estudos posteriores sejam realizados para se avaliar a efetividade da associação de coagulantes químicos com a M. oleifera.

\section{CONCLUSÕES}

No presente estudo, foi possível avaliar a eficiência de sementes trituradas da Moringa oleifera na redução da dureza da água, expressada em carbonato de cálcio (CaCO3), como forma de verificação de sua utilização como alternativa para o tratamento potencial de águas industriais.

As sementes se mostram efetivas na redução de íons bivalentes, se fazendo alternativas para o tratamento de águas em contextos diversos. Tal efetividade, pode ser importante quando se considera a moringa associada ao uso de floculantes químicos.

A partir de observações quantitativas, observou-se que a utilização das sementes de $M$. oleifera são efetivas na remoção de cálcio da água, principalmente quando associada a maiores concentrações de carbonato de cálcio na solução, sendo necessária a realização de novos estudos com um número maior de amostras, e de variação de soluções para se corroborar tal fato.

\section{REFERÊNCIAS}

[1] BLUMBERG, E. \& NETTO, J. M. A. Alcalinidade e dureza das águas naturais: processos de redução de dureza. Revista do departamento de águas e esgoto (DAE), número: 28, São Paulo, 1956. Disponível em: <http://revistadae.com.br/artigos/artigo_edicao_28_n_1033.pdf> Acesso em: 25 de mar. 2017.

[2] BRASIL. Ministério da Saúde. Secretaria de Vigilância em Saúde. Vigilância e controle da qualidade da água para consumo humano. Brasília: Ministério da Saúde, 2006. 212 p. Série B. Textos Básicos de Saúde.

[3] BRASIL. Ministério da Saúde. Portaria no 518, de 25 de março de 2004. Estabelece os procedimentos e responsabilidades relativos ao controle e vigilância da qualidade da água para consumo humano e seu padrão de potabilidade, e dá outras providências. Diário Oficial da União, Brasília, DF, 26 mar. 2004.

[4] ÇENGEL, Y. A. Transferência de Calor e Massa: Uma Abordagem Prática, 3ª Edição. São Paulo, SP: McGrawHill Interamericana do Brasil Ltda., 2009.

[5] FOCHESATTO, C.; KLEN, M.R.F.; SCHMITT, D.M.F.; VEIT, M.T. Estudo da eficiência de processos combinados para tratabilidade de águas residuárias da indústria de produtos lácteos utilizando Moringa oleífera Lam. II Encontro Anual de Iniciação Científica, Tecnológica e Inovação da Universidade Estadual do Oeste do Paraná. Centro de Engenharias e Ciências Exatas. Toledo - PR, 2016. 
[6] FRANCO, M. Remoção de metais pesados da água por filtração lenta em não tecidos com auxilio de coagulante extraído de sementes de Moringa oleifera. Dissertação de doutorado em Engenharia Agrícola na área de concentração de Água e Solo. UNICAMP, Campinas - SP, 2012.

[7] GASPAROTTO, F. A. Avaliação Ecotoxicológica e Microbiológica da Água de Nascentes Urbanas no Município de Piracicaba-SP. 2011. 89 f. Dissertação (Mestrado) - Centro de Energia Nuclear na Agricultura, Universidade de São Paulo, Piracicaba, 2011.

[8] GERHARDT, T. E. SILVEIRA, D. T. Métodos de Pesquisa. Universidade Federal do Rio Grande do Sul. UFRGS Editora. 1a edição. 2009.

[9] KOSLOSKI, V. R.; MEMLAK, D. M.; PIGATTO, J.; CAREZIA, L.R.B. Determinação do método de dureza total em água. Revista banas qualidade, número 275/83, São Paulo, 2015. Disponível em: <http://www.resag.org.br/downloads/metodo_dureza_total.pdf> Acesso em: 25 de mar. 2017.

[10] LIMA, A. B. D. F. Bioadsorção de metais pela semente da moringa oleífera: avaliação do processo empregando a fluorescência de raios x por reflexão total com radiação síncrotron. Dissertação de mestrado em Engenharia Civil na área de saneamento e ambiente. UNICAMP, Campinas - SP, 2015.

[11] MENDES, F. M \& COELHO, N. M. M. Estudo do uso da Moringa oleifera para remoção de prata e manganês em águas. Universidade Federal de Uberlândia - Instituto de química, Uberlândia - MG, 2007.

[12] MOURA, K. S. Cinética de Coagulação da Lectina de Sementes de Moringa oleifera (WSMoL) em Presença de Carboidratos e Íons. Dissertação de mestrado em bioquímica e fisiologia pela Universidade Federal de Pernambuco, Recife - PE, 2013.

[13] PATERNIANI, J. E. S.; MANTOVANI, M. C.; SANT`ANNA, M, R,. Uso de sementes de Moringa oleifera para tratamento de águas superficiais. Revista Brasileira de Engenharia Agrícola e Ambiental. Campina Grande, PB, UAEA/UFCG, 2007.

[14] PIVELI, R. P. Características das Águas: ph, acidez, alcalinidade e dureza. Curso de qualidade das águas e poluição: aspectos físico-químicos da Escola de Engenharia Mauá. São Caetano do Sul - SP, 1994.

[15] POZZOBON, L. KEMPKA, A. P. Sementes de Moringa oleifera na Clarificação de Efluente de Indústria de Ingredientes para Alimentação Animal: comparação com o coagulante convencional e estudo das condições operacionais. Engevista - Revista de Escola de Engenharia da UFF, V. 17, n. 2, p. 196-206, Niteroi - RJ, 2015.

[16] RAMOS, L. M. et. all. "Morfologia de frutos e sementes e morfofunção de plântulas de Moringa (Moringa oleifera Lam.)". Revista Scientiae. 2010.

[17] SCHNEIDER, I. A. H. Biossorção de Metais Pesados com a Biomassa de Macrófitos Aquáticos. Dissertação de doutorado em metalurgia extrativa, na Escola de Engenharia da universidade Federal do Rio Grande do Sul (UFRGS), Porto Alegre, 1995.

[18] SKOOG, D. A, WEST, D. M., HOLLER, F. J., CROUCH, S. R. Fundamentos de Química Analítica, Editora Thomson, tradução da 8a edição, 2006.

[19] SOUZA, D. A. Desenvolvimento de metodologia analítica para determinação de multiresíduos de pesticidas em águas de abastecimento de São Carlos - SP. Dissertação de doutorado em ciências da engenharia ambiental, na Escola de Engenharia de São Carlos, Universidade de São Paulo, São Carlos, 2000. 


\title{
Capítulo 10
}

\section{Estudo de materiais propantes associado a processo de fraturamento hidráulico}

\author{
Matheus Avelino Barbosa de Souza \\ Pedro Prates-Valério
}

Resumo: 0 presente capítulo revisa bibliograficamente alguns dos conceitos atrelados a materiais propantes, relacionando faturamento enquanto abordagem tecnológica. As matérias-primas para a fabricação desses materiais se fazem diversas, tornando relevantes estudos que trazem abordagem de desempenho e eficácia quanto a eventuais utilizações. Nesse sentido, a abordagem do presente capítulo também organiza informações, em sentido de conhecimento fundamental e análise. Ressalta-se o fato de propantes de areia e de materiais derivados da bauxita tenderem a se mostrar usuais, entretanto, unindo-se a materiais alternativos com desempenhos relativamente satisfatórios. $\mathrm{Na}$ observação de trabalhos pesquisados, também se reforça relativa viabilidade de utilização de materiais sustentáveis, para finalidades de abordagem.

Palavras-chave: Propante; Fraturamento Hidráulico; Processos Extrativos; Petróleo; Gás.

Abstract: This chapter reviews bibliographically some of the concepts linked to proppant materials, relating fracturing as a technological approach. The manufacture of such materials has been made diverse, making relevant those studies that also address the performance and effectiveness of future uses and application. In this sense, the approach of this chapter also organises information in the sense of fundamental knowledge and analysis. It should be noted that sand proppants and bauxite-derived materials tend to be usual in contemporaneity; however, those are added to alternative materials with relatively satisfactory performances. Underlining certain works, it is also reinforced relative feasibility of using sustainable materials, for assertive approach purposes.

Keywords: Proppant; Hydraulic Fracturing; Extractive Processes; Petroleum; Gas. 


\section{INTRODUÇÃO}

O consumo de energia mundial atualmente está em pleno crescimento, o que faz com que a exploração de recursos energéticos naturais se intensifique. Duas entre as mais importantes fontes de energia são o petróleo e o gás natural. 0 maior contingente de petróleo vem sendo obtido em campos nas regiões do Irã, Iraque, Kuwait, Rússia, Arábia Saudita, Emirados Árabes, Estados Unidos e Venezuela. Obtém-se, também, ao largo da costa (offshore) no Mar do Norte, Golfo da Guiné e Golfo do México. Em algumas dessas reservas, o material é retirado do solo aplicando-se tecnologia relativamente simplificada (JÚNIOR, 2014).

A exploração das reservas convencionais de óleo e gás, contudo, vêm se mostrando insuficiente para o abastecimento energético mundial. Por este motivo, tecnologias para extração de reservas nãoconvencionais também vêm sendo desenvolvidas, para aplicação em áreas consideradas mais complexas, com consequente elevação de custos. Entre tais técnicas, destacam-se acidificação de matriz, fraturamento hidráulico e ácido. Particularmente, a técnica do fraturamento hidráulico tem se difundido nos Estados Unidos, com reflexo no mercado mundial de energia (BRAGA, 2015).

No que se refere ao Brasil, e considerando recursos não convencionais de gás, o país possui reservas estimadas em 6,4 trilhões de metros cúbicos. Sendo assim, o país se destaca na $10^{\underline{a}}$ colocação entre principais países detentores de reservas desta natureza (BRAGA, 2015; JÚNIOR, 2014).

Retomando-se sobre a técnica, o fraturamento hidráulico consiste na injeção, em profundezas elevadas (> $2500 \mathrm{~m}$ ), do subsolo, de um fluido com um material agente de sustentação. Tal material de sustentação se denomina propante. Sua atuação tecnológica se baseia no fluxo de gás ou óleo, do reservatório natural para a superfície. Atualmente, o potencial de utilização do propante desperta interesses relacionados, por exemplo, a materiais, formas e custos de obtenção e otimização do desempenho. Neste contexto, as areias silicosas naturais, assim como as areias resinadas e os materiais cerâmicos derivados de bauxita, se destacam entre opções de materiais usualmente utilizados para a finalidade mencionada (MORAES, 2016).

CAMPOS et al. (2014) recomenda estudos e pesquisas relacionados a materiais propantes. Sendo assim, observa-se que a verificação de propriedades físico-químicas, caracterizações estruturais, métodos de obtenção, rotas de produção, custos e benefícios se incluem, inclusive, no sentido de busca por base e fundamento de inovação. Tais pesquisas se justificam na importância do propante enquanto coadjuvante no fraturamento hidráulico, influenciando no desempenho da técnica. Também, reforçando relativa escassez de recursos energéticos, traz-se relevância industrial para o fraturamento hidráulico, por exemplo, quando atrelado à exploração energética.

Certamente, a reunião de conhecimentos técnicos se faz capaz de auxiliar na organização de controles e intervenções em processos que considerem contextos ambiental, humano e profissional. Neste sentido, o presente capítulo compila abrangência de fundamentos relacionados a fraturamento hidráulico e materiais de sustentação (CAMPOS et al., 2014; MORAES, 2016; TAVARES, 2010; LUZ et al., 2008).

\section{METODOLOGIA}

O estudo conduzido e apresentado no presente capítulo se desenvolve com base em levantamento bibliográfico. Alguns dos conceitos fundamentais, os quais possibilitam realizar considerações a respeito da aplicação materiais propantes usuais, no contexto mencionado, são pesquisados. Sendo assim, realizase pesquisa exploratória, a partir da qual conhecimentos gerados reúnem-se no sentido da construção de hipóteses, estimulando a compreensão da aplicabilidade de parâmetros e características físico-químicas requeridas por materiais contextualizados, relacionando breves informações sobre suas estruturas físicas e resistência mecânica, contextualizando inovação e perspectivas alternativas. 0 capítulo se complementa com breve análise comparativa de estudos determinados, seguida por discussão dos conteúdos e considerações.

\section{REFERENCIAL TEÓRICO}

\subsection{O FATURAMENTO HIDRÁULICO E O USO DE PROPANTES}

O faturamento hidráulico é uma técnica utilizada para estimulação de poços, principalmente, em reservatórios não-convencionais de óleo e gás. A técnica consiste na injeção de um fluido, a pressões elevadas, em rochas sedimentares de camadas profundas (acima de 2.500 metros), denominadas Xisto. Tal injeção resulta no rompimento estrutural e no acesso às reservas de gás natural e, subordinadamente, petróleo. 0 propante, enquanto material granular de sustentação, viabiliza o fluxo de gás ou petróleo para 
a superfície. Ressalta-se que quantidades de propante utilizadas em reservatórios não-convencionais podem chegar à ordem de 300 mil toneladas/poço (LUZ et al., 2008). A figura 1 ilustra países que se destacaram em 2014, quanto a reservas de Xisto, mundiais.

Entre materiais propantes, verificam-se as utilizações de areias, areias tratadas com resinas, mistura de minerais de alumínio e cerâmicas. A escolha do material envolve dados relacionados a resistências a tensões e temperaturas (TAVARES, 2010). A Tabela 1 apresenta a relação entre valores de densidades e resistências ao esmagamento, para determinados materiais propantes.

Figura 1. Reservas mundiais de xisto: Trilhões de pés cúbicos

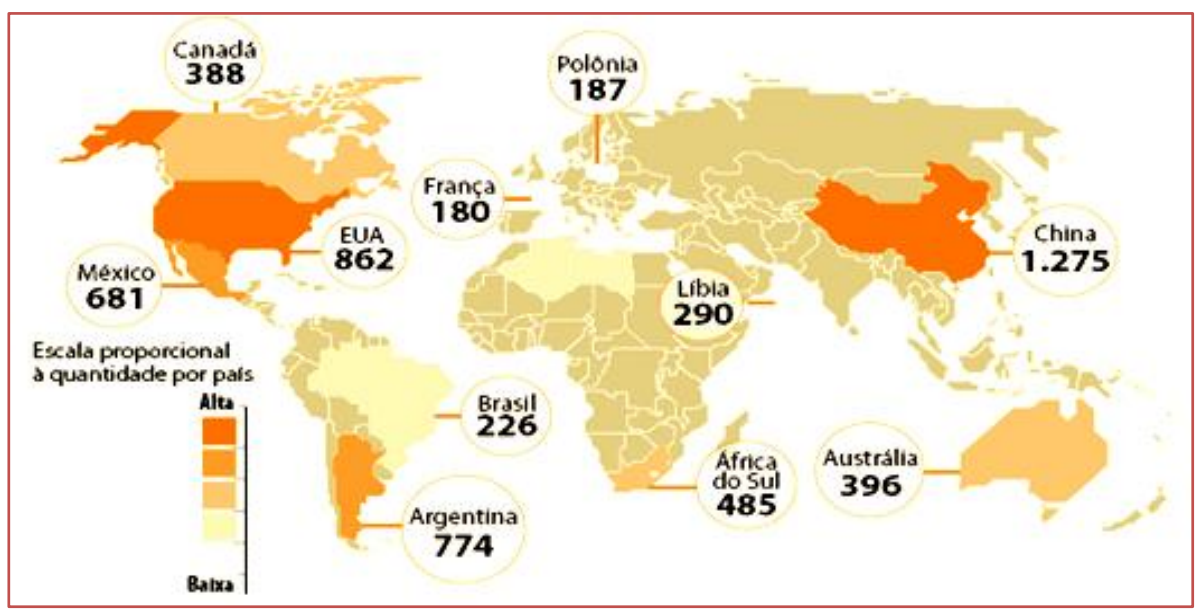

Fonte: MIRANDA (2014)

Tabela 1. Densidades e resistências, médias, de materiais propantes

\begin{tabular}{|c|c|c|}
\hline Tipo de Propante & Densidade $\left(\mathrm{g} / \mathrm{cm}^{3}\right)$ & Resistência ao esmagamento \\
\hline Areia pura & 2,65 & $<6000(\mathrm{psi})$ \\
\hline Areia tratada com resina (RCS) & 2,55 & $>8000(\mathrm{psi})$ \\
\hline Bauxita - mistura de minerais de alumínio & 2,00 & 7500 (psi) \\
\hline Cerâmica - resistência intermediária (ISP) & 3,00 & $>10000(\mathrm{psi})$ \\
\hline Cerâmica - resistência elevada (HSB) & $\geq 3,40$ & \\
\hline
\end{tabular}

Fonte: TAVARES (2010)

\subsection{MATERIAIS PROPANTES}

Areia e Quartzo: As areias são existentes abundantemente na natureza, na forma de material granular, solto não coesivo, cujos grãos e elementos estruturais devem ter, por definição, o tamanho areia (determinado a partir de um diagrama triangular de materiais arenosos). Areias são basicamente grãos compostos quimicamente de quartzo, mas podem estar presentes feldspato, mica, ilmenita, turmalina, granada e o zircão. Enquanto materiais propantes, estas podem ser tratadas e cobertas com resinas, que são compostos poliméricos, as quais conferem melhores desempenhos. Possuem grãos variando entre 0,0625 mm e 2,0 mm (ROCHA, 2015).

A estrutura cristalina do quartzo é trigonal, composta por tetraedros de sílica (dióxido de silício - SiO2), pertencendo ao grupo dos tectossilicatos. Na natureza, cristais de quartzo tendem a ser irregulares, distorcidos, desenvolvidos com cristais adjacentes de outros minerais, ou mesmo com faces cristalinas cujas identificações são dificultadas, que os fazem parecer maciços (CALLISTER, 2012). A figura 2, a seguir, apresenta a estrutura cristalina do quartzo: 
Figura 2. Estrutura cristalina do quartzo

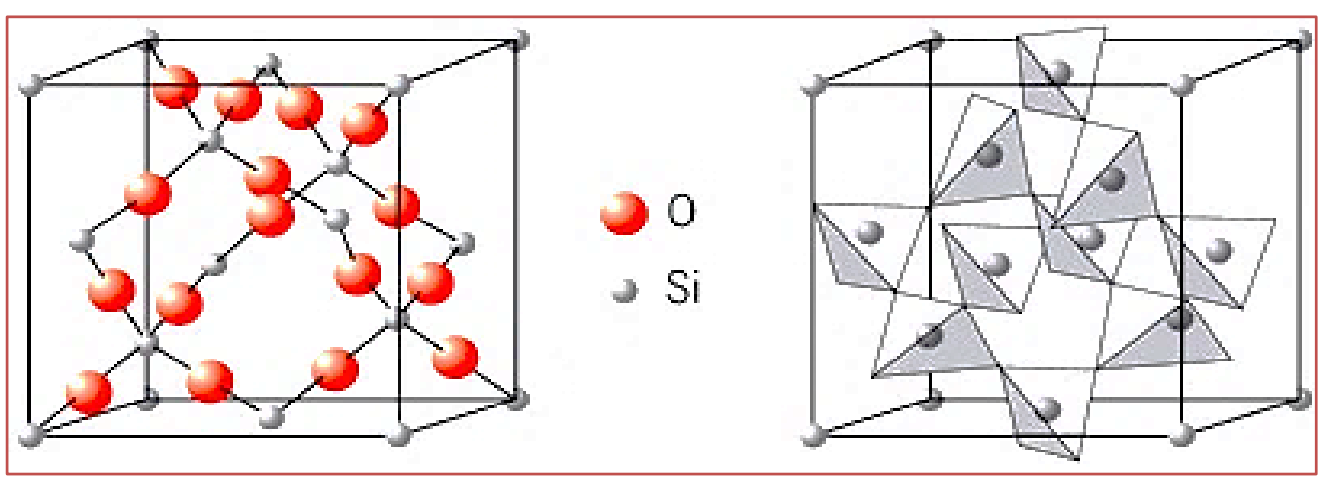

Fonte: CALLISTER (2012)

Bauxita: A bauxita é a fonte natural de alumínio e possui coloração avermelhada, com mais de $40 \%$ de alumina $\left(\mathrm{Al}_{2} \mathrm{O}_{3}\right)$, composta por mistura impura de minerais de alumínio. Entre estes, destacam-se: gibbsita $\mathrm{Al}(\mathrm{OH})_{3}$, diásporo $\mathrm{AlO}(\mathrm{OH})$ e boehmita $\mathrm{AlO}(\mathrm{OH})$. Tais minerais são oxi-hidróxidos de alumínio, e suas proporções na rocha variam entre os depósitos, bem como as impurezas do minério: óxidos de ferro, argila, sílica, dióxido de titânio, entre outros. A maioria das bauxitas economicamente aproveitáveis possui conteúdo de alumina variando entre $50 \%$ e $55 \%$ - tende-se à expectativa, em sentido do aproveitamento, valor próximo a $30 \%$. As cerâmicas de resistência intermediária são derivadas da bauxita e ricas em mulita $\left(3 \mathrm{Al}_{2} \mathrm{O}_{2} \cdot 2 \mathrm{SiO}_{2}\right)$, cerâmicas de resistência elevada, são ricas em óxido de alumínio (SAMPAIO, 2008; ANJOS \& SILVA, 1983).

Em 2010, a reserva mundial de bauxita já era da ordem de 33,4 bilhões de toneladas, quando o Brasil já ocupava a segunda posição entre os maiores produtores mundiais (3,5 bilhões de toneladas), seguindo a Austrália (11,5 bilhões de toneladas). Das reservas nacionais, $95 \%$ correspondem à bauxita metalúrgica. A bauxita não metalúrgica corresponde aos demais $5 \%$ da produção brasileira e, após calcinação, se aplica à manufatura de abrasivos. Para tal bauxita, exige-se maior concentração de alumina e menor concentração de óxidos de ferro. No processo de beneficiamento, busca-se separar a alumina dos outros minerais, podendo-se obter alumina com aproximadamente $97 \%$ de pureza. Nesses propantes, quanto maior o teor de alumina, maior a resistência (Sampaio, 2008; Barreto, 2010). A figura 3 apresenta a estrutura cristalina da alumina (coríndon) - os íons de oxigênio formam estrutura hexagonal fechada, contendo íons de alumínio, com preenchimento de dois terços dos interstícios octaédricos (CALLISTER, 2012).

Figura 3. Estrutura cristalina da Alumina

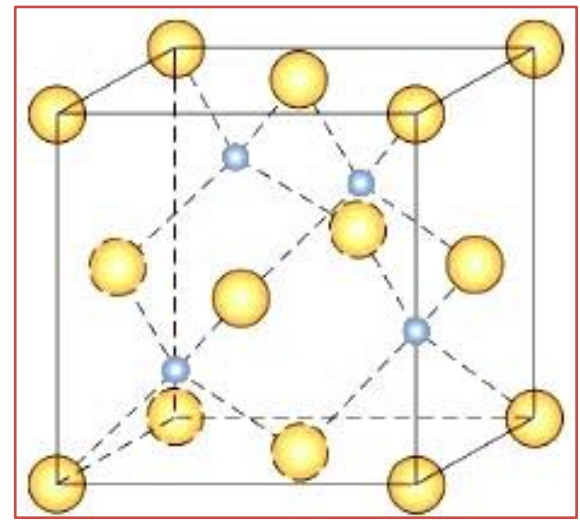

Fonte: CALLISTER (2012)

Salienta-se que, em linhas gerais, a sequência de operações unitárias envolvidas na produção de propantes minerais são: secagem, cominuição, pelotização e sinterização, não necessariamente nesta completude ou ordem. Destaca-se a sinterização, que é a exposição do material a ações com temperaturas elevadas, processo, o qual, elimina as impurezas do mineral e o torna mais denso e com resistência mais elevada. A combustão localizada provoca uma fusão parcial da carga na região mais quente (frente de combustão) e o 
gás quente de combustão, constituído principalmente de $\mathrm{CO}_{2}, \mathrm{~N}_{2}$ e $\mathrm{O}_{2}$, pré-aquece a carga logo abaixo (MOURÃo et al., 2008). A ação da temperatura elimina poros internos, além disto, com alteração em arranjo molecular do material. Tal rearranjo elimina possíveis amorfos, tendendo a ser mais cristalino e compacto. A Figura 4 viabiliza verificação de diagrama de fases da sílica-alumina, incluindo o comportamento entre os óxidos de alumínio e de sílica, com formação de fases mais puras e variações de resistências (LUZ et al., 2008).

Figura 4. Diagrama esquemático de fases sílica-alumina

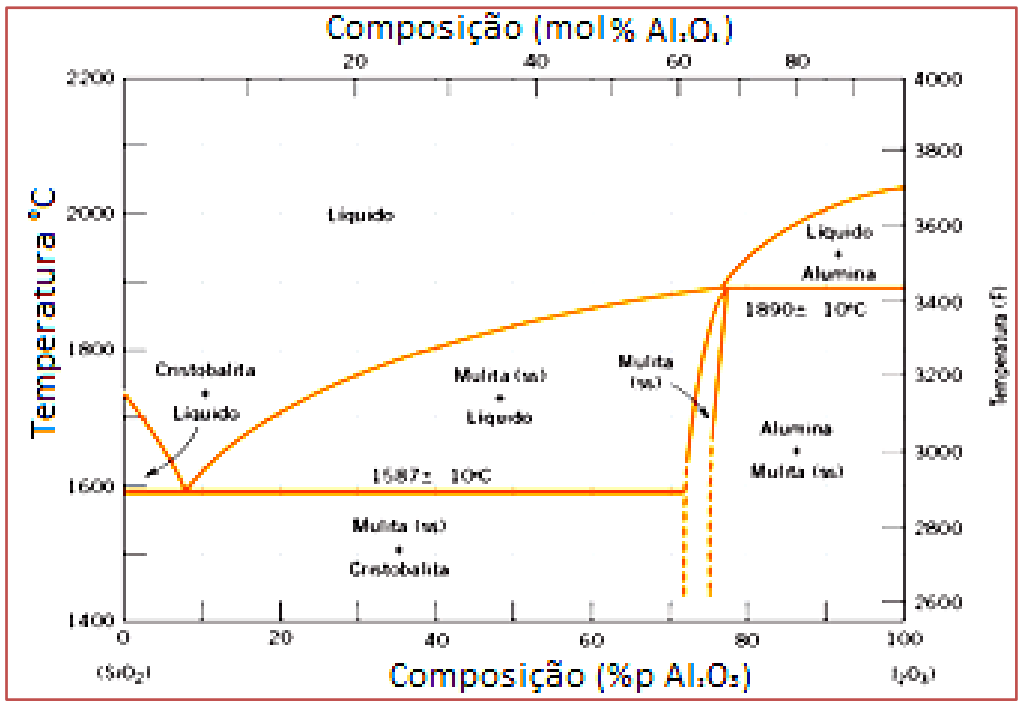

Fonte: CALLISTER (2012)

\subsection{PROPRIEDADES FÍSICO-QUÍMICAS DE PROPANTES}

Segundo MORAES (2016), as normas da API RP 56 fornecem diretrizes recomendatórias, incluindo para testes de areias utilizadas em operações de fraturamento hidráulico. Segundo tais normas, o propante destinado ao fraturamento deve apresentar esfericidade e arredondamento maior ou igual a 0,6. Sua solubilidade em solução ácida (HF 3\%-HCl 12\%) não deve exceder o valor de 2\% em peso, para faixas granulométricas de 6/12 até 30/50 mesh. Para pressão igual a 2000 psi, a porcentagem máxima de finos admitida é igual a 20\%, para amostras com granulometria igual a 6/12 mesh. Para uma pressão igual a 3000 psi, a porcentagem máxima de finos admitidos é igual a 14\%, por peso. Para pressão igual a 4000 psi,, a porcentagem máxima de finos admitidos é igual a $14 \%$ por peso para uma amostra com granulometria variando entre 20 e 40 mesh.

Resistência ao esmagamento: A tensão efetiva máxima, que atua sobre o propante, pode ser estimada entre a pressão de fechamento da fratura e a pressão de produção do poço. Quando o propante é submetido a uma tensão de fechamento superior à sua capacidade, ele se deforma/quebra. Há então a formação de partículas menores que percorrem caminho em sentido do interior do poço, diminuindo sua condutividade (BARRETO, 2010).

Condutividade, tamanho e distribuição granular: A condutividade da fratura é uma grandeza diretamente proporcional ao quadrado do diâmetro dos grãos de propante (VELOZO, 2016). Neste sentido, a Figura 5 apresenta a correlação entre condutividade, dimensão dos grãos de propante e tensão de fechamento (psi).

Arredondamento e esfericidade da partícula: 0 arredondamento é a medida da curvatura do grão. Pela escala de Krumbein/Sloss, materiais com medida de 0,9 x 0,9 são esféricos, e os inferiores a 0,8 x 0,8 são denominados angulares. Grãos arredondados e de tamanho mais uniforme favorecem o aumento da permeabilidade (BARRETO, 2010).

Densidade: Enquanto o propante se bombea para o interior de determinada fratura, sua taxa de sedimentação tende a aumentar, linearmente, com quão mais denso for o material de sustentação. Como forma de equilíbrio, utiliza-se fluido mais viscoso ou aumenta-se a velocidade de injeção de propantes (CACHAY, 2004). Complementarmente à massa específica, a densidade aparente (bulk density) representa 
a massa do propante por unidade de volume total do pacote granular, incluindo o volume de vazios intersticiais. Utiliza-se bulk density para cálculo do volume de propantes, em injeções. A massa específica também viabiliza estimativa de tempo de sedimentação (SERRANO et al., 2013).

Figura 5. Condutividade, dimensão e tensão de fechamento

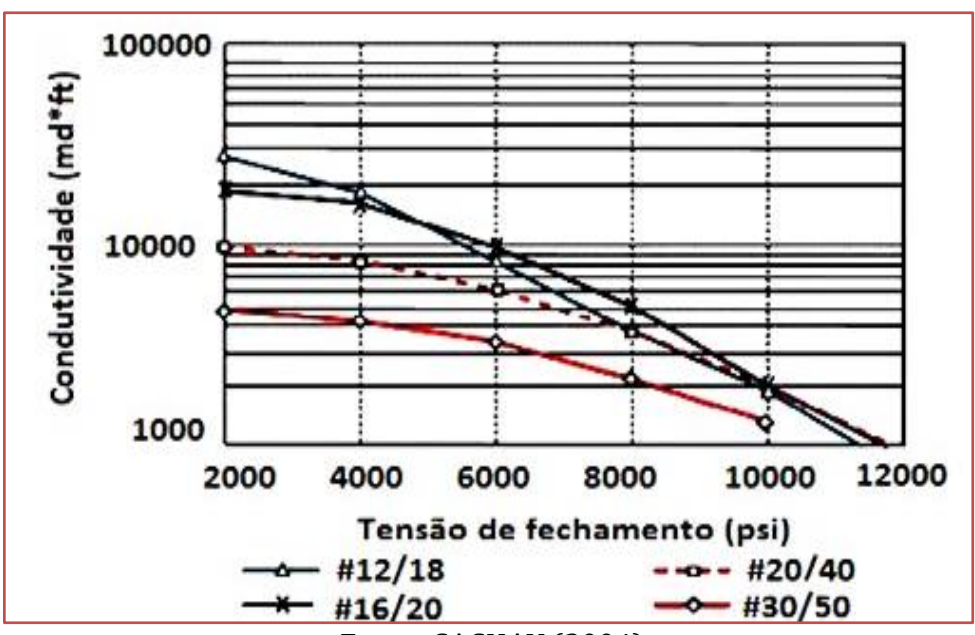

Fonte: CACHAY (2004)

Propriedades cerâmicas: Cerâmicas, quando à temperatura ambiente, se fraturam em antecedência a qualquer deformação plástica. Tais fraturas consistem na propagação de trincas, em direção perpendicular à carga aplicada. A medida da capacidade de um material cerâmico em resistir à fratura, quando uma trinca está presente, é especificada em termos da tenacidade à fratura. A tenacidade à fratura, em deformação plana, $K_{k}$, é definida de acordo com a equação 1.

$$
K_{k}=Y \cdot o \cdot \sqrt{\pi \cdot a}
$$

Sendo $K_{k}$ parâmetro correspondente à deformação plana, Y um parâmetro adimensional, $\sigma$ é a tensão aplicada, e $\alpha$ é o comprimento da trinca superficial ou metade de uma trinca interna.

A propagação da trinca só ocorre quando o conjunto direito da Eq. (1) se torna maior que a tenacidade à fratura em deformação plana do material. Existe uma variação de resistência à tração em um mesmo material, e isso ocorre porque, em diferentes amostras, pode haver defeitos responsáveis por redução de resistência - ocorrendo também com a tensão de compressão, sendo, estas, maiores que a de tração da ordem de um fator igual a 10. Um dos fatores que influenciam negativamente a resistência e as propriedades elásticas é a existência de poros, e a fração volumétrica desses poros reduz de forma exponencial a resistência (CALLISTER, 2014).

Adsorção e mecanismo de extração: No momento da fratura de rochas, ocorre a criação de uma ligação entre superfície e fluido contido nas rochas, gerando uma diferença de pressão. Tal diferença de pressão resulta no transporte espontâneo do fluido das rochas para a superfície, que está sob a influência de uma pressão mais reduzida. 0 fluido fica adsorvido física ou quimicamente nas rochas física ou química. A adsorção é favorecida por altas pressões e baixas temperaturas. Contudo, quanto maior a profundidade (pressão), maior, também, a temperatura. A partir de certa profundidade, tende-se à saturação, com diminuição da capacidade adsortiva (LU et al., 2015). Uma das explicações matemáticas que se fazem diversas, por meio de modelos relacionados ao fenômeno da adsorção, se relaciona ao modelo da isoterma de Langmuir - experimental, com variação de pressão, com resposta de medida de quantidade adsorvida/dessorvida. Tal modelo pode ser representado pela equação 2. 


$$
Q_{e}=\frac{Q_{m} \cdot K_{l} \cdot C_{e}}{1+Q_{m} \cdot C_{e}}
$$

Em que $Q e$ é a quantidade adsorvida, $Q m$ é a quantidade máxima que pode ser adsorvida, $K l$ é a constante de equilíbrio termodinâmica, $C e$ é a concentração de soluto a se adsorver presente.

Ressalta-se que o fenômeno em voga envolve etapas que podem ser estudadas particularmente, tais quais difusão interna e externa, influenciadas por pressão envolvida (LU et al., 2015).

\section{CONSIDERAÇõES FINAIS}

Em sentido de ampliação da abrangência dos dados apresentados, ressalta-se que materiais propantes podem apresentar naturezas distintas, partindo-se do pressuposto que atendam especificações de resistência para processos determinados. Neste sentido, Normas Regulamentadoras, abrangendo NR 56, preconizam ensaios aos quais devem ser submetidos materiais, referenciando limites de valores aceitáveis para cada um dos testes realizados. Avalia-se, então, a viabilidade do material para o uso proposto (BARRETO, 2010). Salienta-se que ampla parcela de material propante utilizado atualmente provém de materiais cerâmicos, tal qual bauxita - já ressaltado, a composição de alumina influencia diretamente a resistência ao esmagamento. A composição quanto ao teor de alumina é dependente de características composicionais de jazidas nas quais se realizam extrações. Há também propantes considerando bauxita pura, decorrente da moagem e queima direta de matéria-prima (LUZ et al., 2008). Em geral, demais materiais propantes tendem a ser submetidos a processos diversos, visando extração de impurezas, diminuição de porosidade, e aumento de teor de alumina. A resistência tende a se fazer relacionada à presença de impurezas em propantes, assim como às etapas de obtenção/fabricação. Segundo DEON et al. (2013), parte considerável de sílica dissolvida se deve à estrutura amorfa e relativamente pouco cristalina, principalmente, em região susceptível à dissolução em meio ácido. A eliminação das impurezas, ao longo do processamento, assim como a etapa de sinterização, tende a se fazer crucial para que arranjo molecular se altere, tornando-se compactos, com formação cristalina. Assim, confere-se solidez mais elevada ao material. Estudos envolvendo materiais propantes alternativos, tais quais os ultraleves, revelam eficiência para tensão reduzida. Assim, para poços profundos, indicam-se materiais cerâmicos - se vai ao encontro de elevada demanda e produção, mundiais (JUNIOR, 2014; LUZ et al., 2018). Contudo, ressalta-se a utilidade de materiais alternativos, os quais, sustentáveis, se produzem a partir de resíduos e de materiais renováveis. Neste mesmo contexto, também ressalta-se crescente aplicabilidade de recursos matemáticos computacionais, auxiliares, em estudos sobre o assunto. Envolvendo previsão de dados e resultados, associam-se efetividade e eficiência, antecipando-se informações relevantes, como as que se relacionam à distribuição de materiais nas fraturas, a proteção à sedimentação no poço, o índice de produtividade entre outras.

Em complemento, compilam-se, na tabela 2, estudos os quais se adicionam às considerações em questão. 0 levantamento traz incidência sobre potenciais técnicos e fraturamentos. Nesse contexto, associam particularidades de materiais, com identificação de parâmetros e características físico-químicas requeridas, bem como informações sobre estruturas físicas e resistências, potencialmente, viabilizando contextualização de inovação e aplicações alternativas. Frente ao cenário, retoma-se o fato de propantes derivados de bauxita tenderem a apresentar resistência elevada à pressão e temperatura. No que se refere a sólidos cristalinos derivados de bauxita, a compactação, e pureza da estrutura cristalina tende à elevação da resistência à compressão do propante. Com relevância, propantes de rejeitos da mineração se aderem a panoramas atuais, reduzindo custos para obtenção da matérias-primas, com adventos de transformação e obtenção de novos produtos, evitando acúmulo, por exemplo, em barragens de contenção. Torna-se razoável observar que, contextualmente, técnicas de fraturamento hidráulico dependem de conjuntos de questões associadas a materiais de sustentação. Estudos práticos que avaliem fraturamento hidráulico, em contextos ambientais, se recomendam, assegurando qualidade de processos extrativos, com esforços e ações convergentes em esferas, entre as quais, tecnológica, científica e industrial. 
Tabela 2. Estudos: desempenho de propantes

\begin{tabular}{|c|c|c|c|}
\hline Título & Objetivo do Estudo & Metodologia & Resultados/Conclusões \\
\hline $\begin{array}{l}\text { Comparação de } \\
\text { diferentes tipos de } \\
\text { propante visando } \\
\text { maximizar os } \\
\text { índices de } \\
\text { produtividade } \\
\text { (MORAES, 2016) }\end{array}$ & $\begin{array}{l}\text { Avaliar características e } \\
\text { desempenho/ propantes } \\
\text { de areias, areias } \\
\text { resinadas, as cerâmicas } \\
\text { de resistência } \\
\text { intermediária, a bauxita } \\
\text { e propantes não } \\
\text { convencionais como a } \\
\text { casca de coco e de noz }\end{array}$ & $\begin{array}{l}\text { Testes laboratoriais } \\
\text { conforme as normas } \\
\text { NR, e aplicação de um } \\
\text { software (PKN) para } \\
\text { calcular o Índice de } \\
\text { produtividade do poço. }\end{array}$ & $\begin{array}{l}\text { Com este estudo se concluiu que para } \\
\text { baixas tensões o propante com maior } \\
\text { produtividade foi o de casca de coco } \\
(1,53) \text { para } 4000 \text { psi. No caso de médias } \\
\text { e altas tensões o mais recomendado seria } \\
\text { a bauxita, porque ela é resistente a essas } \\
\text { tensões }\end{array}$ \\
\hline $\begin{array}{l}\text { Implementação de } \\
\text { propantes } \\
\text { ultraleves no } \\
\text { faturamento } \\
\text { hidráulico de } \\
\text { poços } \\
\text { (SERRANO et al., } \\
\text { 2016) }\end{array}$ & $\begin{array}{l}\text { Avaliação de resistência } \\
\text { e solubilidade propantes } \\
\text { ultraleves em / ULWP } \\
\text { 1.25, ULWP 1.25c, ULWP } \\
\text { 1.08, ULWP 2.02 }\end{array}$ & $\begin{array}{l}\text { Elaborou-se um } \\
\text { diagrama de } \\
\text { implementação em que } \\
\text { se pode escolher um } \\
\text { determinado propantes } \\
\text { dos testados. }\end{array}$ & $\begin{array}{l}\text { Todos estavam dentro dos padrões da } \\
\text { norma e os propantes ultraleves estão } \\
\text { aptos a serem adotados a pressões de } \\
\text { confinamento abaixo de } 7000 \text { psi. }\end{array}$ \\
\hline $\begin{array}{l}\text { Interações } \\
\text { geoquímicas de } \\
\text { propantes } \\
\text { baseados em } \\
\text { alumina com } \\
\text { salmoura } \\
\text { altamente salina } \\
\text { em condições de } \\
\text { temperatura } \\
\text { geotérmicas } \\
\text { (DEON et al., } \\
2015 \text { ) }\end{array}$ & $\begin{array}{l}\text { Avaliação de resistência } \\
\text { a temperatura, e } \\
\text { solubilidade em solução } \\
\text { salina e ácida, de } \\
\text { propantes cerâmicos } \\
\text { derivados da } \\
\text { bauxita./Propantes } \\
\text { cerâmicos com e sem } \\
\text { revestimento. }\end{array}$ & $\begin{array}{l}\text { Foram submetidos a } \\
150^{\circ} \mathrm{C} \text { e temperatura } \\
\text { ambiente e em reatores } \\
\text { de teflon, por variados } \\
\text { dias, variando-se } \\
\text { também o ph e a } \\
\text { salinidade da solução. }\end{array}$ & $\begin{array}{l}\text { A salinidade controla a estabilidade dos } \\
\text { propantes. Se conclui que quanto maior a } \\
\text { salinidade menos Al e Si são dissolvidos e } \\
\text { que quanto menos amorfo e mais } \\
\text { cristalino for o material, menos se } \\
\text { dissolverá. }\end{array}$ \\
\hline $\begin{array}{l}\text { Avaliação da } \\
\text { resistência à } \\
\text { compressão, } \\
\text { temperatura e ao } \\
\text { meio salino/ácido } \\
\text { de Rejeitos de } \\
\text { processo } \\
\text { metalúrgico. } \\
\text { (CAMPOS et al., } \\
\text { 2014) }\end{array}$ & $\begin{array}{l}\text { Avaliação da resistência } \\
\text { à compressão, } \\
\text { temperatura e ao meio } \\
\text { ácido/ Rejeitos: Lama } \\
\text { negra, lama cinza, lama } \\
\text { vermelha. }\end{array}$ & $\begin{array}{l}\text { Foi utilizada a técnica } \\
\text { "DOE". E foram } \\
\text { submetidas a ensaios } \\
\text { de resistência a } \\
\text { compressão, corrosão e } \\
\text { solubilidade, após } \\
\text { terem sido fabricadas } \\
\text { (secas, cominuídas e } \\
\text { queimadas). }\end{array}$ & $\begin{array}{l}\text { As amostras que estavam misturadas e } \\
\text { com adição de fundente apresentaram } \\
\text { uma maior resitência a compressão, } \\
\text { acima de } 120 \text { Mpa, ligeiramente melhor } \\
\text { que nas puras que estiveram na faixa } \\
\text { entre } 10 \text { Mpa e } 120 \mathrm{Mpa} \text {. Submetidas ao } \\
\text { calor e meio salino não tiveram grandes } \\
\text { perdas no material, somente após o } \\
\text { tempo de uma semana. }\end{array}$ \\
\hline
\end{tabular}

\section{REFERÊNCIAS}

[1] BARRETO, N. M. Caracterização de materiais para garantir condutividade de fraturas hidraulicamente induzidas em poços de petróleo e gás. Dissertação (Doutorado em Engenharia Mecânica) - Departamento de Engenharia Mecânica. Pontifica Universidade Católica do Rio de Janeiro, 2010. Rio de Janeiro, 2010.

[2] BRAGA, P.F. A. Areia de faturamento: Mercado características e perspectivas. In: XXVI Encontro Nacional de Tratamento de Minérios e Metalurgia Extrativa Poços de Caldas-MG, 18 a 22 de Outubro 2015. Rio de Janeiro: UFRJ, 2015.

[3] CALLISTER, W. Ciência e engenharia dos materiais: uma introdução. 7ạ edição. Editora LTC. Rio de Janeiro, 2011.

[4] CAMPOS, V.P.P; TOFFOLI, S. M; VALERA, T. S; SILVA, G.F.B.L; NOGUEIRA, F. M; NUNES, R. P. Desenvolvimento de propantes cerâmicos sintéticos de alta resistência à compressão e ao meio salino/ ácido a partir de rejeitos do processamento mineral e metalúrgico. In: 58ํㅡㄹ Congresso Brasileiro de Cerâmica, 2014, Bento Gonçalves, RS. USP, São Paulo, 2014. 
[5] DEON, F; REGENSPURG, S; ZIMMERMANN, G. Geochemical interactions of Al203-based proppants with highly saline geothermal brines at simulated in situ temperature conditions. GFZ German Research Centre for Geosciences, International Centre for Geothermal Research ICGR. In: journal home page: "www.elsevier.com/locate/geothermics". Potsdam, Alemanha, 2015.

[6] JÚNIOR, F. P. B. Analise da recuperação em reservatório de gás com baixa permeabilidade (Tight gas) através do faturamento hidráulico. 2014. Dissertação (Mestrado em Ciência e engenharia de petróleo) - Centro de ciências exatas e da terra. Universidade Federal do Rio Grande do Norte, Natal, 2014.

[7] Lu, Y; Yang. Z; Li. Y; Han. J; Ji. G. Problem and methods for optimization of hydraulic fracturing of deep coal beds in China. State Key Laboratory of Oil and Gas Reservoir Geology and Exploitation, Southwest Petroleum University, Chengdu, 2015.

[8] LUZ, A.B; LINS F.A.F. Rochas \& Minerais industriai: Usos e especificações. $2^{\underline{a}}$ edição. CETEM. Rio de Janeiro, 2008.

[9] Miranda, T. Minas e Energia rejeita suspensão de leilão para explorar gás natural e de xisto. In: <http://www2.camara.leg.br/camaranoticias/noticias/MEIO-AMBIENTE/467616-MINAS-E-ENERGIA-REJEITASUSPENSAO-DE-LEILAO-PARA-EXPLORAR-GAS-NATURAL-E-DE-XISTP.html>.

[10] MORAES, F.F. Comparação de diferentes tipos de propantes visando maximizar o índice de produtividade, 2016. Trabalho (Conclusão de Curso em Engenharia de Petróleo) - Departamento de Engenharia Química e de Petróleo. Universidade Federal Fluminense, Niterói, 2016.

[11] MOURÃO, B.M; Yokoji, A.; Malynowskj. Introdução a Siderurgia. 1ae edição. ABM. São Paulo, 2007.

[12] SAMBERG, E. Aspectos Ambientais e Legais do Método Faturamento Hidráulicos no Brasil. In: IX Simpósio Internacional de Qualidade Ambiental, ABES-RS, 19 a 21 de outubro de 2016, Porto Alegre. Caxias do Sul, Universidade de Caxias do Sul, 2014.

[13] SERRANO, D; GOMÉZ, C.A.P; RUEDA, R.C; NÚÑEZ, R.D.C. Implementación de propantes ultralivianos en el fracturamiento hidráulico de pozos. Revista Fuentes: El Reventón Energético Vol. 11 № 1 de 2013 - Jan/Jun - pg 5/16. Bucaramanga, Colômbia, 2013.

[14] TAVARES, L. Estado da arte da operação de faturamento hidráulico. Niterói: UFF, 2010.

[15] VELOZO, L.T. Estudo da estabilidade do material de sustentação de fraturas estimuladas hidraulicamente em poços de petróleo. 2006. Dissertação (Mestrado em Engenharia Civil) - Departamento de Engenharia Civil. Pontifica Universidade Católica do Rio de Janeiro, Rio de Janeiro, 2006. 


\section{Capítulo 11}

Análise do Gold Dressing Agent (GDA) como reagente alternativo ao cianeto no processo de lixiviação do

\section{ouro}

Willian Dayvson Gualberto

Madrith Sthel Costa Duarte

Julio Cézar Balarini

Resumo: Em face da elevada toxicidade do cianeto aos seres humanos, animais e algumas espécies aquáticas, diversas pesquisas estão sendo realizadas para se encontrar alternativas ao uso do cianeto no processo de lixiviação do ouro. No presente capítulo, foi realizado um estudo para avaliar a utilização do Gold Dressing Agent (GDA), como agente lixiviante alternativo para a extração de ouro. Ensaios preliminares revelaram que o cianeto ainda continua sendo o agente lixiviante o mais indicado no que tange à cinética de extração, embora o GDA apresente vantagens relativas em relação a custos de processo.

Palavras-chave: Gold Dressing Agent, GDA, Lixiviação, Ouro.

Abstract: In view of the high toxicity of cyanide to humans, animals and some aquatic species, several researches are being carried out to find alternatives to the use of cyanide in the gold leaching process. In this chapter, a study was carried out to evaluate the use of the Gold Dressing Agent (GDA) as an alternative leaching agent for the extraction of gold. Preliminary tests revealed that cyanide still remains the most suitable leaching agent for extraction kinetics, although GDA presents relative advantages in relation to process costs.

Keywords: Gold Dressing Agent, GDA, Leaching, Gold. 


\section{INTRODUÇÃO}

O ouro é um metal nobre e ocorre geralmente na natureza no estado elementar devido ao seu caráter inerte. Possui características de resistência a ataques químicos, calor e umidade. Esse metal, quando puro, é extremamente maleável e dúctil (Keskinen, 2013) e possui um papel fundamental na economia mundial, sendo sua extração largamente empregada em todo mundo devido ao seu elevado valor comercial (Kuzugudenli \& Kantar, 1999).

0 beneficiamento do minério de ouro apresenta algumas singularidades que o distingue de outros métodos de tratamento. Em modo geral, as rotas de processamento podem se limitar a uma adequação granulométrica do minério (britagem e moagem), concentração (gravimétrica ou hidrofóbica), lixiviação, recuperação do ouro em solução e refino (Trindade \& Filho, 2002).

O processo de lixiviação do ouro com cianeto tem sido a prática mais utilizada desde o início do século XIX. Devido ao potencial tóxico do cianeto, diversas preocupações ambientais vêm surgindo, acarretando rigorosas restrições para sua utilização. Em função desse cenário, diversas pesquisas estão sendo realizadas para se encontrar alternativas ao uso do cianeto no processo de lixiviação do ouro (Kuzugudenli \& Kantar, 1999).

O presente capítulo tem como objetivo realizar uma avaliação preliminar do potencial do Gold Dressing Agent (GDA) como reagente alternativo ao cianeto, por comparação dos parâmetros cinéticos e econômicos, medidos em laboratório.

\section{REFERENCIAL TEÓRICO}

O ouro pertence ao mesmo grupo do cobre e da prata na tabela periódica e é comumente encontrado associado a estes elementos em minerais (Keskinen, 2013) (Trindade \& Filho, 2002). Sua concentração na crosta terrestre é da ordem de $0,005 \mathrm{~g} / \mathrm{t}$, sendo inferior em relação a maioria dos outros metais como, por exemplo, a prata $(0,07 \mathrm{~g} / \mathrm{t})$ e o cobre $(50 \mathrm{~g} / \mathrm{t})$ (Eugene \& Mujumdar, 2009).

Existem na natureza cerca de 30 minerais de ouro, sendo os mais comuns deles descritos na tabela 1 (Vaughan, 2004).

O ouro também pode ocorrer na forma ultrafina associado a minerais compostos por sulfetos (Tab. 2), que é comumente conhecida como submicroscópica ou invisível (Mardsen \& House, 2009).

Tabela 1. Minerais de ouro mais comuns

\begin{tabular}{l|c}
\multicolumn{1}{c}{ Mineral } & Composição \\
Ouro nativo & $\mathrm{Au}$ \\
\hline Electrum & $\mathrm{Au}-\mathrm{Ag}(20-50 \% \mathrm{Ag})$ \\
\hline Calaverita & $\mathrm{AuTe}_{2}$ \\
\hline Silvinita & $\mathrm{AuAgTe}_{4}$ \\
\hline Petzita & $\mathrm{Ag}_{3} \mathrm{AuTe}_{2}$ \\
\hline Auroestibinita & $\mathrm{AuSb}_{2}$ \\
\hline Maldonita & $\mathrm{Au}_{2} \mathrm{Bi}$ \\
\hline Cupreto áurico & $\mathrm{AuCu}_{3}$ \\
\hline
\end{tabular}


Tabela 2. Minerais sulfetados comumente encontrados em minérios de ouro

\begin{tabular}{|c|c|}
\hline Mineral & Composição \\
\hline Arsenopirita & FeAsS \\
\hline Pirita & $\mathrm{FeS}_{2}$ \\
\hline Tetraedrita & Cu12As4S13 \\
\hline Calcopirita & $\mathrm{CuFeS}_{2}$ \\
\hline Pirrotita & $\mathrm{Fe}_{1-\mathrm{x}} \mathrm{S}$ \\
\hline
\end{tabular}

Fonte: Mardsen \& House (2009)

\subsection{CLASSIFICAÇÃO DOS MINÉRIOS DE OURO}

Os minérios de ouro podem ser classificados em sete categorias, conforme descrito por Oraby (2009):

Free milling: São minérios em que há uma recuperação por cianetação de 95\% do ouro, quando o minério possui uma granulometria de $80 \%$ abaixo de $75 \mu \mathrm{m}$.

Oxidados: São minérios em que seus minerais apresentam na forma oxidada. 0 grau de liberação do ouro aumenta com o grau de oxidação dos minerais presente no minério. Os exemplos mais comuns são magnetita e hematita.

Sulfeto de ferro: 0 comportamento do sulfeto de ferro pode impedir a liberação do ouro, interferindo na escolha do processo de beneficiamento. Pirita, pirrotita e macasita são exemplos mais comuns de minerais de sulfeto de ferro.

Sulfetos de cobre: São minérios que contêm ouro associado a sulfetos de cobre, como a calcopirita, que possui uma contribuição prejudicial para a recuperação do ouro.

Sulfetos de arsênio: São minérios onde o ouro está associado a sulfeto de arsênio, sendo o mineral mais comum a arsenopirita. Esses minérios apresentam efeitos prejudiciais à recuperação de ouro.

Carbonáceos: São minérios onde o ouro está presente em materiais carbonáceos, eles adsorvem o ouro e necessitam ser oxidados para o ouro ser lixiviado.

Teluretos: São minérios onde o ouro está associado à prata e ao telúrio. Estão presentes nesta classe os minerais calaverita, silvinita e petzita.

\subsection{BENEFICIAMENTO DO MINÉRIO DE OURO}

0 beneficiamento do minério de ouro apresenta algumas singularidades que o distingue de outros métodos de tratamento. A espécie submetida ao beneficiamento está em sua forma elementar metálica e presente na forma de minerais. Em modo geral, as rotas de processamento podem se limitar a uma adequação granulométrica do minério (britagem e moagem), concentração (gravimétrica ou hidrofóbica), lixiviação, recuperação do ouro em solução e refino, conforme apresentado na figura 1 (Trindade \& Filho, 2002). 
Figura 1. Fluxograma convencional da extração de ouro.

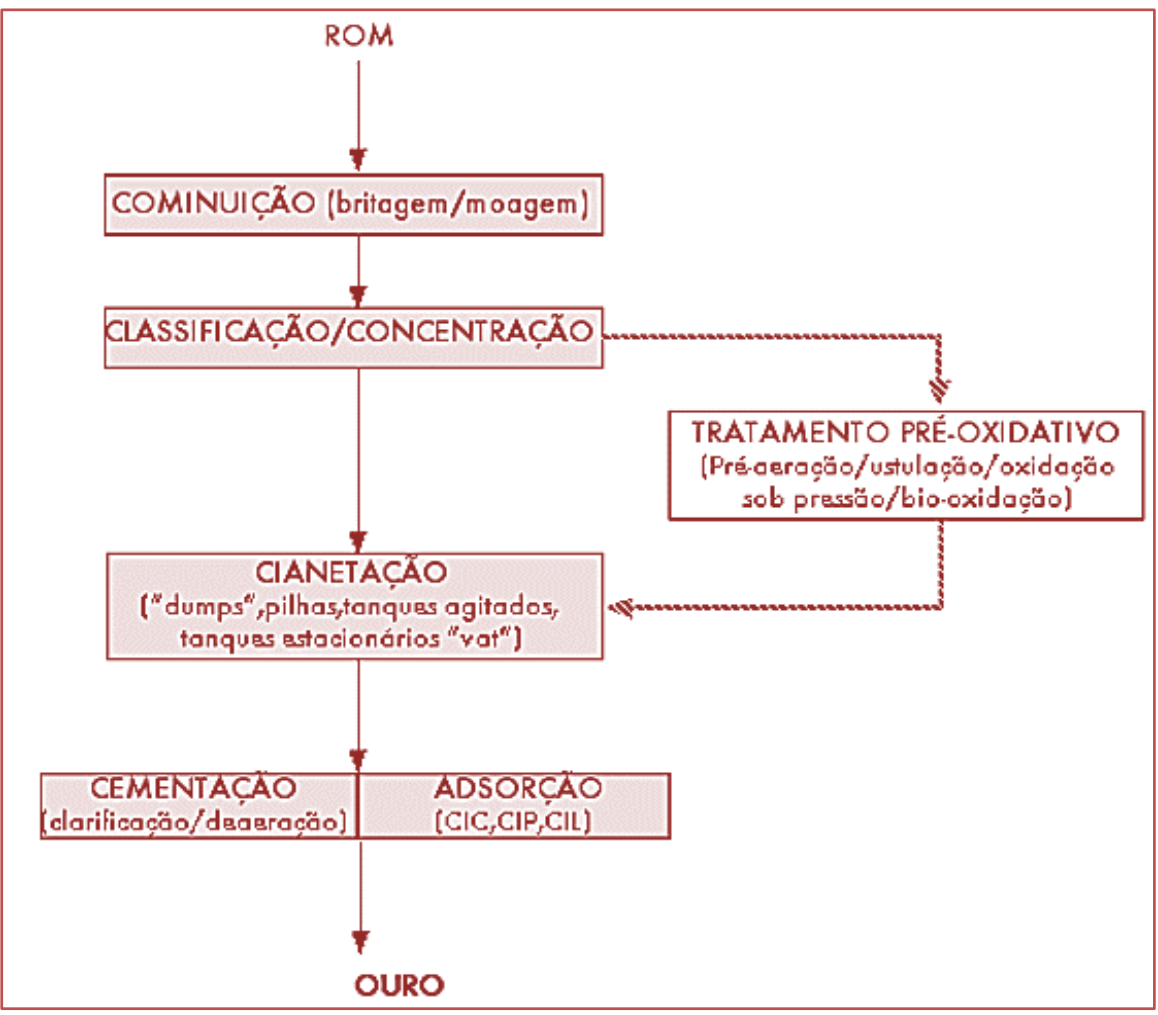

Fonte: Trindade \& Filho (2002)

\subsection{A QUÍMICA DA LIXIVIAÇÃO}

O processo de lixiviação do ouro consiste na dissolução do metal a partir de uma matriz sólida. Esse processo ocorre somente em presença de oxigênio e de um agente complexante, tais como cianeto, haletos, tiossulfato, tioureia e tiocianatos (Mardsen \& House, 2009). A lixiviação com cianeto é a prática mais utilizada para a dissolução do ouro desde o princípio do século XIX. 0 íon cianeto é facilmente obtido em solução através da dissolução de sais, como cianeto de sódio (NaCN) e cianeto de potássio (KCN), conforme representado através das equações 1 e 2 (Keskinen, 2013) (Srithammavut, 2008).

$$
\begin{aligned}
\mathrm{NaCN} & \rightleftharpoons \mathrm{Na}^{+}+\mathrm{CN}^{-} \\
\mathrm{KCN} & \rightleftharpoons \mathrm{K}^{+}+\mathrm{CN}^{-}
\end{aligned}
$$

$\mathrm{O}$ pH influencia diretamente no comportamento dos íons de cianeto em solução. Com o pH aproximadamente de 9.3, metade das moléculas de cianeto se apresentam na forma de cianeto de hidrogênio ( $\mathrm{HCN})$ e metade como íons de cianeto livre $\left(\mathrm{CN}^{-}\right)$, conforme mostrado na figura 2 (Mardsen \& House, 2009; Oraby, 2009). 
Figura 2. Diagrama de especiação de cianeto e cianeto de hidrogênio em função do pH.

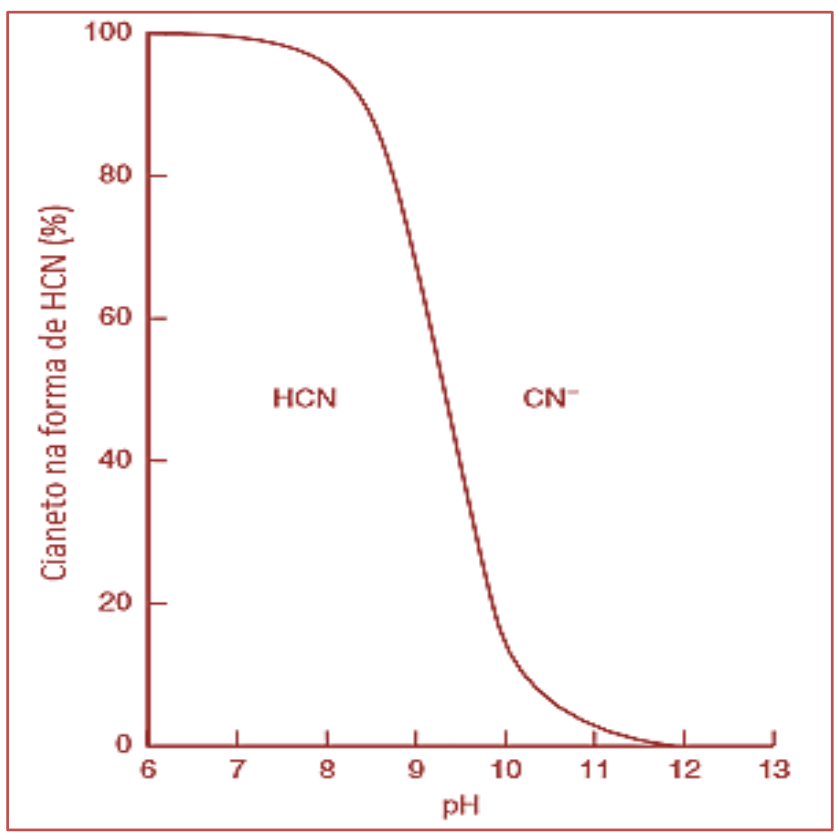

Fonte: Mardsen \& House (2009)

A reação entre o cianeto e o ouro ocorre na forma de oxirredução, onde o íon $\mathrm{CN}^{-}$interage com o íon $\mathrm{Au}^{+}$ formando um complexo estável $\mathrm{Au}(\mathrm{CN})^{2-}$. As equações globais onde o oxigênio é reduzido a peróxido de hidrogênio, que serve como agente oxidante na segunda etapa, estão representadas pelas equações 3 e 4 (Srithammavut, 2008).

$$
\begin{gathered}
2 \mathrm{Au}+4 \mathrm{CN}^{-}+\mathrm{O}_{2}+\mathrm{H}_{2} \mathrm{O} \rightarrow 2 \mathrm{Au}(\mathrm{CN})_{2}{ }^{-}+\mathrm{H}_{2} \mathrm{O}_{2}+2 \mathrm{OH}^{-} \\
2 \mathrm{Au}+4 \mathrm{CN}^{-}+\mathrm{H}_{2} \mathrm{O}_{2} \rightarrow 2 \mathrm{Au}(\mathrm{CN})_{2}{ }^{-}+2 \mathrm{OH}^{-}
\end{gathered}
$$

Somando as duas equações, é obtida a equação geral (Eq. 5) (Keskinen, 2013) (Yannopoulos, 1991).

$$
4 \mathrm{Au}+8 \mathrm{CN}^{-}+\mathrm{O}_{2}+\mathrm{H}_{2} \mathrm{O} \rightarrow 4 \mathrm{Au}(\mathrm{CN})_{2}^{-}+4 \mathrm{OH}^{-}
$$

\subsection{SAÚDE E MEIO AMBIENTE}

A indústria mineradora geralmente apresenta uma imagem negativa no histórico ambiental, poluindo o solo, água e o ar. Os maiores problemas causados pela indústria mineradora de ouro são: drenagem ácida, ruído, poeira, poluição do ar, água e solo com produtos tóxicos como arsênio, mercúrio e cianeto (Taylor, 2006).

Após o processo de extração do ouro por lixiviação, os rejeitos devem ser armazenados em barragens devido à quantidade de cianeto e de alguns metais pesados remanescentes neles (Mcnulry, 2001). A toxicidade do cianeto varia com sua concentração que, em níveis mais elevados, pode ser letal para os seres humanos, animais e algumas espécies aquáticas. 0 cianeto se liga ao ferro, que é a base da molécula da hemoglobina, formando o íon ferrocianeto $\left(\left[\mathrm{Fe}(\mathrm{CN})_{6}\right]^{4-}\right)$, um complexo muito estável. Essa reação inibe o transporte de oxigênio pela hemoglobina, levando à deficiência de oxigenação celular e posterior morte por asfixia (Hilson \& Monhemius, 2006).

Devido a este contexto, diversas pesquisas estão sendo realizadas para se encontrar alternativas ao uso do cianeto no processo de lixiviação do ouro (Kuzugudenli \& Kantar, 1999). 


\subsection{REAGENTES ALTERNATIVOS AO CIANETO}

A grande motivação para a busca de agentes lixiviantes alternativos ao cianeto surgiu a partir dos riscos ambientais gerados pela sua toxicidade e pela dificuldade em se obter novos licenciamentos de projetos que envolvem o seu uso (Kuzugudenli \& Kantar, 1999). Ao longo das últimas três décadas, uma quantidade significativa de trabalhos técnico-científicos foi produzida com o intuito de analisar os reagentes alternativos ao cianeto para a recuperação de ouro em diferentes minérios (Aylmore, 2016). Na tabela 3 estão apresentados alguns dos reagentes alternativos mais investigados (Trindade \& Filho, 2002).

Tabela 3. Principais reagentes alternativos ao cianeto.

\begin{tabular}{|c|c|c|c|}
\hline Reagente & Ligante & $\mathrm{pH}$ & Complexo de $\mathrm{Au}$ \\
\hline Tiouréia & $\mathrm{NH}_{2} \mathrm{CSNH}_{2}$ & $1-4$ & {$\left[\mathrm{Au}\left(\mathrm{NH}_{2} \mathrm{CSNH}_{2}\right)_{2}\right]^{+}$} \\
\hline Brometo & $\mathrm{Br}^{-}$ & $1-7$ & $\mathrm{AuBr}_{4}{ }^{-}$ \\
\hline Iodeto & $\mathrm{I}^{-}$ & $1-5$ & $\mathrm{AuI}_{2}^{-}$ \\
\hline Cloreto & $\mathrm{Cl}^{-}$ & $1-4$ & $\mathrm{AuCl}_{4}^{-}$ \\
\hline Tiocianato & $\mathrm{SCN}^{-}$ & $1-3$ & {$\left[\mathrm{Au}(\mathrm{SCN})_{4}\right]^{-}$} \\
\hline Tiossulfato & $\mathrm{S}_{3} \mathrm{O}_{3}{ }^{2-}$ & $8-11$ & {$\left[\mathrm{Au}\left(\mathrm{S}_{3} \mathrm{O}_{3}\right)_{2}\right]^{3-}$} \\
\hline
\end{tabular}

Fonte: Trindade \& Filho (2002)

Dentre a gama de reagentes alternativos investigados, apenas o cloreto e o tiossulfato foram implementados. Porém, ambos apresentaram cinética desfavorável, dificuldade de controle do processo e alto custo operacional quando comparados ao uso do cianeto (Aylmore, 2016).

\subsection{GOLD DRESSING AGENT}

O Gold Dressing Agent é um composto que surgiu na China com a finalidade de ser um agente lixiviante à altura do cianeto. A literatura não dispõe de muitas informações sobre esse composto, devido à sua recente chegada ao mercado. Sua composição genérica está descrita na tabela 4 (Qingdao Aiweisheng Chemical Co. Ltd., 2016).

Tabela 4. Composição do Gold Dressing Agent.

\begin{tabular}{|l|c|}
\multicolumn{2}{|c|}{ Componente } \\
\hline Carbonato de sódio & $1-70$ \\
\hline Peróxido de sódio & $1-30$ \\
\hline Óxido de cálcio & $1-5$ \\
\hline Ureia & $1-40$ \\
\hline
\end{tabular}

Fonte. QAC (2014).

\section{METODOLOGIA}

\subsection{PREPARO DA AMOSTRA}

Os ensaios de lixiviação foram realizados com uma amostra de minério sulfetado de ouro cedido por uma empresa do estado de Mato Grosso. Foram recebidos $30 \mathrm{~kg}$ do material, o qual passou inicialmente pelas etapas de britagem primária e peneiramento (peneira de $3,2 \mathrm{~mm}$ ). 0 material retido na peneira foi submetido a uma nova britagem até que $100 \% \mathrm{~m} / \mathrm{m}$ da amostra estivesse com a granulometria inferior a $3,2 \mathrm{~mm}$. 
Após essas duas etapas, a amostra foi homogeneizada e amostrada em sacos plásticos, contendo 1 kg de material em cada um deles. Foram retirados $3 \mathrm{~kg}$ da amostra, que passaram pelo processo de moagem a úmido em um moinho de barras. Foram utilizados os tempos de 10, 20 e 25 minutos, a fim de se estabelecer uma curva de moagem do material e determinar o tempo de moagem contendo $80 \% \mathrm{~m} / \mathrm{m}$ do material passante em uma peneira de $200 \#(75 \mu \mathrm{m})$. Esse percentual é uma prática usual de processos industriais.

\subsection{ENSAIOS DE LIXIVIAÇÃO}

Para a avaliação do potencial de uso do Gold Dressing Agent (GDA) como agente lixiviante alternativo ao cianeto foram promovidos dois conjuntos de ensaios de lixiviação. 0 primeiro visou à elaboração de duas curvas de lixiviação. Essas curvas foram realizadas em garrafas mecanicamente agitadas (rolador de garrafas) utilizando $3 \mathrm{~kg}$ de minério cada. A primeira curva foi desenvolvida utilizando o cianeto de sódio (NaCN) como agente lixiviante e a segunda utilizando o GDA. As curvas de lixiviação foram realizadas nas seguintes condições:

- $50 \% \mathrm{~m} / \mathrm{m}$ sólidos;

- $\mathrm{P} 80=75 \mu \mathrm{m}$;

- Ajuste de pH para 10,5 - 11,5 (com cal);

- Concentração inicial do agente lixiviante de $5.000 \mathrm{mg} / \mathrm{L}$;

- Intervalos de tempo para a retirada de alíquotas de solução: 2, 4, 6 e 24 horas;

- Tempo para a retirada de alíquota de rejeito: após 24 horas;

- Tempo máximo de residência: 24 horas.

O segundo conjunto de ensaio teve como objetivo assegurar a repetibilidade dos ensaios, avaliar o consumo dos agentes lixiviantes e a eficiência de recuperação do ouro. Foram realizados 10 ensaios utilizando $1 \mathrm{~kg}$ do minério cada. Os ensaios de 1 a 5 foram executados com cianeto de sódio e os ensaios de 6 a 10 utilizado o GDA. Para a execução desses ensaios, as seguintes condições foram adotadas:

- $50 \% \mathrm{~m} / \mathrm{m}$ sólidos;

- $\mathrm{P} 80=75 \mu \mathrm{m}$.

- Ajuste de pH para 10,5 - 11,5 (com cal);

- Concentração inicial do agente lixiviante de $5.000 \mathrm{mg} / \mathrm{L}$;

- Tomada de alíquotas de rejeito e solução com 24 horas;

- Tempo máximo de residência de 24 horas.

Todas as alíquotas retiradas foram enviadas para a análise do teor de ouro pelo método Fire Assay Gold. Nas alíquotas de solução também foi determinada a concentração final dos reagentes lixiviantes e o pH da solução foi medido.

\subsection{CÁLCULO DO PERCENTUAL DE RECUPERAÇÃo}

Para o cálculo do percentual de recuperação, foi utilizada a equação 6.

$$
\% \text { recuperação }(t)=\frac{C_{\text {alíquota }}(t) \cdot V_{(t-1)}}{m_{\text {total de } A u}} \cdot 100
$$


Na equação 6, C é a concentração, $V$ é o volume e m é a massa.

A massa total de ouro é calculada pela equação 7.

$$
m_{\text {total de Au }}=\sum_{t} C_{\text {alíquota }}(t) \cdot V_{\text {alíquota }}+C_{\text {final }} \cdot V_{\text {final }}+m_{\text {rejeito }} \cdot C_{\text {ppm }}
$$

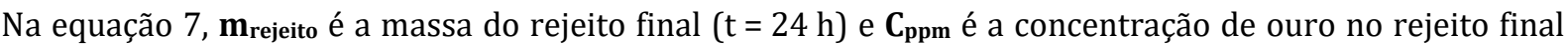
em ppm.

\section{RESULTADOS E DISCUSSÕES}

\subsection{DETERMINAÇÃO DA CURVA DE MOAGEM}

Após submeter as três amostras de minério (1 kg cada) ao processo de cominuição, conforme descrito na metodologia, foi construída a curva de moagem apresentada na figura 3.

Utilizando as informações da curva da figura 3, foi possível determinar que o tempo aproximado para que cerca de $80 \% \mathrm{~m} / \mathrm{m}$ do material estivesse passante em uma peneira de $200 \#(75 \mu \mathrm{m})$ fosse de 14 minutos. A determinação desse tempo serviu como base para a preparação das amostras utilizadas nos ensaios subsequentes de lixiviação.

Figura 3. Curva de moagem do minério de ouro

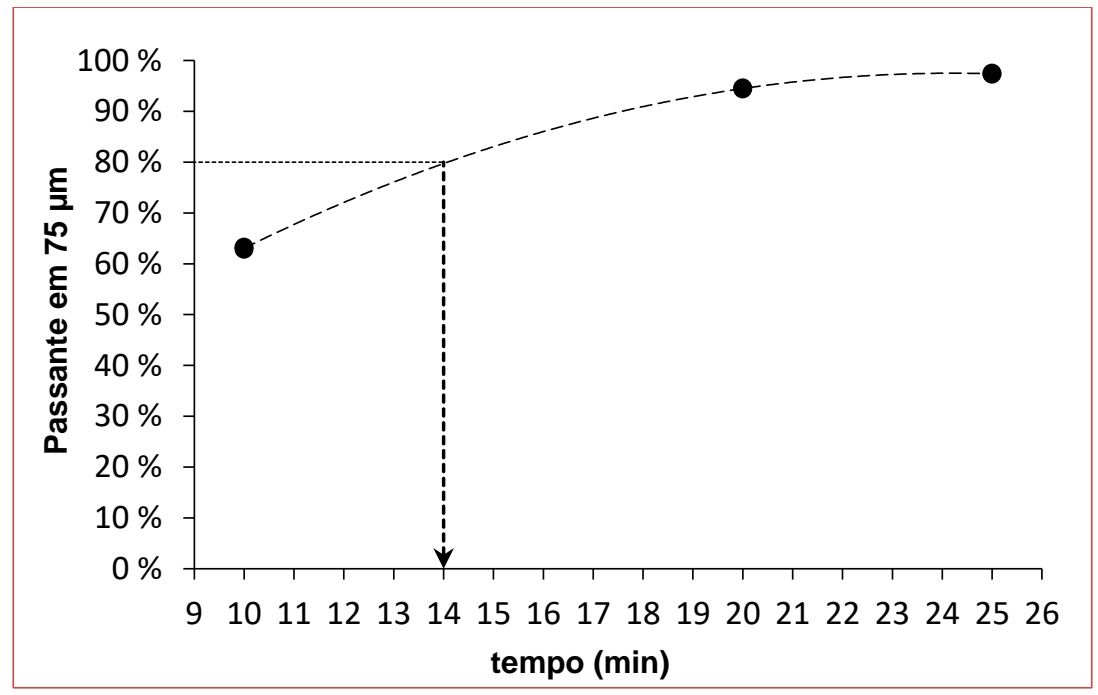

Fonte: Autores

\subsection{ENSAIOS DE LIXIVIAÇÃO}

Os resultados do primeiro conjunto de ensaios de lixiviação estão apresentados nas tabelas 5 e 6.

Tabela 5. Dados do primeiro conjunto de ensaios de lixiviação com NaCN.

\begin{tabular}{|c|c|c|c|c|c|}
\hline $\begin{array}{r}\text { Tempo } \\
\text { (horas) }\end{array}$ & $\begin{array}{c}\text { Alíquota } \\
\text { (mL) }\end{array}$ & $\begin{array}{c}\mathrm{pH} \\
\text { Final }\end{array}$ & $\begin{array}{c}\text { Solução } \\
\text { (mg de Au/L) }\end{array}$ & $\begin{array}{c}\text { Rejeito } \\
\text { (ppm de } \mathrm{Au})\end{array}$ & $\begin{array}{c}\text { Recuperação } \\
(\%)\end{array}$ \\
\hline 2 & 100 & 11,21 & 4,58 & - & 17,39 \\
\hline 4 & 100 & 11,08 & 8,74 & - & 32,66 \\
\hline 6 & 100 & 10,99 & 12,64 & - & 46,49 \\
\hline 24 & 100 & 10,84 & 22,27 & 5,43 & 79,40 \\
\hline
\end{tabular}


Tabela 6. Dados do primeiro conjunto de ensaios de lixiviação com GDA.

\begin{tabular}{c|c|c|c|c|c}
\multicolumn{1}{c|}{$\begin{array}{c}\text { Tempo } \\
\text { (horas) }\end{array}$} & $\begin{array}{c}\text { Alíquota } \\
(\mathrm{mL})\end{array}$ & $\begin{array}{c}\mathrm{pH} \\
\text { Final }\end{array}$ & $\begin{array}{c}\text { Solução } \\
(\mathrm{mg} \text { de Au/L) }\end{array}$ & $\begin{array}{c}\text { Rejeito } \\
(\mathrm{ppm} \mathrm{de} \mathrm{Au})\end{array}$ \\
\hline 2 & 100 & 10,86 & 1,89 & - & 11,10 \\
\hline 4 & 100 & 10,58 & 3,83 & - & 15,34 \\
\hline 6 & 100 & 10,54 & 4,91 & 22,43 & 23,91 \\
\hline 24 & 100 & 6,22 & Fonte: Autores
\end{tabular}

Pelos dados apresentados na tabela 5, observa-se que os valores de $\mathrm{pH}$ se mantiveram dentro da faixa estipulada $(10,5<\mathrm{pH}<11,5)$. Conforme apresentado anteriormente (item 2.2.1), é imprescindível controlar o valor do $\mathrm{pH}$ nessa faixa a fim de que se tenha uma quantidade suficiente de $\mathrm{CN}$ - disponível em solução para que se possa formar o complexo cianeto-ouro. Ainda que aparentemente o GDA não apresente íons cianeto em sua composição (tabela 4), a faixa de pH final dos ensaios de lixiviação também se manteve entre 10,5 e 11,5 (tabela 6). Uma vez que não foram realizadas as caracterizações iniciais nas amostras de minério (fire assay e/ou digestão ácida), a quantidade de ouro foi determinada por balanços de massa, utilizando as concentrações das soluções e do rejeito final (tabelas 5 e 6).

Para o cálculo dos percentuais de recuperação (Eq. 6), foram determinadas as massas totais de ouro segundo a equação 7. Para os ensaios utilizando $\mathrm{NaCN}$ e GDA, as massas de ouro foram, aproximadamente, $78,99 \mathrm{mg}(26,33 \mathrm{ppm})$ e $85,14 \mathrm{mg}(28,38 \mathrm{ppm})$, respectivamente. Ambas tendo como base uma massa de amostra de minério equivalente a $3 \mathrm{~kg}$.

Os percentuais de recuperação estão apresentados nas tabelas 5 e 6 e na figura 4.

Figura 4. Curvas de lixiviação GDA x NaCN.

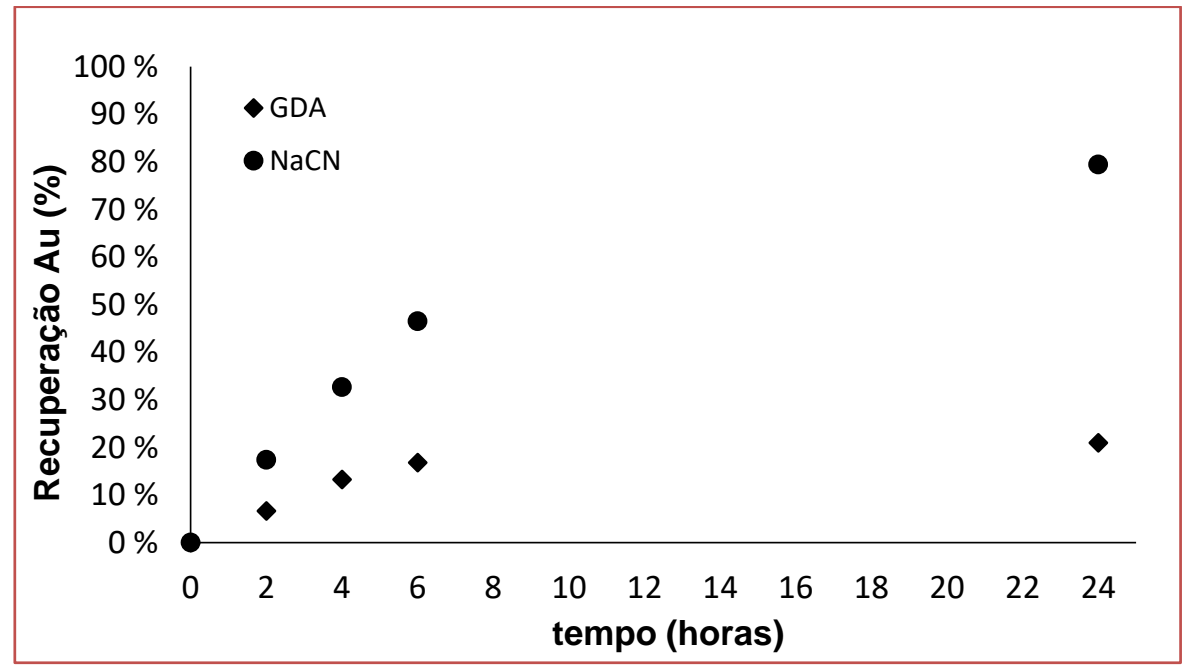

Fonte: Autores

Com base na figura 4, fica evidente que o GDA possui uma cinética de lixiviação desfavorável quando comparado ao cianeto, uma vez que a taxa de extração inicial (inclinação da curva em tempos iniciais) é menor. Pôde-se observar que com 6 horas de ensaio cerca de 18,78\% do ouro havia sido solubilizado, enquanto na curva utilizando NaCN cerca de $46,49 \%$ do ouro já havia sido recuperado. Uma diferença ainda maior entre os dois agentes lixiviantes pode ser evidenciada quando são comparados os pontos finais das curvas. Com 24 horas de ensaio, a curva utilizando GDA apresentou uma recuperação de 23,91\% de ouro, enquanto que a curva utilizando NaCN apresentou 79,40\% de recuperação. Os resultados do segundo conjunto de ensaios estão representados nas tabelas 7 e 8. 
Tabela 7. Dados do segundo conjunto de ensaios de lixiviação com NaCN.

\begin{tabular}{|c|c|c|c|c|c|c|}
\hline \multirow{4}{*}{ Teste } & $\mathrm{pH}$ & Solução & Rejeito & Consumo & $\begin{array}{l}\text { Alimentação } \\
\text { recalculada }\end{array}$ & Recuperação \\
\hline & & & & & & \\
\hline & Final & $(\mathrm{mg} \operatorname{de} \mathrm{Au} / \mathrm{L})$ & (ppm de $A u)$ & $\mathrm{NaCN}$ & (ppm de $A u)$ & $(\%)$ \\
\hline & & & & $(\mathrm{g} / \mathrm{kg})$ & & \\
\hline 1 & 10,93 & 20,83 & 14,47 & 4,03 & 35,3 & 59,01 \\
\hline 2 & 11,03 & 23,74 & 11,64 & 4,06 & 35,38 & 67,1 \\
\hline 3 & 10,97 & 21,95 & 15,46 & 4,03 & 37,41 & 58,67 \\
\hline 4 & 10,64 & 24,3 & 13,18 & 4,04 & 37,48 & 64,83 \\
\hline 5 & 11,01 & 24,17 & 10,22 & 4,05 & 34,39 & 70,28 \\
\hline Média & 10,92 & 23 & 12,99 & 4,04 & 35,99 & 63,98 \\
\hline
\end{tabular}

Fonte: Autores

Tabela 8. Dados do segundo conjunto de ensaios de lixiviação com GDA.

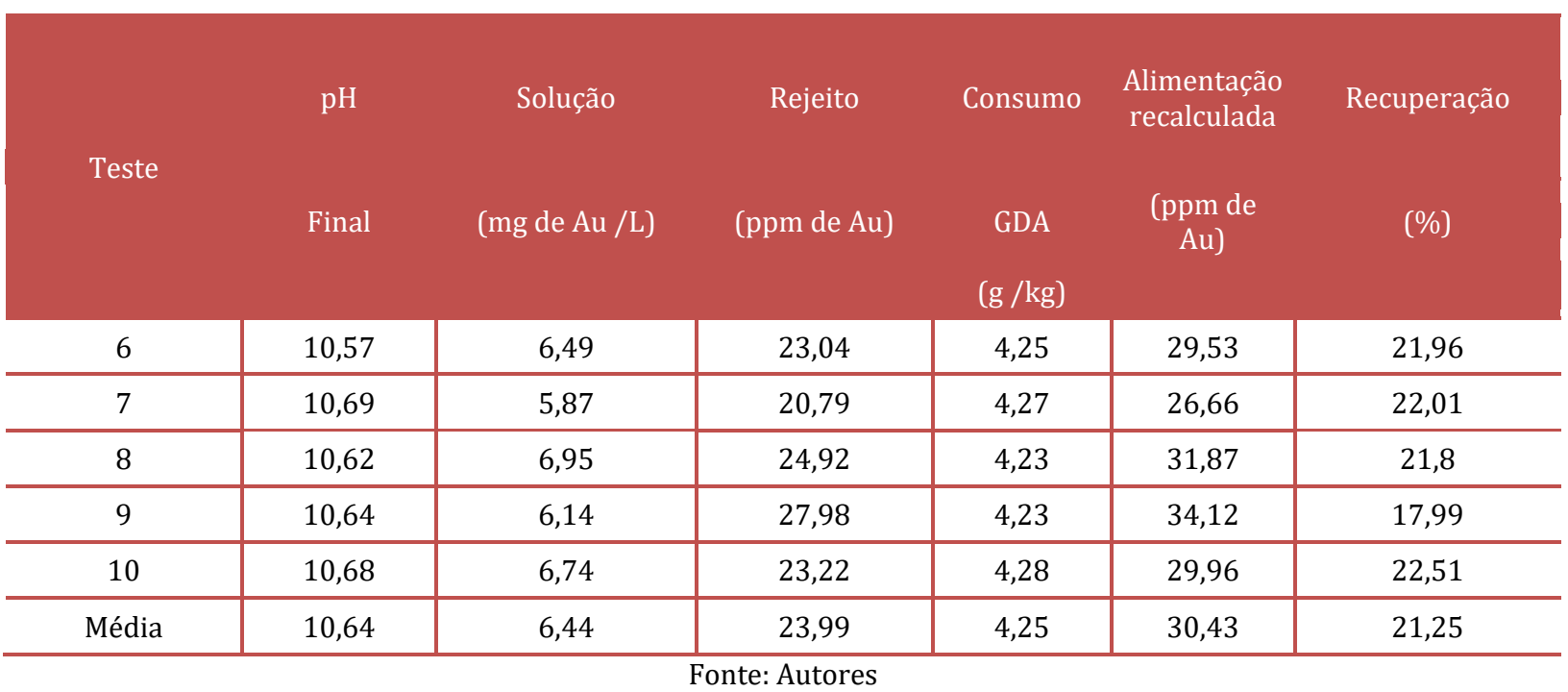

Pelos dados apresentados na tabela 7 e 8, foi possível assegurar a repetibilidade dos ensaios, determinar o consumo dos reagentes e a recuperação máxima do ouro decorrente à utilização de cada agente lixiviante. Observa-se que nos ensaios com a utilização de $\mathrm{NaCN}$ (Tab. 7), é possível obter rejeitos com um valor médio de 12,99 ppm de Au, sendo bem inferior ao valor médio de 23,99 ppm de Au referente aos rejeitos provenientes dos ensaios com a utilização do GDA (Tab. 8). A quantidade de ouro presente nos rejeitos de lixiviação impacta diretamente no valor da recuperação do metal. Conforme observado na tabela 7, os ensaios que foram utilizados $\mathrm{NaCN}$ como agente lixiviante apresentaram uma recuperação média do ouro de 63,98\% enquanto os ensaios que foram ministrados o GDA tiveram uma recuperação média de $21,25 \%$ (Tab. 8). Essa variação entre as recuperações evidencia uma grande diferença existente na capacidade de formação do complexo com o ouro, tendo em vista que o $\mathrm{NaCN}$ se mostrou ser bem mais eficiente que o GDA.

O consumo médio de GDA e NaCN no segundo conjunto de ensaios são respectivamente, 4,25 e 4,04 g/kg de minério lixiviado (tabelas 7 e 8). Observa-se que o consumo médio de GDA se apresentou ligeiramente superior ao consumo médio de $\mathrm{NaCN}$, não o suficiente para descartar a sua utilização.

Outro importante fator na avaliação do GDA como agente lixiviante alternativo ao cianeto é o custo de sua utilização. 0 valor comercial do GDA e do $\mathrm{NaCN}$ são respectivamente de US\$2.000,00 e US\$2.150,00 a tonelada (Kemcore,2017). Levando em consideração o consumo médio dos agentes lixiviantes 
mensurados nos ensaios (tabelas 7 e 8), foi possível realizar uma estimativa do custo total de sua utilização. 0 GDA apresentou um custo para cada tonelada de minério tratado de US\$ 8,50 enquanto o custo referente à utilização de NaCN para cada tonelada de minério tratado seria de US\$ 8,69 . Com base na comparação de custos, fica evidente uma ligeira vantagem da utilização do GDA como agente lixiviante, uma vez que com sua utilização haveria uma economia de US\$ 0,19 para cada tonelada do minério tratado.

\section{CONCLUSÃO}

Com base nos ensaios preliminares realizados, o Gold Dressing Agent não se mostrou um agente lixiviante à altura do cianeto. 0 GDA apresentou cinética de lixiviação desfavorável, lenta velocidade na solubilização do metal, consumo ligeiramente superior e baixa recuperação do ouro. A única vantagem do GDA seria econômica, tendo em vista que os valores estimados para sua utilização serem menores que os valores estimados para o emprego de NaCN. No entanto, ainda não é o suficiente para justificar o seu uso, considerando-se que, por se tratar de ouro, uma ligeira diferença entre as recuperações pode representar uma perda de alguns milhares de dólares. Ainda assim, são necessários estudos complementares para se determinar com maior precisão o potencial de uso do Gold Dressing Agent.

\section{REFERENNCIAS}

[1] AYLMORE, M. (2016). Alternative Lixiviants to Cyanide for Leaching Gold Ores. Curtin University of Technology.

[2] EUGENE, W. W., \& Mujumdar, A. S. (2009). Gold Extraction and Recovery Processes. Faculty of Engineering, National University of Singapore.

[3] HILSON, G., \& Monhemius, A. (2006). Alternatives to Cyanide in the Gold Mining industry: What Prospects for the Future? Journal of Cleaner Production.

[4] KEMCORE. (20 de Junho de 2017). Kemcore. Fonte: http://www.kemcore.com/sodium-cyanide-98.html

[5] KESKINEN, S. (2013). Comparison of Cyanide and Thiosulphate Leaching. Lappeenranta Universityof Technology.

[6] KUZUGUDENLI, O., \& KANTAR, Ç. (1999). Alternates to Gold Recovery by Cyanide Leaching. Kayseri, Turquia.

[7] MARDSEN, J., \& HOUSE, I. (2009). The Chemistry of Gold Extraction. Littleton: Society for Mining, Metallurgy, and Exploration, Inc. (SME) .

[8] MCNULRY, T. (2001). Cyanide Substitutes. Mining Magazine.

[9] ORABY, E. (2009). ORABY, E.A. Gold Leaching in Thiosulfate Solutions and Its Environmental Effects Compared with Cyanide. Curtin University of Technology.

[10] QINGDAO AIWEISHENG CHEMICAL Co. Ltd. (2014). FISPQ Gold Dressing Agent. China.

[11] QINGDAO AIWEISHENG CHEMICAL Co. Ltd. (2016). Fonte: Site da Qingdao Aiweisheng Chemical Co. Ltd.: www.qdawschem.com/class.asp?id=334\&action=Products\&ming=Gold\%20Dressing\%20Agent

[12] SRITHAMMAVUT, W. (2008). Modeling of Gold Cyanidation. Lappeenranta University of Technology.

[13] TAYLOR, M. (2006). Toxicological profile for cyanide. Department of Health and Human Services.

[14] TRINDADE, R., \& FILHO, O. (2002). Extração de Ouro - Princípios, Tecnologia e Meio Ambiente. Rio de Janeiro, Brasil.

[15] VAUGHAN, J. (2004). The Process Minerlogy of Gold: The Classification of Ore Types. Australia. Curtin University of Technology.

[16] YANNOPOULOS, J. (1991). The Extractive Metallurgy of Gold. Nova York: Van Nostrand Reinhold. 
Percepção dos Autores 


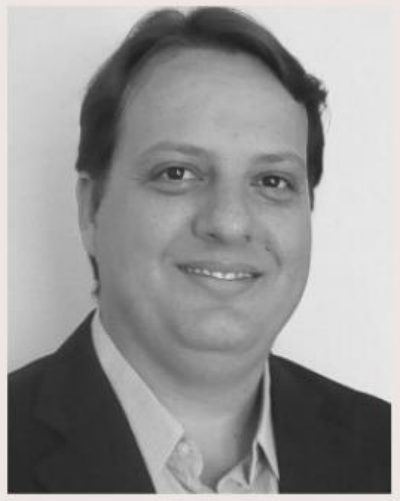

Wanderson (Cap. 03)

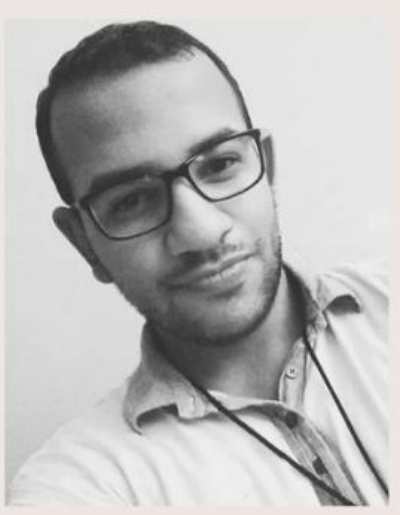

Douglas (Cap. 04)

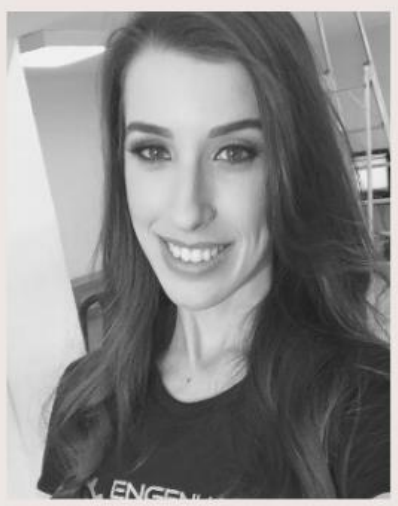

Carolina (Cap. 05)

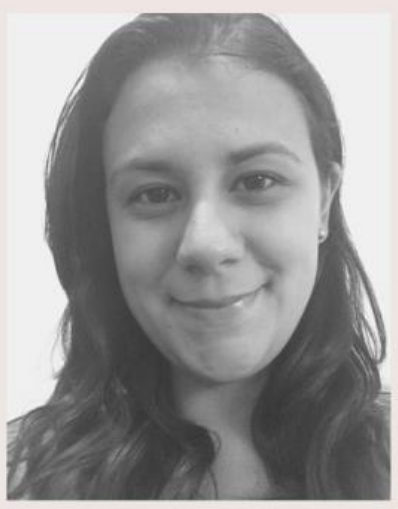

Mariane (Cap. 06)
"O sentimento inicial que motivou a pesquisa foi fundamental quando as complexidades e particularidades do processo de aprendizado foram se apresentado. Noites de distintos e minuciosos estudos, desafiantes ensaios químicos no laboratório, além de horas de planejamento, compuseram a construção de importantes conhecimentos, elevados saberes e imensuráveis valores." (cap. 3)

"Duas das grandes virtudes que muitos carregam dentro de si são a paixão e a sede de conhecimento, tornando-se base para esse trabalho. Minha paixão por cinética química e os questionamentos sobre como a cadeira carbônica poderia interferir na velocidade de formação de produtos me fizeram desenvolver o projeto, o qual me trouxe satisfação por entender um pouco mais sobre uma área que possuo uma grande admiração." (cap. 4)

“A realização desse trabalho me trouxe a certeza de ter escolhido a profissão certa, a Engenharia Química. E que a paixão pela profissão continue me guiando para novos projetos e realizações." (cap. 5)

"Desenvolver este projeto foi um desafio e uma grande honra. Eu jamais o teria concluído sem o apoio e a contribuição de pessoas incriveis às quais sou eternamente grata." (cap. 6) 


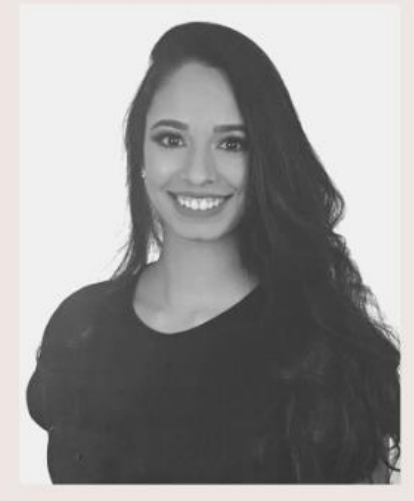

Gabriella (Cap. 07)

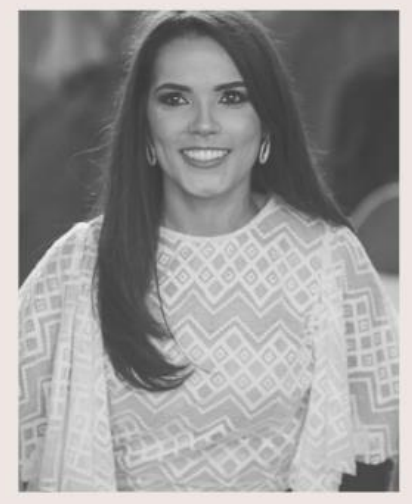

Idianara (Cap. 08)

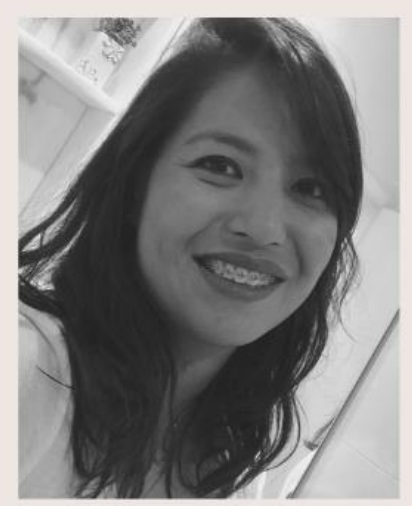

Renata (Cap. 09)

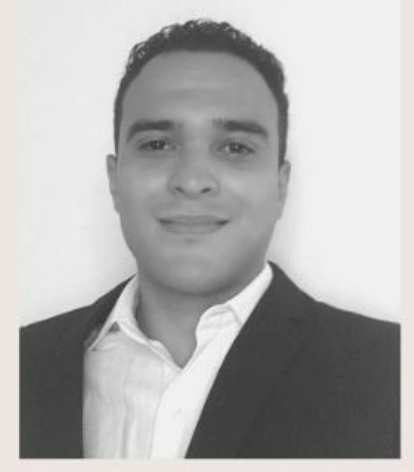

Matheus (Cap. 10)
"Ao ter a ideia do projeto, não imaginava a proporção que alcançaria ao final. Desenvolver um estudo que contribui diretamente para o crescimento sustentável do planeta é fantástico! O sentimento que permanece é de satisfação, além da vontade de me dedicar a novos projetos, tendo como referência à utilização de fontes alternativas de energia, pelo simples fato de preservar o meio ambiente." (cap. 7)

"O estudo do Óleo de Macaúba teve motivação pessoal. Desde criança, meus pais faziam e utilizavam o óleo de macaúba para aplicação capilar. Cresci com a curiosidade de saber se o conhecimento popular dos meus pais tinha fundamento. Ao ingressar na faculdade, já possuía o tema do TCC definido... A possibilidade de estudar e de conhecer um pouco mais sobre a Macaúba foi uma realização pessoal, enriquecedora para meu crescimento profissional." (cap. 8)

"Construir o trabalho foi a garantia de grandes aprendizados, permitindo o conhecimento de um mundo novo, com diversos desafios e o prazer de novas conclusões." (cap. 9)

"Tudo começou com ideias e força de vontade. Com dedicação e determinação fomos em busca do conhecimento. Assim, foi possível construir o trabalho, cujo resultado me enche de gratidão. Obstáculos inicialmente encontrados foram sempre transpostos." (cap. 10) 


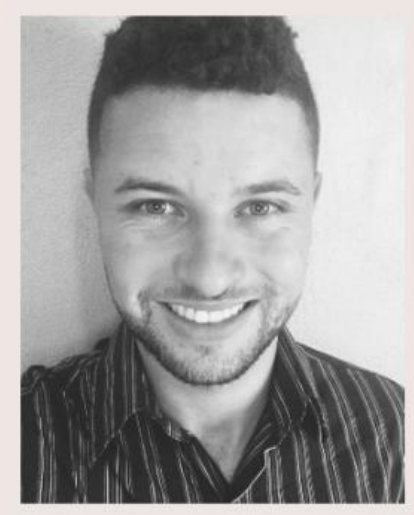

"Tudo começou com ideias e força de vontade. Com dedicação e determinação fomos em busca do conhecimento. Assim, foi possível construir o trabalho, cujo resultado me enche de gratidão. Obstáculos inicialmente encontrados foram sempre transpostos." (cap. 11)

Willian (Cap. 11) 
"Para ser grande, sê inteiro: nada

Teu exagera ou exclui. Sê todo em cada coisa. Põe quanto és

No mínimo que fazes. Assim em cada lago a lua toda Brilha, porque alta vive."

14-2-1933

Odes de Ricardo Reis. Fernando Pessoa. Notas de João Gaspar Simões e Luiz de Montalvor. Lisboa: Portugal. Ática. p. 148 (1946)

Coimbra: Portugal. Presença. (1933) 


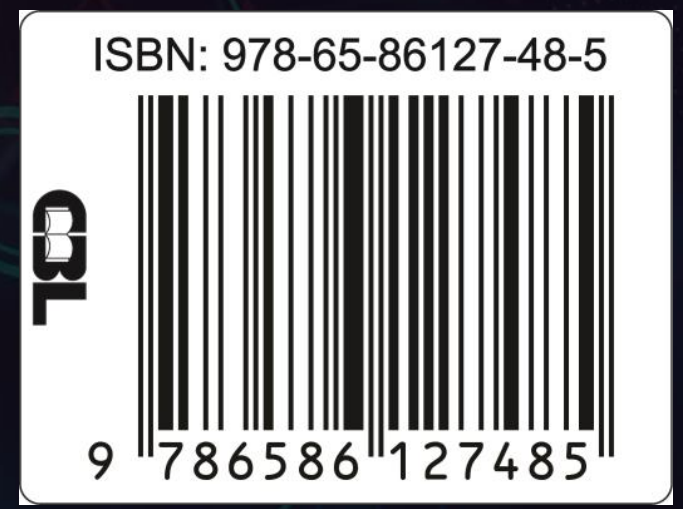

